\title{
Identification and Functional Characterization of Trans-acting Factors Involved in Vegetal mRNA Localization in Xenopus Oocytes
}

\author{
Dissertation \\ zur Erlangung des mathematisch-naturwissenschaftlichen Doktorgrades \\ "Doctor rerum naturalium" \\ der Georg-August-Universität Göttingen
}

vorgelegt von

Patrick Kobina Arthur

aus

Saltpond, Ghana.

Göttingen, 2008. 
Referent: Prof. Dr. Tomas Pieler

Korreferent: Prof. Dr. Ernst A. Wimmer

Date of Thesis Submission: $26^{\text {th }}$ May, 2008.

Date of Thesis Disputation: $27^{\text {th }}$ June, 2008 
Affidavit

Herewith I declare, that I prepared the Doctoral thesis

"Identification and Functional Characterization of Trans-acting Factors Involved in Vegetal mRNA Localization in Xenopus Oocytes"

on my own and with no other sources and aids than quoted.

Patrick Kobina Arthur

Date of submission 
... to Marian my wife with love. 


\section{Acknowledgements}

Now to the King eternal, immortal, invisible, the only God, be honor and glory forever and ever - (I Timothy 1:17 - NIV)

I wish to express my heartfelt appreciation to Prof. Dr. Tomas Pieler for offering me the opportunity to do my PhD thesis project in his laboratory and for the continuous support and encouragement that has seen me thus far. I do hope to carry on with what I have learnt from my time here to benefit others and to make you proud for the good work invested in me. I thank Prof. Wimmer for accepting to be my korreferent. The efforts of Frau Manuela Manafas towards solving the numerous administrative difficulties I got into cannot go unrecognized; she offered such timely and effective assistance that made me lost for words to express my gratitude.

My entire family has supported me in such a manner that made it possible to stay the course and to take this pursuit to a good end, my mother Felicia and father Joseph Arthur, spoke to situations with such wisdom and care it made possible not to spare any effort at reaching my set goals. The last mile, it is said, is always the longest mile and I could not have made it through it all without the love and tacit support of my wife Marian; I am grateful for the constant warning that if I did not complete, I should not consider it an option to return home.

I am grateful to all the members of the department who contributed in various ways to make my work possible, especially the "transport group" - Jana Löber, Katsiaryna Tarbashevich, Stefanie Oswald, Katja Koebernick and Maike Claussen; it was also a joy working with former group members - Britta Dreier*, Susanne Koch, Ines Eckhardt, Marc Püschel, and Katja Horvay. Working in the department was also made a particularly pleasant experience by some very wonderful people namely Andreas Nolte, Marion Dornwell, llona Wunderlich and Gudrun Kracht. Special thanks to Christine Jäckh for her kind support all the time and also to Dr. Yonglong Chen and Dr. Jacob Souopgui for taking a special interest in my work. I appreciate contributions made by my friends outside the lab - Dr. Henry Acquah* and Edward Onumah*; as well as all my compatriots in Göttingen. *Thanks for proofreading parts of the manuscript.

Many thanks to Dr Olaf Jahn, MPI-em, Göttingen for the great collaboration on protein identification part of my work, and also for going the extra step offering advice and ideas that helped me great deal. Finally, I can state that "I have seen thus far not because I am a giant but I have stood on the shoulders of giants". My deepest gratitude to all, who could not be mentioned, but have been a giant for me in my advance towards the PhD. 


\section{TABLE OF CONTENTS}

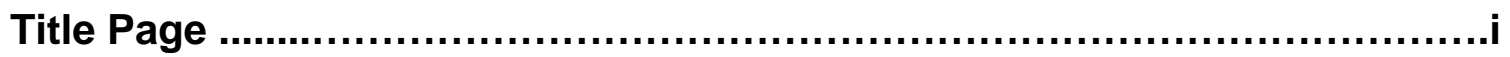

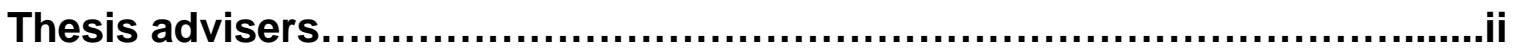

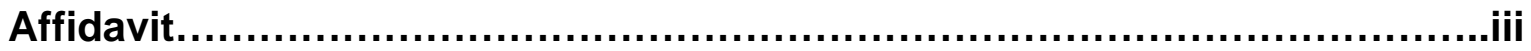

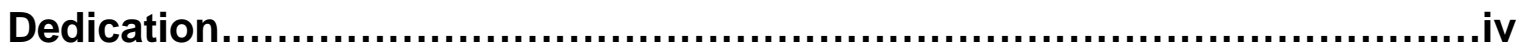

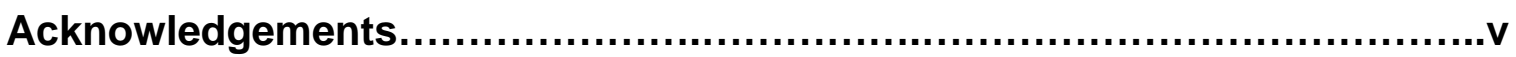

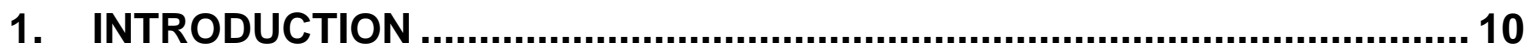

1.1. Biological importance of mRNA localization in different systems .............................10

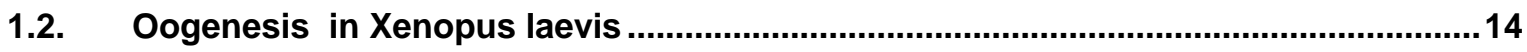

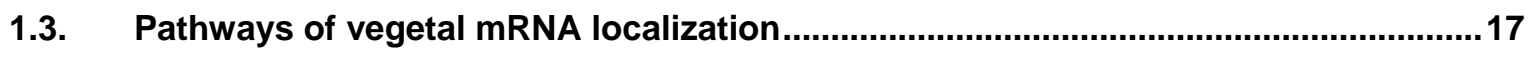

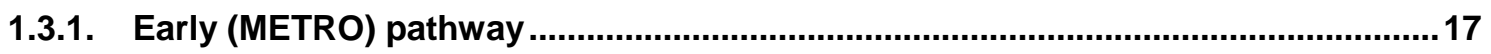

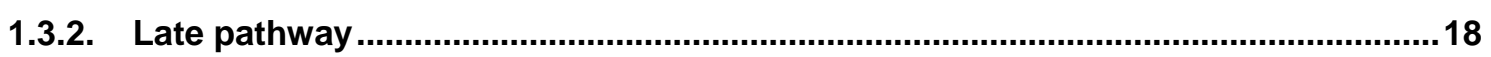

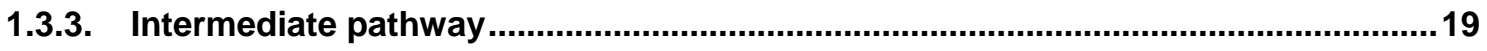

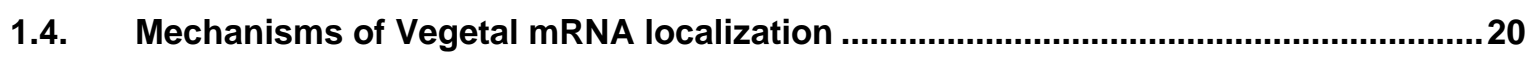

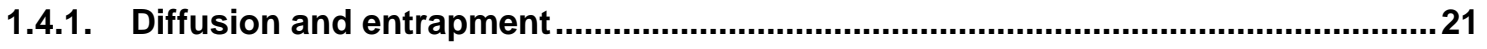

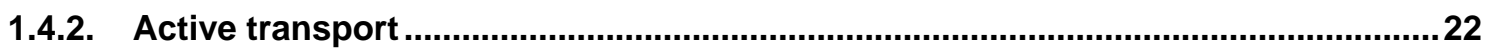

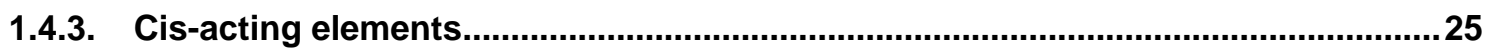

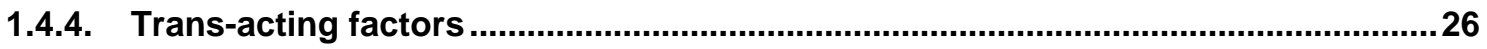

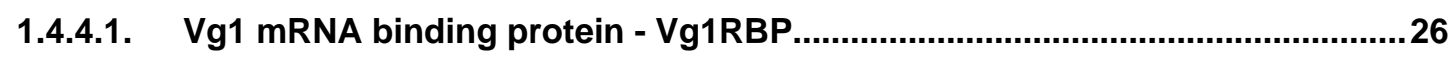

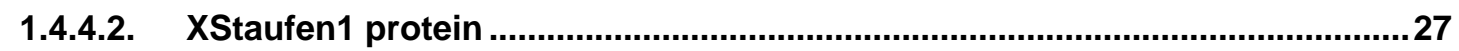

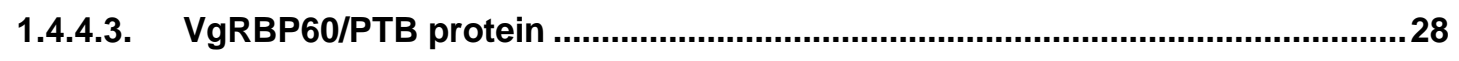

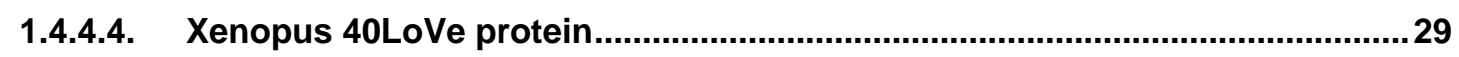

1.4.4.5. Xenopus Proline-rich RNA binding protein - Prrp..........................................29

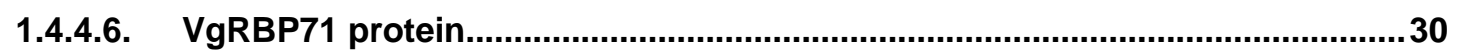

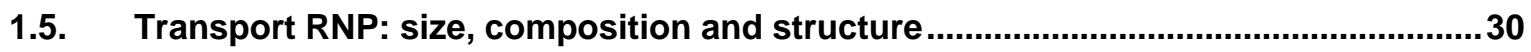

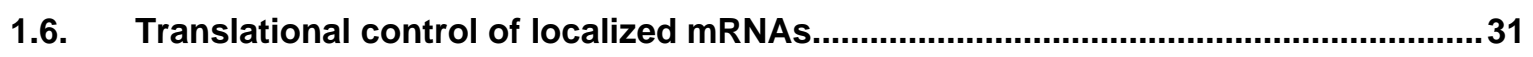

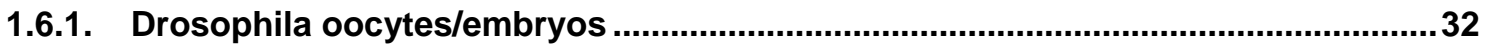

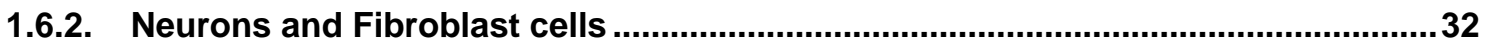

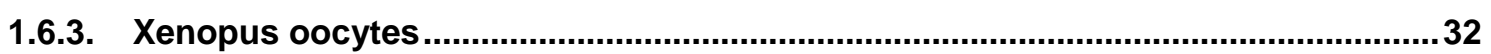




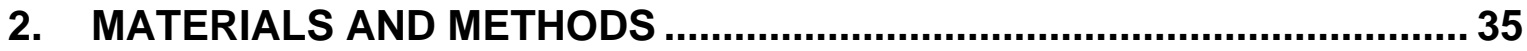

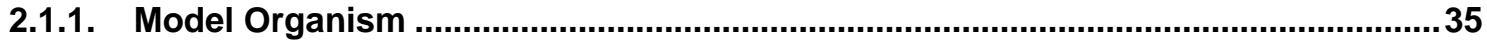

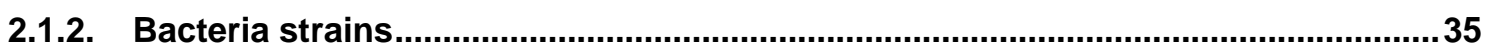

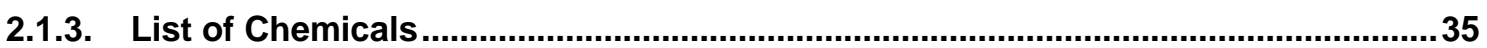

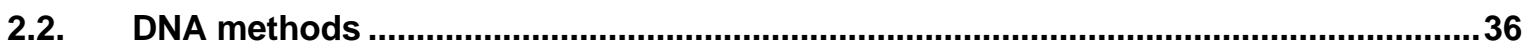

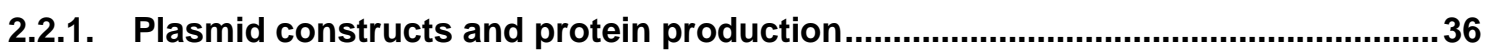

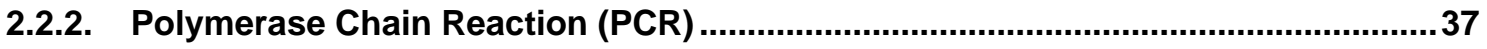

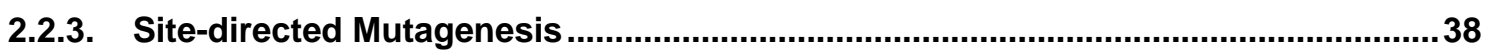

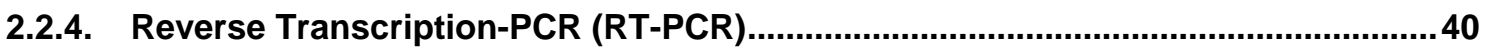

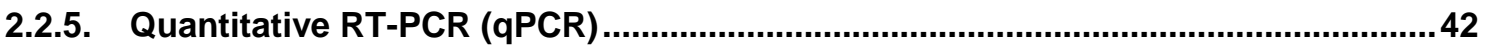

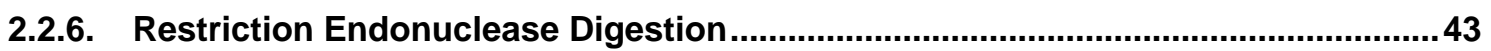

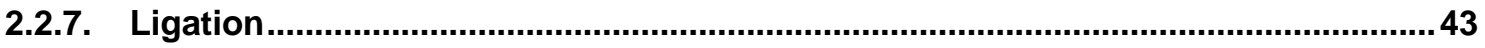

2.2.8. Preparation of Chemical Competent cells ............................................................44

2.2.9. Preparation of Electrocompetent Cells .............................................................. 44

2.2.10. Transformation of chemical competent cells...................................................45

2.2.11. Transformation by Electroporation ................................................................ 45

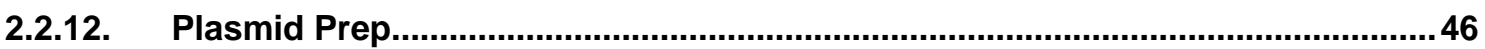

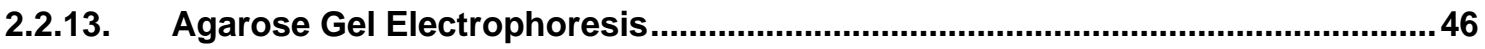

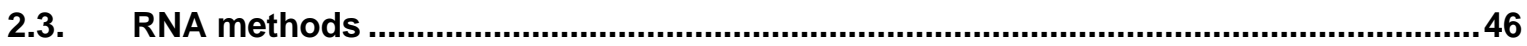

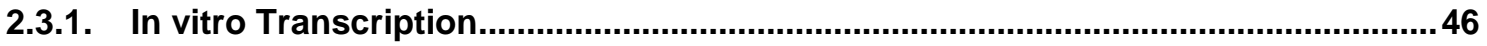

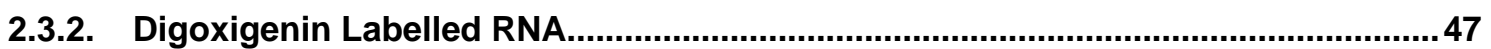

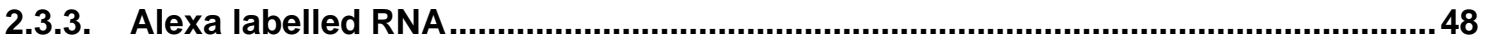

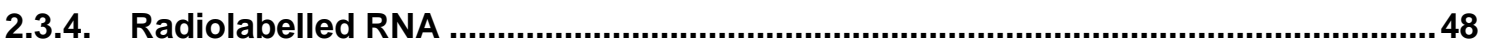

2.3.5. Total RNA Isolation Using Trizol Reagent ...........................................................48

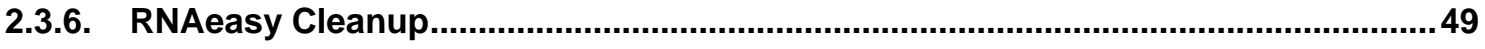

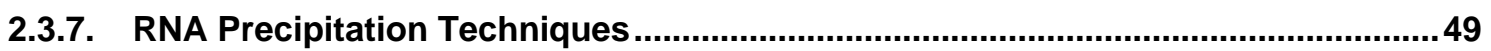

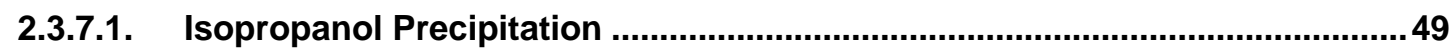

2.3.7.2. Sodium Acetate/Ethanol Precipitation ........................................................49

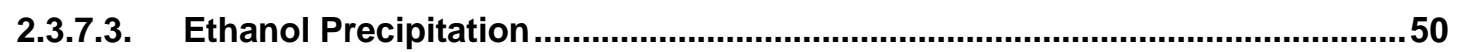

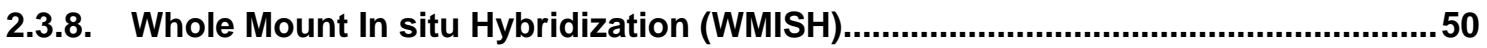

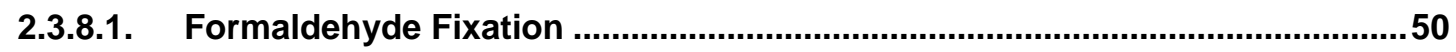

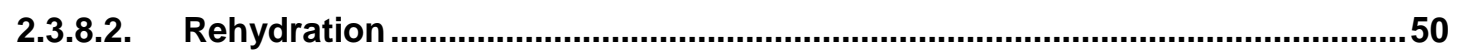

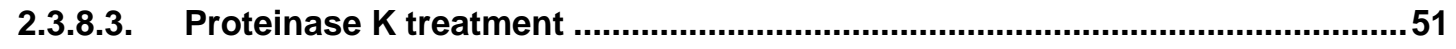

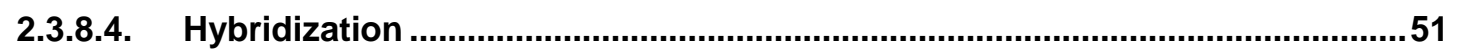

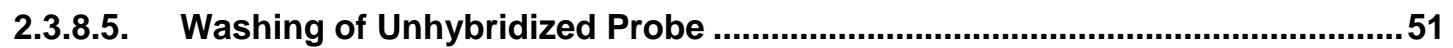

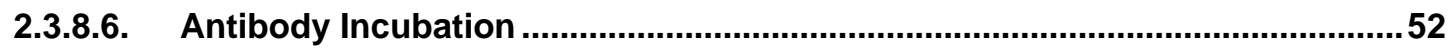

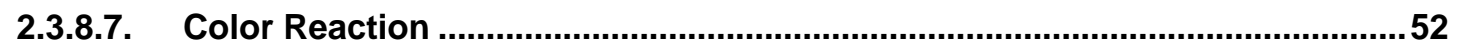

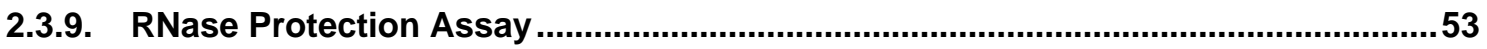

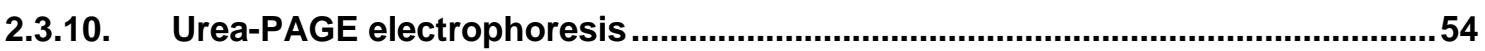




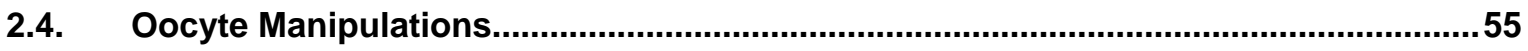

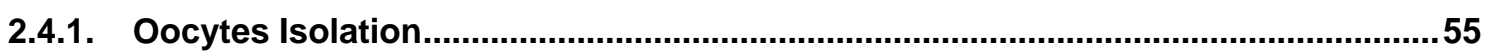

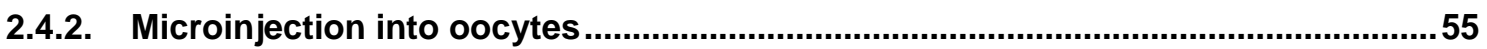

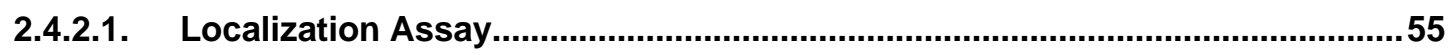

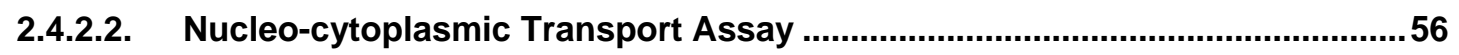

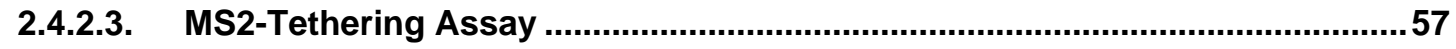

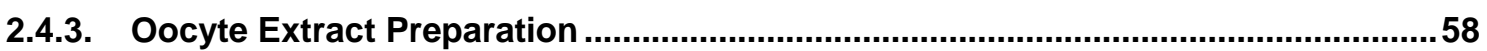

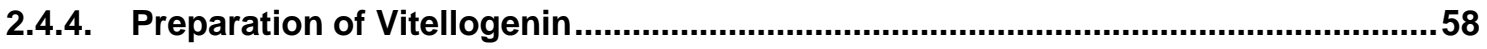

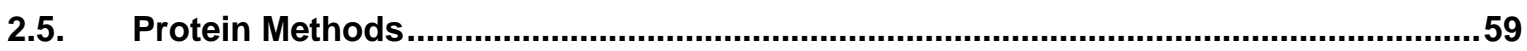

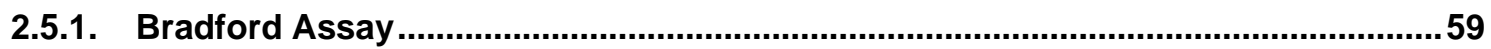

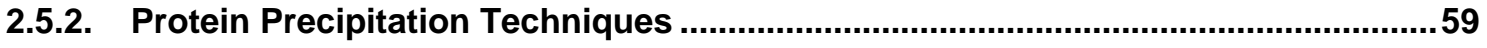

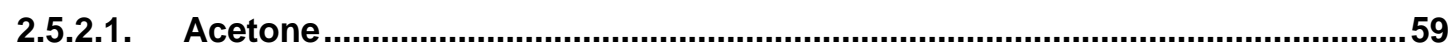

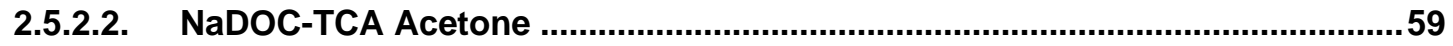

2.5.2.3. Phenol/Chloroform Extraction...........................................................................60

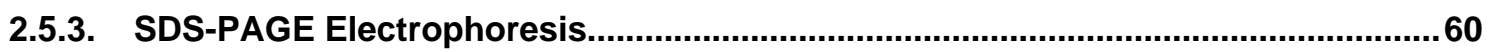

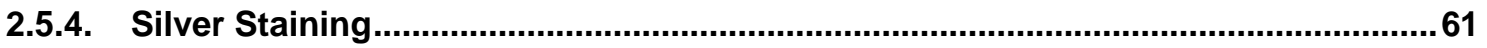

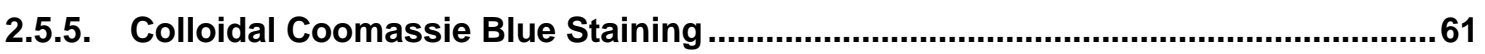

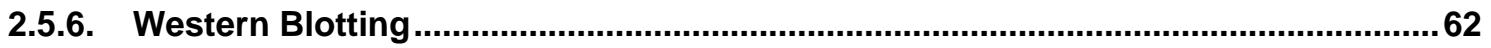

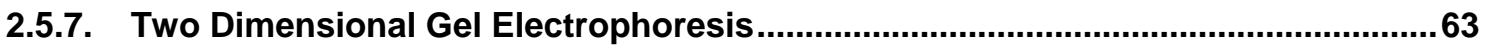

2.5.8. Mass Spectroscopic Protein Identification...............................................................64

2.5.9. Glycerol Gradient Centrifugation and Biochemical Enrichment ............................64

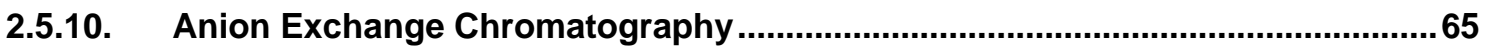

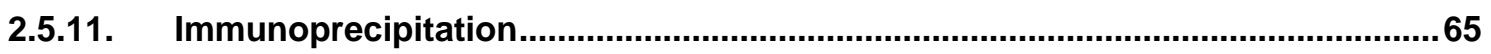

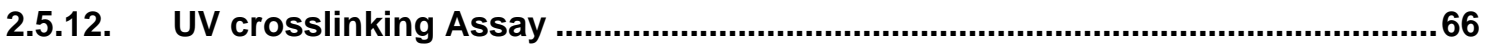

2.5.13. Electrophoretic Mobility Shift Assay (EMSA) ....................................................67

2.5.14. Paraffin Embedding and Sectioning .................................................................68

2.5.15. Immunostaining on Oocyte sections ........................................................68

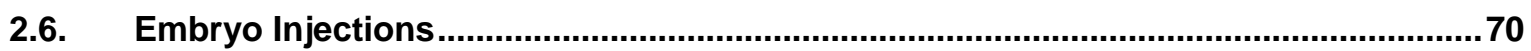

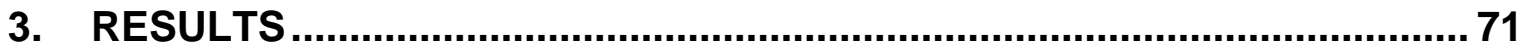

3.1. Identification Xenopus ElrA and ElrB as vegetal localization element binding proteins.

3.2. ElrB isoforms and ElrA exhibit similar specificities in binding to vegetal localization elements

3.3. ElrA/B proteins are part of one RNP complex together with Vg1RBP, XStaufen1, VgRBP60 and 40LoVe. 
3.5. Effect of Elr-type proteins on mRNA stability and translation in oocytes .97

3.6. Loss of ElrA/B binding strongly decreases mRNA stability in primordial germ cells in embryos 101

3.7. Subcellular distribution of Elr-type proteins in Xenopus 103

3.8. ElrA/B proteins are constitutive components of RNPs throughout oogenesis 108

4. DISCUSSION 111

4.1. Elav 111

4.2. Vegetal localization proteins are components of a large RNP 112

4.3. Isolation of ElrA/B as a novel vegetal localization element binding proteins 113

4.4. Heterogeneity of the localizing RNP 114

4.5. Identity of protein components of ElrA/B RNP complexes.

4.6. Participation of Elr-type proteins in vegetal mRNA localization .121

4.7. ElrA/B and translational control in oocytes.

4.8. ElrA/B and mRNA stability in oocytes 124

4.9. Mutations inhibiting ElrA/B binding lead to a reduction in mRNA stability in PGCs 125

4.10. Subcellular distribution of ElrA/B, a constitutive RNP component throughout oogenesis

5. SUMMARY

6. LITERATURE REFERENCES. 
7. APPENDIX 148

7.1. Appendix I. 148

7.1.1. Appendix I: Density gradient profile of localization proteins and ribosomes (leg)..148

7.1.2. Appendix I: Density gradient profile of localization proteins and ribosomes (Fig). 149

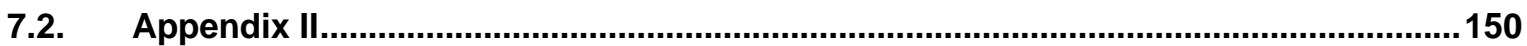

7.2.1. Appendix II: Identification of proteins in the RNP S200 - pH3-10(Legend)............150

7.2.2. Appendix II: Identification of proteins in the RNP S200 - pH3-10(Gel) .................151

7.2.3. Appendix II: Identification of proteins in the RNP S200 - pH3-10(Table) ..............152

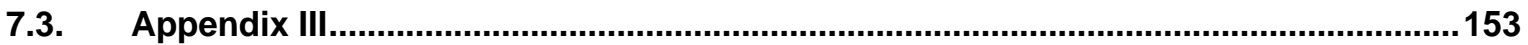

7.3.1. Appendix III: Identification of proteins in the RNP S200 - pH7-11(Legend)........... 153

7.3.2. Appendix III: Identification of proteins in the RNP S200 - pH7-11(Gel) ................ 154

7.3.3. Appendix III: Identification of proteins in the RNP S200 - pH7-11(Table) ............155

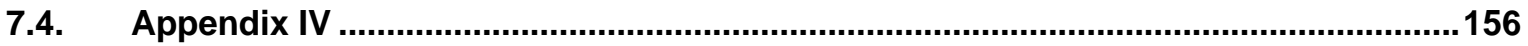

7.4.1. Appendix IV: Identification of proteins in the HS RNP S200 - pH3-10(Legend) .....156

7.4.2. Appendix IV: Identification of proteins in the HS RNPS200 - pH3-10(Gel) ............ 157

7.4.3. Appendix IV: Identification of proteins in the HS RNPS200 - pH3-10(Table) .........158

7.4.4. Appendix IV: Identification of proteins in the HS RNP S200 - pH3-10(Table-contd)159

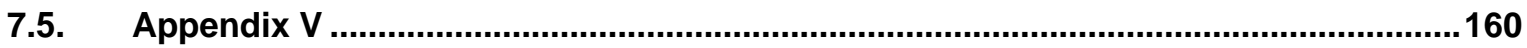

7.5.1. Appendix V: Identification of proteins in the HS RNPS200 \#2 - pH3-10(Legend) .. 160

7.5.2. Appendix V: Identification of proteins in the HS RNPS200 \#2 - pH3-10(Gel)........161

7.5.3. Appendix V: Identification of proteins in the HS RNPS200 \#2 - pH3-10(Table) ..... 162

7.6. Appendix VI 163

7.6.1. Appendix VI: Identification of proteins associated with 40LoVe -pH3-10(Legend)163

7.6.2. Appendix VI: Identification of proteins associated with 40LoVe -pH3-10(Gel)......164

7.6.3. Appendix VI: Identification of proteins associated with 40LoVe -pH3-10(Table)..165

7.7. Appendix VII: Identification of proteins associated with ElrA/B -pH3-10 (Gel) ........166

7.8. Appendix VIII: Identification of proteins associated with 40LoVe -pH3-10 (Gel) ......167 


\section{List of Tables}

Table 1.1 Early localized mRNA in Xenopus oocytes...............................................................18

Table 1.2 mRNAs localized through late pathway....................................................................................19

Table 1.3 mRNAs localized via the intermediate pathway. ...................................................................19

Table 2.1 XDE LE mutagenesis primers..................................................................................... 39

Table 3.1 List of proteins identified from RNP S200 with predicted functional link to RNA .. 76

Table 3.2 List of proteins co-precipitating with the Elr-type proteins .............................................. 89 


\section{List of Figures}

Figure 1.1 Roles of mRNA localization in a variety of systems [from (Kloc et al., 2002b)].....12

Figure 1.2 Examples of mRNA localization in different biological systems 14

Figure 1.3 Stages of Xenopus laevis oogenesis, [modified from (Horvay, 2005)] 15

Figure 1.4 Section of stage I-VI oocytes [from (Hausen and Riebesell, 1991)] ............................16

Figure 1.5 Annotation of oocyte components in a section of a stage VI oocyte,........................17

Figure 1.6 Pathways of vegetal mRNA localization in oocytes..................................................20

Figure 1.7 Model of the mechanism of diffusion and entrapment used by early localized mRNAs in oocytes.

Figure 1.8 Model of the active transport mechanism used by mRNAs localizing via the late pathway.

Figure 1.9 Structure of mRNA depicting its vegetal localization element in the $3^{\prime}$ UTR.........25

Figure 1.10 Domain structure of Xenopus Vg1RBP protein .......................................................26

Figure 1.11 Domain structure of Xenopus Staufen 1 protein ...........................................................28

Figure 1.12 Model for the function of the Drosophila Staufen protein............................................28

Figure 1.13 Domain structure of Xenopus VgRBP60 protein, depicting the 4 RRM domains 29

Figure 1.14 Domain structure of Xenopus 40LoVe (Localization Vegetal) protein depicting the two RRM domains.

Figure 1.15 Domain structure of Xenopus Prrp protein depicting the $2 \mathrm{~N}$-terminal RRM domains and a C-terminal Proline-rich domain. 30

Figure 1.16 Domain structure of Xenopus VgRBP71 protein, showing 4 KH domains drawn to the scale as predicted by the NCBI-protein blast program 30

Figure 2.1 Scheme for PCR-based Multiple Site directed Mutagenesis ......................................... 39

Figure 3.1 Biochemical enrichment of vegetal localization element binding proteins ..............74

Figure 3.2 Identification of RNA binding proteins contained in RNPS200 ..................................... 75

Figure 3.3 Identification of EIrA/B protein as vegetal localization element binding proteins 77

Figure 3.4 Anion exchange chromatographic (ANX) profile of RNA binding proteins in RNP S200 79

Figure 3.5 Vg1RBP and Elr-type proteins bind vegetal localization elements with different specificities. 
Figure 3.6 Comparison of domain structure and sequences of putative Elr-type isoforms expressed in the oocyte

Figure 3.7 Vegetal localization element binding properties are indistinguishable for the tagged versions of and the putative endogenous ElrB isoforms in the oocyte

Figure 3.8 ElrA and B proteins Interact with Vg1RBP and XStaufen1 in an RNA-dependent manner

Figure 3.9 ElrA/B interact with localization proteins VgRBP60 and 40LoVe in an RNA dependent manner.

Figure 3.10b Identification of protein components of immuno-isolated ElrA/B RNPs (analytical scale)

Figure 3.11 Identification of protein components of immuno-isolated ElrA/B RNPs. 90

Figure 3.12 Novel RAP55 related protein co-immunoprecipitated with ElrA/B proteins .92

Figure 3.13 Mutagenesis of putative ElrA/B binding sites in XDE-LE. .93

Figure 3.14 Interference with ElrA/B-binding by mutagenesis blocks vegetal localization of the XDE LE

Figure 3.15 Antisense morpholino mediated Interference with ElrA/B-binding blocks vegetal localization of the XDE-LE.

Figure 3.16 Inhibition of vegetal RNA localization by antisense morpholino oligonucleotides blocking ElrA/B binding to XDE LE.

Figure 3.17 ElrA/B proteins moderately upregulate translation in oocytes and loss of binding mutation in XDE LE does not markedly alters translation levels of reporter mRNA.

Figure 3.18 Interference with EIrA/B binding to XDE LE does not influence mRNA stability in oocytes. .100

Figure 3.19 Loss of binding mutation in XDE LE strongly decreases mRNA stability in PGCs during embryogenesis.

Figure 3.20a Subcellular distribution of ElrA and B in stage III oocytes. 105

Figure 3.20b Subcellular distribution of ElrA and B in stage IV oocytes 106

Figure 3.22 ElrA/B and Vg1RBP proteins are constitutive RNP components throughout oogenesis 
Figure 4.1 Domain structure of Xenopus Elav protein, showing 3 RRM domains... .112

Figure 4.2 Model of RNP heterogeneity exhibited by the various vegetal localization elements 


\section{Introduction}

mRNA localization is a multi-step process of transporting mRNA molecules to a specific domain of a cell; it is initiated by the recognition of a cis-acting signal by trans-acting factors and this most often ultimately results in local protein synthesis and function. It is a mechanism used in wide a variety of biological processes for the establishment of asymmetry vital for cellular function or embryonic development. The occurrence of this process has been reported in several biological systems such as Drosophila oocyte, yeast, Xenopus oocyte, fibroblasts and neuronal cells (Dahm and Kiebler, 2005; Gonsalvez et al., 2005; Kloc et al., 2001; Kloc et al., 2002b; St Johnston, 2005).

\subsection{Biological importance of mRNA localization in different systems}

In Drosophila, the two prominent examples of mRNAs of Bicoid and Oskar are transcribed in the nurse cells and localize to anterior (Fig. 1.2A) and posterior (Fig. $1.2 \mathrm{~B})$ poles of the oocyte respectively. The bicoid protein thus forms an anteriorposterior morphogen gradient (illustrated in Fig. 1.1B), that organizes the anterior structures of the embryo (Driever and Nusslein-Volhard, 1988a; Driever and Nusslein-Volhard, 1988b; Driever et al., 1990). Oskar protein on the other hand serves a dual developmental function of the determination of germ cell fate and posterior polarity (Lehmann and Ephrussi, 1994). In addition Oskar mRNA plays a translation-independent role during oogenesis perhaps as scaffold or regulatory RNA, since Oskar mRNA null mutants were found to be sterile due to arrest in early oogenesis (Jenny et al., 2006). This defines an exception to the notion that localized mRNAs exert their function solely by ensuring high local protein concentration. In Xenopus oocytes, examples of translation-independent function for localized mRNAs have also been described for VegT and XIsirt mRNAs, which are required for the cytokeratin mediated anchoring of vegetally localized mRNAs at the cortex (Kloc et al., 2005).

Another instance for the biological relevance of mRNA localization is the translation of ß-actin mRNA localized at the leading edge of fibroblast cell, (Fig $1.1 \mathrm{~A}$ and $1.2 \mathrm{E}$ ); this then ensures that actin polymerization is in the leading edge of the cell to enable directional migration to occur. The same is true for ß-actin 
mRNA in neurons (Fig 1.1E), where the same mechanism contributes to the regulation of growth and guidance of axons (Dahm and Kiebler, 2005). The mRNA encoding myelin basic protein (MBP) is similarly localized in oligodendrocytes to the dendrites, this is meant to prevent translation of this highly positively charged protein anywhere in the cell except for the site of myelination (Smith, 2004). In budding yeast (Fig 1.2 C), mating type switching is regulated by the exclusive translation of localized ASH1 mRNA in the daughter cell (Chartrand et al., 2001; Gonsalvez et al., 2005). The Ash1 protein in the daughter cell functions as a transcriptional factor which inhibits the expression of the endonuclease $\mathrm{HO}$, which promotes the mating-type switching process (Tekotte and Davis, 2002).

The mRNA localization process is also used to restrict certain transcripts to subcellular structures, e.g. cyclin B1 mRNA is targeted to mitotic spindles in Xenopus embryos (Groisman et al., 2000). This local translation of cyclin B1 at the spindle apparatus is believed to regulate the cell cycle. There are now several mRNAs identified that exhibit localization to the perinuclear region as well as many other subcellular domains previously not described (Lecuyer et al., 2007). These further indicate the importance mRNA localization as an important mechanism for the fine tuning of gene expression and as such aberration in this process could lead to defects in cell function, the developmental program of whole organisms and it can also result in disease (Bassell and Kelic, 2004; Wang et al., 2007) .

During Xenopus oogenesis, the process of vegetal mRNA localization contributes to laying the foundation for germ layer formation and germ cell development later during embryogenesis. There are two distinct populations of localized mRNA in Xenopus oocytes; the first group is involved in germ layer determination, the best studied examples are Vg1 (Melton, 1987; Rebagliati et al., 1985) and VegT mRNA (Horb and Thomsen, 1997; Stennard et al., 1996). These mRNAs encode a TGF beta homolog (Melton et al., 1989) and a T-box transcription factor (Stennard et al., 1996), respectively. They are inherited largely by the vegetal-most blastomeres resulting in vegetal-animal protein gradients essential for the induction of endodermal and mesodermal germ layers (Kofron et al., 1999; Zhang et al., 1998). The second group of mRNAs, such as Xpat, Xcat2, and Xdazl, is 
involved in the specification of germ cells (Houston et al., 1998; Hudson and Woodland, 1998; Mosquera et al., 1993).
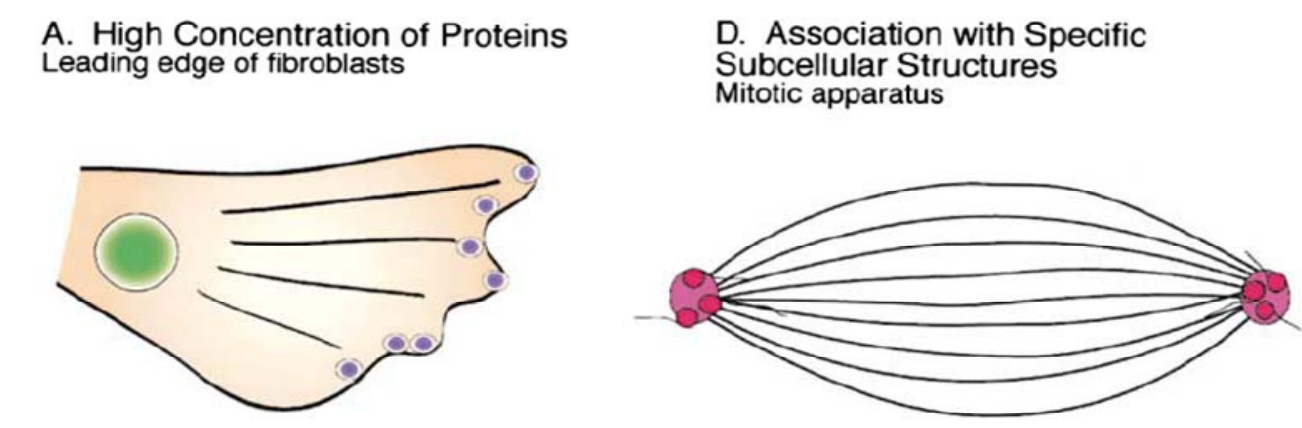

B. Gradients of Morphogens Bicoid in Drosophila

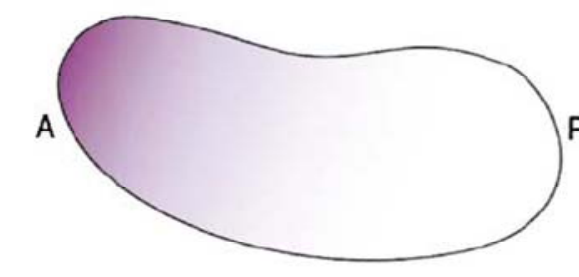

\section{E. Localized Translation} Neurons

C. Cell Lineage Specification Germ plasm in Xenopus

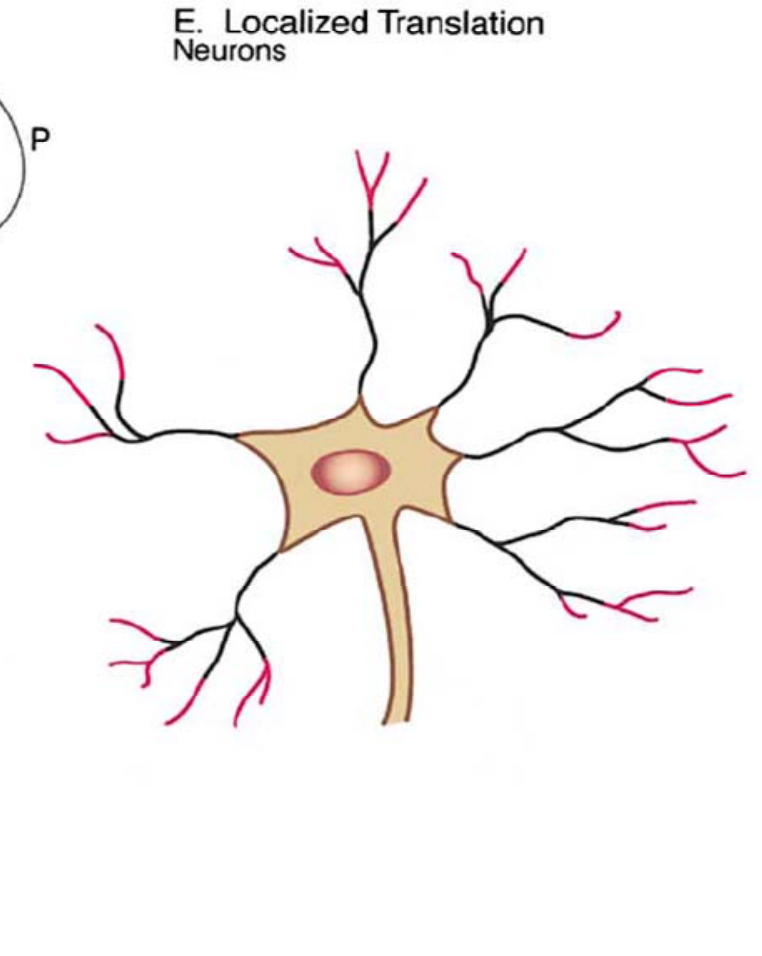

Figure 1.1 Roles of mRNA localization in a variety of systems [from (Kloc et al., 2002b)]

(A) A High level of a protein is produced in a specific domain of a cell as illustrated by ß-actin mRNA and protein accumulation at the leading edge of a fibroblast. (B) The generation of morphogen gradients in oocytes and embryos as found in Drosophila; bicoid mRNA localization produces a gradient of Bicoid protein. (C) Cell lineage is specified by localized mRNAs where determinants are partitioned unequally into daughter cells; Xenopus germplasm containing early localized mRNA specify PGCs. (D) mRNAs associate with different organelles or cellular structures, as exemplified by the localization of cyclin B mRNA at the mitotic spindle poles. (E) Some mRNAs are localized to a specific region of a cell to allow for local translation, e.g. mRNAs at the synapses of neurons (red). 

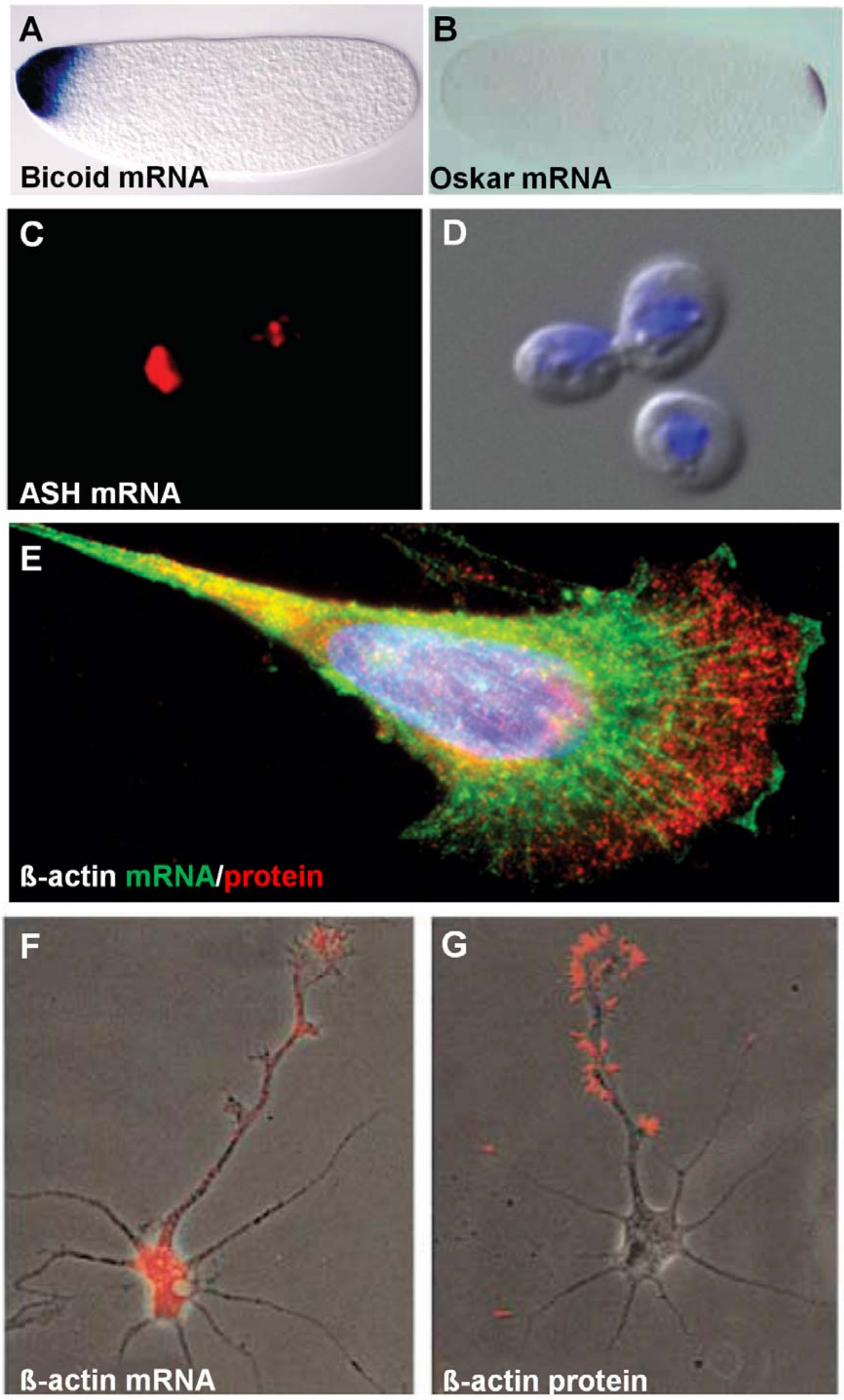
Figure 1.2 Examples of mRNA localization in different biological systems

(A) Drosophila Bicoid mRNA is localized to the anterior pole of a freshly laid egg [from (Irion and St Johnston, 2007)]. (B) Drosophila Oskar mRNA is localized to the posterior pole of a freshly laid egg [from (Vanzo and Ephrussi, 2002)]. (C) ASH1 mRNA is localized to the distal tip of anaphase cells, (D) the corresponding DAPI (blue)/Nomarski merged image [from (Gonsalvez et al., 2005)]. (E) ß-actin mRNA (red) localizes to the fibroblast's leading edge, B-actin protein is shown in green, and the nucleus is stained in blue [from (Dahm and Kiebler, 2005)] (F) B-actin mRNA localization in the neurite and growth cone; (G) B-actin protein is highly enriched in the growth cone and filopodia [from (Kloc et al., 2002b)].

\subsection{Oogenesis in Xenopus laevis}

Oogenesis in Xenopus laevis is divided into six stages (Dumont, 1972); the oogonium is specified from a self-renewing stem cell which gives rise to a large number of oocytes in the female. During oogenesis, the oocyte which is arrested in diplotene stage of prophase I, increases dramatically in size and accumulates all the material needed for the early stages of embryo development. There are two major phases; the previtellogenesis (stage I) and the vitellogenesis phase. At stage II, the oocyte begins to take up large amounts of vitellogenin from the blood by micropinocytosis. Vitellogenin is a $470 \mathrm{kDa}$ protein produced in the liver of the female frog and is delivered to the oocytes through the bloodstream; it serves as the source of nutrition for the embryo at the early stages of development (Gilbert, 2000).

The stage I oocyte is transparent, with a centrally placed nucleus; the first sign of asymmetry is the attachment of the mitochondria cloud (also called the Balbiani body) to one side of the nucleus facing the future vegetal hemisphere (Fig. 1.3 and 1.4A) (Guraya, 1979). The Balbiani body consists of a number of mitochondria, endoplasmic reticulum, germplasm and several mRNAs mostly implicated in the process of germ line specification. A sub-structure of the Balbiani body pointing to the vegetal pole is described as message transport organiser (METRO), it contains the germinal granules. The stage II oocyte begins to acquire pigmentation as well as to take up vitellogenin, whilst the mitochondrial cloud break down into islands and move towards the vegetal cortex. In stage III - VI there is a sharp contrast of the highly pigmented animal half with the vegetal half remaining lightly pigmented (Fig 1.3), the nucleus starts to shift to the animal half 
from stage IV on becoming clearly evident in stage VI (Fig 1.4F), the annotated ultra-structure of the fully grown stage $\mathrm{VI}$ oocyte is shown in (Fig. 1.5). Although the oocyte appears radially symmetrical, there are certain mRNA molecules which localize either to the animal or to the vegetal pole. Some of these mRNAs localizing to the vegetal cortex encode proteins which have been shown to function in embryo axis specification and germ cell development, as mentioned above (Kloc et al., 2001).

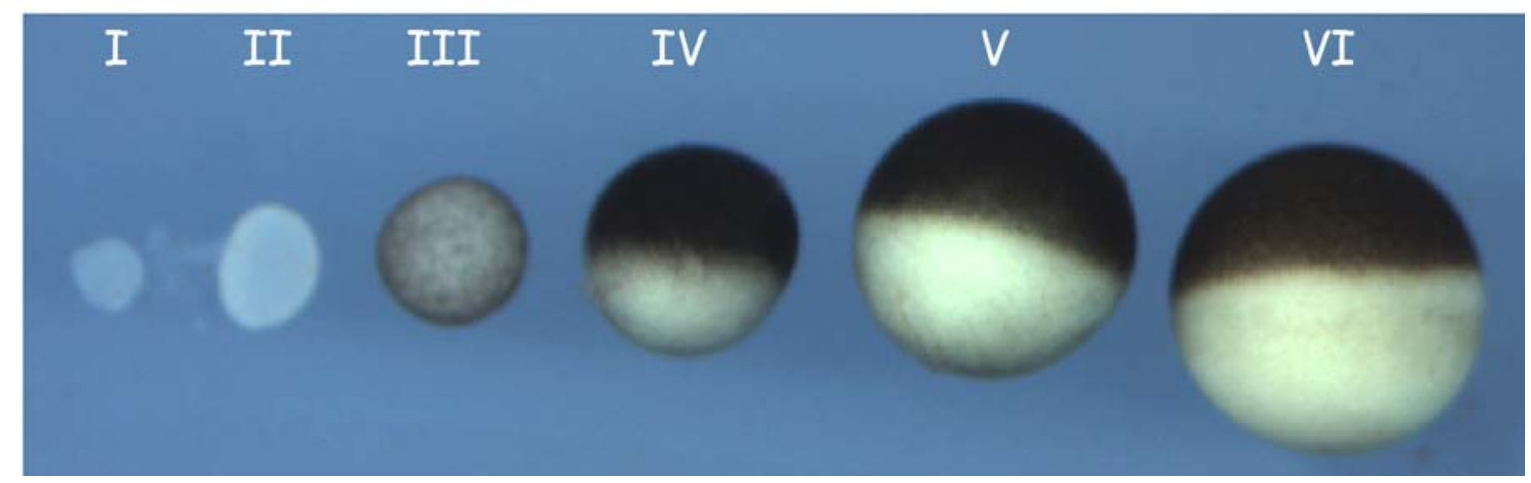

Figure 1.3 Stages of Xenopus laevis oogenesis, [modified from (Horvay, 2005)]

Stage I oocytes (50-300 $\mu \mathrm{m}$ in diameter) are transparent with a centrally placed nucleus. Stage II oocytes are 300-450 $\mu \mathrm{m}$ in diameter and opaque. Stage III oocytes $(450-600 \mu \mathrm{m})$ are lightly and uniformly pigmented. Stage IV oocytes $(600-1000 \mu \mathrm{m})$ have the nucleus placed towards the pigmented animal hemisphere. Stage V oocytes are 1000-1100 $\mu \mathrm{m}$, and Stage VI oocytes are fully-grown with a diameter of 1100-1300 $\mu \mathrm{m}$.

Maturation of oocytes into eggs is triggered by progesterone which is secreted from the follicle cells, leading to the resumption and completion of meiosis. The response of the late stage $\mathrm{VI}$ oocytes to the hormone is indicated by germinal vesicle break-down, which appears within 6 hours of stimulation (Gilbert, 2000). The oocyte which has been arrested in the diplotene stage of prophase I resumes and completes the process of meiosis. There are several post-transcriptional events that take place during maturation, transcription in general seizes completely in late stage $\mathrm{VI}$, and several stored maternal mRNA become translationally active. This stimulation of translation of the quiescent mRNAs, including c-mos, cyclin mRNAs, is correlated strongly to the extension of their poly A tails as well as increased methylation of the $5^{\prime}$ cap structure (Barkoff et al., 1998; Gillian-Daniel et al., 1998; Sheets et al., 1994; Sheets et al., 1995). 


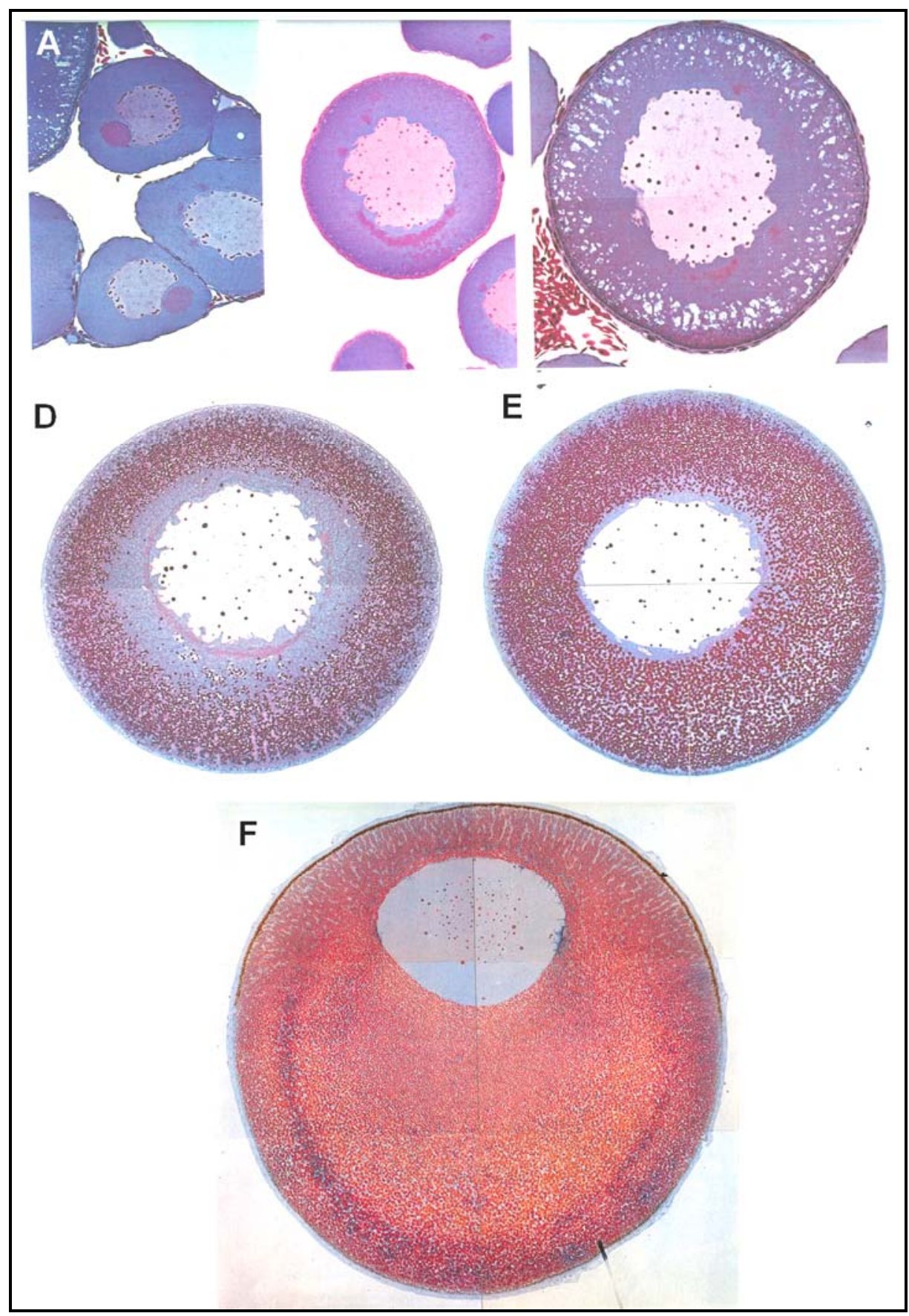

Figure 1.4 Section of stage I-VI oocytes [from (Hausen and Riebesell, 1991)]

(A) Late stage I oocyte with the nucleus showing a slight depression at the side of Balbiani body attachment, displacing the nucleoli. A dense layer of follicle cells covers the oocyte. (B) Early stage II oocyte showing mitochondrial cloud fragments, parts of which surround the nucleus whilst the other part is transported towards the future vegetal pole. (C) Late stage II oocyte, Balbiani body completely fragmented, with part of it settled at the vegetal cortex. (D) Stage III oocyte, Balbiani body almost completely localized to the vegetal cortex, yolk platelets are uniform in size and positioned outwardly in the cytoplasm, cortical granules line the plasma membrane. (E) Stage IV oocytes, the pigment granules make the animal cortex thicker than the vegetal one. The yolk platelets in the vegetal half are larger than at the animal half. (F) Stage VI oocyte, the nucleus is clearly placed in the animal half, pigment granules appear as a dark layer beneath the plasma membrane. 


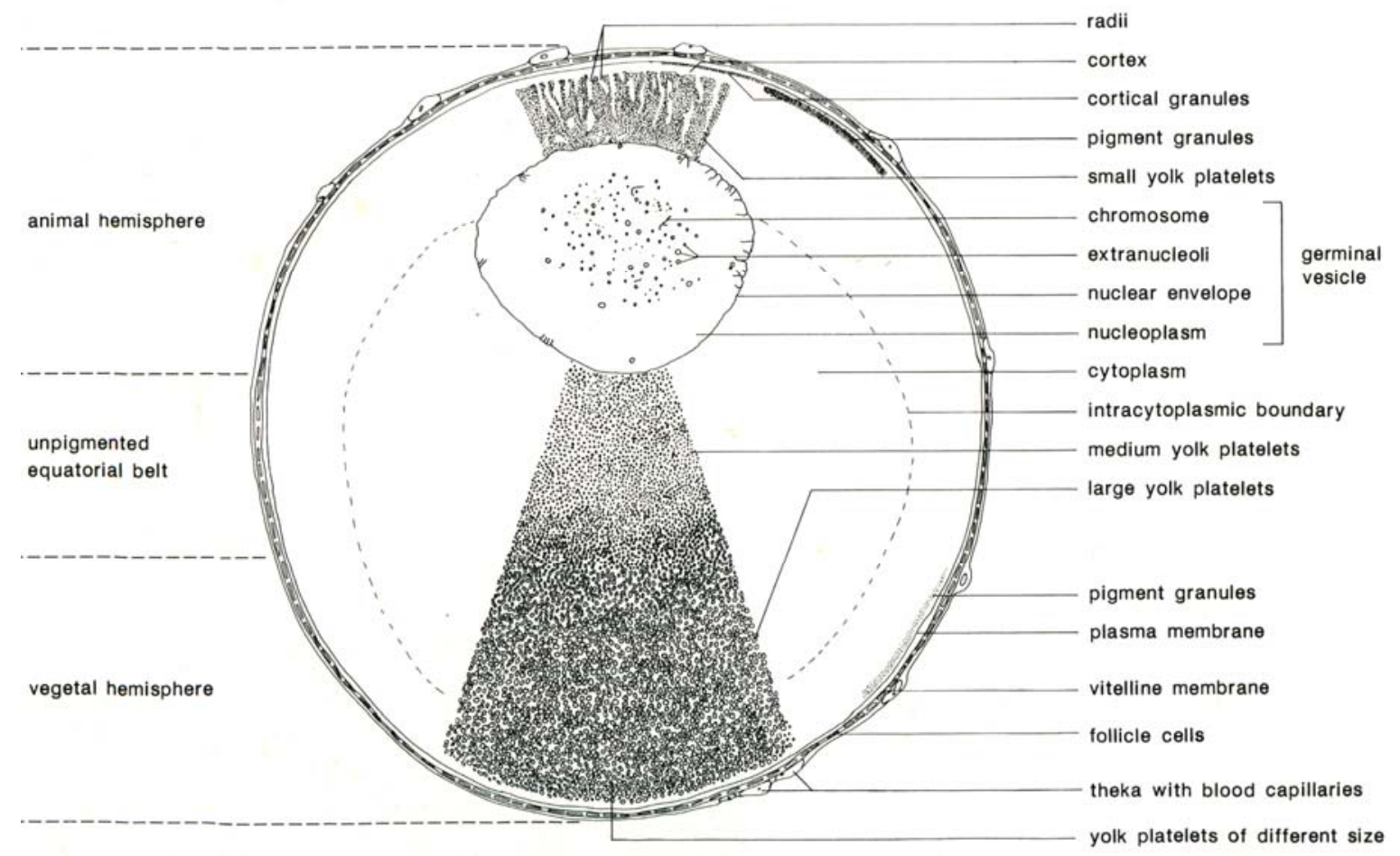

Figure 1.5 Annotation of oocyte components in a section of a stage VI oocyte,

[from (Hausen and Riebesell, 1991)]

\subsection{Pathways of vegetal mRNA localization}

Localization of mRNA to the vegetal cortex of oocytes occurs via two main early and late pathways and a third one that combines features of the first two and is therefore referred to as the intermediate pathway. The mRNAs transported via the early pathway are implicated mainly in germ cell specification whilst those using the late pathway are linked to germ layer specification. There is however an interesting exception in XDead end mRNA which is localized by the late pathway but only becomes restricted to the germplasm and PGCs during early embryogenesis (Horvay et al., 2006).

\subsubsection{Early (METRO) pathway}

There are several examples of mRNAs that use this pathway in localizing to the vegetal cortex; some of these are listed below (Table 1.1). These mRNAs are first enriched in the METRO sub-region of the mitochondrial cloud during stage I of oogenesis by diffusion and entrapment within this structure. Localization to the vegetal cortex occurs passively by stage II of oogenesis, when the Balbiani body disintegrates and migrates to the vegetal cortex (Kloc et al., 2001). At the cortex 
these mRNAs characteristically occupy a narrow region, as shown in Fig. 1.6. Early localized mRNAs remain associated with the germplasm at the vegetal cortex throughout oogenesis and early embryogenesis, where they are selectively taken up by some vegetal blastomeres which later give rise to primordial germ cells (Hudson and Woodland, 1998). There are exceptions to the general rule for early localized mRNAs to encode for proteins that function in germ cell development, e.g. Xwnt11 is reported to be involved in axis specification ( $\mathrm{Ku}$ and Melton, 1993).

Table 1.1 Early localized mRNA in Xenopus oocytes

\begin{tabular}{|c|c|c|}
\hline Localized mRNA & Encoded protein function & References \\
\hline Xcat2 & Zn finger protein, related to Nanos & (Mosquera et al., 1993) \\
\hline Xdazl & RNA binding protein, related to DAZ & (Houston et al., 1998) \\
\hline Xpat & Novel protein & $\begin{array}{c}\text { (Hudson and Woodland, } \\
1998)\end{array}$ \\
\hline Xwnt11 & Wnt ligand & (Ku and Melton, 1993) \\
\hline XIsirts & Non-coding RNA & (Kloc et al., 1993) \\
\hline XNIF & Novel protein & (Claussen et al., 2004) \\
\hline XGRIP2.1 & Glutamate receptor interacting & (Tarbashevich et al., 2007) \\
\hline Centroid & Drotein & (Kloc and Chan, 2007) \\
\hline
\end{tabular}

\subsubsection{Late pathway}

mRNAs transported by the late pathway are found to be uniformly distributed in the cytoplasm of the stage I-II oocyte excluding the Balbiani body (Melton, 1987); several of them are also absent from the germplasm in embryos (Kloc et al., 1998). These mRNAs become enriched within a wedge-shaped structure in the cytoplasm between the nucleus and the vegetal cortex, which overlaps with a subdomain of the ER in late stage II oocytes (Deshler et al., 1997). During mid oogenesis, mRNAs gets localized by an active transport mechanism to the vegetal cortex, where they become tightly anchored. Characteristically, these mRNAs occupy the entire vegetal cortex, which is one of the major distinctions from the early pathway. It has been observed that early localized mRNAs, when injected into stage III-IV oocytes, are able to use the late pathway of transport to the vegetal cortex as well. Vg1 mRNA, as well as other late localized mRNAs remain anchored to the vegetal cortex throughout oogenesis, but are released upon 
oocyte maturation (Thomsen and Melton, 1993). Examples of mRNAs localized via the late pathway are listed in the Table 1.2 (below)

Table 1.2 mRNAs localized through late pathway

\begin{tabular}{|c|c|c|}
\hline Localized mRNA & Encoded protein function & References \\
\hline Vg1 & TGF-ß family member & (Rebagliati et al., 1985) \\
\hline VegT & Transcription factor & (Stennard et al., 1996) \\
\hline XDead end & RNA binding protein (RRM domain) & (Horvay et al., 2006) \\
\hline XPTB & Phosphotyrosine binding & (Claussen, 2002) \\
\hline Xvelo1 & Novel protein & (Claussen and Pieler, 2004) \\
\hline Velo7 & Metabolic enzyme & (Horvay, 2005) \\
\hline Velo76 & Novel protein & (Horvay, 2005) \\
\hline
\end{tabular}

\subsubsection{Intermediate pathway}

This pathway combines features of both early and late pathways, in that mRNAs, e.g. Velo45 mRNA (Fig 1.6), transported by this pathway are uniformly distributed throughout the cytoplasm in stage I oocytes, excluded from the Balbiani body like is the case for late pathway. In stage II oocyte, these mRNAs accumulate in the Balbiani body in a pattern similar to the early pathway, then in stage III enrich in the wedge-shape structure, finally localizing broadly at the vegetal cortex reminiscent of the late pathway (Kloc et al., 2001). What is not clearly understood is whether there exists a distinct intermediate transport pathway, or if these mRNAs are able to use both pathways depending on which is operational at the time of their export into the cytoplasm (King et al., 2005). Examples of mRNAs localizing via this pathway are listed below in Table 1.3.

Table 1.3 mRNAs localized via the intermediate pathway.

\begin{tabular}{|c|c|c|}
\hline Localized mRNA & Encoded protein function & References \\
\hline fatvg & Adipophilin & (Chan et al., 1999) \\
\hline Hermes & RNA binding protein (RRM domain) & (Zearfoss et al., 2004) \\
\hline Xotx1 & Transcription factor & (Pannese et al., 2000) \\
\hline Velo40 & Protein kinase & (Horvay, 2005) \\
\hline Velo45 & Putative Ubiquitin ligase & (Dreier, 2005) \\
\hline
\end{tabular}




\section{Early (METRO) Pathway}

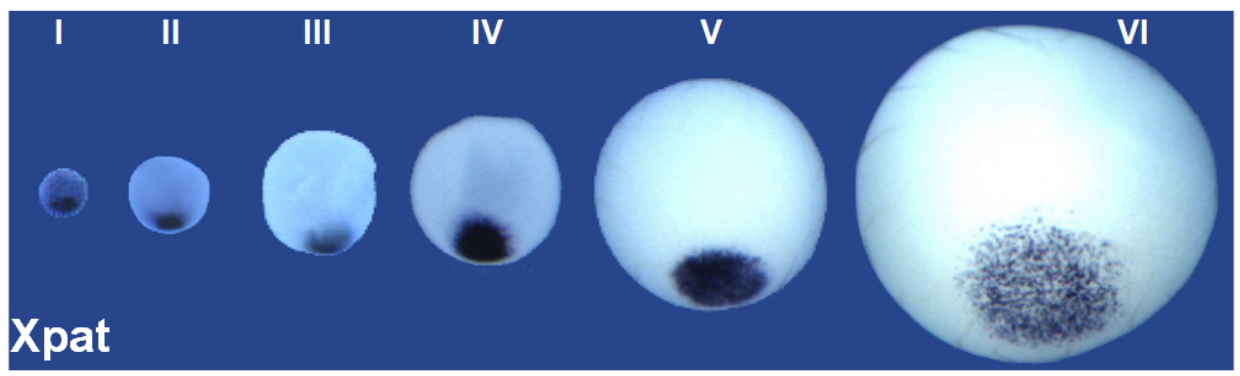

\section{Intermediate Pathway}

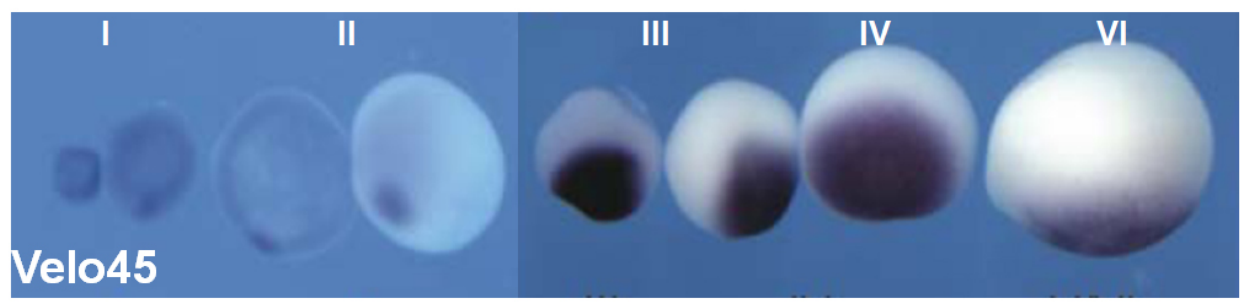

\section{Late Pathway}

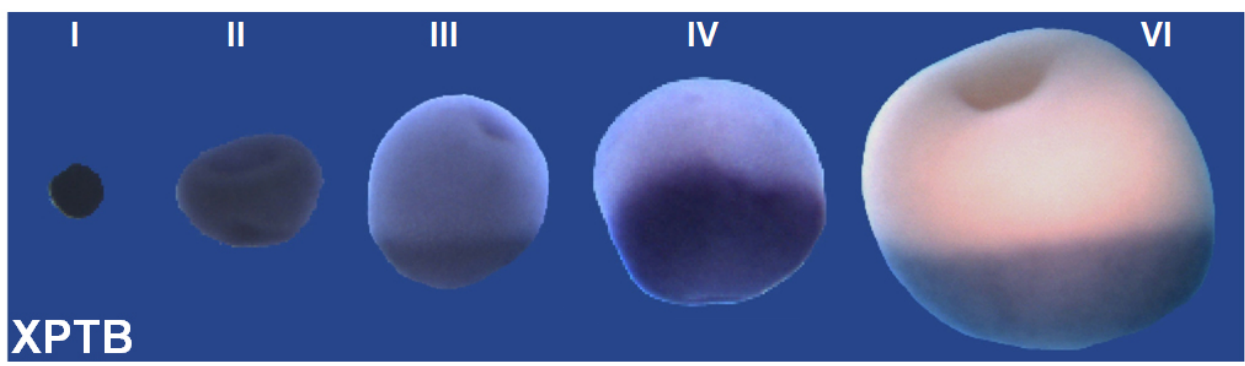

Figure 1.6 Pathways of vegetal mRNA localization in oocytes

In situ hybridization detection of mRNAs in stage I-VI localized via the three different pathways to the vegetal cortex of Xenopus oocytes. Xpat mRNA is early localized (pictures by the courtesy of Katja Koebernick), Velo45 mRNA is localized via the intermediate pathway [picture taken from (Dreier, 2005)], and XPTB mRNA is late localized (pictures by the courtesy of Katja Koebernick).

\subsection{Mechanisms of Vegetal mRNA localization}

Four distinct mechanisms are known to be used by a variety of systems to achieve mRNA localization to a distinct region of the cell; vegetal mRNA transport occurs in Xenopus oocytes via two of these mechanisms. Firstly, there is a diffusion and local entrapment mechanism; in the Drosophila oocyte, the posterior pole localization of Nanos mRNA and proteins such as Oskar, Tudor and Vasa in 
the pole plasm are required for RNA anchoring (Forrest and Gavis, 2003; Wang et al., 1994). A similar situation holds true for early localized mRNAs in Xenopus oocytes (Chang et al., 2004).

The second mechanism is local RNA stabilization; the level of Hsp83 mRNA is found to be markedly reduced within the developing Drosophila embryo, except at the posterior pole, where pole plasm components are thought to mediate its stabilization (Bashirullah et al., 1999). Thirdly, local mRNA synthesis is known to be responsible for the localization of mRNAs encoding different subunits of the acetylcholine receptor in multinucleate myofibers (Merlie and Sanes, 1985).

The fourth and perhaps most widely used mechanism is active transport of ribonucleoprotein (RNP) complexes containing specific mRNAs, requiring motor proteins and cytoskeletal elements. This is used by Bicoid and Oskar mRNAs in the Drosophila oocyte (Lane and Kalderon, 1994; Wilsch-Brauninger et al., 1997), MBP mRNA in Oligodendrocytes (Ainger et al., 1993), ASH1 mRNA in budding yeast (Bertrand et al., 1998), B-actin mRNA to the axons of neurons (Morris and Hollenbeck, 1995) and mRNAs transported via the late pathway in Xenopus oocytes (Melton, 1987).

\subsubsection{Diffusion and entrapment}

The initial accumulation of early localized mRNA to the Balbiani body of Xenopus oocytes (illustrated in Fig. 1.7) has been shown not to require intact microtubules or microfilaments (Kloc et al., 1996). However, the mode of migration by which the Balbiani body fragments together with the associated mRNAs reach the vegetal cortex is still not known. Recent studies have shown that labelled Xcat2 and Xdazl mRNA particles move randomly throughout the cytoplasm of stage I oocytes and continuously aggregate within the METRO substructure of the Balbiani body in a manner distinguishable from the non-localized ß-globin mRNA (Chang et al., 2004). Drosophila Nanos which is related to Xcat2 is also localized by the same mechanism, however, the factors that mediate the entrapment of Xcat2 in Xenopus oocytes remain to be identified. The cis-acting localization elements (LE), usually residing within the 3'UTR, have been mapped for several early localized mRNAs, e.g. Xcat2 mRNA contains in the 3'UTR a $127 \mathrm{nt}$ long 
mitochondrial cloud LE (Zhou and King, 1996) and a 164 nt germinal granule LE (Kloc et al., 2000).

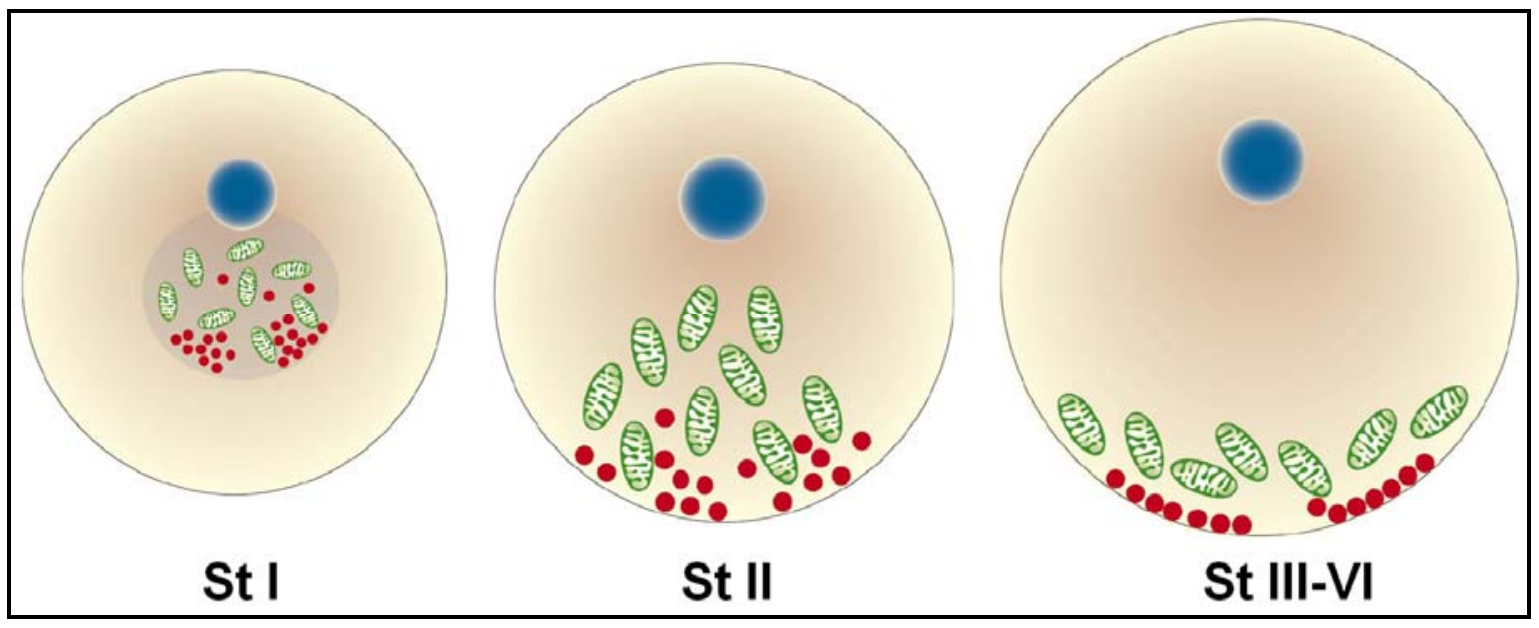

Figure 1.7 Model of the mechanism of diffusion and entrapment used by early localized mRNAs in oocytes.

During stage I of oogenesis, mRNAs (red dots) become selectively anchored within the Balbiani body, which attaches to the nucleus (blue) and contains mitochondria (green) and ER membranes. In stage II, the mRNAs co-migrate with fragmented Balbiani body to the vegetal cortex, [from (Kloc et al., 2002a)].

\subsubsection{Active transport}

Transport of late localizing mRNAs, such as Vg1 mRNA, to the vegetal cortex is dependent on intact microtubules and the anchoring step relies on intact microfilaments (Yisraeli et al., 1990). This finding was the first indication that the late pathway operates by the active directional transport mechanism, and later kinesin I (Yoon and Mowry, 2004) as well as heterotrimeric kinesin (kinesin II) (Betley et al., 2004) have been proposed to be the motor proteins that mediate this process.

Since kinesins are plus directed, the observation that the majority of microtubules in stage III oocyte have their minus end directed towards the vegetal cortex (Pfeiffer and Gard, 1999), could mean that there exist unique tracks of microtubules in stage II-IV oocytes which have their plus end oriented towards the vegetal cortex. These distinct microtubule tracks have been proposed to be established by a microtubule organising center consisting of a $\gamma$-tubulin positive centrosome present in the Balbiani body at stage I (Kloc and Etkin, 1998). The preceding accumulation of the mRNAs within the wedge-shaped structure during 
late stage II takes place in a microtubule-independent manner (Kloc and Etkin, 1998). The active transport process in oocytes is thought to proceed as illustrated in Fig 1.8; several trans-acting factors have been identified as playing a role in this process. The mRNAs have cis-acting vegetal localization elements (LE) usually residing in the 3'UTR, which have been shown to be necessary and sufficient to assemble the transport RNP complex. There are four major steps in this process; firstly, there is nuclear assembly of the core RNP complex involving the recruitment of VgRBP60/PTB along with its direct interacting partner Vg1RBP to the LE which is then exported into the cytoplasm (Kress et al., 2004). In Drosophila oocytes, the localization of Oskar mRNA has been shown to be coupled with nuclear splicing of the pre-mRNA, since mRNA from an intronless Oskar gene is unable to localize to the posterior pole (Hachet and Ephrussi, 2004).

Secondly, when the RNP complex reaches the cytoplasm it undergoes extensive remodelling; VgRBP60 which in the nucleus recruits Vg1RBP to the LE mediates the remodelling of the Vg1RBP to interact directly with the RNA (Lewis et al., 2007). The RNP maturation results from the recruitment of several additional factors such as XStaufen1 (Allison et al., 2004; Yoon and Mowry, 2004), Prrp (Zhao et al., 2001) and presumably 40LoVe (Czaplinski et al., 2005; Czaplinski and Mattaj, 2006). 40LoVe may well associate with the LE in the nucleus given its strong nuclear accumulation (Czaplinski and Mattaj, 2006).

The third step involves the coupling of the transport competent RNP complex to the motor proteins (i.e. kinesins); it is currently not known how this step is achieved, although the kinesins involved have been described (as mentioned above). The final step of anchoring has been shown to require cytokeratin filaments (Kloc et al., 2005), a function which had previously been linked to microfilaments (Yisraeli et al., 1990). The reported delocalization of $\mathrm{Vg} 1 \mathrm{mRNA}$ upon application of agents disrupting the microfilaments could thus be due to requirement of F-actin for linking the cytokeratin network to the vegetal cortex (Gard et al., 1997). Interestingly, the localized RNAs of VegT and Xlsirts have been reported to be integral to the network of cytokeratin (as illustrated in Fig 1.8), mediating the anchoring of the majority of the vegetally localized mRNA (Kloc et 
al., 2005). Protein components of the transport complex appear to remain largely anchored with the mRNA; immuno-florescence studies have shown that these proteins share a vegetal cortex enrichment pattern reminiscent of the localized mRNAs (Czaplinski et al., 2005; Kress et al., 2004; Yoon and Mowry, 2004; Zhang et al., 1999).

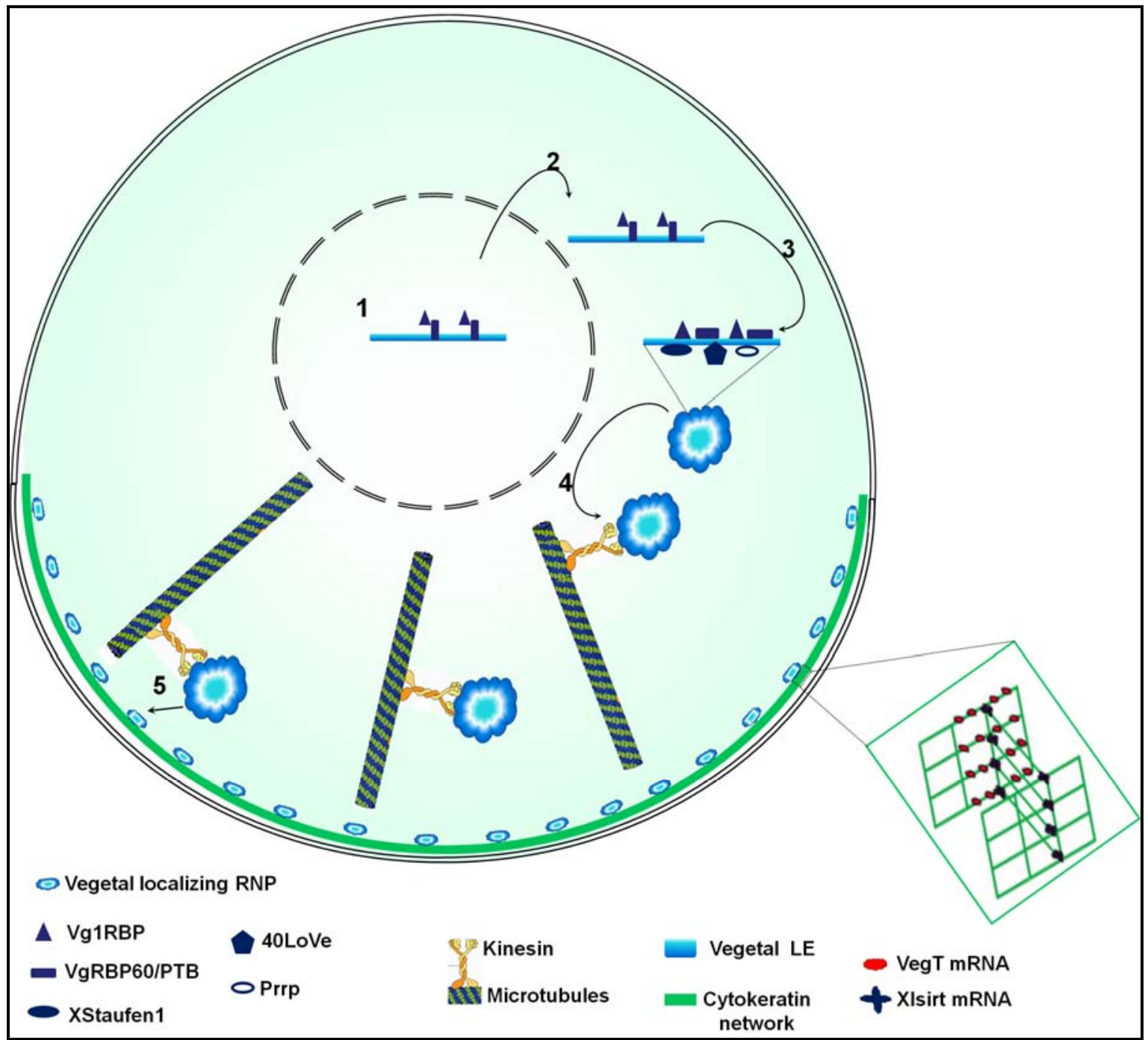

Figure 1.8 Model of the active transport mechanism used by mRNAs localizing via the late pathway

Based on (Jansen, 2001). 1: Formation of core localizing RNP complex in the nucleus, Vg1RBP associates with the LE through VgRBP60 (Kress et al., 2004) 2: mRNA export into the cytoplasm. 3: Remodelling of the RNP through the activity of VgRBP60, Vg1RBP binds directly to the LE (Lewis et al., 2007); additional factors such as XStaufen1, Prrp and 40LoVe are recruited to form the mature, transport competent RNP complex (size not drawn to scale). 4: Coupling of the mature RNP complex to kinesin and transport along microtubules to deliver the cargo to the vegetal cortex. 5: Anchoring of the mRNA to the cytokeratin network, which involves VegT and Xlsirts RNAs; illustration was taken from (Kloc et al., 2005). The illustration of microtubules and kinesin is from (Cooper, 2000). 


\subsubsection{Cis-acting elements}

mRNAs destined for vegetal localization usually harbour sequence elements that have been experimentally determined to be necessary and sufficient to mediate the process in their $3^{\prime}$ UTR; however, XNIF mRNA has been reported to have the localization element (LE) residing in the 5'UTR (Claussen et al., 2004). Vegetal localization elements mapped so far do not appear to share conserved primary sequences (King et al., 2005), whilst secondary structures have not yet been described for these LEs. The LEs vary in size, they can be as long as $340 \mathrm{nt}$ for Vg1 LE (Mowry and Melton, 1992) and 300 nt for VegT (Bubunenko et al., 2002; Kwon et al., 2002). The shortest LE of only $25 \mathrm{nt}$ that mediates localization in oocytes has been mapped for fatvg mRNA (Chan et al., 1999).

Multiple short redundant sequence elements have been found to cluster in the LEs of Vg1 and VegT; these are the so-called E2 (A/CYCAC) and VM1 (YYUCU) sequence elements (Kwon et al., 2002; Lewis et al., 2004). The E2 elements have been proposed to serve as a binding site for Vg1RBP (Deshler et al., 1998) and VM1 may recruit VgRBP60 to the LE (Cote et al., 1999; Lewis et al., 2004). Mutational analysis showed that these elements are crucial for the localization of both Vg1 and VegT mRNAs. However, the non-existence of E2/VM1 clusters in the LEs of Xvelo1, XNIF and XDead end mRNA (Claussen et al., 2004; Claussen and Pieler, 2004; Horvay et al., 2006), argues that they are not absolutely required for vegetal localization. Similarly, competition experiments using multimerized E2 or VM1 elements revealed that whilst molar excess E2 element inhibited the localization of Vg1 LE that of VM1 rather improved the localization efficiency of Vg1 LE (Czaplinski and Mattaj, 2006), suggesting that the VM1 interacting proteins perhaps different from VgRBP60 may function as inhibitors of localization.

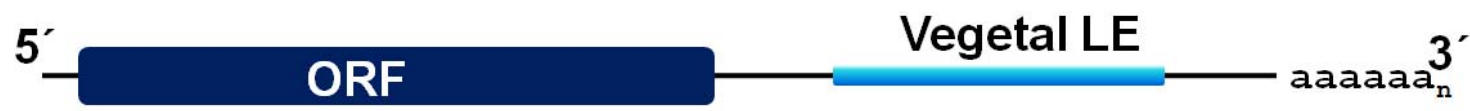

Figure 1.9 Structure of mRNA depicting its vegetal localization element in the 3' UTR. 


\subsubsection{Trans-acting factors}

Vegetal mRNA localization is achieved by the specific recruitment of trans-acting factors to the LE. How these factors work together to exert their function is described above. In Xenopus oocytes factors have been identified by means of biochemical approaches, unlike the predominantly genetic approach used in Drosophila. UV crosslinking analyses have identified a set of proteins, (p78, p69, p60, 40, p36, p30) as binding specifically to Vg1 LE (Cote et al., 1999). The majority of trans-acting factors identified to date in Xenopus oocytes and in other systems has turned out to be RNA binding proteins with classical RNA binding domains. Interestingly, the endosomal sorting complex has been shown to play a role in Bicoid mRNA localization in Drosophila oocytes, and its component proteins exhibit a conserved sequence specific RNA binding activity (Irion and St Johnston, 2007).

\subsubsection{Vg1 mRNA binding protein - Vg1RBP}

Vg1RBP is an RNA binding protein of about $69 \mathrm{kDa}$ that contains two RRM and four $\mathrm{KH}$ domains as depicted in Fig. 1.10; it was independently identified twice as trans-acting factor of vegetal mRNA localization in Xenopus oocytes, firstly as protein binding specifically to the Vg1 LE (Yaniv and Yisraeli, 2001) and secondly as co-fractionating with ER membranes and mediating the association of $\mathrm{Vg} 1$ mRNA with an ER sub-compartment to promote its vegetal localization (Deshler et al., 1998; Deshler et al., 1997). All four $\mathrm{KH}$ domains are required for Vg1 LE binding, whilst the $\mathrm{KH}$ domains 3 and 4 mediate homodimerization (Git and Standart, 2002). Vg1RBP mediates the association of Vg1 mRNA to microtubules in vitro (Elisha et al., 1995; Havin et al., 1998), an RNA binding mutant version of Vg1RBP still localizes to the vegetal cortex, suggesting that the process is dependent on its microtubule interaction and not on RNA binding per se (Rand and Yisraeli, 2007).

\section{Xenopus Vg1RBP protein}

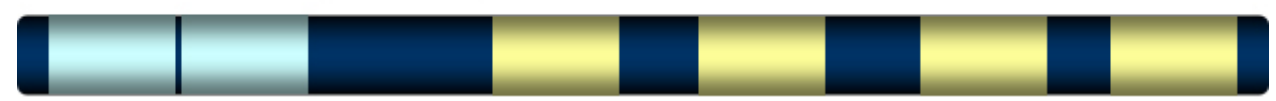

RNA Recognition Motif - RRM

hnRNP K Homology - KH domain

Figure 1.10 Domain structure of Xenopus Vg1RBP protein 
Figure 1.10 Domain structure of Xenopus Vg1RBP protein, showing 2 RRM domains in the Nterminal and $4 \mathrm{KH}$ domains in the $\mathrm{C}$-terminal portion, drawn to the scale as predicted by the NCBIprotein blast program.

A homolog of Vg1RBP, ZBP1, has a function in B-actin mRNA localization to the leading edge of fibroblast cells, dendritic filopodia and filopodial synapses in neurons (Eom et al., 2003; Ross et al., 1997). Additionally, it has a Src kinase mediated function of activation of translation upon its mRNA cargo reaching the periphery of the cell (Huttelmaier et al., 2005). It also plays a role in the regulation of mRNA stability in response to cellular stress in U2OS cells (Stohr et al., 2006). In Drosophila oocytes, insulin-like growth factor II mRNA-binding protein 1 (IMP1), also a homolog of $\mathrm{Vg} 1 \mathrm{RBP}$, is linked to gurken expression (Geng and Macdonald, 2006) and colocalizes with Oskar mRNA at the posterior pole; surprisingly only the mutation of IMP1 binding site in the $3^{\prime}$ UTR affected the translation and anchoring of Oskar mRNA at the posterior, but a IMP1 protein null mutation was found not to have any such effect (Munro et al., 2006).

\subsubsection{XStaufen1 protein}

XStaufen1 is a double-stranded RNA binding protein, $79 \mathrm{kDa}$ in size and consisting of 5 DSRBD and a tubulin binding domain as illustrated in Fig 1.11. Staufen was first isolated in Drosophila, as a gene required for anterior-posterior patterning (Schupbach and Wieschaus, 1986), and subsequently shown to be involved in the localization of both Bicoid mRNA to the anterior and Oskar mRNA to the posterior poles of the oocyte (St Johnston et al., 1991, Ferrandon, 1994 \#246). Xenopus Staufen was recently cloned and two protein isoforms were found to be expressed in the oocyte (Allison et al., 2004); XStaufen1 is the predominantly expressed isoform and plays a role in the vegetal mRNA localization. It interacts with $\mathrm{Vg} 1$ and $\mathrm{Veg} T$ mRNAs and a dominant negative form which is able to inhibit localization also perturbs the interaction between Vg1RBP and VgRBP60 (Yoon and Mowry, 2004). In rat neurons, Staufen proteins have been identified as components of large RNA particles and are required for dendritic mRNA localization (Kiebler et al., 1999). 


\section{Xenopus Staufen1 protein}

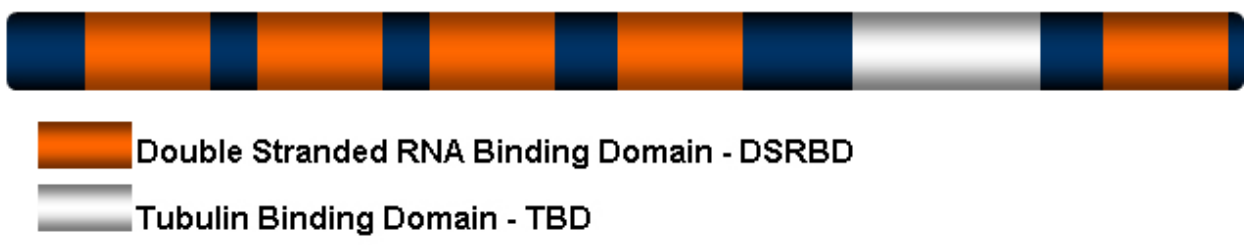

Figure 1.11 Domain structure of Xenopus Staufen 1 protein

It has 5 DSRB domains and a tubulin binding domain, drawn to the scale as predicted by the NCBI-protein blast program.

Drosophila Staufen exhibits distinct roles using two of its different conserved domains (illustrated in Fig. 1.12); the inserted loop region of DSRB domain 2 is required for posterior pole localization of Oskar mRNA, whilst the DSRB domain 5 is implicated in de-repression of localized Oskar mRNA in oocytes (Micklem et al., 2000). Interestingly, the interaction with a protein called Miranda can switch localization of Oskar mRNA from the posterior pole to the anterior pole (Schuldt et al., 1998).

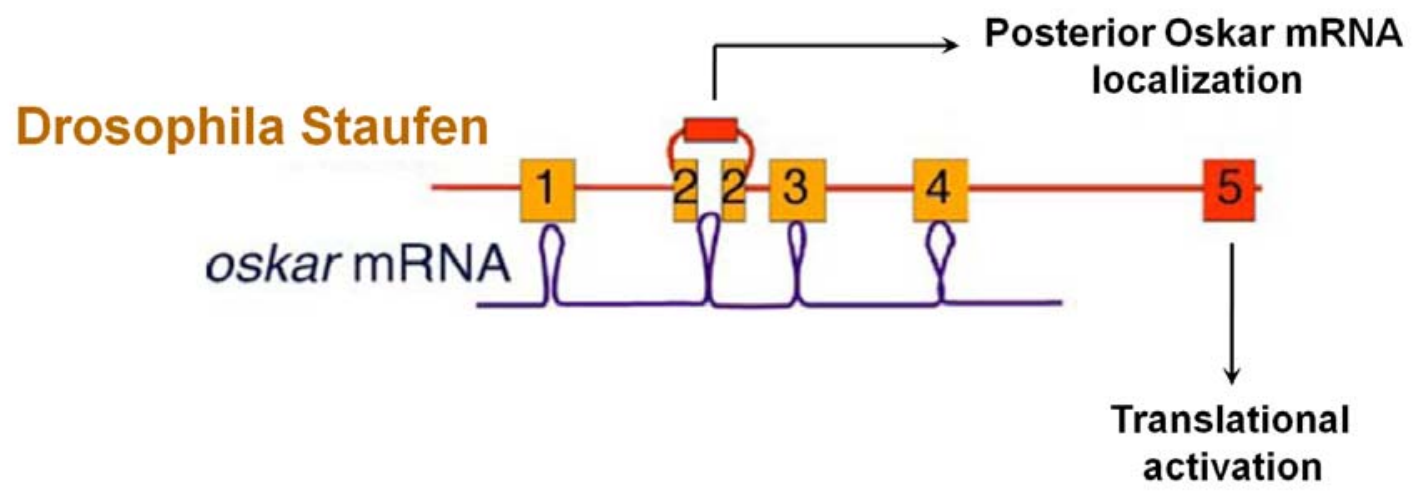

Figure 1.12 Model for the function of the Drosophila Staufen protein

[Taken from (Schuldt et al., 1998)], showing the association of the protein to Oskar mRNA; the DSRB 2 has an inserted loop region.

\subsubsection{VgRBP60/PTB protein}

VgRBP60 is the Xenopus homolog of human hnRNP I; it is approximately $60 \mathrm{kDa}$ in size and contains four RRM domains (Fig. 1.13); it is also referred to as polypyrimidine track binding protein (PTB) with a sequence-specific binding activity to CU-rich motifs and implicated in the regulation of splicing (CoutinhoMansfield et al., 2007). VgRBP60 was isolated as a protein specifically binding to the VM1 repeats in the Vg1 LE and mutations in this binding site blocked vegetal mRNA localization in oocytes (Cote et al., 1999). Interestingly, VgRBP60 recruits 
Vg1RBP to the LE in the nucleus (Kress et al., 2004) and mediates the remodelling of the transport complex upon export into the cytoplasm leading to a switch of indirect association to direct interaction with the LE (Lewis et al., 2007).

\section{Xenopus VgRBP60/PTB protein}

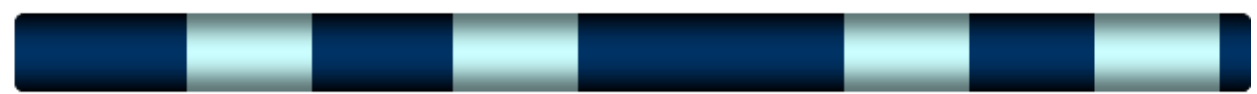

RNA Recognition Motif - RRM

Figure 1.13 Domain structure of Xenopus VgRBP60 protein, depicting the 4 RRM domains

\subsubsection{Xenopus 40LoVe protein}

40LoVe was identified as a $40 \mathrm{kDa}$ vegetal localization protein, which binds specifically to the LE of VegT and Vg1 mRNA; it contains of two RRM domains (Fig 1.14) and it is a member of the hnRNP D family of proteins; three protein isoforms are detected in the oocyte (Czaplinski et al., 2005). It interacts with Vg1RBP and VgRBP60 in an RNA dependent manner and also exhibits a vegetal cortex enrichment reminiscent of the localization pattern of its target mRNA (Czaplinski and Mattaj, 2006). Other hnRNP D proteins, e.g. AUF1, have been implicated in the regulation of mRNA stability, their binding to AU rich elements (ARE) elicits rapid degradation of target mRNAs (Sarkar et al., 2003).

\section{Xenopus 40LoVe protein}

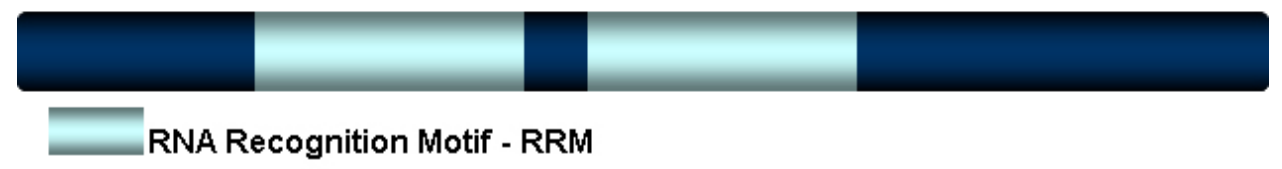

Figure 1.14 Domain structure of Xenopus 40LoVe (Localization Vegetal) protein depicting the two RRM domains.

\subsubsection{Xenopus Proline-rich RNA binding protein - Prrp}

Prrp is an RNA binding protein approximately $40 \mathrm{kDa}$ in size and made up of two RRM domains (Fig 1.15) and a proline-rich domain in the C-terminal region, which directly interacts with Profillin. Xenopus Prrp was isolated through a screen of a phage-cDNA library for Vg1 LE binding proteins; it interacts with endogenous late localizing mRNAs but not early localized ones. Additionally, it co-localizes with Vg1 mRNA at the vegetal cortex (Zhao et al., 2001). 


\section{Xenopus Prrp protein}

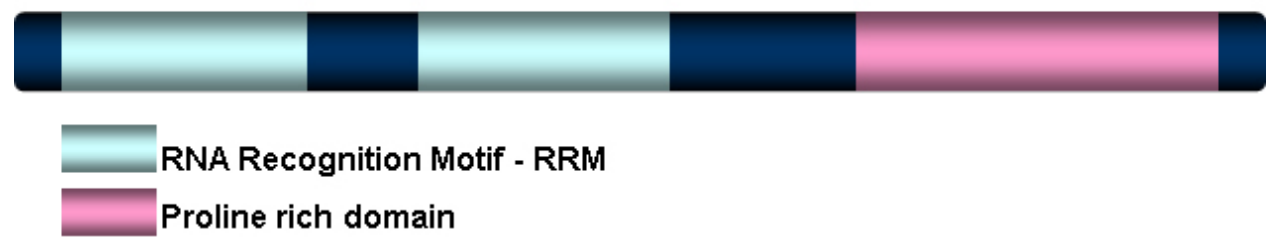

Figure 1.15 Domain structure of Xenopus Prrp protein depicting the $2 \mathrm{~N}$-terminal RRM domains and a C-terminal Proline-rich domain

\subsubsection{VgRBP71 protein}

In the same approach used for isolating Xenopus Prrp, another Vg1 LE interacting protein was identified, called Xenopus VgRBP71. It is about $71 \mathrm{kDa}$ in size and contains four KH domains (Fig. 1.16) (Kroll et al., 2002). VgRBP71 is the Xenopus homolog of human KSRP, implicated in the regulation of splicing (Min et al., 1997). Apart from Vg1 mRNA, VgRBP71 also associates with other localized mRNAs such as for VegT and Xcat2 and is involved in protein-protein interactions with Prrp. VgRBP71 has been proposed to mediate the cleavage of the Vg1 mRNA eliminating the translational control element and thus leading to derepression of translation during late oogenesis (Kolev and Huber, 2003). Although there is no evidence that VgRBP71 has a role in vegetal mRNA localization, ZBP2 the Chicken homolog, has been found to play a role in $B$-actin mRNA localization in fibroblasts and neurons, since a truncated version is able to inhibit this process (Gu et al., 2002).

\section{Xenopus VgRBP71 protein}

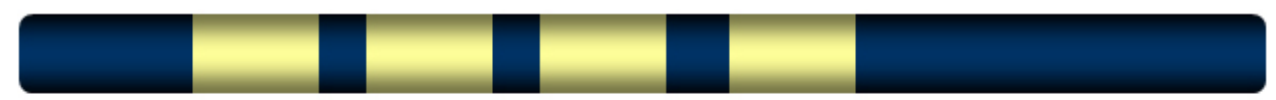

hnRNP K Homology - KH domain

Figure 1.16 Domain structure of Xenopus VgRBP71 protein, showing $4 \mathrm{KH}$ domains drawn to the scale as predicted by the NCBI-protein blast program

\subsection{Transport RNP: size, composition and structure}

Several mRNA molecules which localize have been observed to form a large transport particle, or mRNA granules, needed to achieve localization in a number of systems and termed "locusome" (Bassell et al., 1999) or "locasome" (Gu et al., 
2004) in analogy to ribosomes or spliceosomes. Myelin basic protein (MBP) mRNA granules have been observed in oligodendrocytes and were estimated to have a radius between 0.6 and $0.8 \mu \mathrm{m}$, they colocalize with arginyl-tRNA synthetase, elongation factor 1alpha and rRNA (Barbarese et al., 1995). In Drosophila oocytes, Bicoid mRNA forms Staufen containing particles, held together in part by RNA-RNA interactions (Ferrandon et al., 1994); a fusion protein of GFP-Exuperantia has also been shown to form particles that migrate through ring canals into oocytes (Wang and Hazelrigg, 1994). mRNA transport particles could be biochemically isolated, e.g. the ASH1 mRNA locasome was isolated using affinity tag She2 $p$ and found to contain several additional proteins (Gu et al., 2004). Similarly, GFP-Exuperantia particles which migrate in high density fractions could also be isolated with an antibody against GFP and found to contain Yps protein and Oskar mRNA (Wilhelm et al., 2000a). In human cells (HEK cells), insulin-like growth factor II mRNA-binding protein (IMP) granules were estimated to be $100-300 \mathrm{~nm}$ in diameter and to consist of IMP proteins, 40S ribosomal subunits, shuttling hnRNPs, poly(A)-binding proteins, and several mRNAs (Jonson et al., 2007).

In Xenopus oocytes, Xcat2 RNA was observed in particles that move randomly throughout the cytoplasm (Chang et al., 2004), whilst XStaufen1 protein have been observed in a high density RNP in gradient centrifugation separation of oocyte lysate (Yoon and Mowry, 2004), and as large particle on size exclusion columns (Allison et al., 2004).

These transport mRNA granules are thought to reflect structures that are needed to accomplish the process of mRNA localization; the large size, in some cases many times larger than ribosomes, could be accounted for by the many proteins, mRNAs and sometimes also translational machinery that they contain (Jansen, 2001).

\subsection{Translational control of localized mRNAs}

The widely held belief regarding the relationship between mRNA localization and translational control is that during transport, translation must be repressed to allow for the subsequent local protein synthesis. There are several ways in which 
localized mRNA are controlled translationally in the various biological systems where this phenomenon occurs.

\subsubsection{Drosophila oocytes/embryos}

A number of mRNAs are know to be localized during oogenesis, Nanos mRNA is translated only upon reaching the posterior pole, so unlocalized Nanos is repressed in Drosophila embryos through the activity of a protein called smaug (Smibert et al., 1999; Smibert et al., 1996), which requires a $90 \mathrm{nt}$ translational control element in its $3^{\prime}$ UTR that is distinct from the localization element (Gavis et al., 1996). Oskar mRNA localization is also coupled to its translation; it is repressed by a number of proteins to ensure that no translation occurs apart from at the posterior pole, reflecting its key role as a posterior determinant. Repression of Oskar mRNA is achieved by proteins such as Bruno through the Bruno response element in the 3'UTR (Castagnetti et al., 2000; Chekulaeva et al., 2006; Gunkel et al., 1998) and also by Hrp48 through its association with both $5^{\prime}$ and 3'UTRs (Huynh et al., 2004; Yano et al., 2004).

\subsubsection{Neurons and Fibroblast cells}

mRNA encoding Myelin basic protein (MBP) is repressed during transport to the dendrites in oligodendrocytes by the recruitment of hnRNP E1 to the mRNA by hnRNP A2, which binds to its response element (A2RE) that resides in the 3'UTR (Kosturko et al., 2006). ß-actin mRNA is repressed in a similar manner during transport to the axons of neurons and to the leading edge of migrating fibroblasts by ZBP1, dependent on the 54 nt zipcode in the 3'UTR, the same element that mediates the localization process; translation is activated at the destination by the activity of Src kinase on ZBP1 (Huttelmaier et al., 2005).

\subsubsection{Xenopus oocytes}

The only example of translational control elements (TCE) described for localized mRNAs in Xenopus oocytes is for Vg1 mRNA. Two overlapping Vg1 mRNA TCEs have been mapped in the 3'UTR; they are distinct from the LE and ElrB protein has been implicated in mediating the repression during early oogenesis by direct 
binding to the $250 \mathrm{nt}$ Vg1 TCE (Colegrove-Otero et al., 2005), whilst a $38 \mathrm{kDa}$ unknown protein was found to bind the $350 \mathrm{nt} \mathrm{TCE}$ and also suggested to mediate repression (Wilhelm et al., 2000b). 


\subsection{Aims of the project}

mRNA localization in Xenopus oocyte is thought to occur by specific recruitment of trans-acting factors to the localization element; several of these factors have been identified, including Vg1RBP, VgRBP60 and XStaufen1. However, UV crosslinking analysis using LEs reveals proteins that do not correspond to the factors identified so far (Horvay et al., 2006). Identification of the complete set of proteins interacting with a localized mRNA is imperative since this will make it possible to improve the understanding of the mechanisms involved. The first part of the project is an attempt to identify novel trans-acting factors with a function in vegetal mRNA localization; for this, a biochemical purification strategy is established. This strategy was based on the principle that localized mRNAs and the associated trans-acting factors form large RNP complexes. The second part involved the functional characterization of candidate proteins identified with a focus on (i) their interaction with known localization proteins, (ii) their subcellular distribution, and (iii) their role in the process of localization of mRNAs to the vegetal cortex of oocytes, as well as (iv) for possible function in other aspects of mRNA metabolism. 


\section{Materials and Methods}

\subsubsection{Model Organism}

Oocytes and embryos used in this work were from African clawed frogs Xenopus leavis (family: Pipidae). Pigmented and albino frogs were ordered from Nasco (Fort Atkinson, Wisconsin, USA) and Dipl.-Ing. Hoest Kähler (Hamburg, Germany),

\subsubsection{Bacteria strains}

Escherichia coli (E. coli) strains used were obtained from Stratagene XL1-Blue: RecA1, endA1, gyrA96, thi-1, hsdR17, supE44, relA1, lac[F'proAB, lacl ${ }^{\mathrm{q}} \mathrm{Z} \Delta \mathrm{M} 15, \mathrm{Tn} 10\left(\right.$ Tet $\left.\left.^{\mathrm{r}}\right)\right]^{\mathrm{c}}$.

BL21 (DE3): E.coli B F' , ompT, hsdS( $\left.r_{B}-m_{B}-\right)$, dcm $^{+}$, Tet ${ }^{r}$, gal $\lambda(D E 3)$ endA Hte [argU proLCamr] [argU ileY leuW Strep/Specr]

\subsubsection{List of Chemicals}

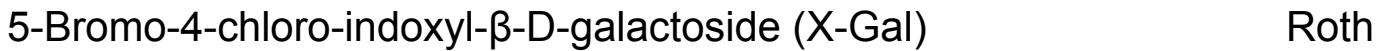

Acrylamide Roth

Agarose Roth

Ampicillin Roche

Bromophenol blue Sigma

Blendzyme (Collagenase) Roche

CHAPS Sigma

Chloroform Merck

Coomassie Brilliant Blue G-250 Serva

Brilliant Blue R-250 Serva

Digoxigenin UTP Sigma

Dimethyl Sulfoxide (DMSO) Sigma

Dithiothreitol (DTT) Biomol

Ethidiumbromide Sigma

Ethylenediaminetetraacetic acid (EDTA) Roth

Formaldehyde Merck

Glycerol Merck 
Glycine $\quad$ Roth

Heparin Sigma

Isopropyl $\beta$-D-1-thiogalactopyranoside (IPTG) Roth

Kanamycin

Sigma

3-(N-Morpholino) propanesulfonic acid (MOPS)

Sigma

$\mathrm{N}-2-\mathrm{Hydroxyethylpiperazine-N'-2-ethansulfonic} \mathrm{acid} \mathrm{(HEPES)} \mathrm{Roth}$

Nonidet P-40 (NP-40) Fluka

$\mathrm{N}, \mathrm{N}, \mathrm{N}^{`}, \mathrm{~N}^{\prime}$-Tetramethylethylenediamine (TEMED) Sigma

Polyethylene glycol (PEG) Sigma

Protease Inhibitor Cocktail Tablet Roche

Triethanolamine Sigma

Tris(hydroxymethyl)aminomethane (Tris) Roth

Triton X-100 Sigma

Trizol reagent Invitrogen

Tween $20 \quad$ Sigma

Urea/Thiourea Roth

Xylene cyanol Sigma

Xylene Roth

\subsection{DNA methods}

\subsubsection{Plasmid constructs and protein production}

Full length cDNA clones of ElrA (accession number BC086269) and ElrB (accession number NM_001087566) in pSPORT vector were obtained from RZPD genome resource center (https://www.rzpd.de). The corresponding IMAGE clone numbers for ElrA and ElrB were IMAGp998E0114218Q and IRBHp990C0179D respectively. The ORFs of ElrA, ElrB1, ElrB2 were all amplified by PCR from plasmids and subcloned into Stul and Xbal sites of pCS2+ myc tagged vector (Rupp et al., 1994). ElrB3 was amplified from total oocyte cDNA using the ElrB2_F and ElrB_R primer pair and cloned similarly.

The primers used:

ElrB1_F 5': (AATAGGCCTATGGCAGTCAGACTGTGTGATGTGGCT) - Tm $56{ }^{\circ} \mathrm{C}$

ElrB2_F 5': (AATAGGCCTATGGAAACACAGCTATCCAATGGACCCACTT) - Tm $56{ }^{\circ} \mathrm{C}$ 
ElrB_R 5: (GCCTCTAGATTAAGCTTTGTGTGTTTTGCTCGTTTTGAAC) -Tm $56^{\circ} \mathrm{C}$

ElrA_F 5': (TCAAGGCCTATGTCTAACGGTTATGAAGATCACA) - Tm $56{ }^{\circ} \mathrm{C}$

ElrA_R 5': (ATATCTAGATTATTTGTGTGA CTTGCTGGTTTTG) - Tm $56{ }^{\circ} \mathrm{C}$

For recombinant protein production, the ElrB2 ORF was subcloned into the Ncol and Notl sites of pET21d (Novagen). The plasmid construct of His-tagged Vg1RBP used was described in (Havin et al., 1998). His-tagged proteins expressed in E. coli BL21(DE3) cells (Stratagene) were purified over the Ni-NTA columns (Qiagen) according to the manufacturer's instructions.

\subsubsection{Polymerase Chain Reaction (PCR)}

PCR components used were usually obtained from the high fidelity PCR Enzyme mix kit (Fermentas), for generating PCR products used in cloning and mutagenesis. For PCR products where sequence integrity was not essential, Taq Polymerase kit (Qbiogene) was used. Reactions were routinely incubated in T3 Thermoblock (Biometra).

The reaction set up:

10x PCR buffer (including $\mathrm{MgCl}_{2}$ ) : $5 \mu \mathrm{l}$

dNTPs (25 mM each)

$: 0.5 \mu \mathrm{l}$

Primer pair $(10 \mu \mathrm{M})$

$: 0.5 \mu$ each

DNA polymerase $(5 \mathrm{U} / \mu \mathrm{l})$

$: 0.5 \mu \mathrm{l}$

$\mathrm{H}_{2} \mathrm{O}$

$: 42.5 \mu \mathrm{l}$

DNA template $(40 \mathrm{ng} / \mu \mathrm{l})$

$: 1 \mu \mathrm{l}$

$50 \mu \mathrm{l}$

Reaction Condition:

$\left.\begin{array}{lcll} & \text { Temperature } & & \text { Time } \\ \text { Denaturation : } & 95^{\circ} \mathrm{C} & & 5 \mathrm{~min} \\ \text { Denaturation : } & 95^{\circ} \mathrm{C} & 50 \mathrm{sec} \\ \text { Annealing : } & \sim 56{ }^{\circ} \mathrm{C} & 50 \mathrm{sec} \\ \text { Extension : } & 72{ }^{\circ} \mathrm{C} & 0.5-4 \mathrm{~min}\end{array}\right] 25-35$ cycles




\subsubsection{Site-directed Mutagenesis}

The XDE-LE was amplified with primers reported in (Horvay et al., 2006) and cloned into the pGEM-T easy vector (Promega). Mutant versions of XDE-LE were generated by site-directed mutagenesis using a two-step overlap extension PCR as originally described in (Ho et al., 1989) and illustrated in Fig 2.1. Complementary primers containing the desired mutations together with external vector primers were used to generate two DNA fragments. The two fragments were combined in equimolar amounts in a subsequent fusion PCR reaction (5 cycles) step without primers, where the complimentary ends anneal allowing the 3 'end of each strand to be extended. The resultant PCR fusion product was further amplified by PCR (30 or more cycles) using the external primers. This PCR product served as template for additional rounds of mutagenesis for obtaining multiple-mutants.

PCR reactions were done using high fidelity DNA polymerase kit (Fermentas) and DNA fragments were purified from agarose gel with a PCR purification kit (Qiagen). The mutant XDE LE was cleaved with BamHI and Xhol for cloning into the pBK-CMV-lacZ tagged vector (Claussen and Pieler, 2004; Horvay et al., 2006). The pSP64-mGFP constructs (Koebernick, submitted 2008) of the mutant versions of XDE LE were obtained by re-amplification with specific primers containing the Xhol and Not I sites. See Table 2.1 for list of primers used for the mutagenesis.

External primers:

T7 5': TAATACGACTCACTATAGGG

SP6 5': GATTACGCCAAGCTATTTAGgTGACACTATAGAATACTCA

Primers for pSP64-mGFP constructs

XDE LE Xho_F 5': GCCTCTCGAGCTGCCCTTGCATCCTACATT

XDE LE Not_R 5': GCCGCGGCCGCGCAGGGAGCAGGCAGATGACGTTTC 


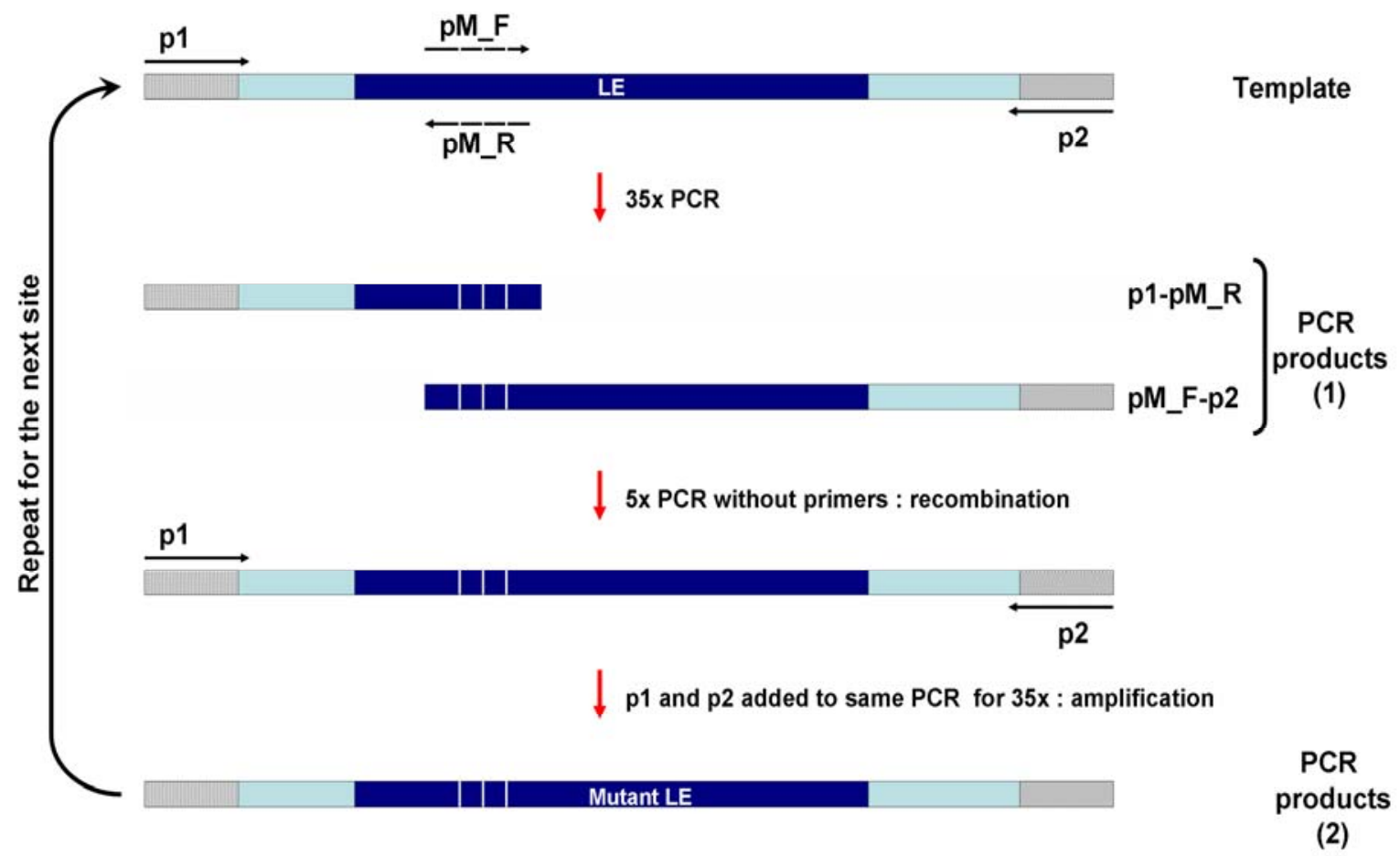

Figure 2.1 Scheme for PCR-based Multiple Site directed Mutagenesis

Table 2.1 XDE LE mutagenesis primers

\begin{tabular}{|l|l|}
\hline $\begin{array}{l}\text { Primer } \\
\text { Name }\end{array}$ & Primer Sequence: 5 $^{\prime}$ - ${ }^{\prime}$ \\
\hline XDE P1f & ACATTTTAAAGGGAGATTATTATTATTGCATTGGTGTAAAGC \\
\hline XDE P1r & GCTTTACACCAATGCAATAATAATAATCTCCCTTTAAAATGT \\
\hline XDE P2f & GCATTGGTGTAAAGCTAATTATTATTACACTTTATTTATT \\
\hline XDE P2r & AATAAATAAAGTGTAATAATAATTAGCTTTACACCAATGC \\
\hline XDE P3a f & TTTTGTTTCACTTTATATATTATTATCACTTGTTATTGCAC \\
\hline XDE P3a r & GTGCAATAACAAGTGATAATAATATATAAAGTGAAACAAAA \\
\hline XDE P3b f & TATTATTACACTTTATATATTATTATCACTTGTTATTGCAC \\
\hline XDE P3b r & GTGCAATAACAAGTGATAATAATATATAAAGTGTAATAATA \\
\hline XDE P4f & CACTTGTTATTGCACTTATTATGTATGTGTGTATCTTGCAC \\
\hline XDE P4r & GTGCAAGATACACACATACATAATAAGTGCAATAACAAGTG \\
\hline XDE P5 f & CTGTCTTGATTATCACCTGGAAAGGCAGTATATCATAAAGGGC \\
\hline XDE P5 r & GCCCTTTATGATATACTGCCTTTCCAGGTGATAATCAAGACAG \\
\hline XDE m2a F & ACATTGTAAAGGGAGATGATTATGATTGCATTGGTGTAAAGC \\
\hline XDE m2a R & GCTTTACACCAATGCAATCATAATCATCTCCCTTTACAATGT \\
\hline XDE m2b F & GCATTGGTGTAAAGCTAATGATTAGTACACTGTATATATT \\
\hline XDE m2b R & AATATATACAGTGTACTAATCATTAGCTTTACACCAATGC \\
\hline XDE m2c F & GATTAGTACACTGTATATATGATGATCACTTGCTATTGCAC \\
\hline XDE m2c R & GTGCAATAGCAAGTGATCATCATATATACAGTGTACTAATC \\
\hline XDE m2d F & CACTTGGTATTGCACTGATGATGTATGTGTGTATCTTGCAC \\
\hline XDE m2d R & GTGCAAGATACACACATACATCATCAGTGCAATACCAAGTG \\
\hline
\end{tabular}




\subsubsection{Reverse Transcription-PCR (RT-PCR)}

Complimentary DNA (cDNA) template was generated from isolated total oocyte RNA using the reaction set up below, the PCR step was performed as described section 2.2.2. MuLV Reverse Transcriptase and RNaseOUT were obtained from Invitrogen.

RT-PCR Reaction set up:

$\begin{array}{ll}\mathrm{MgCl}_{2}(25 \mathrm{mM}) & : 2 \mu \mathrm{l} \\ \text { 10X PCR buffer II (without MgCl2) } & : 1 \mu \mathrm{l} \\ \text { dNTPs }(25 \mathrm{mM}) & : 2 \mu \mathrm{l} \\ \text { RNase Inhibitor }(40 \mathrm{U} / \mu \mathrm{l}) & : 0.5 \mu \mathrm{l} \\ \text { MuLV Reverse Transcriptase }(50 \mathrm{U} / \mu \mathrm{l}) & : 0.5 \mu \mathrm{l} \\ \text { Random Hexamers }(50 \mathrm{mM}) & : 0.5 \mu \mathrm{l} \\ \text { Total RNA } & : \text { up to } 0.5 \mu \mathrm{g} \\ \text { DEPC } \mathrm{H}_{2} \mathrm{O} & : \text { to } 10 \mu \mathrm{l}\end{array}$

Reaction Conditions:

$25^{\circ} \mathrm{C} \quad 10$ mins

$42{ }^{\circ} \mathrm{C} \quad 60$ mins

$96{ }^{\circ} \mathrm{C} \quad 5$ mins

The reaction was incubated in the T3 Thermoblock (Biometra).

Primers for RT-PCR:

XDead end (Horvay, 2005)

20-F 5': AAAGAGACCCTGCTAAGTGCTGTC

20-R 5': CTTGCAGTGACGTCTCCCAGTGAG

Cycle \#: 28; $\mathrm{Tm}: 63^{\circ} \mathrm{C}$; product: $300 \mathrm{bp}$

Vg1 (Claussen, 2002)

F 5': TATTTCTACTTTATTTCTACACTG

R 5': GCAAGTCATATGGACTATTATATAT

Cycle \#: 30; $\mathrm{Tm}: 56^{\circ} \mathrm{C}$; product: $379 \mathrm{bp}$ 
Velo1 (Claussen, 2002)

F 5': TAAAAATGAACACGACGGCACCTC

R 5': CACAGCCTTTACCGTCTGAACTATGT

Cycle \#: 30; Tm: $56{ }^{\circ} \mathrm{C}$; product: 429 bp

XNIF (Claussen, 2002)

F 5: $\quad$ CTGCTAGACCGGTGGgGAGTGT

R 5: AGgGTGGAGAAGCGAAGAGTCAA

Cycle \#: 30; Tm: $56^{\circ} \mathrm{C}$; product: 380 bp

Deadsouth (Claussen, 2002)

F 5': ACAAATTGTGTAGAATCGCCCACTTCAC

R 5:: CAGACCGAAATAACTGTTGCTAAA

Cycle \#: 30; Tm: $56{ }^{\circ} \mathrm{C}$; product: 251 bp

XPTB (Claussen, 2002)

F 5': TCCTGCAGCCATTTTAGAACCAA

R 5': ATAGCAGGGAAGACCAAACGAAATG

Cycle \#: 30; Tm: $56{ }^{\circ} \mathrm{C}$; product: 378 bp

velo45 (Dreier, 2005)

F 5': GAAACAACCAATACCAGCAAAATCCTCACAG

R 5: $\quad$ TTAATATCAGATGCAACGCCTACTTTCACCAG

Cycle \#: 28; Tm: $60^{\circ} \mathrm{C}$; product: 388 bp

Xdazl (velo61) (Susanne, unpublished)

F 5': AATCCCATGTCACTGATGAGC

R 5': ACAAAGTGAACGGGGCTATGT

Cycle \#: 30; Tm: $56{ }^{\circ} \mathrm{C}$; product: 154 bp

$28 S$ rRNA

F 5' CTCAGACCTCAGATCAGACGCGGCG

R 5' TCTTCAAAGTTCTTTTCAACTTTCC

Cycle \#: 30; Tm: $56{ }^{\circ} \mathrm{C}$; product: 385 bp 


\section{S rRNA}

F 5': ACgATACATTCGgATGTCTgCCCTA

R 5': TCCATTATTCCTAGCTGAAGTATCC

Cycle \#: 30; $\mathrm{Tm}: 56^{\circ} \mathrm{C}$; product: 529 bp

TFIIIA (Wischnewski, 2002)

TFIIA f1 5' AACTGTGGCAAAGCATTCAAG

TFIIA r1 5' AGCGGTCACAGCCATCTC

Cycle \#: 32; $\mathrm{Tm}: 56^{\circ} \mathrm{C}$; product: $360 \mathrm{bp}$

\section{H4 (control)}

H4 F 5':

CGGGATAACATTCAGGGTATCACT

H4 R 5':

ATCCATGGCGGTAACTGTCTTCCT

Cycle \#: 26; $\mathrm{Tm}: 56^{\circ} \mathrm{C}$; product: $189 \mathrm{bp}$

\subsubsection{Quantitative RT-PCR (qPCR)}

The cDNA template used in this procedure was generated as described in section 2.2.4 and the reaction mixtures were incubated in iCycler (Bio-Rad). Reaction mixture was made up of iQ SYBR Green Supermix (Bio-Rad), containing buffer, polymerase, nucleotides and fluorophores, together with 50-200 ng cDNA. The primer pairs were used at end concentration of $100 \mathrm{nM}$ and were designed to yield an optimal amplicon size of $250-400$ bp in length. The calibration curve was obtained by titrating linearised pGEMT plasmids containing the amplicon with a concentration range from $10^{2}$ to $10^{8}$ molecules. The calculation of the quantities of specific target mRNAs was done using the software iCycler iQ v3 supplied by the manufacturer.

Reaction set up:

iQ SYBR Green Supermix $\quad: 12.5 \mu \mathrm{l}$

Primer pair $(10 \mu \mathrm{M}) \quad: 0.25 \mu$ leach

cDNA template $\quad: 1 \mu \mathrm{l}$

$\mathrm{H}_{2} \mathrm{O} \quad$ : up to $25 \mu \mathrm{l}$ 
Reaction conditions:

\begin{tabular}{|c|c|c|c|}
\hline & Temperature & Time & \\
\hline Denaturation: & $95^{\circ} \mathrm{C}$ & $1 \mathrm{~min}$ & \\
\hline Denaturation: & $95^{\circ} \mathrm{C}$ & $15 \mathrm{sec}$ & \\
\hline Annealing: & $56{ }^{\circ} \mathrm{C}$ & $15 \mathrm{sec}$ & 50 cycles \\
\hline Extension: & $72{ }^{\circ} \mathrm{C}$ & $30 \mathrm{sec}$ & \\
\hline Melting curve: & $55-95^{\circ} \mathrm{C}$ & & \\
\hline
\end{tabular}

qPCR Primers: product length of $400 \mathrm{bp}$ (Obtained from Barbara Rust)

Firefly F 5': GCAACTGCATAAGGCTATG

Firefly R 5': CGTGTACATCGACTGAAATC

Renilla F 5': GGCCAGATGTAAACAAATG

Renilla R 5': CATCCCATGAATCAATCAC

\subsubsection{Restriction Endonuclease Digestion}

Preparation of DNA fragments, for cloning or use as transcription templates, were done by incubating plasmid DNA with $0.2-1$ unit of enzyme per $1 \mu \mathrm{l}$ of reaction volume in the appropriate buffer. Incubations were usually at $37^{\circ} \mathrm{C}$ for at least 2 hours, but overnight for exhaustive digests. DNA fragments to be used for cloning were purified from 1-2\% agarose gel using Gel purification kit (Qiagen), whilst transcription templates of linearised plasmids were purified after incubation using PCR purification kit (Qiagen). Vectors with compatible sticky ends for cloning were dephosphorylated during the restriction reaction by the addition of Shrimp Alkaline Phosphatase (Fermentas). Modified from (Sambrook et al., 1998)

\subsubsection{Ligation}

PCR generated DNA fragments were ligated into the pGEMT vector from the pGEMT easy kit (Promega) according to the provided instructions. Excised DNA fragments from e.g. pGEMT clones for subcloning were usually ligated into the appropriate vectors, with the compatible ends, in reactions set up as below and incubated at $4{ }^{\circ} \mathrm{C}$ overnight. Modified from (Sambrook et al., 1998) 
Ligation reaction set up:

$\begin{array}{ll}\text { Vector } & : 1 \mu \mathrm{l} \\ \text { Insert } & : 6 \mu \mathrm{l} \\ \text { PEG } & : 1 \mu \mathrm{l} \quad \text { (PEG - polyethylene glycol) } \\ \text { 10X Buffer } & : 1 \mu \mathrm{l} \\ \text { T4 ligase } & : 1 \mu \mathrm{l} \\ & 10 \mu \mathrm{l}\end{array}$

\subsubsection{Preparation of Chemical Competent cells}

A $5 \mathrm{ml}$ liquid LB medium inoculated with single colony of an $E$. coli (XL1blue) from a LB/Agar plate. After an overnight incubation at $37^{\circ} \mathrm{C}$ with slight shaking, this preculture was used then to inoculate $50 \mathrm{ml}$ liquid LB medium supplemented with $0.125 \mathrm{ml} 1 \mathrm{M} \mathrm{MgSO}_{4}$ and $1 \mathrm{M} \mathrm{MgCl}_{2}$, to ensure rapid growth of the cells. The cells in culture was grown until it reached OD600 of 0.5 after which it was incubated on ice for $20 \mathrm{~min}$ and the cells were harvested by centrifugation at $4000 \mathrm{rpm}, 4^{\circ} \mathrm{C}$ for $15 \mathrm{~min}$ in a sterile falcon tube. The cell pellet was resuspended in $10 \mathrm{ml}$ of icecold transformation buffer 1 , incubated on ice for 2 hours and then cells were centrifuged at $4000 \mathrm{rpm}, 4^{\circ} \mathrm{C}$ for $15 \mathrm{~min}$. The cell pellet was again resuspended in $2 \mathrm{ml}$ ice-cold transformation buffer 2 and then aliquoted in $200 \mu \mathrm{l}$ volumes and stored at $-70^{\circ} \mathrm{C}$ until used. Modified from (Sambrook et al., 1998)

Transformation buffer 1 (50 ml): $30 \mathrm{mM}$ Potassium Acetate $(0.174 \mathrm{~g}), 100 \mathrm{mM}$ $\mathrm{RbCl}(0.605 \mathrm{~g}), 50 \mathrm{mM} \mathrm{MnCl}$ (0.495 g), $10 \mathrm{mM} \mathrm{CaCl} 2$ (0.075 g)

The buffer was adjusted to $\mathrm{pH} 5.8$ with acetic acid and sterile filtered $(0.20 \mu \mathrm{m}$ sterile filter - Sartorius).

Transformation buffer 2 (100 ml): $10 \mathrm{mM}$ MOPS $(0.2093 \mathrm{~g}), 10 \mathrm{mM} \mathrm{RbCl}$ (0.1203 g), $75 \mathrm{mM} \mathrm{CaCl}_{2}(1.102 \mathrm{~g}), 15 \%$ (v/v) Glycerol.

The buffer was adjusted to $\mathrm{pH} 7$ with acetic acid and sterile filtered $(0.20 \mu \mathrm{m}$ sterile filter - Sartorius).

\subsubsection{Preparation of Electrocompetent Cells}

Cell suspension was prepared as in section 2.2.8 and the cell pellet was then washed to remove all salts with sterile distilled $\mathrm{H}_{2} \mathrm{O}$ and centrifuged again at 500 
$\mathrm{rpm}, 20 \mathrm{~min}$, and $4{ }^{\circ} \mathrm{C}$. This pellet was suspended in $40 \mathrm{ml}$ of $10 \%$ glycerol, centrifuged (500rpm, $10 \mathrm{~min}$ at $4{ }^{\circ} \mathrm{C}$ ). After this the cell pellet was resuspended in an equal volume of $40 \%$ glycerol and aliquoted in $60 \mu \mathrm{l}$ volumes and stored at $70{ }^{\circ} \mathrm{C}$. Modified from (Sambrook et al., 1998)

\subsubsection{Transformation of chemical competent cells}

Competent cells (E. coli - XL1 blue strain - Stratagene) aliquots were thawed on ice after which the ligation reaction was added, gently mixed and incubated on ice for $30 \mathrm{~min}$. The cells were heat shocked at $42{ }^{\circ} \mathrm{C}$ for $90 \mathrm{sec}$ and then incubated on ice for $5 \mathrm{~min}$. Transformed cells were precultured in $1 \mathrm{ml}$ of LB medium at 37 ${ }^{\circ} \mathrm{C}$ for 1 hour and was centrifuged at $13000 \mathrm{rpm}$ for $1 \mathrm{~min}$. The cell pellet was resuspended in $100 \mu \mathrm{LB}$ and plated out on antibiotic containing agar plate for overnight incubation at $37^{\circ} \mathrm{C}$. Modified from (Sambrook et al., 1998)

Luria Bertani (LB) medium : Yeast Extract $10 \mathrm{~g}$, Trypton $5 \mathrm{~g}, \mathrm{NaCl} 5 \mathrm{~g}$ dissolved in $1 \mathrm{~L}$ distilled $\mathrm{H}_{2} \mathrm{O}$ and autoclaved before storage at $4{ }^{\circ} \mathrm{C}$. LB/Agar plates, $14 \mathrm{~g}$ of agar was dissolved in 1 L LB medium and poured into Petri dishes, it was stored at $4{ }^{\circ} \mathrm{C}$ after it solidified.

The medium was supplemented with Ampicillin $(50 \mu \mathrm{g} / \mathrm{ml})$, Kanamycin $(20 \mu \mathrm{g} / \mathrm{ml})$, IPTG (100 mM stock, $100 \mu l /$ plate), X-gal (100 mM stock, $100 \mu l / p l a t e)$ where appropriate.

\subsubsection{Transformation by Electroporation}

The electrocompetent cells were thawed on ice for $10 \mathrm{~min}$ from the stored aliquots at $-70{ }^{\circ} \mathrm{C}$, about $1-5 \mu \mathrm{l}$ of the ligation reaction was added and mixed gently. It was then pipetted into the cuvette and incubated on ice for $20 \mathrm{~min}$. The cuvette was dried and inserted in the electroporator (Gene Pulser; BIO-RAD), with settings of resistance $-200 \Omega$, Voltage $-2.5 \mathrm{kV}$, capacitance $-25 \mu \mathrm{F}$. The two buttons for generating high voltage pulse were pressed down together until the beeping sound and the cuvette was removed from the holder. The electroporated cells were mixed with $1 \mathrm{ml}$ LB medium, transferred to an eppendorf tube and incubated for 1 hour at $37{ }^{\circ} \mathrm{C}$. The cells were then plated out on LB/Agar plates 
supplemented with Ampicillin/Kanamycin to a final concentration of $50 / 20 \mu \mathrm{g} / \mathrm{ml}$ and the plates were incubated overnight at $37^{\circ} \mathrm{C}$.

\subsubsection{Plasmid Prep}

Plasmid from $5 \mathrm{ml}$ mini-cultures was prepared using the Mini Plasmid Prep Kit (Qiagen) and large plasmid preps from $50 \mathrm{ml}$ cultures were done using the Midi Plasmid Prep Kit (Qiagen) according to the manufacturer's instruction.

\subsubsection{Agarose Gel Electrophoresis}

The amount of agarose for 1-2 \% gel was weighed and boiled in $50 \mathrm{ml}$ of $1 \mathrm{x}$ TBE or TAE buffer using a microwave at $800 \mathrm{~W}$ for $2 \mathrm{~min}$, the molten agarose was cooled to about $55^{\circ} \mathrm{C}$ and $1 \mu \mathrm{l}$ of $20 \mathrm{mg} / \mathrm{ml} \mathrm{EtBr}$ was added. The agarose gel was poured into plexiglass casting chamber and left to solidify at RT (room temperature). Samples were mixed with appropriate volumes of loading buffer and loaded on the gel. The gel was run at $120 \mathrm{~V}$ in a chamber with $1 \mathrm{x}$ TBE or $1 \mathrm{x}$ TAE (completely covering it) until the desired length was reached. Modified from (Sambrook et al., 1998)

2x loading buffer: $10 \mathrm{mM}$ Tris-Cl (pH 7.5), 5 mM EDTA, $0.025 \%$ Bromophenol blue, $0.025 \%$ Xylene cyanol, $30 \%$ Glycerol

10x TBE buffer: $0.89 \mathrm{M}$ Tris-Cl, $0.89 \mathrm{M}$ Boric acid, $20 \mathrm{mM}$ EDTA pH $\sim 8.2$

10x TAE buffer: $0.4 \mathrm{M}$ Tris- $\mathrm{Cl}, 0.2 \mathrm{M}$ Acetic Acid, $10 \mathrm{mM}$ EDTA pH $\sim 7.7$

\subsection{RNA methods}

\subsubsection{In vitro Transcription}

Short RNAs were synthesized using the Megashortscript kit (Ambion), while capped RNA for injection was made with T3, T7, or SP6 MESSAGE MACHINE kit (Ambion) depending on the construct according to provided instructions. Templates from pGEMT and pBK-CMV-LacZ tag constructs of XDE LE were prepared by cutting with $\mathrm{Xhol}$ and transcribing with T7 and T3 polymerase 
respectively. Whilst that from pSP64-mGFP-XDE LE and pCS2+ (containing the various ORFs) constructs were cut with Notl and transcribed with SP6 polymerase. T7-promoter containing primers were used also to generate templates for some short RNAs by PCR amplification.

DEPC $\mathrm{H}_{2} \mathrm{O}$ preparation: $0.1 \%$ Diethylpyrocarbonate - DEPC (Roth) was added to distilled water and stirred overnight before autoclaving.

\subsubsection{Digoxigenin Labelled RNA}

Dig-labelled antisense RNA was transcribed from linearised plasmid construct using high concentration T7 or SP6 RNA Polymerase-200 U/ $\mu$ lFermentas) and Digoxigenin UTP (Sigma). After the transcription reaction at $37^{\circ} \mathrm{C}$ for 2 hours, the DNA template was degraded and the Dig-RNA was purified using RNAeasy kit (Ambion).

Reaction set up:

$\begin{array}{ll}\text { 5x Transcription buffer } & : 5 \mu \mathrm{l} \\ \text { Dig-NTP mix } & : 2.5 \mu \mathrm{l} \\ \text { DTT }(0.75 \mathrm{mM}) & : 1 \mu \mathrm{l} \\ \text { RNaseOUT } & : 1 \mu \mathrm{l} \\ \text { DEPC- } \mathrm{H}_{2} \mathrm{O} & : 13.5 \mu \mathrm{l} \\ \text { T 7 RNA polymerase } & : 1 \mu \mathrm{l} \\ \text { DNA template }(1 \mu \mathrm{g} / \mu \mathrm{l}) & : 1 \mu \mathrm{l} \\ & 25 \mu \mathrm{l}\end{array}$

The Dig-NTP mix consisted:

$\begin{array}{ll}\text { ATP } & 2 \mathrm{mM} \\ \text { CTP } & 2 \mathrm{mM} \\ \text { GTP } & 2 \mathrm{mM} \\ \text { UTP } & 1.6 \mathrm{mM}\end{array}$

Dig-11-UTP $\quad 0.4 \mathrm{mM}$ 


\subsubsection{Alexa labelled RNA}

Megashortscript kit (Ambion) was used for synthesizing the Alexa-RNA by supplementing a $10 \mu \mathrm{l}$ reaction with $1 \mu \mathrm{l}$ of $1 \mathrm{mM}$ ChromaTide Alexa Fluor 546-14UTP (Molecular Probes/Invitrogen).

\subsubsection{Radiolabelled RNA}

Radiolabelled $\alpha-{ }^{32} \mathrm{P}$ UTP (800 Ci/mmol, $10 \mu \mathrm{Ci} / \mu \mathrm{l}$ ) from GE healthcare was used to synthesize internally RNA. Transcription reaction was incubated at $37{ }^{\circ} \mathrm{C}$ for 2 hours, after that the template was degraded with $2 \mu$ of DNase I for $30 \mathrm{~min}$ and the RNA was purified using the RNAeasy kit (Qiagen). The RNA quality was checked on $7 \%$ Urea-PAGE (section 2.3.10).

$\begin{array}{ll}5 x \text { Transcription Buffer } & : 5 \mu \mathrm{l} \\ 10 \mathrm{mM} \text { ATP } & : 2 \mu \mathrm{l} \\ 10 \mathrm{mM} \text { GTP } & : 2 \mu \mathrm{l} \\ 10 \mathrm{mM} \text { CTP } & : 2 \mu \mathrm{l} \\ 0.75 \mathrm{M} \mathrm{DTT} & : 1 \mu \mathrm{l} \\ \text { RNaseOUT }(40 \mathrm{U} / \mu \mathrm{l}) & : 1 \mu \mathrm{l} \\ \text { Polymerase }(200 \mathrm{U} / \mu \mathrm{l}) & : 2 \mu \mathrm{l} \\ \text { Template } & : 2 \mu \mathrm{l}(\sim 1 \mu \mathrm{g}) \\ {\left[\alpha-{ }^{32} \mathrm{P}\right] \mathrm{UTP}(800 \mathrm{Ci} / \mathrm{mmol}, 10 \mu \mathrm{Ci} / \mu \mathrm{l})} & : 5 \mu \mathrm{l} \\ \text { DEPC } \mathrm{H}_{2} \mathrm{O} & : 3 \mu \mathrm{l} \\ & 25 \mu \mathrm{l}\end{array}$

\subsubsection{Total RNA Isolation Using Trizol Reagent}

Frozen oocytes (10 in number) were thawed in $500 \mu$ l trizol reagent and homogenized by 3 passages through the insulin syringe (Braun). The lysate was incubated at RT for $5 \mathrm{~min}$ and $100 \mu \mathrm{l}$ of chloroform was added, vortexed for 15 $\mathrm{sec}$ and centrifuged at $13000 \mathrm{rpm}$ at $4{ }^{\circ} \mathrm{C}$ for $10 \mathrm{~min}$. The upper aqueous phase was carefully removed into a new tube and the RNA was precipitated with 1 volume of isopropanol at RT for $10 \mathrm{~min}$. The precipitated RNA was centrifuged for 10 min and the pellet was washed with $70 \%$ ethanol in DEPC treated water. The 
washed pellet was then dissolved in $30 \mu$ of $1 \mathrm{x}$ DNase I buffer containing $12 \mathrm{U}$ $(3 \mu \mathrm{l})$ of DNase I and incubated at $37^{\circ} \mathrm{C}$ for at least 2 hours. The DNA-free RNA was precipitated using the Sodium Acetate/Ethanol Precipitation (see section 2.3.7.2). The RNA quality and concentration was assayed using the Bioanalyser (Agilent) or $2 \%$ agarose gel and OD measurement (Ultrospec 1100 pro, Amersham Biosciences). Modified from (Sambrook et al., 1998)

1x DNasel buffer: $40 \mathrm{mM}$ Tris $\mathrm{Cl}(\mathrm{pH}$ 8), $6 \mathrm{mM} \mathrm{MgCl} 2,10 \mathrm{mM} \mathrm{NaCl}, 0.1 \mathrm{mM}$ $\mathrm{CaCl}_{2}$

\subsubsection{RNAeasy Cleanup}

In vitro transcribed RNA was purified using Qiagen RNAeasy kit according to the manufacturer's instructions. RNA bound to the column was eluted with warm DEPC water and quality checked on $2 \%$ agarose/TBE gel.

\subsubsection{RNA Precipitation Techniques}

\subsubsection{Isopropanol Precipitation}

RNA samples were mixed with equal volumes of $100 \%$ isopropanol and incubated at RT for $5 \mathrm{~min}$. Precipitated RNA was centrifuged at $13000 \mathrm{rpm}, 4{ }^{\circ} \mathrm{C}$ for 20 min and washed with $70 \%$ ethanol in DEPC treated water.

\subsubsection{Sodium Acetate/Ethanol Precipitation}

RNA samples were mixed with 3 volumes of $100 \%$ ethanol and 0.1 volumes $3 \mathrm{M}$ Sodium Acetate and incubated at $-80{ }^{\circ} \mathrm{C}$ for 2 hours or $-20^{\circ} \mathrm{C}$ overnight. Precipitates were centrifuged at $13000 \mathrm{rpm}, 4{ }^{\circ} \mathrm{C}$ for $20 \mathrm{~min}$ and washed with 70 $\%$ ethanol diluted with DEPC treated water. The pellet was dried in the speed vac for $1 \mathrm{~min}$ and dissolved in DEPC treated water. 


\subsubsection{Ethanol Precipitation}

This is done as described for Sodium Acetate/Ethanol Precipitation, only excluding the use of sodium acetate.

\subsubsection{Whole Mount In situ Hybridization (WMISH)}

This method was used to detect the distribution of RNA within fixed oocytes or embryos with digoxigenin labelled antisense RNA (Dig RNA) and performed as described in (Harland, 1991; Hollemann et al., 1999). The entire procedure was carried out in glass vials over 3 days.

\subsubsection{Formaldehyde Fixation}

Oocytes and embryos were fixed in 1x MEMFA for 1 hour at RT, and stored in 100 $\%$ ethanol at $-20^{\circ} \mathrm{C}$ until WMISH was performed.

10x MEM: 1 M MOPS, 20 mM EGTA, $10 \mathrm{mM} \mathrm{MgSO}_{4}$ (autoclaved)

MEMFA: 1x MEM, $3.7 \%$ Formaldehyde

\section{First Day}

\subsubsection{Rehydration}

PTw: 1xPBS, 0.1\% Tween-20

10x PBS: $100 \mathrm{mM} \mathrm{Na}_{2} \mathrm{HPO}_{4}, 20 \mathrm{mM} \mathrm{KH}_{2} \mathrm{PO}_{4}, 1.4 \mathrm{M} \mathrm{NaCl}, 28 \mathrm{mM} \mathrm{KCl}$,

\begin{tabular}{|l|l|cc|c|c|}
\hline & $\%$ Ethanol & $\% \mathrm{H}_{2} \mathrm{O} /$ Buffer & Time/min & Repeat \# \\
\hline 1 & 100 & & - & 5 & 1 \\
\hline 2 & 75 & 25 & $\mathrm{H}_{2} \mathrm{O}$ & 5 & 1 \\
\hline 3 & 50 & 50 & $\mathrm{H}_{2} \mathrm{O}$ & 5 & 1 \\
\hline 4 & 25 & 25 & PTw & 5 & 1 \\
\hline 5 & & 100 & PTw & 5 & 4 \\
\hline
\end{tabular}




\subsubsection{Proteinase $\mathrm{K}$ treatment}

Rehydrated oocytes were incubated in PTw containing $10 \mu \mathrm{g} / \mathrm{ml}$ proteinase $\mathrm{K}$ for 5 minutes whilst embryos at stage 8 were for $12 \mathrm{~min}$ and stage 32 for $23 \mathrm{~min}$ at RT. The treatment was stopped and oocytes re-fixed as stated in the table below:

\begin{tabular}{|l|l|c|c|c|}
\hline & Buffer & Added components & Time /min & $\begin{array}{c}\text { Repeat } \\
\#\end{array}$ \\
\hline 1 & $\begin{array}{l}100 \mathrm{mM} \text { Triethanolamine } \\
\mathrm{pH} 7.5\end{array}$ & 5 & 2 \\
\hline 2 & $\begin{array}{l}100 \mathrm{mM} \text { Triethanolamine } \\
\mathrm{pH} 7.5\end{array}$ & $\begin{array}{l}\text { Acetic anhydride } \\
12.5 \mu \mathrm{l} / 5 \mathrm{ml}\end{array}$ & 5 & 1 \\
\hline 3 & $\begin{array}{l}\text { Without changing step 2 } \\
\text { buffer }\end{array}$ & $\begin{array}{l}\text { Acetic anhydride } \\
12.5 \mu \mathrm{l} / 5 \mathrm{ml}\end{array}$ & 5 & 1 \\
\hline 4 & PTw & - & 5 & 2 \\
\hline 5 & $\begin{array}{l}\text { PTw+ } \\
3.7 \% \text { Formaldehyde }\end{array}$ & 20 & 1 \\
\hline 6 & PTw & 5 & 5 \\
\hline
\end{tabular}

\subsubsection{Hybridization}

The re-fixed oocytes in PTw was washed once with $0.5 \mathrm{ml}$ hybridization buffer and then equilibrated in $1 \mathrm{ml}$ hybridization buffer at $65^{\circ} \mathrm{C}$ for $10 \mathrm{~min}$. Pre-hybridization of the oocytes in hybridization buffer was done in a shaking water-bath at $65{ }^{\circ} \mathrm{C}$ for 5 hours after which the Dig-labeled antisense in a fresh buffer was added for overnight incubation at $65^{\circ} \mathrm{C}$.

Hybridization buffer: 50 \% Formamide, 5x SSC, $1 \mathrm{mg} / \mathrm{ml}$ Torula RNA, $100 \mu \mathrm{g} / \mathrm{ml}$ Heparin, 1x Denhardt's reagent, $0.1 \%$ Tween-20, $0.1 \%$ CHAPS, 10 mM EDTA. 100x Denhardt's reagent: 2 \% BSA, 2 \% PVP, 2 \% Ficoll 400

20X SSC: 300 mM NaCl, 300 mM Sodium Citrate $\mathrm{pH} 7.0$

\section{Second Day}

\subsubsection{Washing of Unhybridized Probe}

The probe containing buffer was removed and stored at $-20{ }^{\circ} \mathrm{C}$ for re-use and oocytes were extensively washed as stated below. 


\begin{tabular}{|l|l|c|c|c|}
\hline & Buffer & Temperature $\left({ }^{\circ} \mathrm{C}\right)$ & Time $(\min )$ & Repeat \# \\
\hline 1 & hybridization buffer & 65 & 10 & 1 \\
\hline 2 & 2x SSC & 65 & 20 & 3 \\
\hline 3 & 2x SSC with RNase & 37 & 30 & 1 \\
\hline 4 & $0.2 x$ SSC & 65 & 20 & 2 \\
\hline 5 & 1x MAB & RT & 10 & 2 \\
\hline
\end{tabular}

RNase - $20 \mu \mathrm{g} / \mathrm{ml}$ RNase A, $10 \mathrm{U} / \mathrm{ml}$ RNase T1.

\subsubsection{Antibody Incubation}

The hybridized Dig-RNA was detected using anti-Dig antibody (Roche) coupled to alkaline Phosphatase which catalyses the color reaction.

\begin{tabular}{|c|c|c|c|c|}
\hline & Buffer & Temperature $/{ }^{\circ} \mathrm{C}$ & Time & Repeat \# \\
\hline 1 & $1 \times M A B+2 \% B M B$ & RT & $10 \min$ & 1 \\
\hline 2 & $\begin{array}{l}1 \times \mathrm{MAB}+2 \% \mathrm{BMB}+ \\
20 \% \text { Serum }\end{array}$ & RT & $60 \min$ & 1 \\
\hline 3 & $\begin{array}{l}\text { MAB + } 2 \% \text { BMB + } \\
20 \% \text { Serum* }+ \\
\text { Antibody }(1 / 5000)\end{array}$ & RT & 4 hour & 1 \\
\hline 4 & $1 \times M A B$ & RT & $10 \min$ & 5 \\
\hline 5 & $1 \times \mathrm{MAB}$ & $4^{\circ} \mathrm{C}$ & overnight & 1 \\
\hline
\end{tabular}

*Horse Serum (Biochrom KG)

5x MAB: 500 mM Malic Acid, $750 \mathrm{mM} \mathrm{NaCl}$, pH 7.5 (autoclaved)

2\% BMB: $2 \%$ Boehringer blocking reagent in 1x MAB (autoclaved and store at $\left.20^{\circ} \mathrm{C}\right)$

\section{Third Day}

\subsubsection{Color Reaction}

Oocytes were washed twice with 1x MAB and equilibrated in Phosphatase buffer with two exchanges. The color reactions were incubated at $4{ }^{\circ} \mathrm{C}$ or RT until dark blue stain was visible. The staining reaction stopped by exchanging the samples into water, the background stain washed as stated below and oocytes were refixed with MEMFA for 1 hour at RT. 


\begin{tabular}{|l|c|c|c|}
\hline & \% Methanol & Time & Repeat \# \\
\hline 1 & 100 & $2-10 \mathrm{~min}$ & 1 \\
\hline 2 & 75 & $5 \mathrm{~min}$ & 1 \\
\hline 3 & 50 & $5 \mathrm{~min}$ & 1 \\
\hline 4 & 25 & $5 \mathrm{~min}$ & 1 \\
\hline 5 & $\mathrm{H}_{2} \mathrm{O}$ & $5 \mathrm{~min}$ & 1 \\
\hline
\end{tabular}

Alkaline Phosphatase buffer (APB): $100 \mathrm{mM}$ Tris- $\mathrm{HCl}(\mathrm{pH} 9.5), 50 \mathrm{mM} \mathrm{MgCl}_{2}$, $100 \mathrm{mM} \mathrm{NaCl}, 0.1 \%$ Tween-20.

Colour reagent (NBT/BCIP): to each $1 \mathrm{ml}$ APB, $1.75 \mu \mathrm{l}$ of NBT (Roche, 100 $\mathrm{mg} / \mathrm{ml}$ in $70 \%$ dimethylformamide) and $3.5 \mu \mathrm{l}$ of BCIP (Roche, $50 \mathrm{mg} / \mathrm{ml}$ in $100 \%$ dimethylformamide) were added. $2 \mathrm{ml}$ of the colour reagent was added to each vial.

\subsubsection{RNase Protection Assay}

The radiolabelled antisense probe used was obtained from in vitro transcription using PCR generated templates with reverse primers having a T7 promoter overhang. The total RNA samples were dried in speed vac and dissolved in the $1 \mathrm{x}$ RPA hybridization buffer, $1 \mu \mathrm{l}$ of the probe $\left(\sim 1 \times 10^{6} \mathrm{cpm}\right)$ was added and incubated in a heating block. Temperature of the heating increased from RT to 95 ${ }^{\circ} \mathrm{C}$ after tubes were placed on and after $95{ }^{\circ} \mathrm{C}$, it was reset to $56{ }^{\circ} \mathrm{C}$ for the 14 hour overnight hybridization. When $500 \mu \mathrm{l}$ tubes were used, hybridization was done in a PCR machine with program set, as described, for the heating block. After hybridization, RNase A and T1 were added in $380 \mu \mathrm{l} 1 \mathrm{x}$ RNase buffer and incubated at RT for 30 min.

The RNA digestion was stopped with $20 \mu$ of $10 \%$ SDS, $10 \mu$ Proteinase K (10 $\mathrm{mg} / \mathrm{ml}$ ) carefully mixed and incubated at $37^{\circ} \mathrm{C}$ for $15 \mathrm{~min}$. The samples were the phenol/chloroform extracted and the RNA precipitated from $340 \mu \mathrm{l}$ of the aqueous phase using $1 \mathrm{ml} 100 \%$ ethanol and $1 \mu \mathrm{l}$ tRNA. The precipitated RNA was dissolved in formamide loading buffer and loaded on 7 \% Urea-PAGE. 
Primers for PCR are:

FF luc probe_F: GCCGGTGTTGGGCGCGTTATTTATCGGAGT

I7 FF luc probe_R: GTAATACGACTCACTATAGGGCTCTGGCATGCGAGAATCTGACGC

Ren luc probe _F: CATGGTAACGCGGCCTCTTCTTATTTATGG

I7 Ren probe_R: GTAATACGACTCACTATAGGGCAAGCACCCCAATCATGGCCGACA

10x RPA Hybridization buffer: 400 mM PIPES, 4 M NaCl, 10 mM EDTA, pH 6.7 1x RPA Hybridization buffer: $(30 \mu \mathrm{l})-24 \mu \mathrm{l}$ Formamide, $3 \mu \mathrm{l}$ 10x RPA Hybridization buffer, $3 \mu \mathrm{L}$ DEPC $\mathrm{H}_{2} \mathrm{O}$

2x RNase Buffer: $20 \mathrm{mM}$ Tris pH 7.5, $10 \mathrm{mM}$ EDTA, $0.6 \mathrm{M} \mathrm{NaCl}$

\subsubsection{Urea-PAGE electrophoresis}

The gel mixture was prepared as below and poured into mounted glass plates (wiped with $70 \%$ ethanol) with $1 \mathrm{~mm}$ spacers, and sealed with cello-tape. RNA samples were loaded on the gel in formamide loading buffer, after the gel was pre-run for $30 \mathrm{~min}$ at between $10-20 \mathrm{~W}$ depending on the size. After loading, the gel was run at $10-20 \mathrm{~W}$ up to the required length. Gels from samples of Radiolabelled RNA were exposed to the phosphor plate after drying in the gel drier (Bio-Rad) and analysed by Phosphoimaging. Non-radioactive RNA gel were visualised by silver staining.

$\begin{array}{ll}40 \% \text { Acrylamide }(19: 1) & \underline{7 \% \text { gel }} \\ \text { Urea } & 4.38 \mathrm{ml} \\ 10 x T B E & : 10.51 \mathrm{~g}(7 \mathrm{M}) \\ 10 \% \text { APS } & : 2.5 \mathrm{ml} \\ \text { TEMED } & : 300 \mu \mathrm{l} \\ \mathrm{H}_{2} \mathrm{O} & : 30 \mu \mathrm{l} \\ & : \text { to } 25 \mathrm{ml}\end{array}$




\subsection{Oocyte Manipulations}

\subsubsection{Oocytes Isolation}

Female frogs were anesthetized in $0.2 \%$ 3-aminobenzoic acid ethyl ester (Sigma) for 12 min and then placed on its back on ice. Surgical scissors and forceps used were sanitised with $70 \%$ ethanol before use. A small incision of about $\sim 1 \mathrm{~cm}$ was made on the lateral ventral surface of the lower abdomen through both the skin and the underlying muscle with scissors to reveal the ovaries. Several ovary lobes as needed were removed through the incision with forceps and cut off with scissors and transferred into new Petri dish without buffer. The incision was closed with three stitches using a surgical thread; the muscle was sutured together first before doing the same for the overlying skin. The frog was placed in $6 \mathrm{mg} / \mathrm{L}$ salt water to recover. The oocytes were released from the sac of follicle cells by $0.2 \mathrm{mg} / \mathrm{ml}$ collagenase treatment (Blendzyme, Roche) in $50 \mathrm{ml}$ falcon tubes with head-over-tail rotation at RT for 1-2 hours. After the treatment was complete, oocytes were washed 5 times with $1 \mathrm{x} \mathrm{MBSH}$ and sorted into Dumont stages (Dumont, 1972) using nylon grid of different mesh sizes. Grid cut-off size used to separate the various stages were St I - $50 \mu \mathrm{m}$, St II - $150 \mu \mathrm{m}$, St III - 300 $\mu \mathrm{m}$, St IV $-600 \mu \mathrm{m}$ and St $\mathrm{V}-\mathrm{VI}-1 \mathrm{~mm}$. Oocytes were incubated at $18^{\circ} \mathrm{C}$ in $1 \mathrm{x}$ MBSH until injections were performed.

1x MBSH (Modified Barth Solution in 브EPES buffer): $80 \mathrm{mM} \mathrm{NaCl}, 1 \mathrm{mM} \mathrm{KCl}$, $2.4 \mathrm{mM} \mathrm{NaHCO}_{3}, 20 \mathrm{mM}$ HEPES (pH 7.5), $0.82 \mathrm{mM} \mathrm{MgSO}_{4}, 0.33 \mathrm{mM} \mathrm{Ca}\left(\mathrm{NO}_{3}\right)_{2}$, $0.41 \mathrm{mM} \mathrm{CaCl}_{2}$

Collagenase buffer: $82.5 \mathrm{mM} \mathrm{NaCl}, 2 \mathrm{mM} \mathrm{KCl}, 1 \mathrm{mM} \mathrm{MgCl}, 5 \mathrm{mM} \mathrm{HEPES}(\mathrm{pH}$ 7.5)

\subsubsection{Microinjection into oocytes}

\subsubsection{Localization Assay}

Capped RNA (5 nl of $10 \mathrm{ng} / \mu \mathrm{l}$ ) were injected into stage III-IV oocytes, which were sorted with Nylon mesh of the appropriate size, and maintained in culture for 4-5 days at $18{ }^{\circ} \mathrm{C}$ in a vitellogenin containing L15 medium as described in (Kloc and Etkin, 1999; Yisraeli and Melton, 1988). Distribution of the injected RNA after the 
incubation period was visualized by whole mount in situ hybridization using Digoxigenin-labelled anti-sense lacZ RNA. For the morpholino co-injection experiments (performed by Katsiaryna Tarbashevich), $0.3 \mathrm{fmol}$ RNA and $50 \mathrm{fmol}$ MO mixtures were injected with $2 \mathrm{nl}$ drop size into stage III-IV oocytes and cultured for 3-4 days (MO sequences used are shown below).

L15 Medium (with Vitellogenin):

$50 \%$ Leibovitz L15 culture medium without L-glutamine (Invitrogen)

$15 \mathrm{mM}$ HEPES/NaOH $(\mathrm{pH} 7.5)$

$1 \mathrm{mM}$ L-Glutamine (Invitrogen)

$1 \mu \mathrm{g} / \mathrm{ml}$ Insulin (Sigma)

$100 \mu \mathrm{g} / \mathrm{ml}$ Gentamycin (Invitrogen)

$50 \mu \mathrm{g} / \mathrm{ml}$ Tetracycline (Sigma)

$50 \mathrm{U} / \mathrm{ml}$ Nystatin (Invitrogen)

$5 \mathrm{mg} / \mathrm{ml}$ Vitellogenin (prepared in the lab - see section 2.4.4)

\section{Morpholino sequences: 5'-3'}

MO1 taaataaagtgaaacaaaaattagc

MO2 aaagtgcaataacaagtgaaaaaaa

MO3 aagtgcaagatacacacatacaaaa

MO4 ggtggcaacactattttccgatctt

MO5 actgcctttccaggtgaaaatcaag

MO6 gttttcaccaggaaagccetttatg

MO7 tacaaaaaaagtgcaataacaagtg

sMO7 cacttgttattgcacttttttgtat

\subsubsection{Nucleo-cytoplasmic Transport Assay}

This assay was carried out as originally described in (Rudt and Pieler, 1996). ${ }^{35}$ Slabelled myc-tagged ElrA and ElrB proteins were prepared using TnT system (Promega) and ${ }^{35} \mathrm{~S}$ methionine (Hartmann Analytic) using pCS2+ MT-ElrA and ElrB as template. The ${ }^{35} \mathrm{~S}$-labelled proteins were injected into either nucleus or cytoplasm of stage $\mathrm{VI}$ oocytes and cultured in 1x MBSH. MT-ElrA/B was immunoprecipitated from manually dissected oocytes, separated on SDS-PAGE 
gel and the gel analyzed by Phosphoimaging (TY9400 Typhoon ScannerAmersham). (This experiment was performed by Susanne Koch).

\title{
2.4.2.3. MS2-Tethering Assay
}

The constructs used for this assay, pET-MS2, pET-MS2-PABP as well as firefly luciferase-MS2, firefly luciferase (recloned into pBK-CMV by Susanne Koch) and pCS2+-Renilla luciferase reporters were kindly provided by Dr. Nancy Standart, Cambridge, UK. Construct for the MS2-ElrA and ElrB1 were made by reamplification of the ORF with primers containing Nhel/BamHI (see below) and cloned into $\mathrm{pET}$-MS2 vector.

\author{
ElrA_ORF_MS2-Nhel_F: TCAGCTAGCATGTCTAACGGTTATGAAGATCACA \\ ElrA_ORF_MS2-BamHI_R: ATAGGATCCTTATTTGTGGGACTTGCTGGTTTTG \\ ElrB1_ORF_MS2-Nhe_F: GCTAGCATGGCAGTCAGACTGTGTGATGTGGCT \\ ElrB1_ORF_MS2-Bam_R: GATCCTTAAGCTTTGTGTGTTTTGCTCGTTTTGAAC
}

A 73 nucleotide long polyA tail was added to pET-MS2-ElrB1 using the primers below; pET-MS2-EIrA had no polyA tail.

pA_Bam F: GCAGGATCCCCGATCCTCTAGAGTCGACCTGC

pA_Cla R: CCTAATCGATGTCGACGGGATCGAAAAGC

The assay was done essentially as described by (Minshall and Standart, 2004), and mRNA for microinjection into oocytes was prepared as follows:

pET-MS2 constructs - Clal cut template, T7 polymerase transcription

pBK-CMV firefly luciferase constructs - Mlul cut template, T3 polymerase transcription

pCS2+ -Renilla construct - Notl cut template, SP6 polymerase transcription

In vitro transcribed mRNA encoding MS2 fusion proteins (10 $\mathrm{nl}$ of $1 \mu \mathrm{g} / \mu \mathrm{l})$ were first injected into oocytes and cultured in $1 \mathrm{X} \mathrm{MBSH}$ overnight at $18{ }^{\circ} \mathrm{C}$. The reporter mRNA ( $5 \mathrm{nl}$ mixture of $10 \mathrm{ng} / \mu \mathrm{l}$ firefly luciferase and $2.5 \mu \mathrm{g} / \mu \mathrm{l}$ Renilla luciferase) were then injected and cultured for further 24 hours. The luciferase activity was measured using reagents from the Dual-Glo ${ }^{\mathrm{TM}}$ Luciferase Assay 
System (Promega) and detected in the luminometer (Berthold Technologies). Renilla luciferase activity was used as an internal standard.

\subsubsection{Oocyte Extract Preparation}

Oocytes were homogenized in a S100 buffer containing $50 \mathrm{mM}$ Tris pH 7.5, 50 $\mathrm{mM} \mathrm{KCl}, 0.1 \mathrm{mM}$ EDTA, protease inhibitor cocktail (Roche), $10 \%$ glycerol and supplemented with PMSF $0.1 \mathrm{mM}$, using a syringe with $24 \mathrm{G}$ and $27 \mathrm{G}$ needles. Crude extract was centrifuged at $13000 \mathrm{rpm}(16000 \mathrm{~g})$ for $20 \mathrm{~min}$ at $4^{\circ} \mathrm{C}$ using Biofuge (Haraeus). The supernatant was extracted with equal volume of Freon (Merck) and the centrifugation was repeated to remove residual yolk. The upper phase of $\mathrm{S} 16$ extract was carefully removed and aliquots stored at $-80^{\circ} \mathrm{C}$ for longterm and $-20^{\circ} \mathrm{C}$ for immediate use.

\subsubsection{Preparation of Vitellogenin}

Female frogs used for this procedure were usually old ones that were not laying or laying poor quality eggs using the protocol described by (Kloc and Etkin, 1999). For the enrichment of Vitellogenin in the blood, frogs were injected with $200 \mu \mathrm{l}$ ßestradiol (Sigma - E4389 at $6.7 \mathrm{mg} / \mathrm{ml}$ ), into the dorsal lymph sacs 13 and 10 days before obtaining the blood. Blood was obtained by cutting off the sternum followed by an incision in the heart and the blood collected directly into $50 \mathrm{ml}$ falcon tubes containing $1 \mathrm{ml}$ PBS/citrate buffer. Blood from two frogs were collected in each tube and kept constantly on ice and later centrifuged at $2500 \mathrm{~g}$, $4{ }^{\circ} \mathrm{C}$ for $15 \mathrm{~min}$ in a table top centrifuge (Heraeus).

The supernatant was carefully transferred into new tubes and the centrifugation was repeated, $5 \mathrm{ml}$ of the supernatant was then mixed with $20 \mathrm{ml}$ of $20 \mathrm{mM}$ EDTA and $1.6 \mathrm{ml}$ of $0.5 \mathrm{M} \mathrm{MgCl}_{2}$ and placed on ice for $5 \mathrm{~min}$ for the vitellogenin to precipitate. After the centrifugation, at $2500 \mathrm{~g}, 4{ }^{\circ} \mathrm{C}$ for $15 \mathrm{~min}$, the green Vitellogenin pellet was dissolved in $3 \mathrm{ml}$ of buffer $\mathrm{A}$ in the $4{ }^{\circ} \mathrm{C}$ cold room for 2 hours. The dissolved Vitellogenin was dialyzed in buffer $\mathrm{A}$ in the $4{ }^{\circ} \mathrm{C}$ cold room for 2 hour and then changed into fresh buffer $A$ for overnight, after which it was dialysed twice in $10 \mathrm{mM}$ Tris- $\mathrm{Cl}$ buffer, $\mathrm{pH}$ 7.5. The Vitellogenin was adjusted to 
$25 \mathrm{mg} / \mathrm{ml}$ and then stored at $-20{ }^{\circ} \mathrm{C}$ in $1 \mathrm{ml}$ aliquots. (This was usually performed by a team of 4 or more people)

\subsection{Protein Methods}

\subsubsection{Bradford Assay}

Bradford reagent was prepared by dissolving $100 \mathrm{mg}$ Coomassie Brilliant Blue G-250 in $50 \mathrm{ml} 95 \%$ ethanol and $100 \mathrm{ml} 85 \%$ (w/v) phosphoric acid. When the dye was completely dissolved, the volume was increased to 1 litre and filtered through Whatman \#1 paper. The ready to use reagent was stored in the dark at 4 ${ }^{\circ} \mathrm{C}$ for up to 6 months. A standard curve was made using 0-20 $\mu \mathrm{g}$ BSA to determine the concentration factor. Measurement of protein concentration was done by adding $5 \mu \mathrm{l}$ of the sample to $1 \mathrm{ml}$ of the Bradford reagent and thoroughly mixing in disposable plastic cuvettes. After incubation at RT for $5 \mathrm{~min}$, the OD was measured at $595 \mathrm{~nm}$ (Ultrospec 1100 pro, Amersham Biosciences). The protein concentration was estimated using the concentration factor from the standard curve.

\subsubsection{Protein Precipitation Techniques}

\subsubsection{Acetone}

Protein sample was mixed thoroughly with 5 volumes of cold acetone and incubated at $-80{ }^{\circ} \mathrm{C}$ for 1 hour or $-20{ }^{\circ} \mathrm{C}$ overnight. The precipitates were centrifuged at $13000 \mathrm{rpm}, 4^{\circ} \mathrm{C}$ for $20 \mathrm{~min}$, the pellet was air dried and appropriate volume of protein sample buffer added to dissolve it.

\subsubsection{NaDOC-TCA Acetone}

Protein samples were mixed with 0.1 volume of $1 \%$ sodium deoxycholate ( $\mathrm{Na}$ Doc) solution, incubated at RT for 15 minutes, then 0.22 volumes of $50 \%$ Trichloro acetic acid (TCA) solution added and mixed thoroughly. After 2 hours of incubation at $4{ }^{\circ} \mathrm{C}$, the samples were centrifuged at $13000 \mathrm{rpm}, 4{ }^{\circ} \mathrm{C}$ for $30 \mathrm{~min}$. The pellet was incubated with $1 \mathrm{ml}$ of cold acetone at $-20{ }^{\circ} \mathrm{C}$ for at least $15 \mathrm{~min}$ 
and centrifuged again at $1300 \mathrm{rpm}, 4{ }^{\circ} \mathrm{C}$ for $15 \mathrm{~min}$. The pellet was air-dried and dissolved in the required volume of protein sample buffer.

\subsubsection{Phenol/Chloroform Extraction}

Samples of cell lysate or nucleic acid modifying reactions were separated into protein and nucleic acid phases by adding equal volumes of phenol : chloroform : Isoamyl alcohol (25:24:1). The samples were then vortexed vigorously for $15 \mathrm{sec}$ and centrifuged at $13000 \mathrm{rpm}$ for $5 \mathrm{~min}$ at RT. The upper phase containing nucleic acid was carefully removed with a pipette into a new tube from which RNA or DNA was isolated using appropriate techniques as described above. Proteins from the interphase and the phenol phase were precipitated using acetone. Proteins obtained in this manner were usually applied to 2D gel electrophoresis (see section 2.5.7).

\subsubsection{SDS-PAGE Electrophoresis}

Gel for the electrophoresis was prepared according to the protocol of (Laemmli, 1970 ) and cast in assembled glass plates with $1 \mathrm{~mm}$ plastic spacers. The gel solution was always prepared fresh, whilst the glass plates were wiped with $70 \%$ ethanol. The resolving gel was poured first and allowed to polymerise with a layer of Isopropanol on top. After the resolving gel had polymerised, the stacking gel solution was poured and a plastic comb was inserted to mould the pockets for loading samples. Samples were loaded on the gel along with pre-stained protein markers (Bio-Rad), and mounted in a plexi-glass chamber and run at $100 \mathrm{~V}$ for the stacking gel and then $200 \mathrm{~V}$ for the resolving gel.

2x Protein Sample Buffer: $125 \mathrm{mM}$ Tris, 20 \% Glycerol, 5 \% SDS, $0.01 \%$ Bromo- phenol blue, 200 mM DTT.

10x Running Buffer: 250 mM Tris, 1.92 M Glycine, 1 \% SDS, pH 8.3

$$
30.3 \mathrm{~g}, \quad 144 \mathrm{~g}, \quad 10 \mathrm{~g} \text { - make up } 1 \mathrm{~L} \mathrm{H}_{2} \mathrm{O}
$$


Resolving Gel Solution (12 \%): (30 ml)

$\begin{array}{ll}\mathrm{H}_{2} \mathrm{O} & : 9.87 \mathrm{ml} \\ 1.5 \mathrm{M} \text { Tris } \mathrm{HCl} \mathrm{pH} 8.8 & : 7.5 \mathrm{ml} \\ \text { Acrylamide }(30 \%) & : 12 \mathrm{ml} \\ 10 \% \text { SDS } & : 300 \mu \mathrm{l} \\ 10 \% \text { APS } & : 300 \mu \mathrm{l} \\ \text { Temed } & : 30 \mu \mathrm{l}\end{array}$

Stacking Gel Solution (4 \%):

$\mathrm{H}_{2} \mathrm{O} \quad: 5.96 \mathrm{ml}$

$1.5 \mathrm{M}$ Tris $\mathrm{Cl} \mathrm{pH} 8.8 \quad: 2.5 \mathrm{ml}$

Acrylamide $(30 \%) \quad: 1.33 \mathrm{ml}$

$10 \%$ SDS $\quad: 100 \mu \mathrm{l}$

$10 \%$ APS $\quad: 100 \mu \mathrm{l}$

Temed $\quad: 10 \mu \mathrm{l}$

$10 \mathrm{ml}$

\subsubsection{Silver Staining}

This procedure was modified from (Blum, 1987) and all solutions used for this procedure were prepared fresh just before use. After the run, gel was carefully removed from the disassembled glass plates and fixed for at least 1 hour with fixing reagent. The fixed gel was washed twice with $40 \%$ ethanol, followed by a minute incubation in $0.02 \% \mathrm{Na}_{2} \mathrm{~S}_{2} \mathrm{O}_{3}$ and washed with distilled water for $2 \mathrm{~min}$. A $0.2 \%$ silver nitrate $\left(\mathrm{AgNO}_{3}\right)$ and $0.04 \%$ formaldehyde solution was added to the gel and incubated for $20 \mathrm{~min}$. The gel was developed with a solution of $3 \% \mathrm{~K}_{2} \mathrm{CO}_{3}$ and $0.02 \%$ formaldehyde after three washing with distilled water until bands were sufficiently visible. The developing stain was stopped with $10 \%$ glycine solution.

\subsubsection{Colloidal Coomassie Blue Staining}

The procedure was modified from (Neuhoff V., 1985) by Proteomics Group, MPlem, Göttingen. The stock staining solution was made up of $0.1 \%(\mathrm{w} / \mathrm{v})$ Coomassie Brilliant Blue G250, 2 \% (w/v) ortho-phosphoric acid and $10 \%(\mathrm{w} / \mathrm{v})$ ammonium sulfate which were stored up to 3 months. The working staining 
solution was prepared just before use by mixing 4 parts of the stock staining solution and 1 part methanol. Gels for staining were fixed for 1 hour, with $40 \%$ ethanol and $10 \%$ acetic acid, and washed twice with distilled water before the working staining solution was added. Staining was done overnight on a shaking table at RT and destained with distilled water.

\subsubsection{Western Blotting}

A semi-dry blotting technique (Sambrook et al., 1998) was used to transfer proteins from SDS-PAGE onto Nitrocellulose paper (Schleicher and Schuell). Blotting, at $20 \mathrm{~V}$ (for Metal electrode) or $40 \mathrm{~V}$ (for Carbon electrode) for 1 hour, was set up with protein gel placed on nitrocellulose sandwiched between layers of three filter papers (Whatman) soaked in blotting buffer using Fastblot machine (B34/B44 Fastblot - Biometra). After blotting, the nitrocellulose membrane was incubated on a shaking table at $4{ }^{\circ} \mathrm{C}$ in blocking buffer overnight followed by specific primary antibodies diluted to the appropriate concentration in blocking buffer for further 2 hours at $4{ }^{\circ} \mathrm{C}$. The membrane was washed three times for 10 min each, with TBS-Tween at RT and HRP coupled secondary antibody was added and incubated at RT for 2 hours. Detection was done with the ECL plus system and hyperfilm (GE Healthcare) according to the provided instructions; films were developed with Optimax Typ TR (MS-Laborgeraete).

Primary antibodies used were at the concentration of $1 / 10,000$ for anti-HuR (Santa Cruz), 1/5000 for anti-Vg1RBP (Zhang et al., 1999) and 1/4000 for anti40LoVe (Czaplinski et al., 2005).

Blotting buffer: 39 mM Glycine, 48 mM Tris-Cl, $0.037 \%$ SDS, 20 \% Methanol

Blocking buffer: 20 mM Tris-Cl (pH 6.8), 150 mM NaCl, $0.05 \%$ Tween-20, $5 \%$ milk powder

TBS/Tween: $\quad 20 \mathrm{mM}$ Tris-Cl (pH 6.8), $150 \mathrm{mM} \mathrm{NaCl,} 0.05 \%$ Tween-20 


\subsubsection{Two Dimensional Gel Electrophoresis}

The Biorad 2-D gel system was used according to the manufacturer's instruction; however a brief working protocol adapted from the Biorad manual is described here. The protein samples were phenol extracted to remove nucleic acids and proteins were then precipitated from the phenol phase with cold acetone as described in (section 2.5.2.1). The 2-D gel protein sample buffer recipe from the manual was modified, replacing DTT with hydroxyethyl-disulfide (HED), DeStreak reagent (Amersham Biosciences) see (Gorg et al., 2004).

Precipitated protein samples were dissolved in $200 \mu \mathrm{l}$ of sample buffer overnight at $20{ }^{\circ} \mathrm{C}$ with vigorous shaking, after which it was centrifuged at $200,000 \mathrm{~g}, 4{ }^{\circ} \mathrm{C}$ for 30 min before loading in the IEF tray. Routinely an $11 \mathrm{~cm} \mathrm{IPG} \mathrm{strip} \mathrm{was} \mathrm{used}$ and the protein amount loaded for preparative gel was between $0.25-1 \mathrm{mg}$. The IPG strip was placed gel-side down on the dissolved protein in the IEF tray and overlaid with mineral oil. The program set for the isoelectric focusing: 1 - active rehydration step (rapid mode in 15 min to $250 \mathrm{~V}$ ), 2 - Focusing step 1 (linear mode to $8000 \mathrm{~V}$ in $1 \mathrm{hr}$ ) and hold at $8000 \mathrm{~V}$ for $40,000 \mathrm{Vhr}, 3$ - pause at $500 \mathrm{~V}$ until ready. After focusing, IPG strips placed with gel-side up were equilibrated sequentially in 2 freshly prepared buffers for 15 min each on a shaking table. The equilibrated IPG strip was rinsed in SDS-PAGE running buffer then mounted on the pre-cast SDS-PAGE gel stabilized with $0.5 \%$ agarose and run as stated in section 2.5.3.

Sample Buffer: 7 M Urea, 2 M Thiourea $0.2 \%$ Biolytes $2 \%$ CHAPS, 2 \% HED, $0.001 \%$ bromophenol blue.

Equilibration buffer: 6 M Urea, 2 \% SDS, 50 mM Tris-Cl (pH 8.8), 20 \% Glycerol, (frozen till use)

Equilibration buffer 1: $10 \mathrm{ml}$ stock $+2 \%$ DTT,

Equilibration buffer 2: $10 \mathrm{ml}$ stock $+2.5 \%$ lodoacetamide. 


\subsubsection{Mass Spectroscopic Protein Identification}

Manually excised gel plugs were subjected to an automated platform for the identification of gel-separated proteins (Jahn et al., 2006) as described in the framework of recent large-scale proteome studies (Reumann et al., 2007; Werner et al., 2007). An Ultraflex MALDI-TOF-mass spectrometer (Bruker Daltonics) was used to acquire both peptide mass fingerprint (PMF) and fragment ion spectra, resulting in confident protein identifications based on peptide mass and sequence information. Database searches in the NCBI non-redundant primary sequence database restricted to the taxonomy Xenopus laevis were performed using the Mascot Software 2.0 (Matrix Science) with parameter settings described earlier (Reumann et al., 2007; Werner et al., 2007). All datasets were re-searched without taxonomy restriction to account for potential matches to sequences from Xenopus tropicalis. The minimal requirement for accepting a protein as identified was at least one peptide sequence match above homology threshold in coincidence with at least four peptide masses assigned in the PMF. This procedure was performed entirely by our collaborator - Proteomics Group of MPI EM, Göttingen (Dr Olaf Jahn).

\subsubsection{Glycerol Gradient Centrifugation and Biochemical Enrichment}

This procedure was adapted from (Abe and Davies, 1986). The gradient was formed using separate S100 buffers containing either $5 \%$ or $60 \%$ glycerol. A polyallomer centrifuge tube $(2.2 \mathrm{ml})$ was filled with $1 \mathrm{ml}$ of the $5 \%$ glycerol buffer and $1 \mathrm{ml}$ of the $60 \%$ glycerol buffer gently loaded underneath. The tubes were then sealed with paraffin and gently placed sideways on a flat plate and incubate at $4{ }^{\circ} \mathrm{C}$ for at least 1-2 hours. An approximate linear gradient was formed after the tubes were returned to the upright position. Protein samples (usually total of 200 $\mu \mathrm{g}$ S16 in $200 \mu \mathrm{l}$ volume) were carefully loaded on top of the pre-formed gradient. High speed centrifugation was done in TLS 55 rotor at a speed of 50,000 rpm $(214,200 \mathrm{~g})$ for 4 hours at $4^{\circ} \mathrm{C}$ using Optima TL Ultracentrifuge (Beckmann). Fractions of $200 \mu \mathrm{l}$ were carefully taken from the top of the gradient and processed for western blotting analysis. 
The fractions identified as enriched in specific RNPs were pooled and the glycerol concentration reduced by ultrafiltration at $4{ }^{\circ} \mathrm{C}, 4000 \mathrm{rpm}$ using amicon ultra tubes (Millipore) or vivaspin (Vivascience) in a swing-bucket rotor (Sorvall). RNPs were disrupted either by RNase A treatment $(10 \mu \mathrm{g} / \mathrm{ml})$; [RNP S200] or high salt (400 $\mathrm{mM} \mathrm{NaCl}$ ); [HS RNP S200] for 2 hour at $4{ }^{\circ} \mathrm{C}$ and then subjected to another round of ultracentrifugation at $\sim 200,000 \mathrm{~g}(68,000 \mathrm{rpm})$ in the TLA100.2 rotor (Beckmann). Another preparation [HS RNP S200 \#2] was generated by subjecting the pellet of high salt treated RNP fraction to RNase treatment followed by another high speed centrifugation. The high speed supernatants were routinely concentrated to the desired levels using the ultrafiltration tubes.

\subsubsection{Anion Exchange Chromatography}

ÄKTA ${ }^{\text {TM }}$ FPLC Chromatography System (Amersham) was used mounted with 1 $\mathrm{ml}$ MonoQ columns (Amersham) using the operating settings supplied by the manufacturer. Protein samples in the volume of $500 \mu \mathrm{l}$ were loaded using a syringe and then eluted with a linear $\mathrm{NaCl}$ gradient generated from buffer 1 (20 $\mathrm{mM}$ Tris- $\mathrm{Cl}, \mathrm{pH} 7.5)$ and buffer $2(20 \mathrm{mM}$ Tris- $\mathrm{Cl}, \mathrm{pH} 7.5,1 \mathrm{M} \mathrm{NaCl})$. The binding and washing steps were done with 5 column volumes (i.e. $5 \mathrm{ml}$ ) of $5 \%$ buffer 2 (i.e. $50 \mathrm{mM} \mathrm{NaCl}$ ) and elution was done with a linear gradient of $5 \%$ to $100 \%$ over 20 column volumes. The fraction size of $0.5 \mathrm{ml}$ was collected during the elution step; pools of 5 fractions as well as individual fractions of interest were concentrated and elution buffer exchanged into $\mathrm{S} 100$ buffer using ultrafiltration as described in (section 2.5.10.). After these steps, protein fractions were analysed using UV crosslinking and western blotting.

\subsubsection{Immunoprecipitation}

This procedure was performed as described in (Colegrove-Otero et al., 2005); with NET buffer containing $10 \%$ glycerol instead of $0.25 \%$ gelatin and referred to as G10-IP buffer. Antibody was immobilised on Protein A Sepharose CL-4B beads (GE Healthcare) in $1 \mathrm{ml} \mathrm{G} 10-I P$ buffer and incubated with head-over-tail rotation for at least 1 hour at $4{ }^{\circ} \mathrm{C}$. The unbound fraction was removed after a low speed centrifugation (2000 rpm) at RT to sediment the beads. An optimal amount of 0.5 $\mathrm{mg}$ oocytes extract was used in $0.5 \mathrm{ml} \mathrm{IP}$ volume and incubated with head-over- 
tail rotation overnight at $4{ }^{\circ} \mathrm{C}$. After the overnight incubation, the beads were washed 3 times with $1 \mathrm{ml}$ of G10-IP buffer and boiled in an appropriate volume of protein sample buffer and analysed by SDS-PAGE/western blotting. Preparative scale IP (2-D gel analyzed) was typical 100 fold of what was used for western blots whilst 4 fold was used for silver stained $11 \%$ SDS-PAGE analysis.

The co-immunoprecipitation of Alexa-labelled XDE-LE RNA - antisense morpholino oligos hybrids (concentrations were: 1 pmol Alexa-XDE-LE and 2.5 pmol $\mathrm{MO}$ ) and myc-tagged in vitro translated ElrB protein were done under the same IP conditions. The myc-tagged ElrB protein was prepared using TnT system (Promega), $12.5 \mu \mathrm{l}$ of $\mathrm{TnT}$ was pre-incubated with RNA-MO hybrids in $1 \mathrm{x}$ crosslinking buffer for $30 \mathrm{~min}$ at RT and then added to anti-myc-protein A beads. Alexa RNA was eluted from the beads after 2 hours at RT by phenol extraction then precipitated by ethanol/NaAcetate and analyzed by Urea PAGE. The AlexaRNA gel was scanned using TY9400 Typhoon scanner (Amersham).

Antibodies used were at the concentration of 1/100 for anti-myc (Sigma), 1/100 for anti-HuR (Santa Cruz), 1/200 for anti-Vg1RBP (Zhang et al., 1999) and 1/200 for anti-40LoVe (Czaplinski et al., 2005).

G10-IP buffer: $50 \mathrm{mM}$ Tris (pH 7.5), $150 \mathrm{mM} \mathrm{NaCl}, 0.5 \%$ NP40, 1 mM EDTA, $0.05 \% \mathrm{NaN}_{3}, 10 \%$ glycerol.

\subsubsection{UV crosslinking Assay}

The UV crosslinking assay was done with slight modification of protocol described in (Claussen and Pieler, 2004; Mowry, 1996). The crosslink reaction as set up below was pre-incubated at RT for 10 min before the ${ }^{32} \mathrm{P}$ labelled RNA was added and incubated for further $10 \mathrm{~min}$. The reaction was UV irradiated in the UV Crosslinker (Stratagene) for $10 \mathrm{~min}$, with tubes placed $4 \mathrm{~cm}$ from the UV source. RNA was degraded after crosslinking with $40 \mu \mathrm{g}$ RNaseA for at least 30 min at 37 ${ }^{\circ} \mathrm{C}$, after which 2 volumes of protein sample buffer was added and the samples were boiled at $95{ }^{\circ} \mathrm{C}$ for $5 \mathrm{~min}$. Samples were resolved on SDS-PAGE, after the electrophoresis the gel was dried in a Gel Drier (Bio-Rad) for 2 hours at $80^{\circ} \mathrm{C}$ and analysed using the Phosphoimager (Typhoon 9400 - Amersham Biosciences). 
For crosslinking reactions using Radiolabelled XDE-LE RNA and antisense morpholino oligos hybrids (concentrations were: $1 \mathrm{pmol}\left(2.0 \times 10^{5} \mathrm{CPM}\right){ }^{32} \mathrm{P}$-UTP$\mathrm{XDE}-\mathrm{LE}$ and $2.5 \mathrm{pmol} \mathrm{MO}$ ), $2 \mu \mathrm{l}$ of this mixture was added to the reaction and proceeded as described above.

\section{Crosslink reaction set up}

$\begin{array}{ll}\text { 5x Crosslink buffer } & : 2 \mu \mathrm{l} \\ \text { Protein } & : 1-5 \mu \mathrm{l} \text { (up to } 20 \mu \mathrm{g}) \\ \text { Competitor RNA } & : 1 \mu \mathrm{l}(0.5-3 \mu \mathrm{g}: 1-20 \text { molar excess) } \\ \text { RNaseOut } & : 1 \mu \mathrm{l} \\ \text { DEPC } \mathrm{H}_{2} \mathrm{O} & : \text { to } 9 \mu \mathrm{l} \text { reaction volume } \\ { }^{32} \mathrm{P} \text { RNA } & : 1 \mu \mathrm{l}\left(\sim 5 \times 10^{5} \mathrm{cpm}\right) \\ & 10 \mu \mathrm{l}\end{array}$

5x Crosslink buffer : $5 \mathrm{mg} / \mathrm{ml}$ heparin, $1 \%$ glycerol, $50 \mathrm{mM} \mathrm{KCl}, 10 \mathrm{mM}$ DTT, $5 \mathrm{mM}$ HEPES (pH 7.8), $1 \mathrm{mM} \mathrm{MgCl} 2,0.1 \mathrm{mM}$ EDTA, $40 \mu \mathrm{g} / \mathrm{ml}$ yeast tRNA

\subsubsection{Electrophoretic Mobility Shift Assay (EMSA)}

This procedure was carried out essentially as described in (Chung et al., 1996). The reaction mixtures were set up typically as stated below and incubated at RT for $30 \mathrm{~min}$ after which equal volumes of EMSA loading buffer $(50 \mathrm{mM}$ Tris-Cl pH 7.5, $50 \%$ glycerol, $0.01 \%$ Bromophenol blue) was added and loaded on $1 \%$ agarose. The agarose gel was prepared and run with $1 \mathrm{x}$ TAE at $40 \mathrm{~V}$ for 1.5 hours in an EtBr-free chamber. After the run was completed, the gel was scanned with the Typhoon 9400 (Amersham Biosciences) in fluorescence mode (cy3, Alexa $546)$.

\section{EMSA reaction set up}

5x Crosslink buffer $\quad: 2 \mu \mathrm{l}$

Protein $\quad: 1-5 \mu l$

Competitor RNA $\quad: 1 \mu \mathrm{l}(0.5-3 \mu \mathrm{g}: 1-50$ molar excess)

DEPC $\mathrm{H}_{2} \mathrm{O}$ : to $9 \mu$ reaction volume

Alexa RNA $\quad: 1 \mu \mathrm{l}(1 \mathrm{pmol})$

$10 \mu \mathrm{l}$ 


\subsubsection{Paraffin Embedding and Sectioning}

Oocytes fixed in MEMFA (see section 2.3.8.1) were embedded in paraffin (PolyFin, Ployscience: melting point $55^{\circ} \mathrm{C}$ ), by washing twice with $100 \%$ ethanol followed by two times washes with Xylene. The paraffin, melted at $60{ }^{\circ} \mathrm{C}$, was added to the oocytes and incubated in a heating block for 1 hour at $60{ }^{\circ} \mathrm{C}$, this was repeated. After this oocytes in paraffin were transferred into paper moulds for the paraffin to solidify while ensuring that oocytes were well placed separate from each other. The sectioning was done using Microtome (Leica Instruments) with settings to obtain $5 \mu \mathrm{m}$ thin sections, which were then mounted on TESPA coated glass slides (Sigma - A3648) over a layer of water and fixed onto the slide by keeping it on a $40{ }^{\circ} \mathrm{C}$ hot metal plate (Schütt Labortechnik). This fixing process was to ensure strong adhesion of the paraffin sections to the glass slide through the action of the TESPA coating. Sections on slides were stored at $-20{ }^{\circ} \mathrm{C}$ until staining procedure was preformed.

\subsubsection{Immunostaining on Oocyte sections}

Paraffin sections of pigmented stage III-IV oocytes were used for this procedure which was performed as described in (Afelik et al., 2006; Collombat et al., 2003) with the slight modification of an antigen retrieval step after the rehydration step. Primary antibodies used were at the concentration of 1/300 for anti-HuR (Santa Cruz), anti-Vg1RBP (Zhang et al., 1999) and anti-40LoVe (Czaplinski et al., 2005). The secondary antibodies used were 1/250 of anti-mouse-Cy3 and anti-rabbitFITC (Sigma). 
The immunostaining procedure used:

\begin{tabular}{|c|c|c|c|c|}
\hline Step & Buffer & No. of Times & Time & Temperature \\
\hline 1 & Xylene & 2 & $5 \mathrm{~min}$ & RT \\
\hline 2 & $100 \%$ Ethanol & 1 & $5 \mathrm{~min}$ & RT \\
\hline 3 & $95 \%$ Ethanol & 1 & $5 \mathrm{~min}$ & RT \\
\hline 4 & $80 \%$ Ethanol & 1 & $5 \mathrm{~min}$ & RT \\
\hline 5 & $60 \%$ Ethanol & 1 & $5 \mathrm{~min}$ & RT \\
\hline 6 & $30 \%$ Ethanol & 1 & $5 \mathrm{~min}$ & RT \\
\hline 7 & $\mathrm{H}_{2} \mathrm{O}$ & 2 & $5 \mathrm{~min}$ & RT \\
\hline 8 & $\begin{array}{r}\text { Antigen Ret } \\
20\end{array}$ & $\begin{array}{l}\text { ral : } 10 \mathrm{mM} \mathrm{Na} \\
\text { Microwave a }\end{array}$ & $\begin{array}{l}\text { Citrate, } \mathrm{pH} \\
650 \mathrm{~W}\end{array}$ & 6.0 \\
\hline 9 & 1x PBS & 3 & $5 \min$ & RT \\
\hline 10 & $10 \%$ FCS in $1 \times P B S$ & 1 & $45 \mathrm{~min}$ & RT \\
\hline 11 & $1^{\circ} \mathrm{Ab}$ in $10 \% \mathrm{FCS}$ & 1 & Overnight & $4{ }^{\circ} \mathrm{C}$ \\
\hline 12 & $1 \times$ PBS & 3 & $5 \mathrm{~min}$ & RT \\
\hline 13 & $2^{\circ} \mathrm{Ab}$ in $10 \% \mathrm{FCS}$ & 1 & 1 hour & RT \\
\hline 14 & 1x PBS & 3 & $5 \mathrm{~min}$ & RT \\
\hline
\end{tabular}

$1^{\circ}$ - primary; $2^{\circ}$ - secondary

All washing steps were done in a glass chamber with slides arranged vertically; this was changed to a horizontal orientation with sections side up for the $\left(1^{\circ}\right.$ and $\left.2^{\circ} \mathrm{Ab}\right)$ antibody incubation. The step 14 was done in the dark, stained sections were mounted in moviol solution and cover slide, the images were acquired using Axioplan2 fluorescence microscope (Zeiss). Moviol mounting solution was prepared by dissolving $5 \mathrm{~g}$ moviol in $20 \mathrm{ml}$ PBS (for 16 hours), $10 \mathrm{ml}$ 100\% glycerol was then added to the dissolved moviol and aliquots stored at $-20^{\circ} \mathrm{C}$. 


\subsection{Embryo Injections}

Embryos were obtained from female frogs, by injecting them with HCG to induce egg-laying (800 - 1000 U HCG approximately 12 hours preceding the egg-laying). Eggs were fertilized in vitro with minced testis in $0.1 \times \mathrm{MBS}$, de-jellied with $2 \%$ cystein- $\mathrm{HCl}, \mathrm{pH} 7.5$ and cultured in $0.1 \times \mathrm{MBSH}$ at $12{ }^{\circ} \mathrm{C}$.. RNA (4 $\left.\mathrm{nl}\right)$ was injected vegetally into 2-cell stage embryo in injection buffer. Embryos were then kept for 1 hour in the same buffer and then transferred into $0.1 \mathrm{x} \mathrm{MBSH}$ and cultured first at $12.5{ }^{\circ} \mathrm{C}$ till stage 12 then at $18{ }^{\circ} \mathrm{C}$ until stage 32 . For albino embryos, Nile blue was used to stain them for 10 min at RT before injections were done, making it easier to distinguish between animal and vegetal poles, (embryo injections were performed by Jana Löber). In vitro transcribed RNA of mutant version of XDE LE in p64SP-mGFP vector were injected at $150 \mathrm{ng} / \mu \mathrm{l}(4 \mathrm{nl})$, embryos were fixed at stage 8 and stage 32 for in situ hybridization using Dig labelled antisense GFP RNA.

HCG - $2000 \mathrm{U} / \mathrm{mL}$ human chorionic gonadotropin (Sigma)

De-jellying solution: $2 \%(w / v)$ L-cysteine hydrochloride in $0.1 \times \mathrm{MBSH}$ pH 8.0

Nile blue staining solution: $0.01 \%(\mathrm{w} / \mathrm{v})$ Nile blue, $89.6 \mathrm{mM} \mathrm{Na} \mathrm{HPO}_{4}, 10.5 \mathrm{mM}$ $\mathrm{NaH}_{2} \mathrm{PO}_{4}, \mathrm{pH} 7.8$;

Injection buffer: $1 \%(w / v)$ Ficoll in $1 \mathrm{X} \mathrm{MBSH}$ 


\section{Results}

\subsection{Identification Xenopus ElrA and ElrB as vegetal localization element binding proteins}

mRNAs enriched at the vegetal cortex of oocytes accomplish this localization by the specific recruitment of proteins to their respective localization elements (LE) that mediate the process. While a number of these factors have been identified, there are indications from UV crosslinking assays (Horvay et al., 2006), that some additional factors remain to be identified. Isolation of the complete set of proteins that participate in vegetal mRNA localization is a prerequisite to gain a better understanding of the exact mechanisms of this process. In an effort to isolate novel proteins that function in vegetal mRNA localization in Xenopus oocytes, a biochemical purification strategy was established to generate protein fractions enriched in components of the localization complex as illustrated in Fig. 3.1A. This included the use of glycerol gradient centrifugation to enrich large RNPs containing known localization proteins. These partially purified RNPs were then disrupted using RNase or high salt treatment; RNA binding proteins released by these procedures were then separated from the remaining large particles and aggregates by high speed centrifugation.

The profiles of known localization proteins, such as Vg1RBP and XStaufen1, in the glycerol gradient fractions were monitored by western blotting, these proteins were detected in high density fractions and they shift into low density fractions upon RNase treatment (Fig. 3.1B). Glycerol gradient centrifugation thus allows for a significant enrichment of these RNPs, since the high density fractions have a much reduced protein complexity as compared to the low density fractions (Fig. 3.1C). Disruption of the RNPs followed by high speed centrifugation yielded preparations (RNP S200 and HS RNP S200) highly enriched in RNA binding proteins; the average enrichment factor for Vg1RBP and XStaufen1 was approximately 18 in the RNP S200 as compared to the total (S16) oocyte lysate (Fig. 3.1D). In the coomassie stained protein gel (Fig. 3.1D), a number of additional bands become visible in the lane "b" compared to lane "a" (RNP S16) indicating the proteins enriched in the RNP fractions; the protein band pattern 
changed even more strikingly from RNP S16 to RNP S200 as a result of the removal of a number of proteins after the high speed centrifugation. Enrichment of certain proteins is clearly visible, e.g. bands suspected to be FRGY2-type proteins, appearing as a duplet of bands just above the $50 \mathrm{kDa}$ size marker in lanes "c" and "d". It could be seen that the RNase mediated disruption of RNPs was more effective in releasing the $\operatorname{Vg} 1 \mathrm{RBP}$ and XStaufen1, as judged by western blotting, compared to the use of high salt (Fig. 3.1D); in addition, there are bands between 37-50 kDa range which appear in either of the two protein preparations. Protein precipitations (cloudy solution) were observed during RNase treatment even when incubated at $4^{\circ} \mathrm{C}$, which was not the case with the high salt approach.

The RNP S200 and the HS RNP S200 preparations could contain novel LE binding proteins; to determine whether this was indeed the case, UV-crosslinking analysis was performed. This revealed the enrichment of additional RNA binding proteins as specifically binding to the XDead end vegetal localization element used; in particular a group of four low molecular weight proteins in the range of 35 to $45 \mathrm{kDa}$ was detected, (Fig. 3.1E). However, the radiolabelled protein bands could not be matched directly to bands in the lanes "c" and " $\mathrm{d}$ " on the coomassie stained gel, although the $70 \mathrm{kDa}$ Vg1RBP band could be correlated on both gels (Fig. 3.1D); this implied that other steps were needed for further enrichment and to improve separation to make it possible to identify these specific proteins.

Employing high resolution 2D gel-electrophoresis for the separation of RNP S200, individual proteins could be identified by mass spectroscopic analysis (Fig. 3.2) and this sample was found to contain the known vegetal localization proteins Vg1RBP, XStaufen1 and 40LoVe (Table 3.1). The most abundant proteins in the RNP S200 as well as in HS RNP S200 (appendix IV) are the FRGY2-type proteins. Vg1RBP focuses to the extreme negative end of the immobilised $\mathrm{pH}$ gradient (IPG) strip due to its basic pl; other basic proteins focus in a similar manner but those with low molecular weight could easily diffuse out of the IPG strip (Fig. 3.2A). RNA binding proteins tend to be highly basic, so to increase the possibility of identifying basic proteins below $50 \mathrm{kDa}$, IPG strip of pH 7-11 was also used to minimise proteins loss from the ends of the IPG strips during the 
isoelectric focussing step (IEF). Using pH 7-11 IPG strip, Vg1RBP along with other proteins such as the FRGY2-type proteins, appear to be considerably shifted into the middle of the gel making it easier for a lot more of low molecular weight basic proteins to be identified (Fig. 3.2B); in contrast to $\mathrm{pH}$ 3-10 where these proteins mostly diffuse out or were unresolved (Fig. 3.2A).

Candidate LE-interacting proteins identified in the range of 35 to $45 \mathrm{kDa}$ include one Elr (Elav-related) -type protein referred to as ElrB1 (Fig. 3.2B). It appears as a prominent band with a staining intensity comparable to Vg1RBP. A partial list of proteins with a functional link to RNA metabolism identified from the RNP S200 sample is given in Table 3.1, a complete list of all the individual proteins identified is shown in appendices II and III. The complete list of all the individual proteins identified from the HS RNP S200 preparation is found in appendix IV; it contains much more proteins and includes ribosomal proteins. Proteins identified from a sample referred to as HS RNP S200 \#2 is shown in appendix V, this sample was generated from the pellet of the HS RNP S200 preparation which makes is possible to examine the complexes that were not disrupted by the high salt treatment. Interestingly, this fraction included significant amounts of the FRGY2type proteins.

\section{Figure 3.1 Biochemical enrichment of vegetal localization element binding proteins}

(A) Proteins contained in large RNPs of Xenopus oocytes were biochemically enriched as shown schematically. (B) Glycerol gradient fractionation of stage 1-4 oocyte extracts $(200 \mu \mathrm{g})$, native or treated with RNase A; In: input; lane 1-11 are fractions taken from top to bottom of the gradient; P: pellet. Western blot analysis using antibodies directed against XStaufen1 and Vg1RBP. Underlined fractions represent the peak localizing RNP fractions collected as RNP S16, depicted in Fig 1A. (C) Coomassie stained SDS gel of the same gradient fractions isolated under native conditions as analysed by western blot in panel (B). (D) Estimation of the enrichment factor (EF) of specific proteins (Vg1RBP and XStaufen1) in the different protein preparations as defined in panel A by western blot; EF was calculated as the relative signal intensities of the western blot normalized to the total protein loaded $(5-20 \mu \mathrm{g})$ as in the Coomassie stained gel below the western blots. (E) UV cross-linking assay using ${ }^{32}$ P-labelled XDE LE RNA to monitor the enrichment of LEbinding proteins in the different protein preparations; candidate LE binding proteins are marked with red stars. Unlabeled XDE LE and LacZ RNAs served as specific and non-specific competitors, respectively. 
A

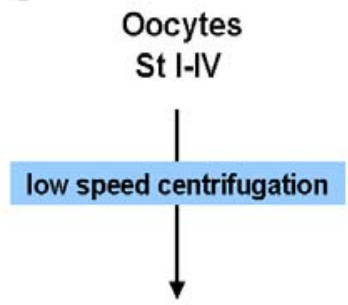

S16 Extract

glycerol gradient
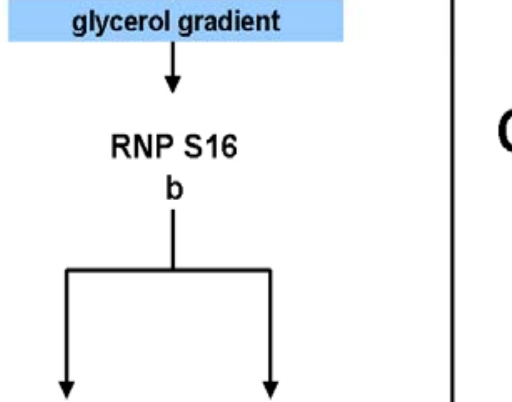

RNase High Salt

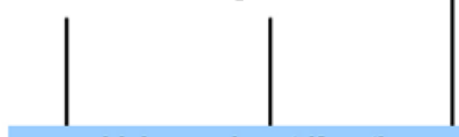

high speed centrifugation

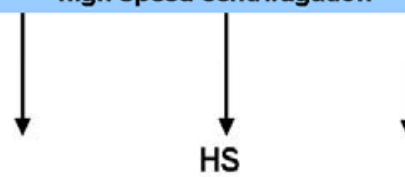

RNP S200

RNP S200
B

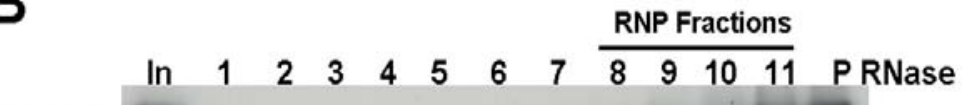
Vg1RBP

Vg1RBP

XStau1

C

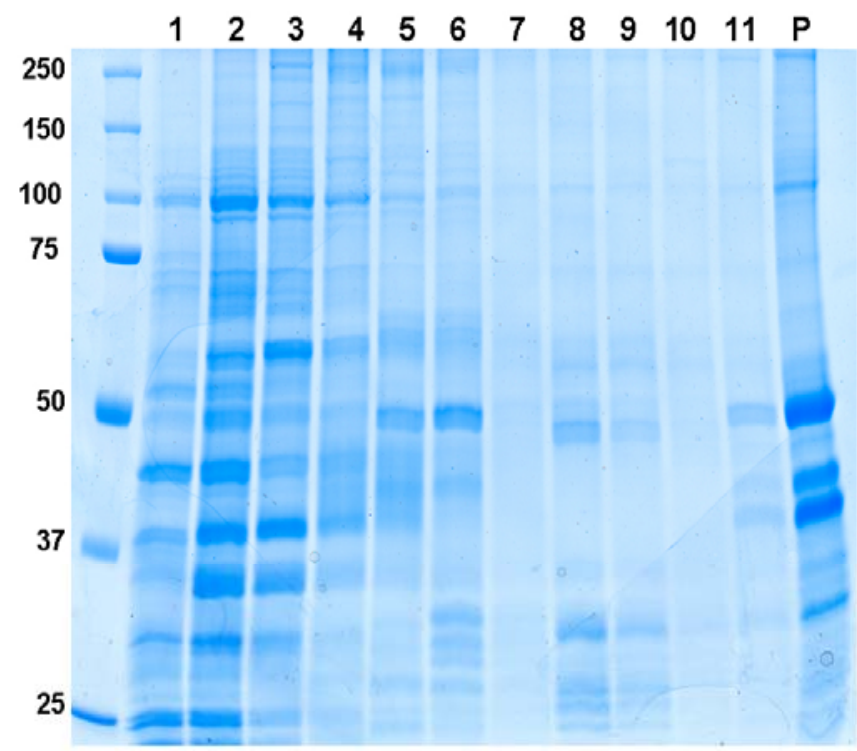

D

\begin{tabular}{l|c|c|c|c|} 
Enrichment & \multicolumn{1}{c}{$\boldsymbol{a}$} & $\boldsymbol{b}$ & $\mathrm{c}$ & \multicolumn{1}{c}{$\boldsymbol{d}$} \\
\cline { 2 - 5 } \begin{tabular}{l} 
Factor \\
\cline { 2 - 6 }
\end{tabular} & 9,4 & 14,5 & 18,3 \\
\hline
\end{tabular}

$\alpha$-Vg1RBP -

$\alpha$-XStaufen1
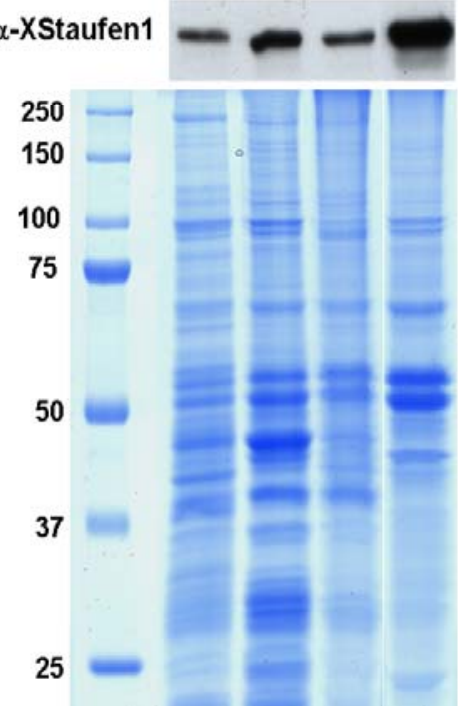

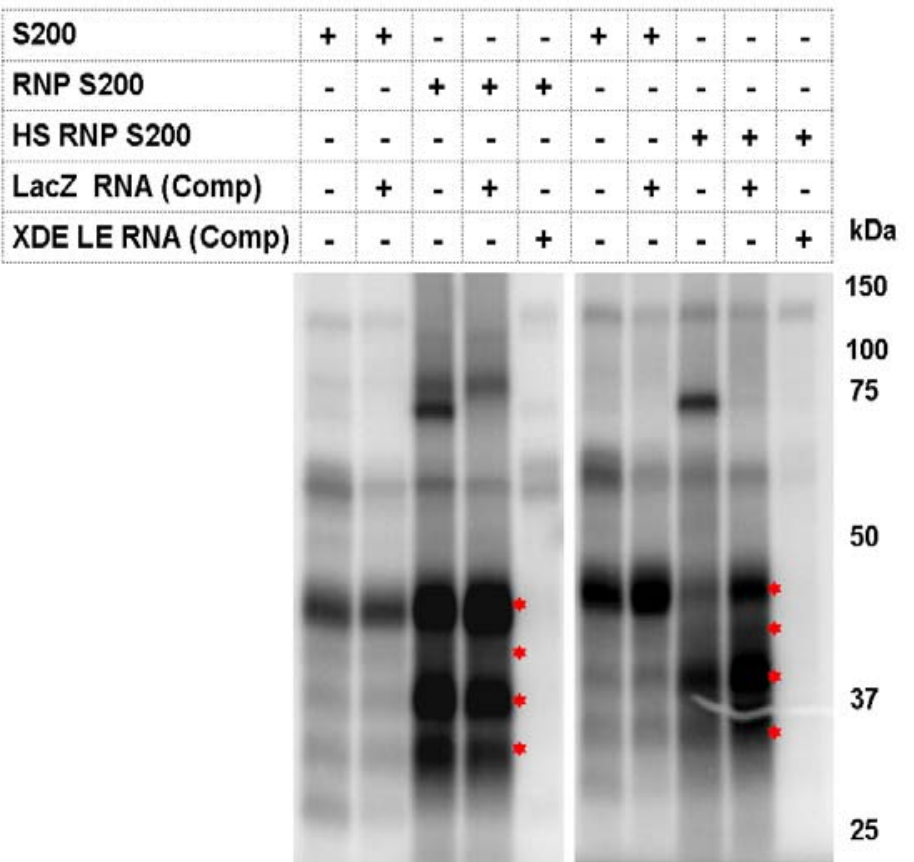

Figure 3.1 Biochemical enrichment of vegetal localization element binding proteins 

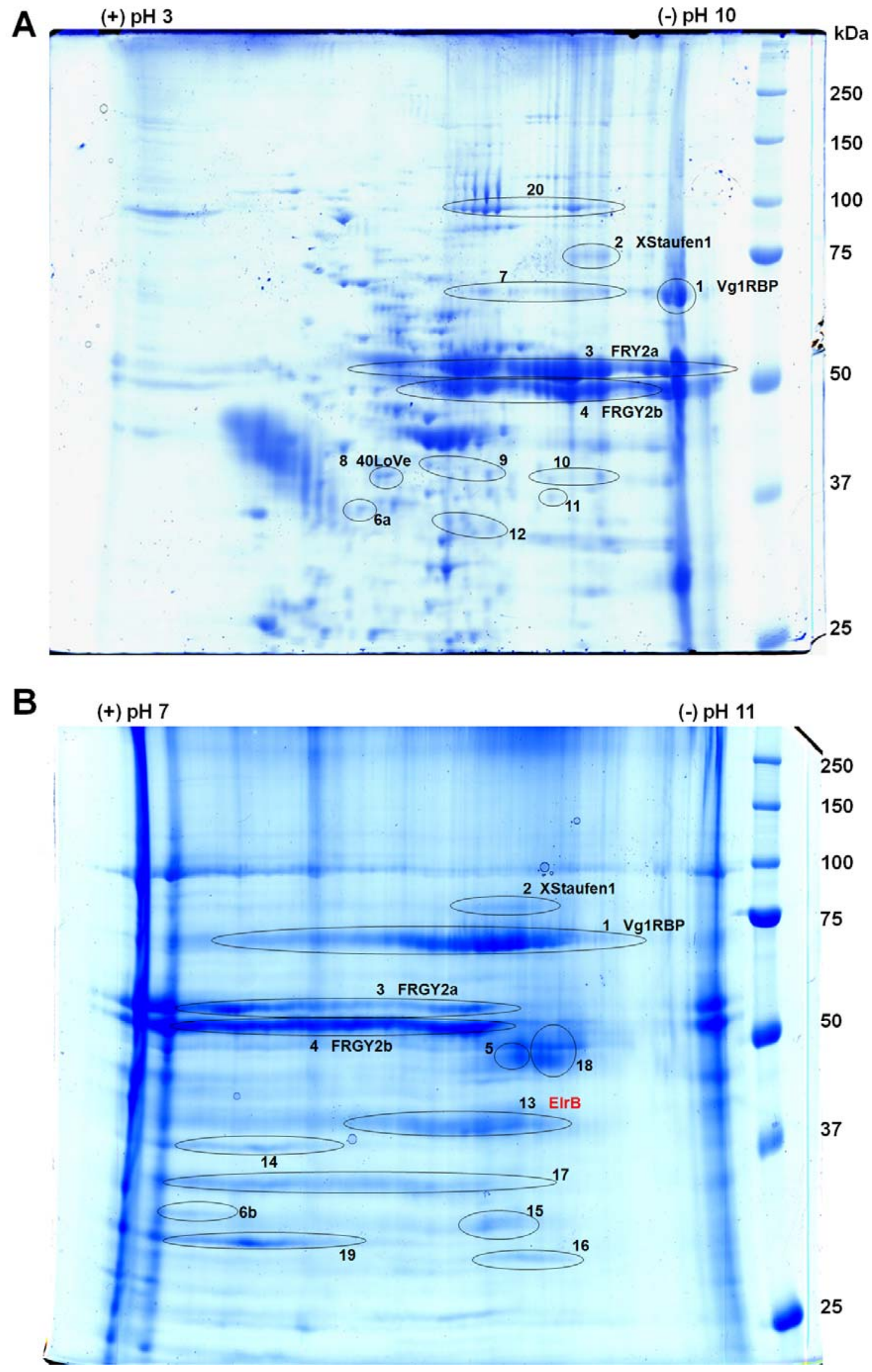

Figure 3.2 Identification of RNA binding proteins contained in RNPS200 
Figure 3.2 Identification of RNA binding proteins contained in RNPS200

Mass spectroscopic protein identification from the same RNP S200 preparation resolved by 2D gel electrophoresis using different immobilised pH gradient (IPG) strips (Bio-Rad). The first dimension IPG strips used had in (A) pH 3-10 and (B) pH 7-11 gradients (to allow highly basic proteins to be resolved). Circles cover groups of protein spots identified and found to be the same protein but which, for no clear reason, did not focus into one discrete spot during the IEF. The proteins highlighted were selected on the basis of their predicted putative functional link to RNA metabolism; numbered circles correspond to spot numbers in Table 3.1.

\begin{tabular}{|c|c|c|c|c|}
\hline Spot \# & Protein Name & Accession \# & kDa & pl \\
\hline 1 & $\begin{array}{c}\text { KH domain-containing transcription factor B3 } \\
\text { (Vg1RBP) }\end{array}$ & gi|148229563 & 65.6 & 9.08 \\
\hline 2 & XStaufen1 & gi|49256219 & 78.1 & 9.6 \\
\hline 3 & FRGY2a & gi|1175535 & 37.2 & 10.0 \\
\hline 4 & FRGY2b & gi|11755344 & 35.9 & 9.4 \\
\hline 5 & Hypothetical protein (RAP42) & gi|71679779 & 42.0 & 9.7 \\
\hline $6 a$ & p37 AUF1/hnRNP D & gi|52082714 & 33.1 & 5.7 \\
\hline $6 b$ & hnRNP D-like & gi|46249880 & 33.1 & 8.9 \\
\hline 7 & Similar to G3BP 2 & gi|148236557 & 54.4 & 5.4 \\
\hline 8 & hnRNP A/B (40LoVe) & gi|49257602 & 35.9 & 5.7 \\
\hline 9 & hnRNP A3b & gi|147905111 & 39.4 & 6.8 \\
\hline 10 & hnRNP A3a & gi|148230657 & 38.6 & 6.8 \\
\hline 11 & hnRNP A1 & gi|148237229 & 40.5 & 9.3 \\
\hline 12 & hnRNPA1a & gi|147900728 & 37.9 & 9.1 \\
\hline 13 & ElrB & gi|608539 & 42.7 & 9.7 \\
\hline 14 & hnRNP E2 & gi|5459450 & 37.5 & 7.6 \\
\hline 15 & dsRNA Binding Protein A - XIRBPA & gi|3334381 & 33.3 & 8.5 \\
\hline 16 & ePABP2 (embryonic nuclear type) & gi|28273596 & 24.5 & 8.8 \\
\hline 17 & GAPDH & gi|27882192 & 36.1 & 8.2 \\
\hline 18 & EF1 $\alpha$ & gi|416929 & 50.9 & 9.7 \\
\hline 19 & Guanine nucleotide BP B2-like 1 & gi|27371211 & 35.5 & 7.6 \\
\hline 20 & Eukaryotic translation elongation factor 2, & gi|27882475 & 95.42 & 6.45 \\
\hline
\end{tabular}

Table 3.1 List of proteins identified from RNP S200 with predicted functional link to RNA

\section{metabolism}

The partial list of proteins identified by mass spectroscopy (MS) from the two gels in Fig 3.2; which were selected on the basis of their predicted link to function in RNA metabolism. Proteins were identified using peptide mass fingerprinting and proteins with MASCOT score of 50 or higher were confirmed by sequencing of two peptides from each using MS/MS (see section 2.5.8). The database search with peptide masses and sequences, the nominal molecular mass and the putative isoelectric point $(\mathrm{pl})$ estimation from the amino acid sequences were done using Mascot Software 2.0 (Matrix Science). Spot number corresponds to numbered circles indicated on the gels in Fig 3.2. 
The fact that a significant amount of the $43 \mathrm{kDa}$ ElrB1 co-purified with known localization proteins made it a prime candidate to be responsible for the RNA binding activity detected in the UV crosslinking analysis with RNP S200 (Fig. 3.1E). In order to test for a direct interaction of Elr-type proteins with the XDE LE, immunoprecipitation experiments from crosslinking reactions of RNP S200 and radiolabelled XDE LE were performed. Radiolabelled protein bands corresponding to ElrB1, which is the most abundant protein crosslinking, and its two isoforms EIrB2 and ElrB3 were specifically precipitated, along with a protein of the appropriate size of ElrA (Fig 3.3). The radiolabelled ElrA and the three putative isoforms of ElrB immuno-precipitate could be responsible for the majority of the four RNA binding activities detected in the 35-45 kDa range (Fig. 3.1E). It was observed that a high molecular weight protein appears above the $75 \mathrm{kDa}$ marker; this might reflect dimers formed by the Elr-type proteins. Crosslinking of Vg1RBP to the XDE LE was verified using the same type of assay (Fig. 3.3).

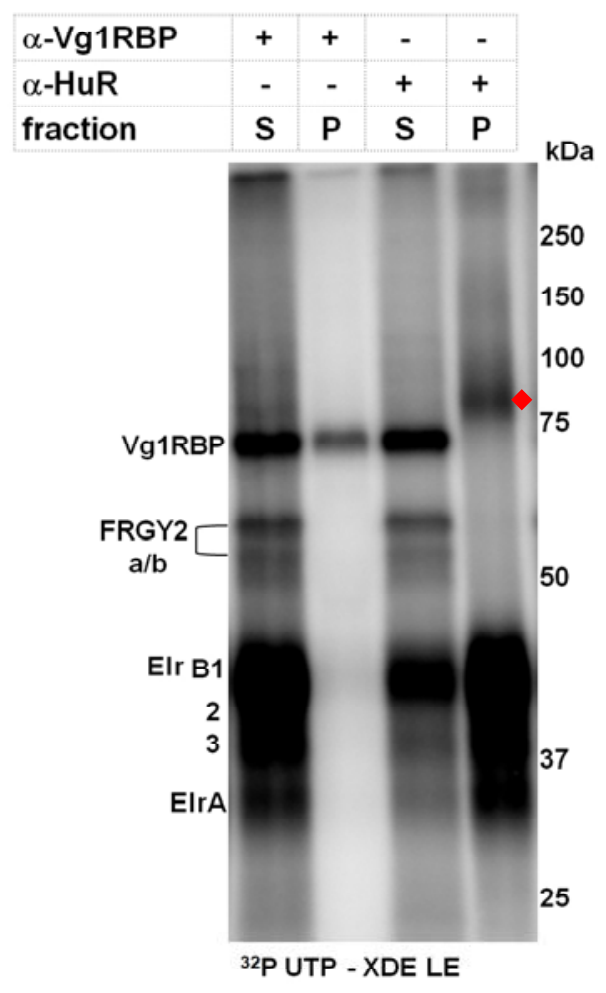

Figure 3.3 Identification of ElrA/B protein as vegetal localization element binding proteins Immunoprecipitation of radiolabelled $\mathrm{Vg} 1 \mathrm{RBP}$ and ElrA/B proteins from UV cross-linking reactions. Proteins were precipitated from the RNP $S 200 /\left[{ }^{32} P\right]-X D E$ LE cross-linking reaction by using $\alpha-$ $\operatorname{Vg} 1 \mathrm{RBP}$ and $\alpha-\mathrm{HuR}$ antibodies. Supernatant $(\mathrm{S})$ and bound $(\mathrm{P})$ fractions were separated by SDSPAGE. Red diamond marks putative dimer of ElrA/B. 
Anion exchange chromatographic (ANX) separation of the RNP S200 protein preparation was performed as an additional step with the aim of further reducing the complexity of the protein mixture as well as enriching the specific RNA binding proteins detected to allow for their identification. The profile of RNA binding activities obtained from the UV crosslinking analysis of these fractions revealed a rather complex pattern of proteins binding to the XDE LE (Fig 3.4A). The ANX profiles yield further evidence in support of the identity of the 35-45 kDa specific XDE LE binding activities as Elr-type proteins, judging from the strong correlation between the profile of RNA binding activity (Fig 3.4A) and the Elr-type proteins detected by western blotting (Fig 3.4B). The profile of $\mathrm{Vg} 1 \mathrm{RBP}$ also showed a strong correlation to an RNA binding activity in similar analysis; however the profile of 40LoVe protein, which is also detected in the 35-45 $\mathrm{kDa}$ range, did not suggest it contributed significantly to the RNA binding activities in the same size range but might rather be due largely to the activity of the Elr-type proteins. However, the protein composition of the individual fractions was still complex making any such identification difficult (Fig. 3.4C).

\subsection{ElrB isoforms and ElrA exhibit similar specificities in binding to vegetal localization elements}

Binding of Elr-type proteins could be a specific property of the LE of XDE mRNA or that property could be shared by LEs of several vegetally localizing mRNAs; to address this issue, a comparative UV crosslinking assay making use of a collection of different LEs and the RNP S200 preparation was performed (Fig. 3.5). This collection contained LEs which were previously known, as well as a set of novel LEs that were mapped in the laboratory (Loop and Pieler, unpublished). Out of 14 different LEs tested, which belonged to either the early, the intermediate or the late localization pathway, 8 were found to crosslink with high, and four additional ones with low efficiency to the Elr-type proteins, while only two exhibit no or hardly any such binding activity. These two LEs from XNIF and XVelo1 mRNAs were nonetheless crosslinked efficiently to Vg1RBP (Fig. 3.5). The Elrtype proteins do bind within the 3'UTR of Xvelo1 mRNA but outside of the LE; the translational control element of $\mathrm{Vg} 1 \mathrm{mRNA}$ (Vg1 TE) cross-links efficiently to Elrtype proteins while the opposite is true $\mathrm{Vg} 1 \mathrm{RBP}$. 


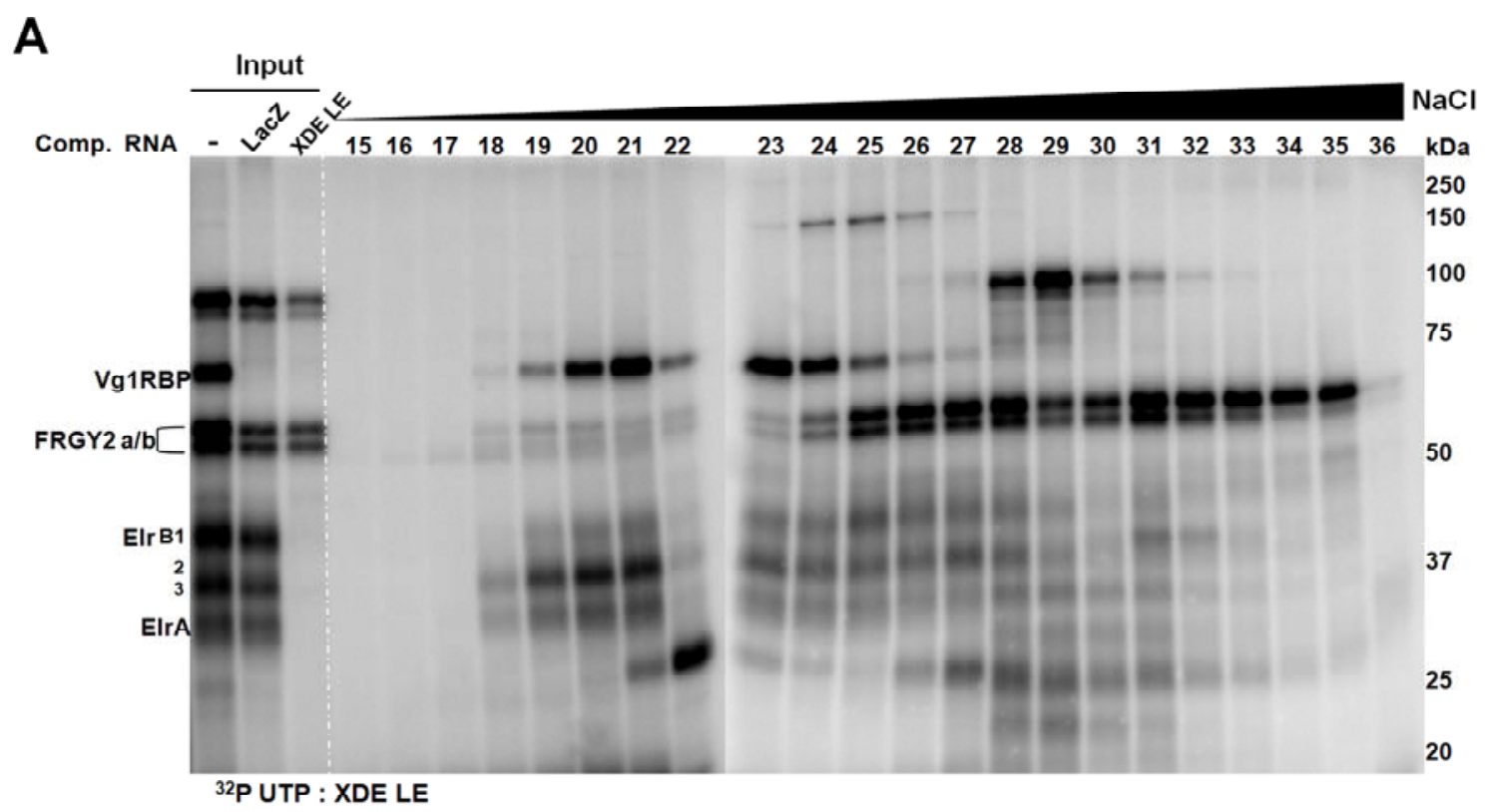

B $\begin{array}{lllllllllll}15 & 16 & 17 & 18 & 19 & 20 & 21 & 22 & 23 & 24 & 25\end{array}$

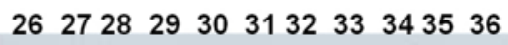

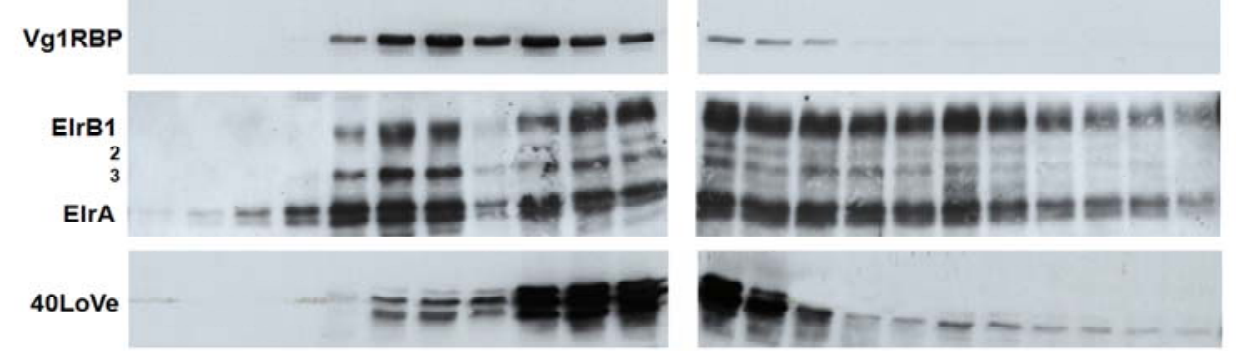

C

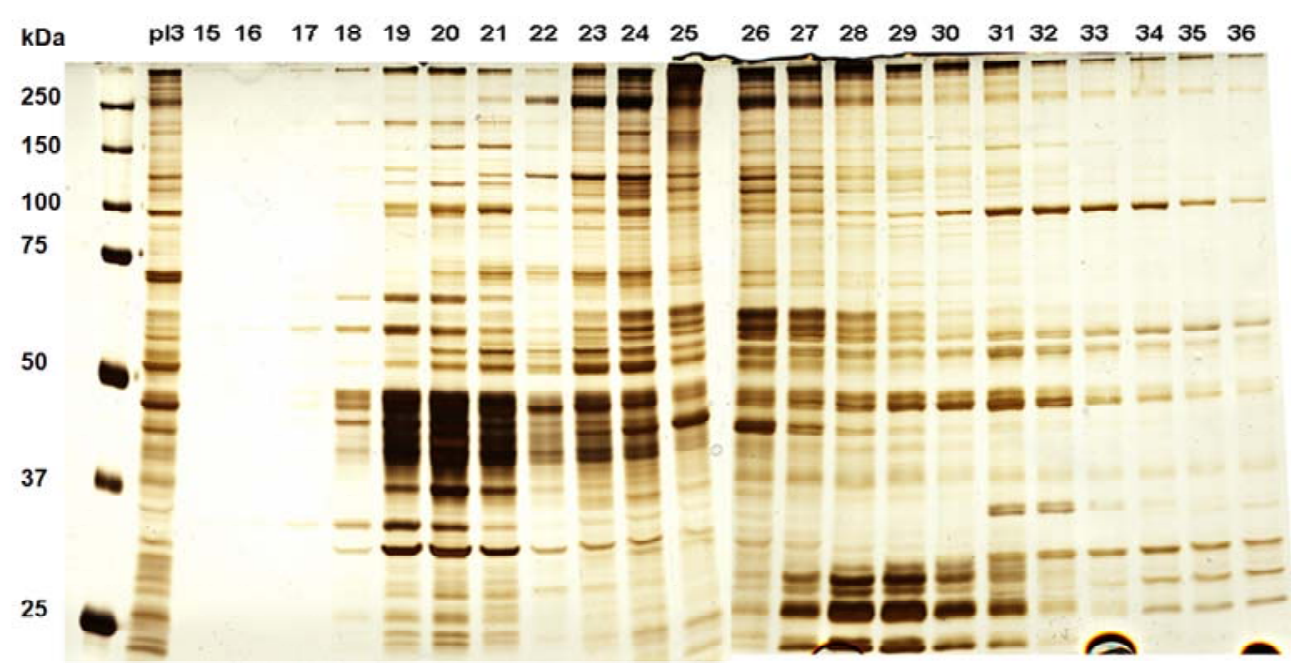

Figure 3.4 Anion exchange chromatographic (ANX) profile of RNA binding proteins in RNP S200

(A) UV crosslinking analysis of ANX protein fractions of RNP $S 200$ eluted with $\mathrm{NaCl}$ concentrations between 220-760 mM using ${ }^{32} \mathrm{P}$ labelled XDE LE; the input RNP S200 was analysed in the same way with lane 1 without competition whilst lane 2 and 3 correspond to reactions with unspecific and specific competition respectively. (B) Western blot analysis of the distribution of specific proteins in the same fractions as in (A), using anti-Vg1RBP, anti-HuR and anti-40LoVe. (C) Analysis of the total proteins in the ANX fraction on a silver stained $11 \%$ SDS-

PAGE. 
Interestingly, all three putative ElrB isoforms show similar binding preferences to the different LEs used, but it appears that they could be dispensable for the localization of some RNAs.

ElrB expression is observed in three putative isoforms in the oocyte; to further confirm the identity of these isoforms and their RNA binding specificities, tagged versions of the proteins were overexpressed in stage VI oocytes and tested in a comparative UV crosslinking analysis. ElrB1 is the most abundant of the three isoforms, with concentrations in the RNP fractions comparable to that of Vg1RBP (Fig 3.2B); this protein contains an N-terminal insertion which is not found in sequences of homologs from other systems, resulting in a roughly $3 \mathrm{kDa}$ increase in size. Short peptides identified from this $\mathrm{N}$-terminal region by mass spec analysis confirmed the presence of ElrB1 as an endogenous protein in the oocyte (Fig. 3.6A). The smallest isoform of ElrB (referred to here as ElrB3) was detected with a size of about $38 \mathrm{kDa}$ as apparently the second most abundant ElrB isoform in comparison to the one with an intermediate size of about $40 \mathrm{kDa}$ (ElrB2) (Fig. 3.4 A and B). Overexpression of ElrB2 in St VI oocytes making use of a construct that has the $\mathrm{N}$-terminal peptide deleted and is thus more similar to homologs from mouse and humans, showed a migration on SDS-PAGE comparable to the endogenous ElrB2 isoform (Fig. 3.7A and B). Similarly, overexpressed ElrB3 (a novel $X$. laevis sequence isolated) correlated strongly in size with the $38 \mathrm{kDa}$ endogenous ElrB isoform (Fig. 3.7A and B). These indirect evidences indicate the existence of $3 \mathrm{ElrB}$ isoform along with ElrA as the expressed Elr-type proteins in the oocyte, with the possible amino acid sequences and domain structure comparison depicted in Fig. 3.6B and C.

All the tagged versions of the different Elr-type proteins overexpressed in stage VI oocytes, indeed exhibited similar binding specificities in a comparative UV crosslinking assay reminiscent of that obtained with the endogenous proteins in RNP S200 (Fig. 3.7C). This indicates that all Elr-type protein isoforms expressed in the oocyte might be functionally redundant, since they do not differ in target specificity. 
Taken together, the biochemical purification approach used has resulted in a significant enrichment of LE-binding proteins from total Xenopus oocyte extracts. These include known components of the localization machinery, such as Vg1RBP, XStaufen1 and 40LoVe, but they also contain the Xenopus Elr-type proteins previously not known to interact with these regulatory RNA elements. 32P UTP LEs :

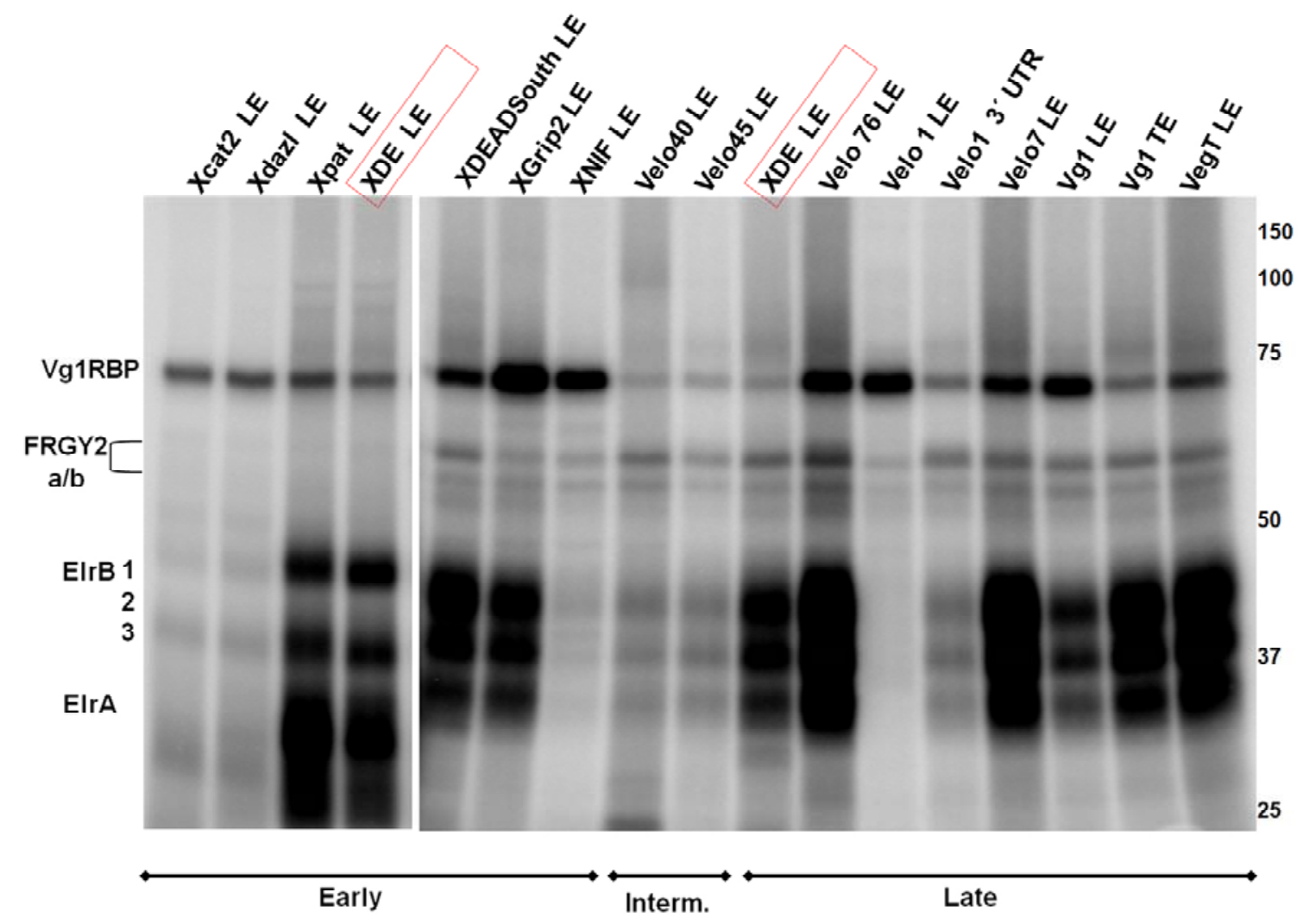

Figure 3.5 Vg1RBP and Elr-type proteins bind vegetal localization elements with different specificities

Comparative UV cross-linking assay using RNP S200 protein preparation and ${ }^{32} \mathrm{P}$-labelled vegetal localization elements from mRNA localized through all three pathways in oocytes.

Figure 3.6 Comparison of domain structure and sequences of putative Elr-type isoforms expressed in the oocyte

(A) Peptides (highlighted in red) detected for ElrB1 band (accession number NM_001087566) by mass spec identification. The underlined sequence corresponds to the peptide not present in the ElrB3 isoform. (B) Domain structure comparison between the 3 putative ElrB isoforms and ElrA, drawn to scale as predicted by web-based NCBI/ BLAST/ blastp program. (C) Amino acid sequence comparison of the 3 putative ElrB isoforms (ElrB1 and 2 sequence information from accession number NM_001087566) and ElrA (BC086269), using the Clone Manager program. The ElrB3 sequence information was generated entirely from a cloned PCR fragment using primers corresponding to ElrB2; this was not in the NCBI database; however there is a Xenopus tropicalis hypothetical protein sequence (with accession number gi|71896477). 
A

ElrB1

1 mavrlcdvasllrsgswaaepwtgqviaametql sngptcnntancpntincsspvesnn

61 tedsktnlivnyl pqnmtqeelkslfgsigeiescklvrdkitegqslgygfvnyidpkd

121 aekaintlnglrlqtktikvsyarpssasirdanlyvsglpktmtqkeleqlfsqygri

181 tsrilvdqvtgvsrgvgfirfdkrieaeeaikglngqkppgatepitvkfannpsqkvnh

241 tilsqlyqspnrrypgplaqqaqrf rldnllnmayggiksrfspmaidgmtslaginfpg

301 hagtgwcifvynlapdadesil wqmfgpfgavtnvkvirdfntnkckgfgfvtmtnydea

361 amaiaslngyrlgdrvlqusfktskthka

B

\begin{tabular}{|l|l|l|l|l}
\hline RRM1 & RRM2 & $\begin{array}{l}\text { Hinge } \\
\text { Region }\end{array}$ & RRM3 \\
\hline & & & \\
\hline
\end{tabular}

C

ElrB1 1 mavr ledvas1lrsgswaaeputgorviaamet qlsngptenntancpnt incsspvesnntedsktnl ivny lpqrmt qe E1rB2 1 --------------------------metqlsngptennt ancpnt incsspvesnntedskt nl ivny lpqnmt qe ElrB3 1 ----------------------------metqlsngptenntancpnt incsspvesnntedsktnl ivny lpqumt qe Elr\& 1 -------------------------------msngyedhmddver ddi-------------grtnl ivny lpqnmtqd

ElrB1 81 elks lfgsige iescklvrdki tegqslgygfvny idpkdaekaint lnglrlqtkt ikvsyarpssasirdan lyvsgl ElrB2 52 elks lfgsigeiescklvrdkitegqslgygf nnyidpkdaekaint lnglrlqtkt ikvsyarpssasirdan lyvsgl ElrB3 52 elks lfgsige iescklvrdkitegqslgygf nnyidpkdaekaint lnglrlqtkt ikvsyarpssas irdan lyvsgl ElrA 35 elrslfssigevesakl irdkva-ghslgygfvny lnakdaeraint lnglrlqskt ikvsfarpsset ikdan lyisgl

ElrB1 161 pktmtqke leqlfsqygri itsrilvdqutgvsrgvgf irfdkr ieaeeaikg lngqkppgatep itvkfannpsqkvnh ElrB2 132 pktmtqke leq lfsqygri itsr i lvdovtgvsrgvgf ir fdkr i eaeea ikg lngqkppgatep itvkfannpsqkvnh ElrB3 132 pktmt qke leq lfsqygri itsrilvdqvtgvsrgvgf ir fdkr ieaeeaikg lngqkppgatep itvkfannpsqkvnh

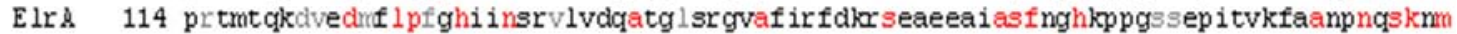

ElrB1 241 tilsqlyqspnrrypgp laqqaqrfr ldnll nmayggiksr fspmaidgmtslaginfpghagtgweifvynlapdades E1rB2 212 tilsqlyqspnrrypgp laqqaqrfr ldnll nmayggi ksr fspmaidgmtslaginfpghagtgweifvyn lapdades ElrB3 212 tilsqlyqspnrrypgp laqqaqrf--------------srfspmaidgmtslaginfpghagtgwcifvynlapdades ElrA 194 allsqichsparr fggpwhqaqrf----------------rfspmgvdhmssissvnvassassgwcif iynlgqdadeg

ElrB1 321 il wcgmfgp fgavt nvkvirdfntnkckgfgfvtmt nydeaamaias lngyr lgdrv lqvsfkt skt hka

ElrB2 292 il womfgp fgavt nvkvird fnt nkekgf gfvtmt nydeaamaias lngyr lgdrv lovsfkt skt hka

ElrB3 278 il wçmfgp fgavt nvkvird fnt nkckgfgf f tm nydeaamaias lngyr lgdrv lqvsfkt skt hka

ElrA 259 il wogmfgp fgavt nvkvird fnt nkekgfoff tme nyeeaamaias lngyr lgdkt lovssfkt skshk-

Figure 3.6 Comparison of domain structure and sequences of putative Elr-type isoforms expressed in the oocyte 
A

B

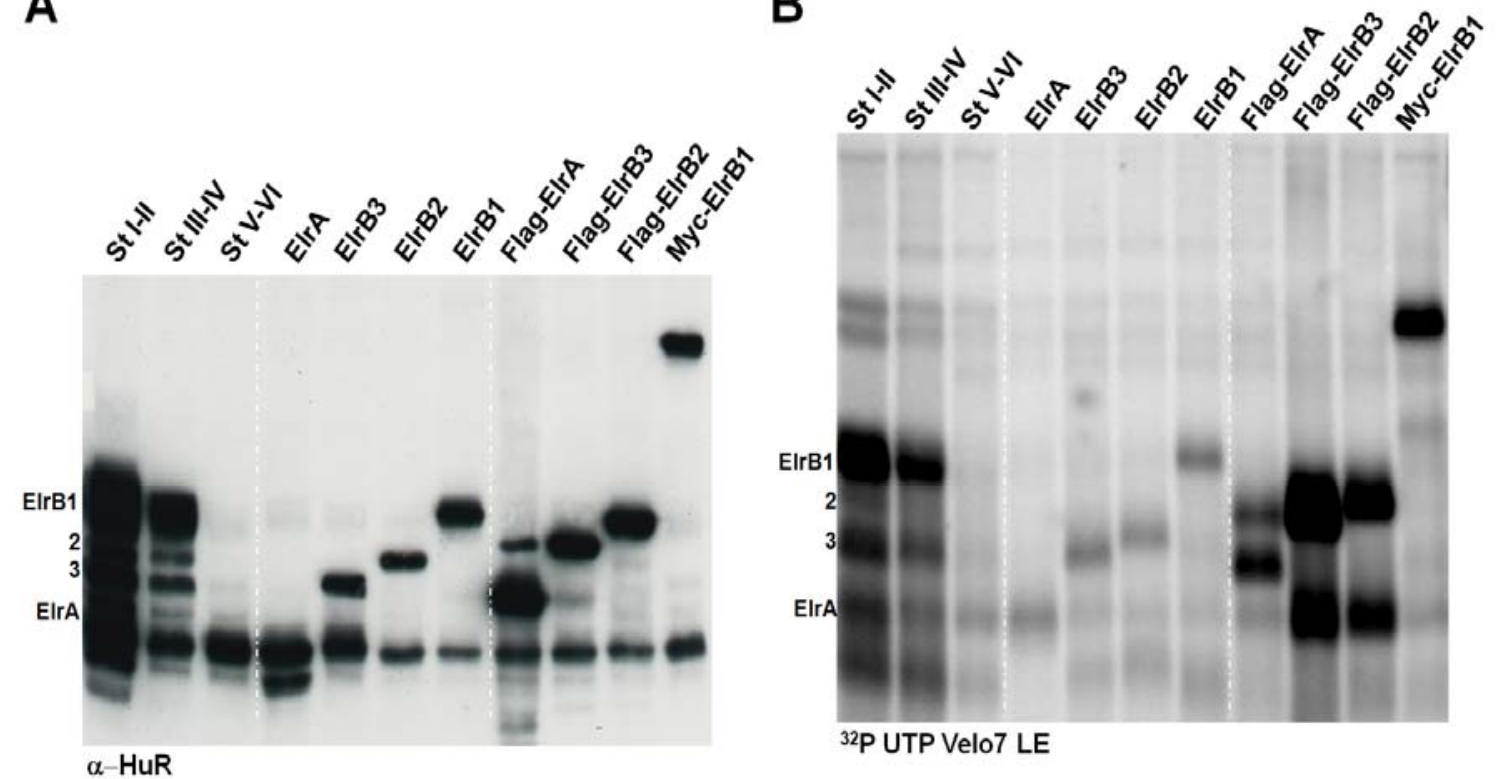

C
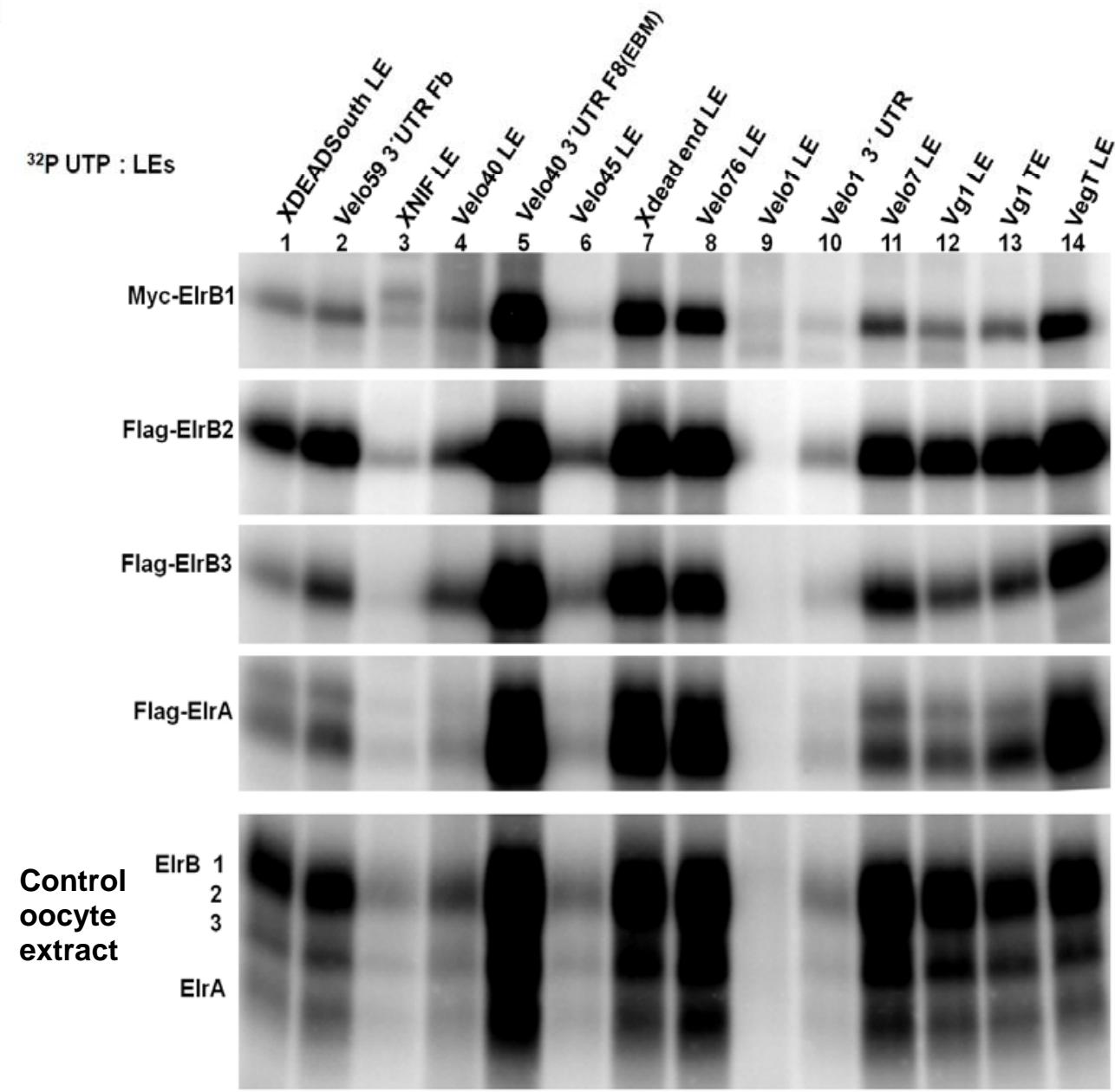

Figure 3.7 Vegetal localization element binding properties are indistinguishable for the tagged versions of and the putative endogenous ElrB isoforms in the oocyte 
Figure 3.7 Vegetal localization element binding properties are indistinguishable for the tagged versions of and the putative endogenous ElrB isoforms in the oocyte

(A) Western blot analysis of extracts from stVI oocytes injected with mRNAs encoding ElrB1-3 and their tagged versions, first 3 lanes corresponds to uninjected oocytes extracts from stI-II, stIII-IV and stV-VI respectively as control. Anti-HuR antibody was used. (B) The same oocyte extracts as in (A) were subjected to UV crosslinking analysis using ${ }^{32} \mathrm{P}$ labelled Velo7 LE; bands obtained correlate perfectly with the western blot signals. Reactions in all lanes included lacZ as unspecific competitor. (C) Comparative UV crosslinking analysis using extracts from stVI oocytes expressing myc-tagged ElrB1, flag-tagged ElrA, ElrB2 and ElrB3 and vegetal localization elements. These reactions also included lacZ as unspecific competitor; the same set of RNA elements was analysed using RNP S200 to obtain the binding pattern of binding of the endogenous ElrA/B (control).

\subsection{ElrA/B proteins are part of one RNP complex together with Vg1RBP, XStaufen1, VgRBP60 and 40LoVe}

Co-enrichment of ElrA/B in protein preparations from gradient RNP fractions indicates that these proteins may be associated with Vg1RBP and XStaufen1. In order to determine whether EIrA/B proteins were components of the same RNP with these other trans-acting factors, co-immunoprecipitation experiments were carried out (Fig. 3.8). Vg1RBP was specifically co-precipitated with XStaufen1 and vice versa, which is in full agreement with previous studies (Kress et al., 2004). The same antibodies were also able to pull down ElrA/B proteins, indicating that Vg1RBP, XStaufen1 and ElrA/B proteins are part of one and the same RNP. Similarly, antibodies directed against ElrA/B proteins also precipitated Vg1RBP and XStaufen1, providing further support for the same notion. These interactions are lost upon RNase treatment prior to protein isolation, indicating that these three different proteins are held together via an RNA scaffold. Antibodies directed against VgRBP60 and 40LoVe were also able to co-immunoprecipitate the ElrA/B proteins (Fig. 3.9); both antibodies also pulled down Vg1RBP, consistent with earlier reports that VgRBP60 and 40LoVe interact with Vg1RBP (Czaplinski and Mattaj, 2006; Kress et al., 2004).

The three isoforms of EIrB and ElrA are equally co-precipitated by antibodies against Vg1RBP, XStaufen1, VgRBP60 and 40LoVe. Interestingly, much more Elr-type proteins are pulled down upon RNase treatment prior to protein isolation, 
indicating that the RNP structure which they are involved in obscures a significant portion of these proteins.

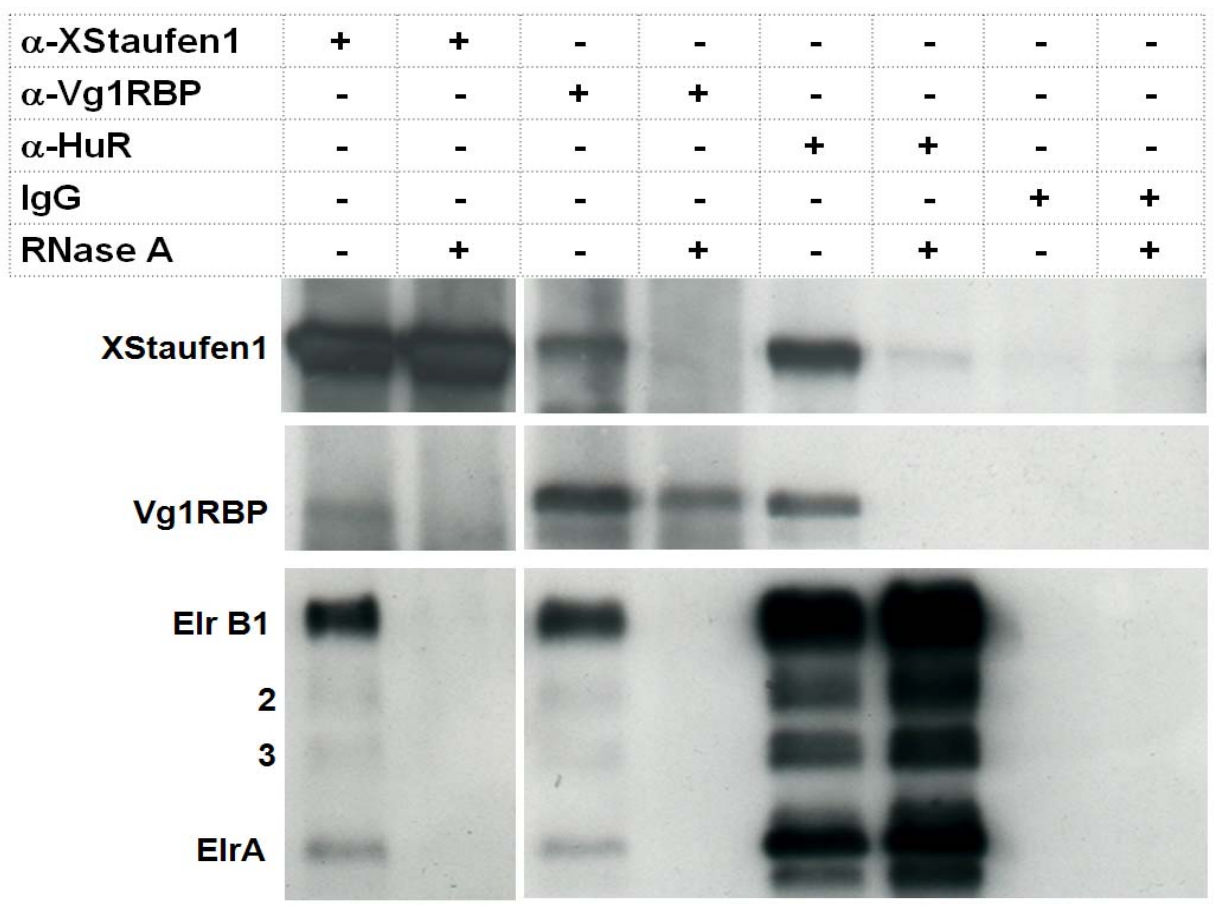

Figure 3.8 ElrA and B proteins Interact with Vg1RBP and XStaufen1 in an RNA-dependent manner

Co-immunoprecipitation reactions using $\alpha-X S t a u f e n 1, \alpha-V g 1 R B P, \alpha-H u R$ and control IgGs were performed in the absence or presence of RNase A. Co-precipitated proteins were detected by western blot.

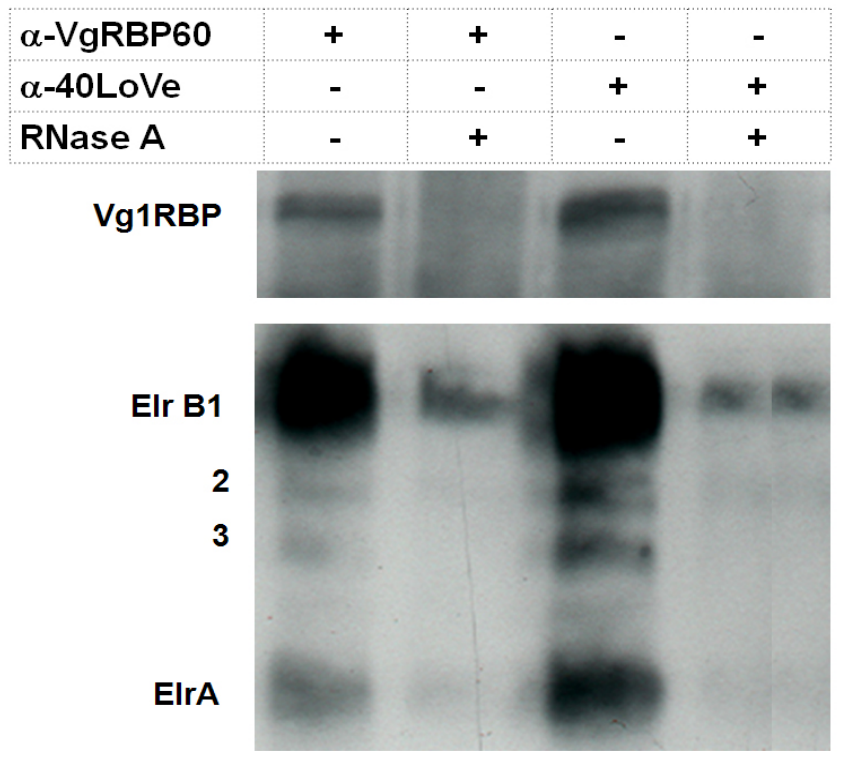

Figure 3.9 ElrA/B interact with localization proteins VgRBP60 and 40LoVe in an RNA dependent manner

Co-immunoprecipitations using $\alpha-\operatorname{VgRBP} 60$ and $\alpha-40 \mathrm{LoVe}$ were performed in the absence or presence of RNase A. Co-precipitated proteins were detected by western blot. 


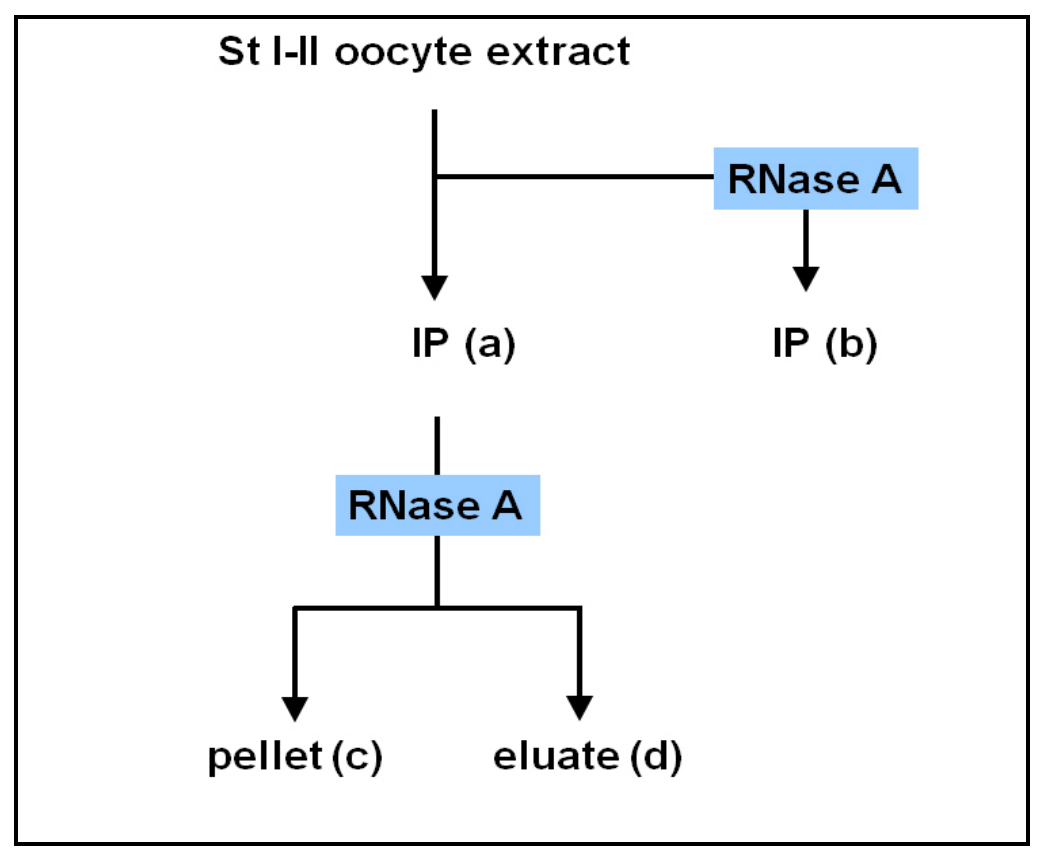

Figure 3.10a $A$ schematic workflow for the identification of proteins co-precipitating with Elr-type proteins ( $\alpha$-HuR) in an RNA-dependent or independent manner from stage I-II S16 extracts.

Co-precipitations with lgGs served as a control.

The fractionation profile of the localizing RNPs suggests that their size is comparable to ribosomes (appendix I) and as such might contain more proteins than those examined in the western blot analyses. In an attempt to identify other proteins that might be part of the Elr-type protein containing RNPs, coimmunoprecipitation experiments were performed on a preparative scale, as depicted schematically in (Fig. 3.10a). After protein isolation, a portion of the ElrA/B-associated proteins were released by RNase treatment; the proteins in the eluate should correspond to those involved in RNA dependent interactions, while those in the pellet fraction should reflect direct protein-protein contacts.

The protein samples generated in this manner were analysed on a 1D SDS-PAGE (Fig. 3.10); in addition, samples from the preparative scale experiment were separated by 2D gel electrophoresis and identified by mass spectroscopy (Fig. 3.11 and Table 3.2). As above, Vg1RBP was found to copurify specifically with the Elr-type proteins, as well as with the unspecific FRGY-type RNA binding proteins which were released by the RNase treatment in substantial quantities (Fig. 3.11). 


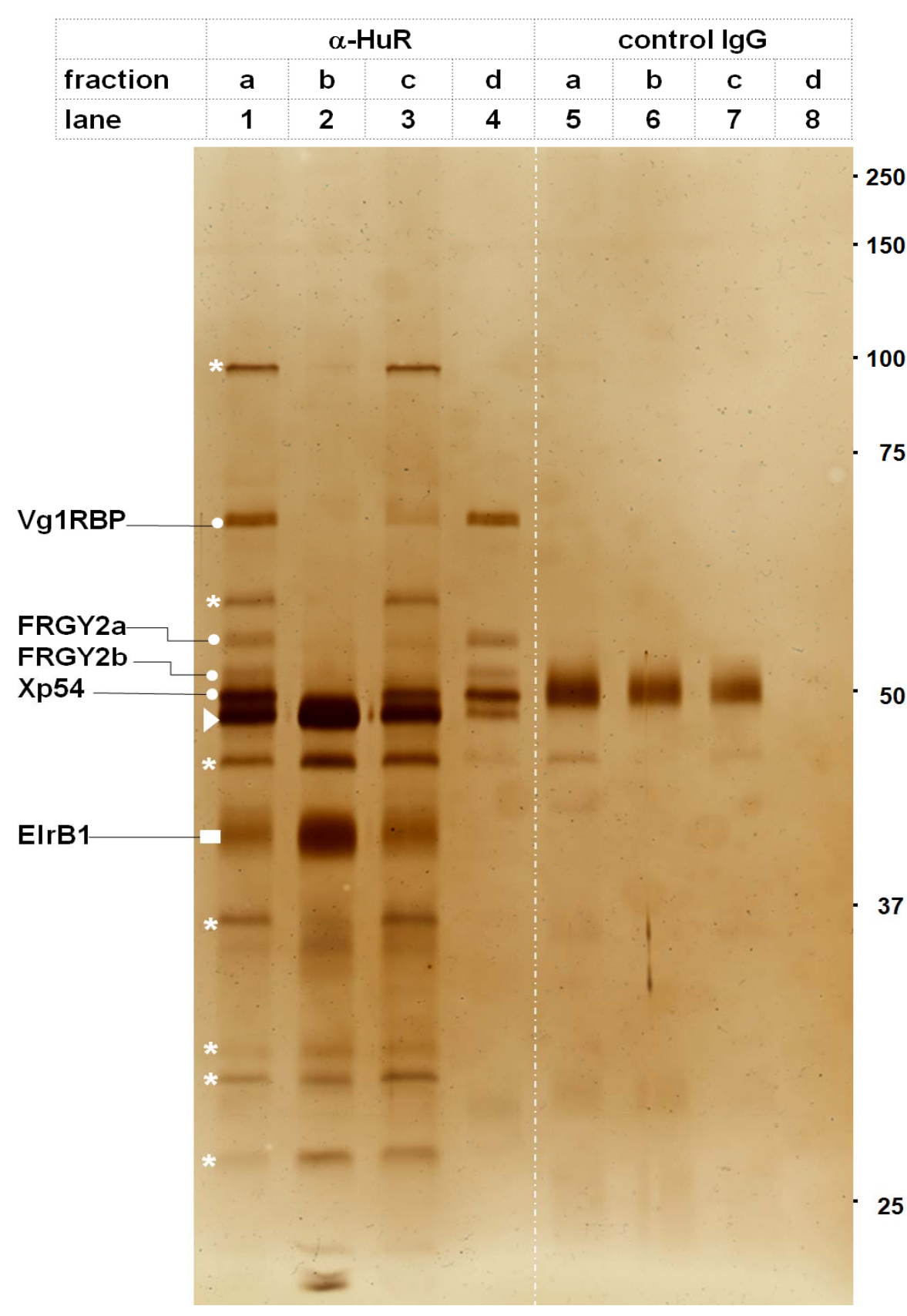

Figure 3.10b Identification of protein components of immuno-isolated EIrA/B RNPS (analytical scale)

Protein fractions generated as depicted in (Fig. 3.10a) were separated by SDS-PAGE and detected by silver staining. Protein bands marked by dots indicate proteins that interact in an RNAdependent manner and were identified from protein fraction "d" by mass spec. after 2D-gel electrophoresis (see Fig. 3.11A and Table 3.2). Proteins that appear to interact in an RNAindependent manner are marked by an asterisk and were identified from protein fraction "c" along with ElrB1 protein marked by a rectangle (see Fig. 11B and Table 3.2). IgG heavy chains are marked by an arrowhead.

However, XStaufen1, demonstrated above by western blot analysis to coprecipitate with Elr-type proteins (Fig. 3.8A), was not among the polypeptides 
identified in this second approach, indicating that it is either only present in substoichiometric amounts in RNPs with Elr-type proteins or, alternatively, there exist different classes of EIr-RNPs, those with and those without XStaufen1. Other proteins eluted by RNase digestion from the Elr-containing RNPs included the RNA helicase Xp54 (Ladomery et al., 1997), as well as two previously unknown proteins related to RAP55 (Tanaka et al., 2006) and therefore termed here RAP42 and RAP46 (Table 3.2 and Fig. 3.12).

Several additional proteins which were not released by RNase treatment and therefore found in the pellet fraction together with significant amounts of ElrB1 (Fig. 3.11B), and identified by mass spectroscopy (Table 3.2). A number of different proteins were identified from the fraction " $\mathrm{C}$ " as ElrA/B associated proteins, eg SLBP2, GAPDH, LDH, hnRNP E2, Gnbl1 and XhermesR; these proteins have not been previously detected in isolated RNPs from Xenopus oocytes. Other proteins identified, such as Xp54, CPEB1, egg specific protein and ePABP1, have been identified as components of FRGY2 RNPs from stage VI oocytes (Tanaka et al., 2006). The same gels as shown in Fig 3.11 have been placed in appendix VII without the annotations. The presence of these proteins in the pellet fraction "c"/lane 3 (Fig 3.10b) indicates that they may directly interact with EIrA/B; however the fact that these protein bands cannot be seen in fraction "b"/lane 2 (Fig 3.10b), where total extracts were treated with RNase prior to protein isolation, suggests otherwise.

In a similar manner, a preparative scale immuno-isolation as depicted in Fig. 3.10a was performed using antibodies directed against 40LoVe. The proteins eluted by RNase treatment and those in the pellet fraction were separated by $2 \mathrm{D}$ gel electrophoresis and identified by mass spec analysis (see Appendix VI). The pattern of proteins in the eluate fraction was strikingly similar to that obtained for ElrA/B associated proteins, also identified as Vg1RBP, FRGY-type proteins, RAP46 and ß-actin; the relative quantities are also remarkably similar. Even though the proteins in the 40LoVe pellet fraction were fewer than those identified in the ElrA/B pellet fraction, the high similarity of the proteins in their eluate fractions makes it consistent with the observation that EIrA/B are components of 
the 40LoVe RNP (Fig 3.9). However, ElrA/B proteins were not identified in isolated 40LoVe RNPs.

\begin{tabular}{|c|c|c|c|c|}
\hline Protein Name & Accession \# & Size (kDa) & pl & Remarks \\
\hline $\mathrm{NMHC}-\| \mathrm{A}$ & gi|3660672 & 227,6 & 5,44 & $\begin{array}{l}\text { nonmuscle myosin II heavy } \\
\text { chain A }\end{array}$ \\
\hline Vg1RBP & gi|2801766 & 65,6 & 9,08 & \\
\hline FRGY2a & gil1175535 & 37,2 & 9,6 & \\
\hline FRGY2b & gil1175534 & 36 & 7,93 & \\
\hline Xp54 & gi|1709533 & 54,5 & 8,9 & \\
\hline RAP46 & gi|51258579 & 46,2 & 9,37 & \multirow{2}{*}{$\begin{array}{l}\text { unknow protein related to } \\
\text { RAP55, both with N-terminal } \\
\text { Lsm14 domain }\end{array}$} \\
\hline RAP42 & gil71679779 & 42 & 9,72 & \\
\hline$\beta$-actin & gi|1703123 & 42,1 & 5,3 & \\
\hline Egg specific Protein & gi|214636 & 83,8 & 5,3 & \\
\hline elF4E-T & gi|50414847 & 85,8 & 8,07 & \\
\hline DDX1/RNA helicase & gi|58331968 & 83,2 & 6,92 & \\
\hline ePABP1b & gi|82236619 & 70,8 & 9,35 & Embrynoic tpye \\
\hline CPEB1b & gi|62871738 & 63,6 & 7,83 & \\
\hline$\alpha$-tubulin & gi|47122943 & 50,9 & 5,02 & \\
\hline$\beta$-tubulin & gi|401166 & 50,2 & 4,79 & \\
\hline EF1 $\alpha$ & gi|416929 & 50,9 & 9,69 & \\
\hline hnRNP E2 & gi|5459450 & 37,5 & 7,63 & \\
\hline $\mathrm{Xe}-1$ (ElrB1) & gil728726 & 43,1 & 9,04 & \\
\hline Elav2-A (ElrB2) & gi|62739311 & 39,9 & 9,17 & \\
\hline $\begin{array}{c}\text { Xt: Hypothetical protein } \\
\text { (ElrB3) }\end{array}$ & gil71896477 & 38,3 & 9,11 & $\begin{array}{l}\text { Hit in Xt seq database, } \\
\mathrm{XI} \text { is unknown }\end{array}$ \\
\hline ElrA & gi|53749734 & 36,2 & 9,08 & \\
\hline GAPDH & gi|27882192 & 36,1 & 8,16 & \\
\hline Zygote Arrest Protein & gi|45477271 & 34,8 & 9,36 & No conserved domains \\
\hline SLBP2 & gi|9789803 & 29,1 & 5,29 & $\begin{array}{l}\text { Oocyte Specific isoform, no } \\
\text { conserved domain }\end{array}$ \\
\hline $\mathrm{LDH}$ & gil1170735 & 36,7 & 6,25 & L-lactate Dehydrogenase \\
\hline Gnb2l1 & gi|27371211 & 35,5 & 7,6 & $\begin{array}{l}\text { activated protein kinase C } \\
\text { receptor; RACK1 }\end{array}$ \\
\hline $\begin{array}{l}\text { Hypothetical protein } \\
\text { (Xhermes-related) }\end{array}$ & gi|51703926 & 21,7 & 8,63 & $\begin{array}{l}\text { Related to Xhermes (early } \\
\text { localized) with } 95 \% \text { identity }\end{array}$ \\
\hline
\end{tabular}

Table 3.2 List of proteins co-precipitating with the Elr-type proteins

Most of the individual proteins were identified multiple times from a number of gel plugs picked from the same band (Fig 8). The nominal molecular mass and the putative isoelectric point (pl) were estimated from the amino acid sequences using Mascot Software 2.0 (Matrix Science). 
A

$(+)$ pH 3

(-) $\mathrm{pH} 10$

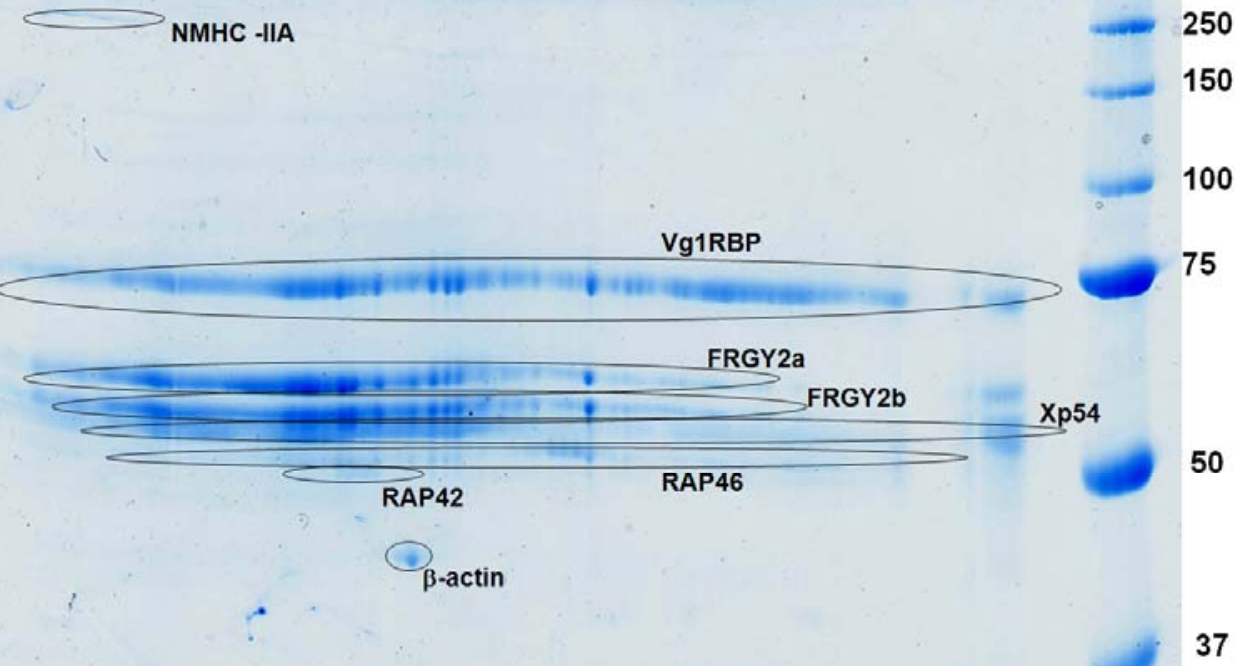

B

$(+) \mathrm{pH} 3$

$(-) \mathrm{pH} 10$
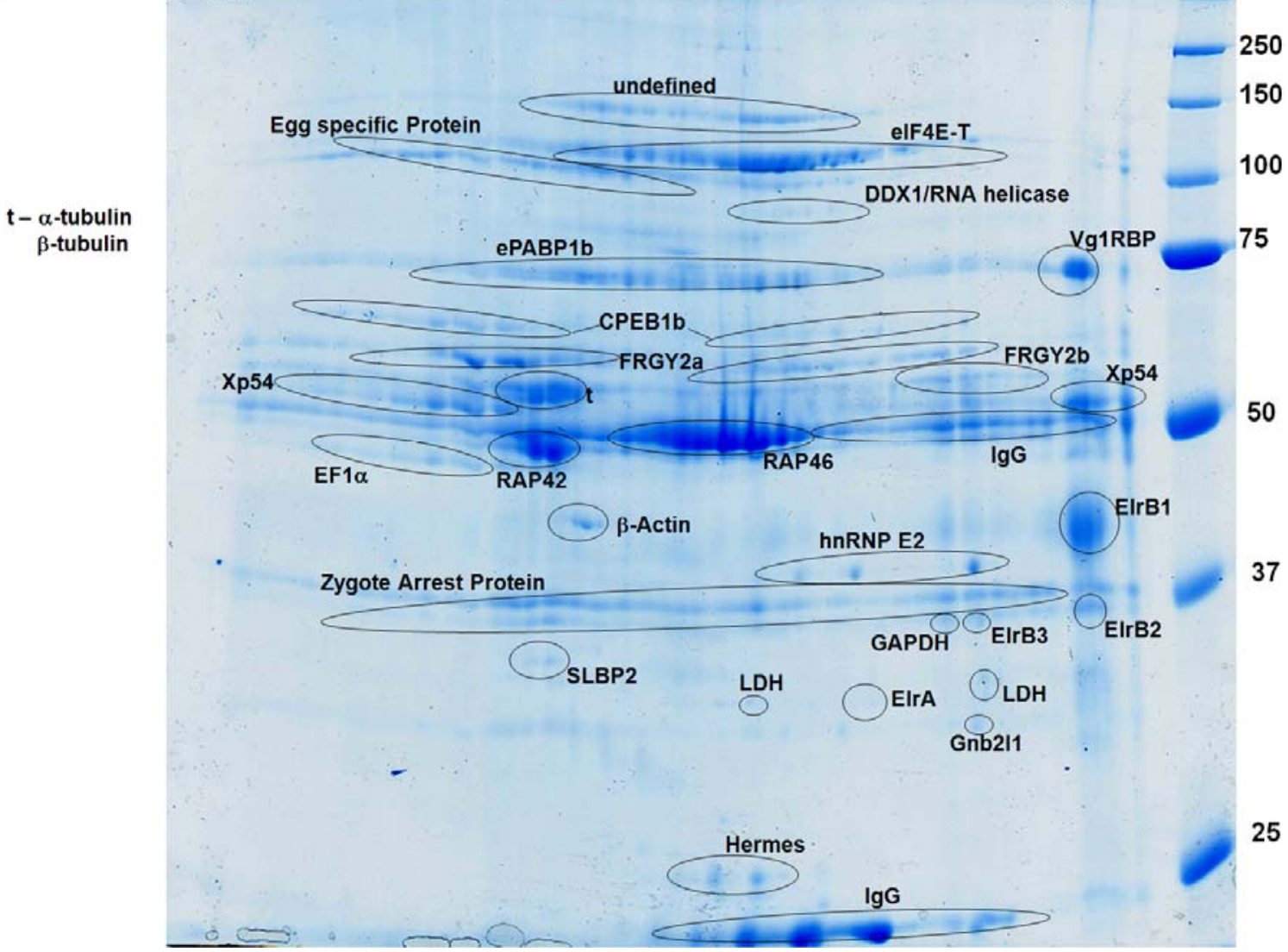

Figure 3.11 Identification of protein components of immuno-isolated ElrA/B RNPS 
Figure 3.11 Identification of protein components of immuno-isolated ElrA/B RNPs

(A) Mass spec. identification of proteins co-immunoprecipitated with ElrA/B proteins. 2D gel analysis of proteins eluted by RNase A treatment which corresponds to fraction "d" in lane 4 of Fig 3.10b. The 2D gel was done using an IPG strip with $\mathrm{pH} 3-10$ and separated on $11 \%$ SDS-PAGE; the spots picked from the entire circled protein band were identified as the proteins indicated. (B) $A$ similar type of analysis as in (A) was performed for fraction "c" in lane 3 of Fig 3.10b, this corresponds to proteins that not released upon RNase treatment and appear to interact with ElrA/B in an RNA-independent manner. It is clearly visible that all of the proteins with the exception of one were not properly focussed into discrete spots.

\section{Lsm domain}

\begin{tabular}{|c|c|c|}
\hline hLsm14 & 1 & MSGGTPYIGSKISL ISKAEIRYEGILYTIDTENSTVALAKVRSFGTEDRP \\
\hline XRAP55 & 1 & 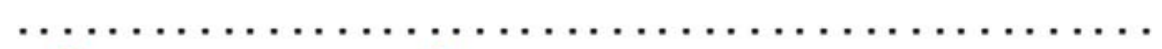 \\
\hline RAP46 & 1 & 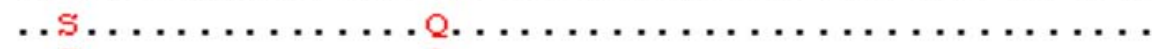 \\
\hline L 42 & 1 & $\ldots \ldots \ldots \ldots \ldots$ \\
\hline Lsm14 & 51 & TDRPIPPRDEVFEY I IF RGSD IKDLTVCEPPKPQCSLPQDPÄIUQSSLGS \\
\hline RuP55 & 51 & 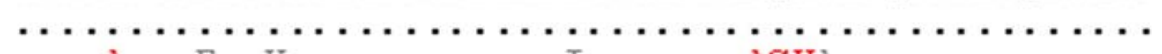 \\
\hline is 46 & 51 & 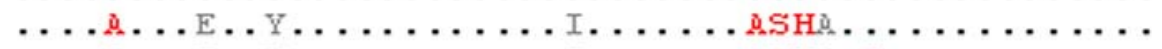 \\
\hline $\mathrm{PP} 42$ & 51 & 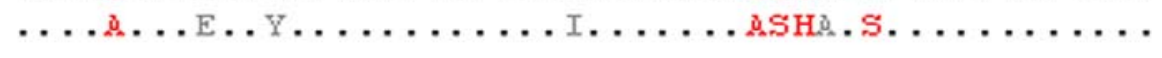 \\
\hline m14 & 01 & S-T-SSFQSMGSYGPFGRMPTYSQFSPSSLVGQQFGA-VGVA--GSSLTS \\
\hline P55 & 01 & - SA. . . VS ........... T.P.....-- . . . . . \\
\hline 46 & 01 & 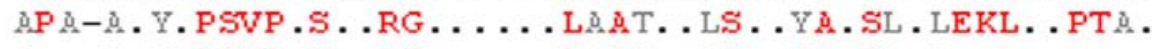 \\
\hline 42 & 101 & 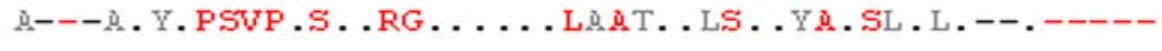 \\
\hline Lsm14 & 46 & FGTETSNSGTLPQSSAVGSAF TQDTRSLKTQLSQGRSSPQLDPLRKSPTM \\
\hline RAP 55 & 145 & ..A.TS.TS..P..V..T...EA.T.......SP..S....I \\
\hline isp 46 & 150 & A. ASS.C. SPS. . PV .P----EP . VP ÄEPP . . .NÄGY . SI- . V. . MV \\
\hline ip 42 & 41 & $-------------------------------------F \cdot S I-. V . . M V$ \\
\hline hLsm14 & 96 & EQAVQT ÄSA-HLPAP ÄAV--GRRSPVSTRPLPSÄSQKÄGENQEHRQÄEVH \\
\hline P5 5 & 195 & 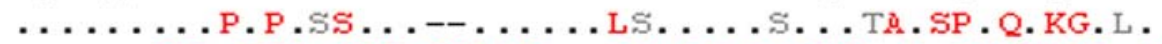 \\
\hline 46 & 195 & .... . GPL-ENQ. QKK. QQẢKGÄ. . GQ. GV----RQS. PQSQPAPLN. P \\
\hline P42 & 153 & .... GPL-ENQ. QKK. QQÃKGA. . GL. GV----RQS. PQSQPAPLN . P \\
\hline 14 & 43 & KVSRPENEQLRNDNKRQV MP GMP----SAPRRGRGGHRGGRGRFGIRRDG \\
\hline 55 & 43 & . IQ . . DT. . -K. . Y . NDLSRRQ.VLSA AQ . . . . . . . . . . . . \\
\hline 46 & 40 & PPAB. VLGTINDE. R.--P. RRR---- . GN . . T.NRS . - QN . PTTVKEN \\
\hline 42 & 98 & PPẢ. VLGTUNDE. R.--P. RRR---- . GN. . T.NRS.- . QN . PTTVKEN \\
\hline hLsm14 & 89 & PMKFEKDF DFES ANA AFNKEE ID REF HIKL KL KED KLEKQEKPVNGED KG \\
\hline P 55 & 292 & 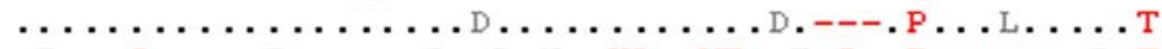 \\
\hline 46 & 283 & 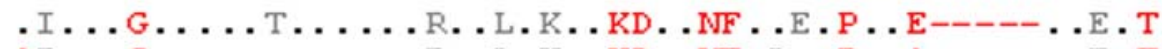 \\
\hline 42 & 41 & AI...G........R..L.K..KD. INF.D..P.A A---- .E.T \\
\hline $\min 14$ & 39 & DSGUDTQNSEGNADEEDPLGPN-CYYDKTKSF F DNISCDDNRERRPTW AE \\
\hline AP 55 & 339 & 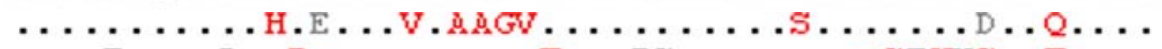 \\
\hline P46 & 328 & $\ldots$..... . . P- .....-T.. RS .....-SEMKS . T... \\
\hline P42 & 286 & 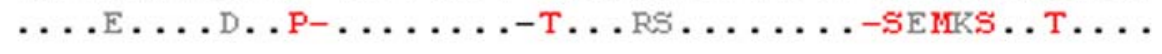 \\
\hline 14 & 388 & ERRLNDETF GIPLRPNRGRGGYRGRGG-LGFRGGRGRGGGRGGT------ \\
\hline P55 & 389 & 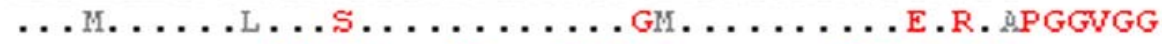 \\
\hline 46 & 375 & .K. . . . .VSG FL. . .S-F..----- . . . . . S------------- \\
\hline 42 & 333 & . K..T...VSG.FL...S-F..----- .....S------------- \\
\hline$a 14$ & 431 & 2GFRGGF RGGRGGREF ADF E YRKDNKVג A \\
\hline P55 & 439 & 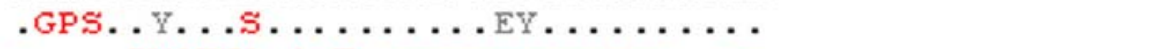 \\
\hline & 406 & $-\mathrm{A} . . \mathrm{RINQTTQ} \cdot \mathrm{A} \cdot \mathrm{T} \cdot-------------\mathrm{R} \cdot--$ \\
\hline ר? & 64 & A. . RNQT TQ. A. T. . R-------------R.-- \\
\hline
\end{tabular}


Figure 3.12 Novel RAP55 related protein co-immunoprecipitated with EIrA/B proteins

Amino acid sequence comparison between human LSM14A protein (accession number NM_015578), Xenopus RAP55 (accession number AAH42251), Xenopus RAP46 (accession number BC079811) and Xenopus RAP42 (accession number BC100174). The alignment was done with the Clone Manager program which gave protein identities of xRAP55 (79\%), xRAP46 $(52 \%)$ and XRAP42 $(49 \%)$ to $\mathrm{hLSM} 14 \mathrm{~A}$ protein. The box marks the conserved N-terminal Lsm domain.

\subsection{Inhibition of ElrA/B binding correlates with a loss of vegetal mRNA transport}

Evidence presented so far has clearly established that the ElrA/B proteins bind specifically to the XDE-LE as well as to several other LEs, and that they are part of one RNP together with other proteins known to be involved in vegetal transport. This indirectly implicates the Elr-type proteins in vegetal mRNA localization, but in order to directly address their functional role in this process, mutant versions of the XDE-LE were generated which are impaired in their ability to bind to these proteins. Mutant versions of XDE-LE (Fig. 3.13), containing different sets of point mutations in its $A / U$-rich elements, were first analysed in respect to their ability to compete for binding of ElrA/B to the wild type version of XDE LE in a UV crosslinking assay with partially purified (RNP S200) oocyte extracts (Fig. 3.1A), as well as in an electrophoretic mobility shift assay using recombinantly expressed versions of ElrB1 and Vg1RBP (Fig. 3.14B). While mut1 is only moderately reduced in its ability to compete for ElrA/B binding, mut2 was severely impaired to do the same.

Interestingly, binding to Vg1RBP seems to be equally affected in this assay by all competitor RNAs tested, indicating that the mutations introduced do not perturb its binding to this localization protein (Fig. 3.14A and B). Since the assembly of a specific RNP complex on the localization element is thought to be required for the process of vegetal mRNA localization, localization assays were perform to determine whether recruitment of ElrA/B to the XDE LE is crucial for this process. The XDE LE mutant versions were employed in the oocyte microinjection assays testing for vegetal transport activity (Fig. 3.14C). While localization efficiency of a reporter RNA fused to mut1 was comparable to wt, mut2 was not able to mediate 
localization to the vegetal cortex of the oocytes. Furthermore, the localization efficiency of mut1 was observed to be only slightly decreased compared to wt when molar excess of EBM RNA element (see Fig. 3.7C; lane 5) was co-injected (data not shown).

\begin{tabular}{|c|c|c|}
\hline $\mathrm{XDE}$ & LE & \\
\hline XDE & $\mathrm{LE}$ & mut 1 \\
\hline$X D E$ & LE & mut2 \\
\hline $\mathrm{XDE}$ & LE & \\
\hline $\mathrm{XDE}$ & LE & mut 1 \\
\hline$D E$ & LE & mut2 \\
\hline $\mathrm{XDE}$ & LE & \\
\hline $\mathrm{XDE}$ & LE & mut 1 \\
\hline $\mathrm{XDE}$ & LE & mut2 \\
\hline$X D E$ & LE & \\
\hline$X D E$ & LE & mut 1 \\
\hline $\mathrm{XDE}$ & LE & mut2 \\
\hline $\mathrm{XDE}$ & LE & \\
\hline $\mathrm{XDE}$ & LE & mut 1 \\
\hline $\mathrm{XDE}$ & LE & mut 2 \\
\hline XDE & LE & \\
\hline v & LE & mut 1 \\
\hline $\mathrm{DE}$ & LE & mut2 \\
\hline
\end{tabular}

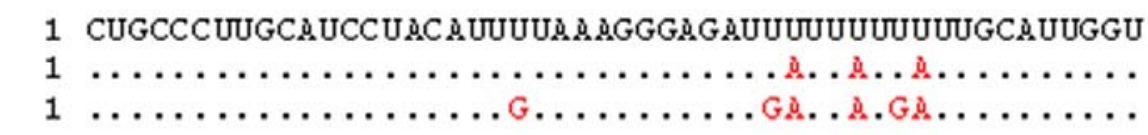

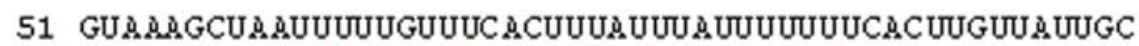

$51 \ldots \ldots \ldots \ldots \ldots \ldots \ldots \ldots \ldots \ldots \ldots \ldots \ldots \ldots \ldots$ A.

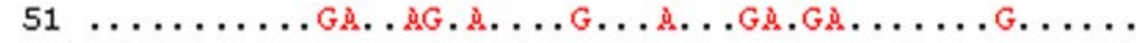

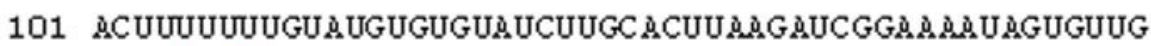

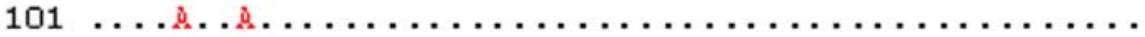

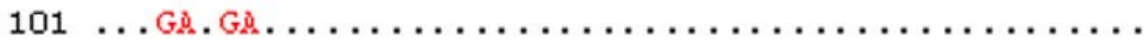

151 CC ACCUGUCUUG AUUUUC ACCUGG MAgGC AGUUUUUCAUAMGGGCUUU

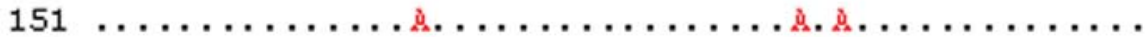

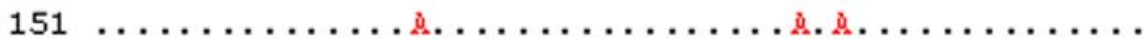

201 CCUGGUGA

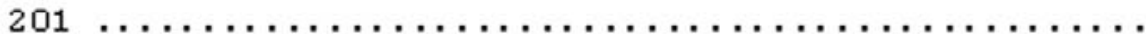

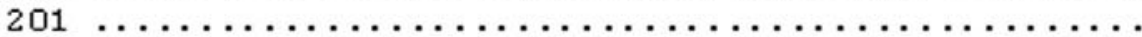

251 ACGUC AUCUGCCUGCUCCCUGC

$251 \ldots \ldots \ldots \ldots \ldots \ldots \ldots \ldots \ldots \ldots \ldots \ldots \ldots \ldots$

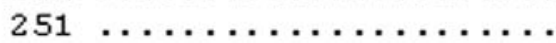

Figure 3.13 Mutagenesis of putative EIrA/B binding sites in XDE-LE

Sequence comparison of XDE-LE wt and the mutants, having U-rich elements interrupted with $A$ residues in mutant 1 and with additional $\mathrm{G}$ residues in the case of the mutant 2.

Figure 3.14 Interference with ElrA/B-binding by mutagenesis blocks vegetal localization of the XDE-LE

(A) Point mutations in the AU-rich regions of the XDE-LE affect ElrA/B binding (point mutations of XDE-LE mut1 and 2 are depicted in fig. 3.13). UV cross-linking reactions were performed with RNP S200 extracts and ${ }^{32}$ P-labelled XDE-LE wt in the absence or presence of either non-specific lacZ $(L)$ or increasing amounts of XDE-LE wt, XDE-LE mut1 and XDE-LE mut2 competitor RNAs. (B) Electrophoretic mobility shift assay using 1 pmol Alexa-labelled XDE-LE wt and 10 pmol or 25 pmol recombinant ElrB and Vg1RBP proteins, respectively. RNA-protein complexes were allowed to assemble either in the absence or presence of increasing amounts of XDE-LE wt, XDE-LE mut1 or XDE-LE mut2 competitor RNAs. (C) ElrA/B-binding affecting point mutations in the XDE-LE interfere with vegetal cortex localization. LacZ-tagged XDE-LE wt and mutant RNAs were injected into stage IV oocytes and analyzed for subcellular localization by in situ-hybridization after 4-5 days. The localization efficiencies, standard deviations and numbers of oocytes analyzed were as follows: wt $(92 \%+/-8.7 ; n=177)$, mut1 $(95 \%+/-8.6 ; n=119)$ and mut2 $(0 \% ; n=170)$. 
A

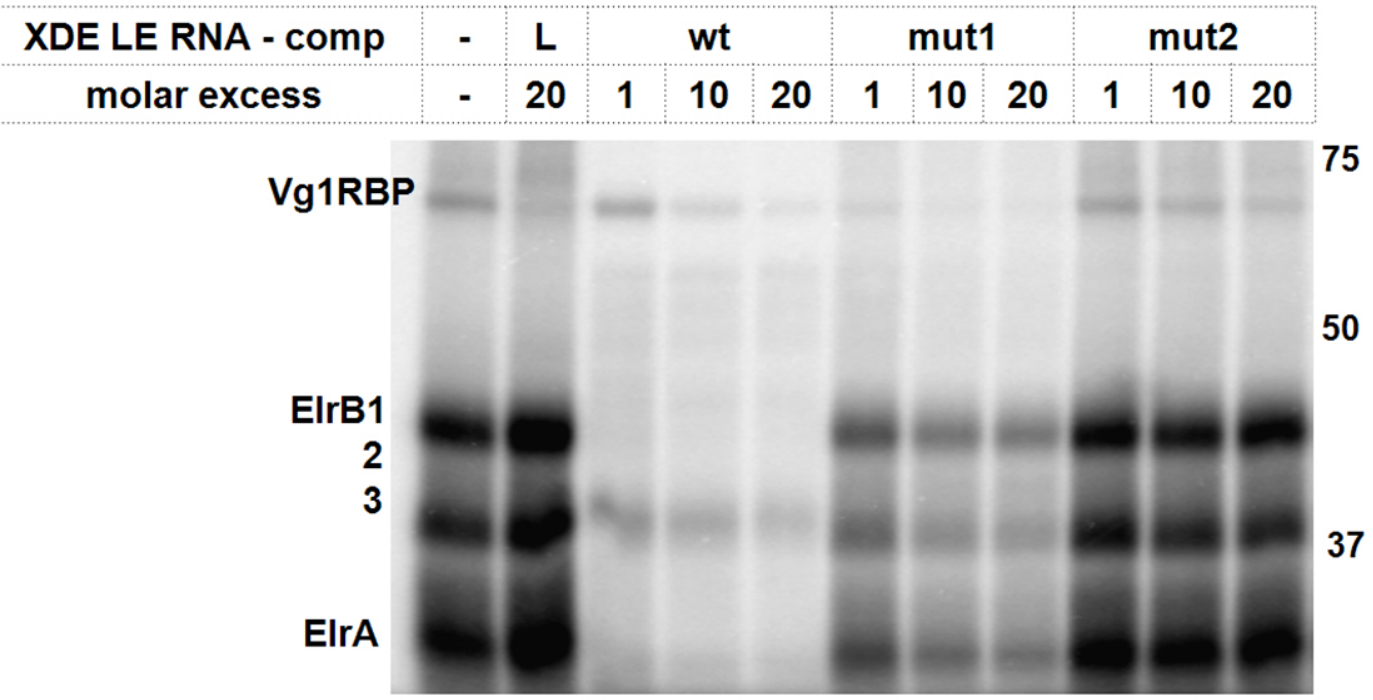

B

\begin{tabular}{|c|c|c|c|c|c|c|c|c|c|c|c|}
\hline XDE LE RNA - comp & - & - & \multicolumn{3}{|c|}{ wt } & \multicolumn{3}{|c|}{ mut1 } & \multicolumn{3}{|c|}{ mut2 } \\
\hline molar excess & - & - & 1 & 10 & 50 & 1 & 10 & 50 & 1 & 10 & 50 \\
\hline Protein & - & + & + & + & + & + & + & + & + & + & + \\
\hline
\end{tabular}

ElrB

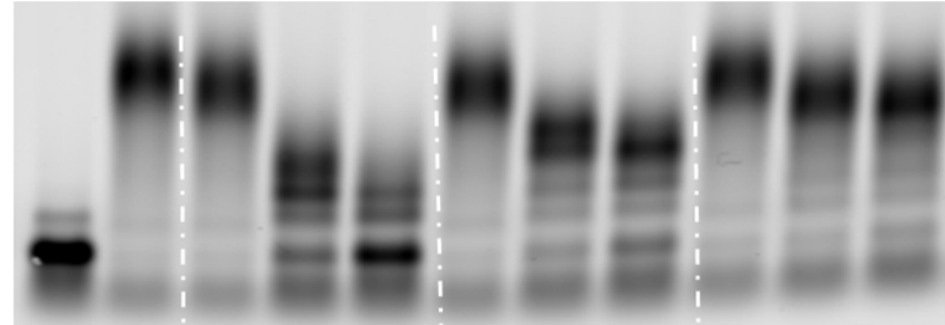

Vg1RBP

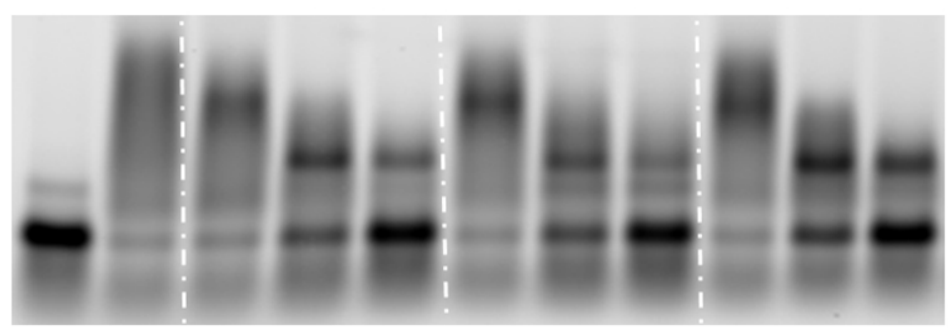

C
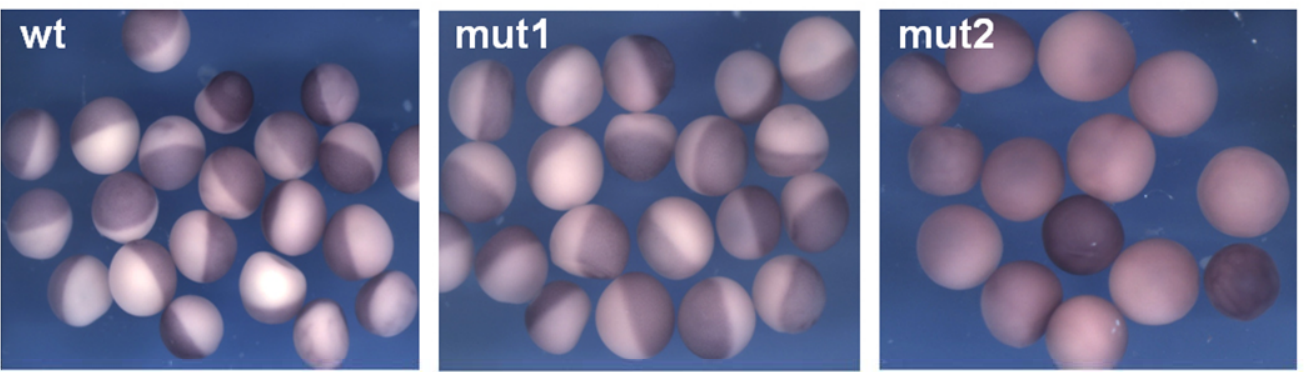

Figure 3.14 Interference with ElrA/B-binding by mutagenesis blocks vegetal localization of the XDE LE 
In an alternative experimental approach, a set of antisense morpholino oligonucleotides was designed, which target different regions of the XDE LE (Fig 3.15A), and tested for their ability to compete for Elr-type protein binding to XDE LE on the one hand (Fig. 3.15B and C) and to interfere with vegetal RNA localization in the oocyte on the other hand (Fig. 3.16). The inhibition of binding by the morpholino correlated well with the inhibition of vegetal localization (oocyte injections of MO:RNA mixtures were by Katsiaryna Tarbashevich). Thus, taken together, these experiments provide strong indications for Elr-type proteins to be actively involved in the events that allow for RNA localization to the vegetal cortex in Xenopus oocytes.

A

XDE LE 1

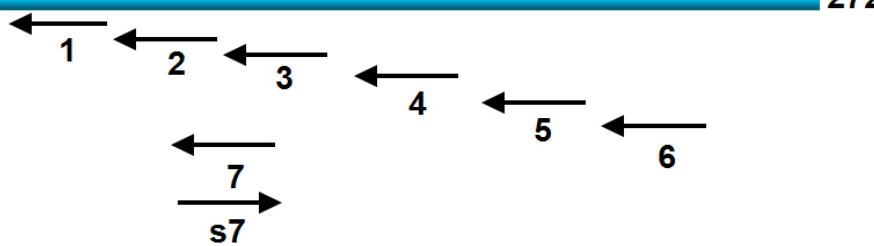

B

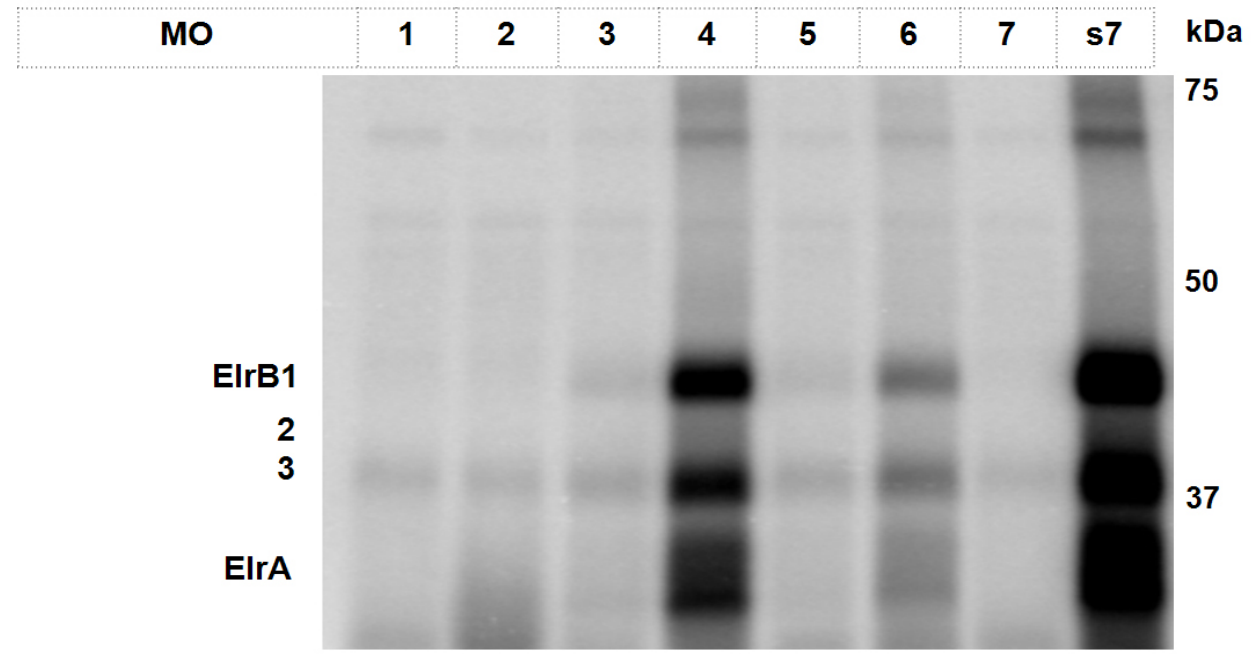

C

\begin{tabular}{c|c|c|c|c|c|c|c|c|c|c|c|} 
MO & + & - & - & 1 & 2 & 3 & 4 & 5 & 6 & 7 & 57 \\
ElrB & $\vdots$ & - & + & + & + & + & + & + & + & + & + \\
anti-Myc IP & $\underline{E}$ & + & + & + & + & + & + & + & + & + & +
\end{tabular}

XDE LE

Figure 3.15 Antisense morpholino mediated Interference with ElrA/B-binding blocks vegetal localization of the XDE-LE 
Figure 3.15 Antisense morpholino mediated Interference with ElrA/B-binding blocks vegetal localization of the XDE-LE

(A) Antisense morpholino oligos directed against the XDE-LE interfere with binding to ElrB. Schematic representation of binding regions of the different antisense morpholinos in the XDE LE (B) UV crosslinking assay using radiolabelled XDE LE-MO hybrids (concentrations were: $2 \times 10^{5}$ $\mathrm{CPM} / 1 \mathrm{pmol}{ }^{32} \mathrm{P}$-XDE-LE and $2.5 \mathrm{pmol} \mathrm{MO}$ ) and RNP S200. Radiolabeled proteins were separated by $11 \%$ SDS-PAGE and the gel was analysed by Phosphoimaging. (C) Alexa-labelled XDE-LE RNA was co-immunoprecipitated along with myc-tagged, in vitro translated ElrB protein in the absence or presence of antisense morpholino oligos (MO1-7) or sense MO s7 (concentrations were: $1 \mathrm{pmol}$ Alexa-XDE-LE and $2.5 \mathrm{pmol} \mathrm{MO}$ ).

A

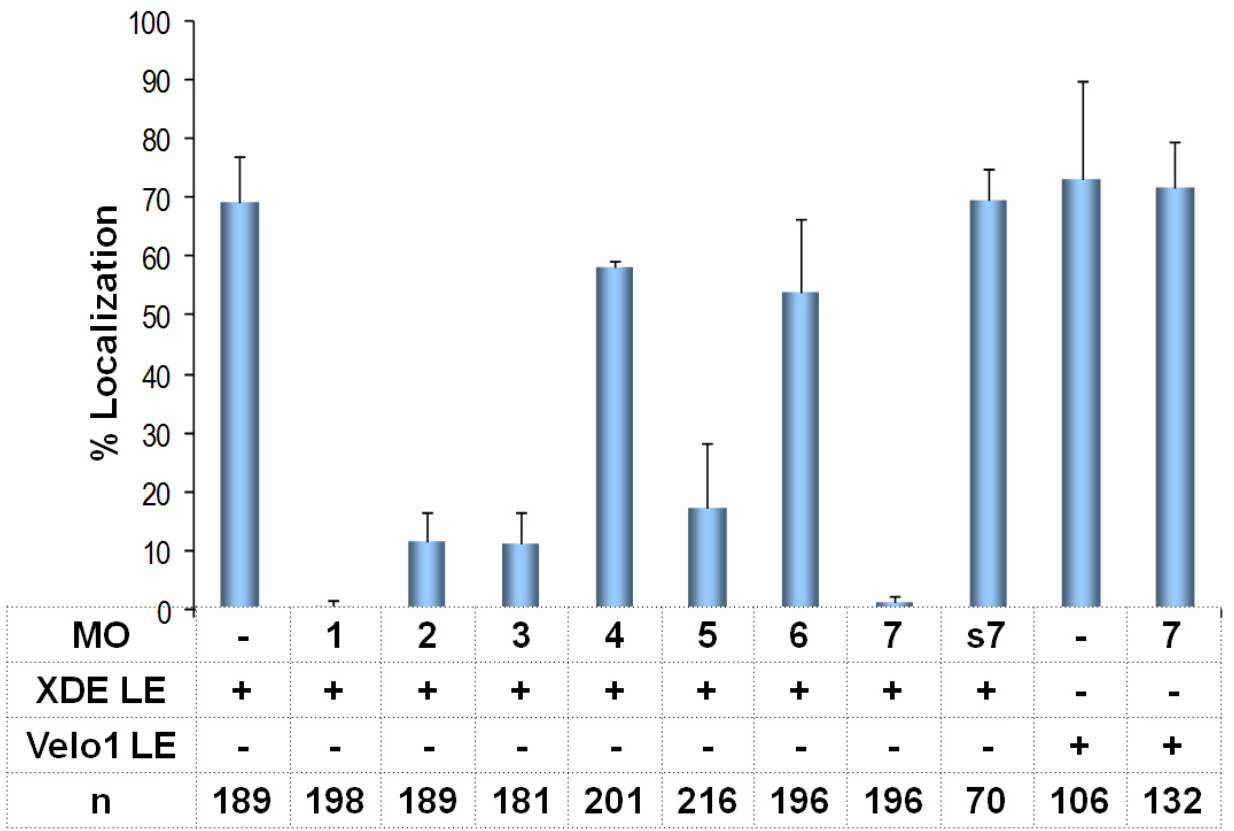

B
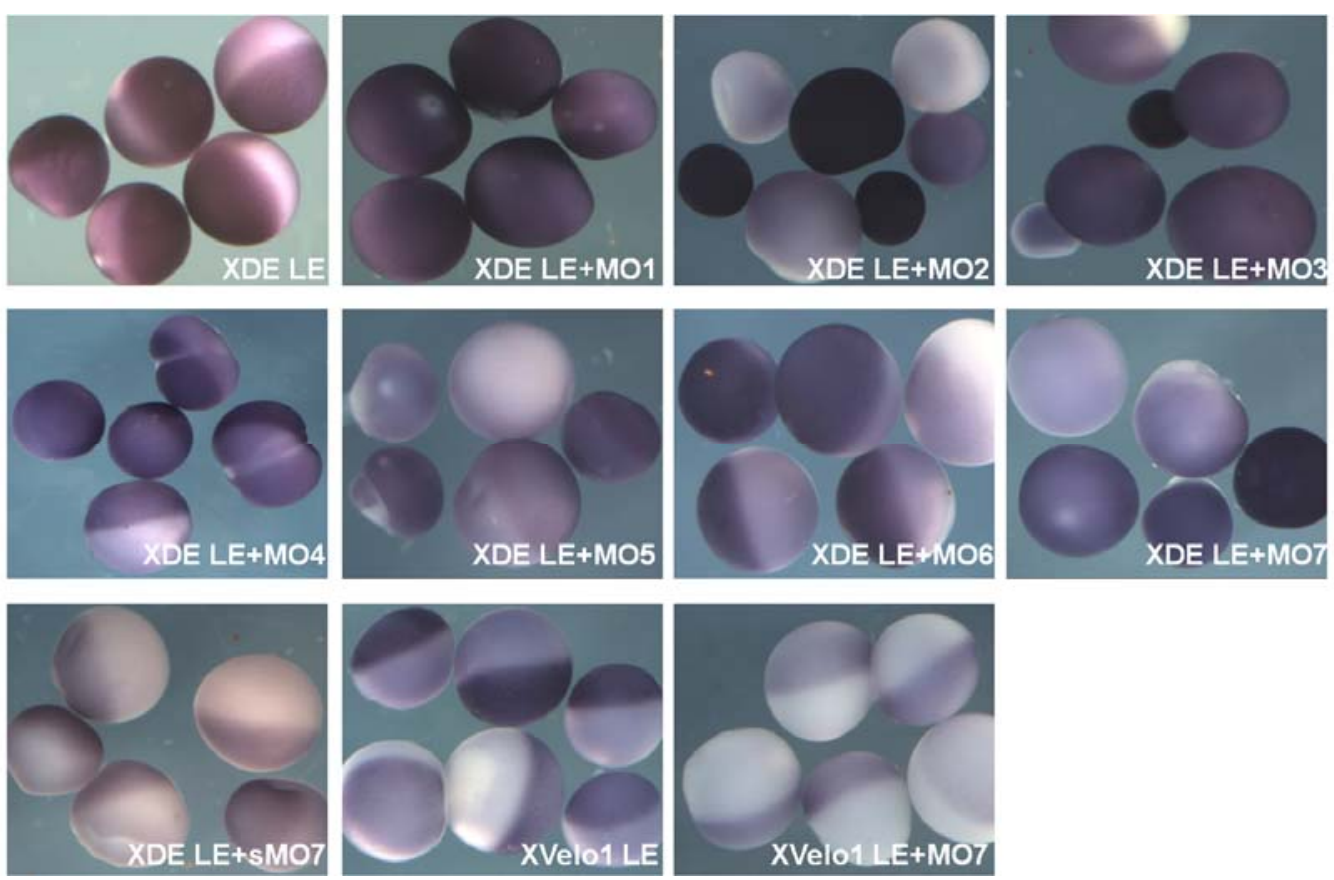
Figure 3.16 Inhibition of vegetal RNA localization by antisense morpholino oligonucleotides blocking EIrA/B binding to XDE LE

(A) Co-injection of ElrB binding blocking MOs interferes with localization of XDE-LE RNA. Average localization efficiencies of XDE-LE RNA alone $(0.3 \mathrm{fmol})$ and co-injected with different MOs $(50 \mathrm{fmol})$ of three independent injection experiments are shown in the graph. XVelo1-LE doesn't contain a MO7 target site and used as a control. (B) Representative sets of oocytes from experiments depicted in the graph (A).The distribution of the XDE-LE RNA was visualised by whole mount in situ hybridization using antisense lacZ probe.

\subsection{Effect of Elr-type proteins on mRNA stability and translation in oocytes}

The most widely studied function of Elav proteins in a variety of systems is that of their involvement in the regulation of mRNA turnover and translation. To test a possible the role of ElrA/B proteins in these aspects of mRNA metabolism in the oocyte, the MS2-tethering assay was used. The fusion protein of MS2 with ElrA and ElrB1, both showed a moderate increase in the levels of translation, when they were recruited to the $3^{\prime}$ UTR of the reporter MRNA via the MS2 binding sites (Fig. 3.17A). This effect was observed to roughly the same extent in stage III and $\mathrm{VI}$ oocytes. On the other hand, PABP used as a positive control in this assay, showed a robust up-regulation of translation.

Reporter mRNAs bearing the XDE LE wt and mutant versions in their $3^{\prime}$ UTR were also used to test the effect of Elav binding on the rate of translation and mRNA stability (Fig 3.17B and 3.18); the translational levels of the reporter did not change significantly in a comparison of the different versions of XDE LE used. Two control reporter mRNAs were used in this assay, one containing the translational control element Vg1 mRNA (VTE) and the other an Elav binding element (EBM) that binds strongly to the Elr-type proteins; the VTE reduced the levels of translation as previously shown (Otero et al., 2001), whilst the EBM did not have any significant effect (Fig 3.17B). 
A

Luciferase_MS2 bs mRNA

$\mathrm{m}^{7} \mathrm{GpppG} \longrightarrow$

Firefly Luciferase
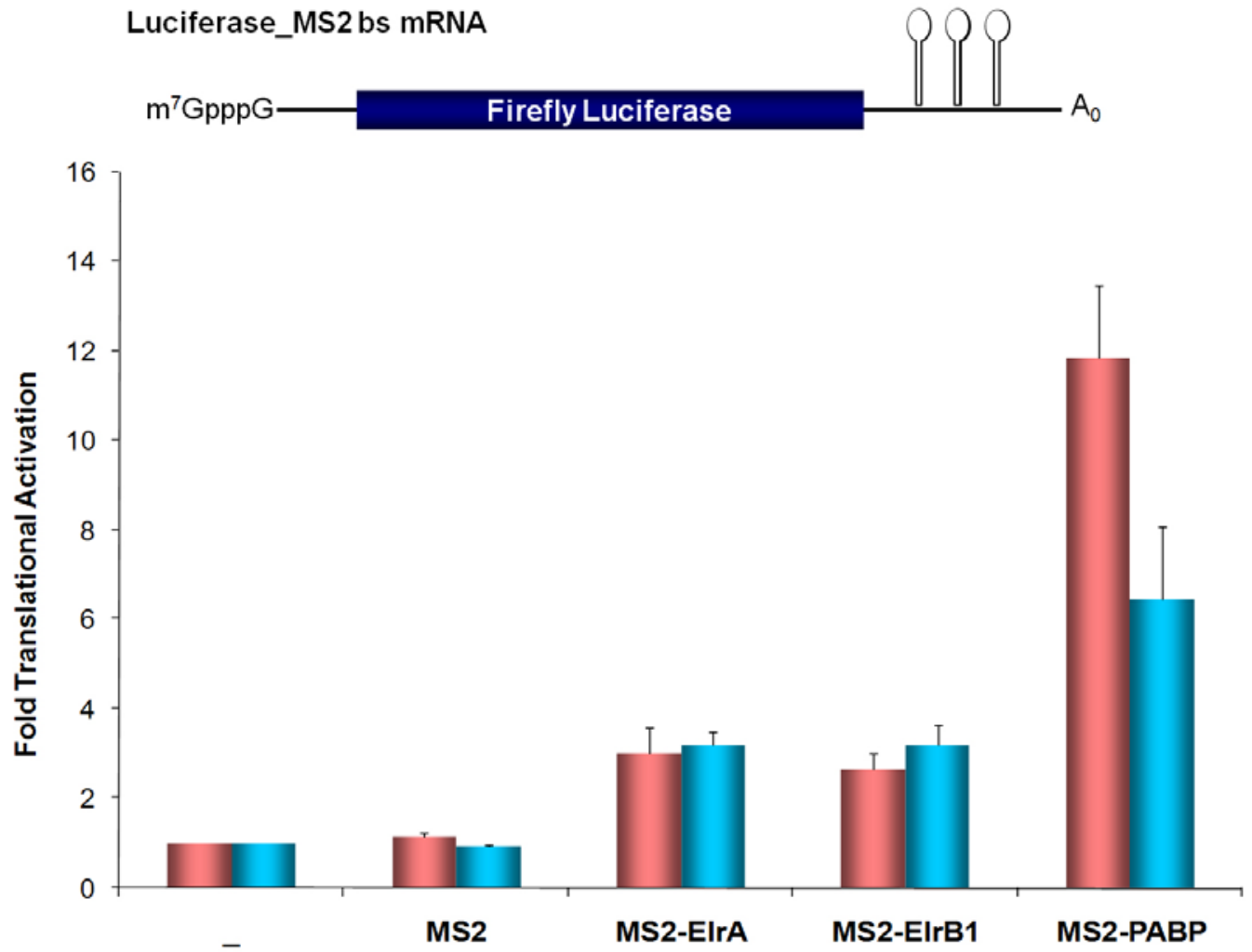

B

Luciferase - (LE) mRNA

$\mathrm{m}^{7} \mathrm{GpppG}$

Firefly Luciferase

LE - $A_{0}$

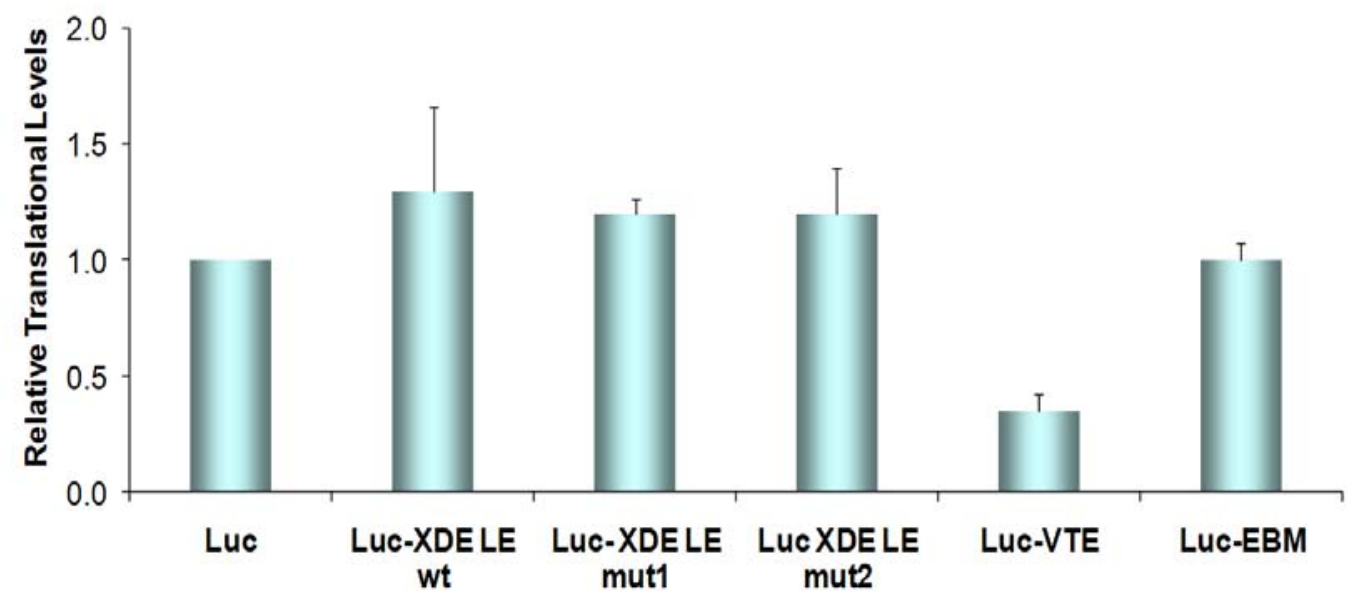

Figure 3.17 ElrA/B proteins moderately upregulate translation in oocytes and loss of binding mutation in XDE LE does not markedly alters translation levels of reporter mRNA 
Figure 3.17 ElrA/B proteins moderately upregulate translation in oocytes and loss of binding mutation in XDE LE does not markedly alters translation levels of reporter mRNA.

(A) MS2 tethering assay using MS2 fusion proteins of ElrA and B1, with PABP as control. The mRNA encoding the fusion proteins (25 ng per oocyte) were pre-injected into stage III (red bars) and $\mathrm{VI}$ (blue bars) oocytes and cultured for about 12 hours at $18{ }^{\circ} \mathrm{C}$, followed by a second injection of a reporter ( $0.3 \mathrm{fmol}$ per oocyte), Firefly luciferase mRNA harbouring MS2 binding sites in the 3'UTR (depicted as 3 stem loops) along with Renilla luciferase mRNA as internal control, oocytes cultured for another 24 hours. Protein effects on translation were measured as fold increase of luciferase activity in oocytes injected with reporter mRNA alone and into oocytes expressing the different fusion proteins. (B) Firefly luciferase reporter mRNA ( $0.3 \mathrm{fmol}$ per oocyte) harbouring in the 3' UTR XDE LE wt, mut1 and mut1 or the Vg1 translational control element (VTE)(Otero et al., 2001), or the EBM (fragment from 3'UTR of Velo40 mRNA) were injected into stage IV oocytes together with Renilla luciferase mRNA and cultured for 24 hours. Effects of the elements on translation were measured as firefly luciferase activity normalised to the Renilla luciferase activity.

The levels of the different reporter mRNAs containing various versions of XDE LE in their 3'UTR were measured in an RNase protection assay, but they did not also change significantly even when oocytes were cultured up to 72 hours (Fig 3.18). These observations give the impression that the rate mRNA turnover in oocytes maybe generally very slow.

Figure 3.18 Interference with ElrA/B binding to XDE LE does not influence mRNA stability in oocytes

Firefly luciferase reporter mRNA (6 fmol per oocyte) harbouring XDE LE wt, mut1 and mut 1 in the 3' UTR were injected into stage IV oocytes together with Renilla luciferase mRNA and cultured for 24, 48 and 72 hours. Total RNA was isolated from a pool of 10 oocytes at each time point with oocytes collected just after injection serving as control ( 0 hours). The amount of the injected RNA remaining after the culture was determined using the RNase protection assay (RPA). A radiolabelled antisense probe mixture against both firefly (400 nt) and Renilla (300 nt) mRNAs were used and the protected RNA was resolved on 7\% Urea-PAGE and quantified by Phosphoimaging. (A) -; RPA reaction with probe mix only, 0;total RNA from uninjected oocytes, 14; luc, 5-8;luc_XDE LE wt, 9-12; luc_XDE LE mut1, 13-16; luc_XDE LE mut2 over 0, 24, 48 and 72 hours of culture. Band marked by star corresponds to a second protected firefly RNA (B) Graph of the RNA band intensities over the culture period measured using the ImageQuant software (Amersham), from Urea-PAGE gel in (C) Quality control analysis of isolated total RNA using the bioanalyser (Agilent); lanes correlate with RPA gel and sample arrangement shown in panel B. 
A

$$
\begin{aligned}
& \text { Control }{ }^{32} \mathrm{P} \text { Probe }
\end{aligned}
$$

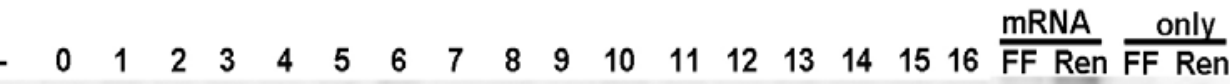

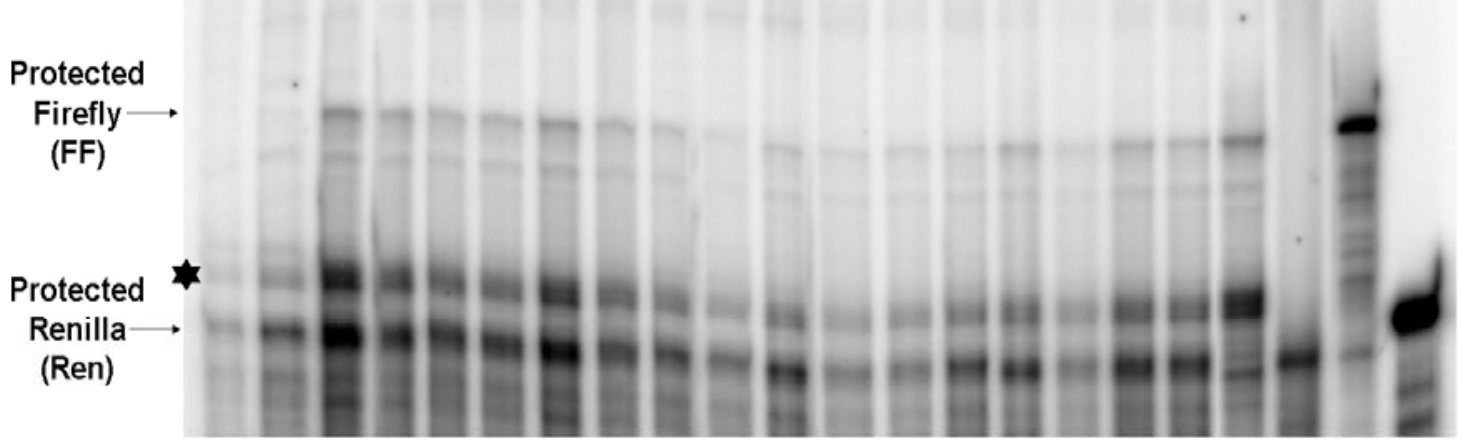

B

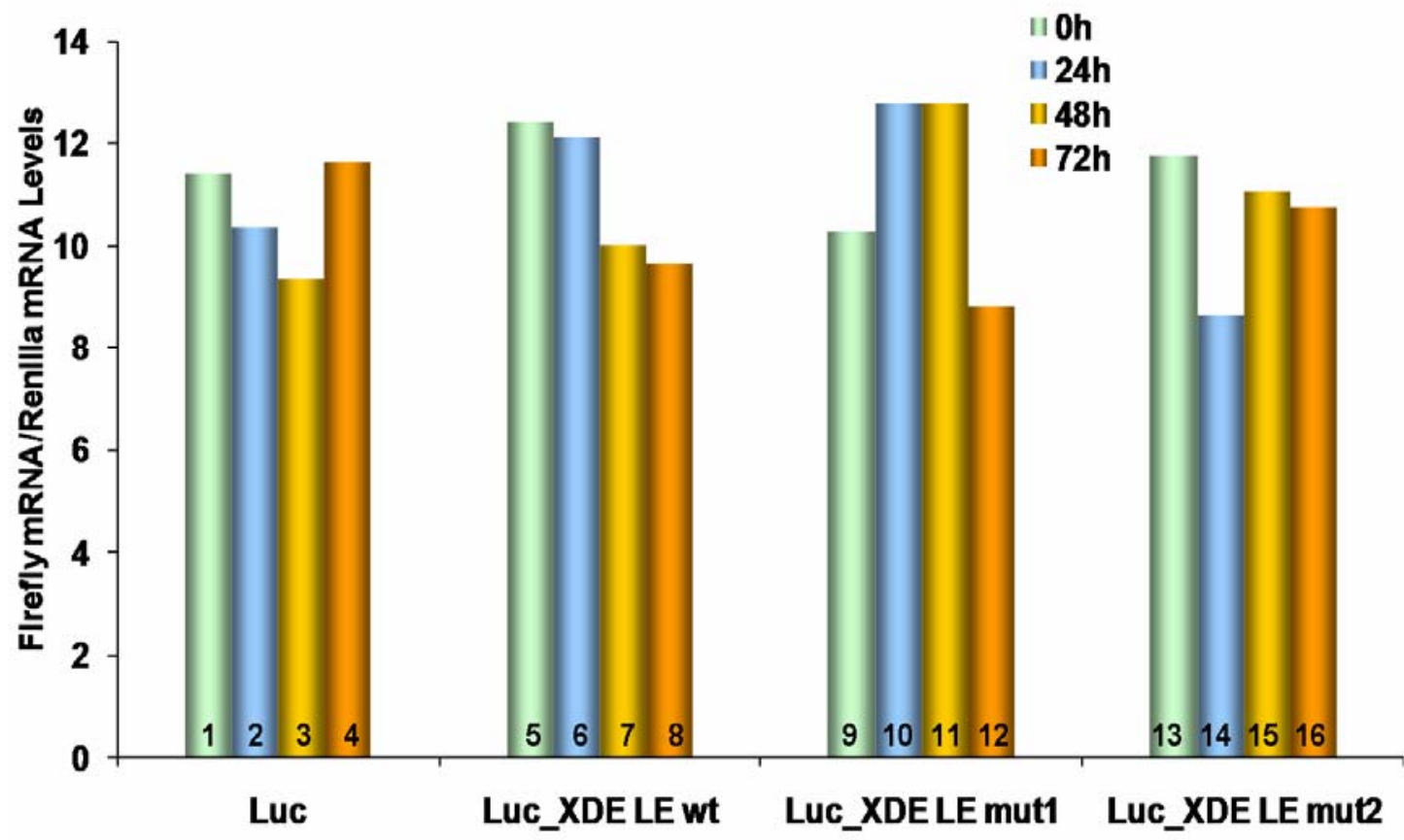

C

$$
\begin{array}{llllllllllllllll}
1 & 2 & 3 & 4 & 5 & 6 & 7 & 8 & 9 & 10 & 11 & 12 & 13 & 14 & 15 & 16
\end{array}
$$

Figure 3.18 Interference with EIrA/B binding to XDE LE does not influence mRNA stability in oocytes 


\subsection{Loss of ElrA/B binding strongly decreases mRNA stability in primordial germ cells in embryos}

XDead end 3'UTR has been reported to mediate selective stabilization of reporter RNA in the PGCs of embryos, an activity which has been mapped to the same region as the vegetal localization element (Koebernick et al, submitted). It has also been proposed that the protein machinery that assembles on this LE in the oocyte driving vegetal localization could be the same as the one that mediates the selective PGC stabilization.

To test whether the XDE LE mutant versions impaired in their vegetal localization activity may exhibit reduced stability in PGCs due to their loss of Elav binding, microinjections of reporter RNA bearing the XDE LE mut1 and mut2 into embryos were performed. Embryos injected (done by Jana Löber) with these reporter constructs were grown to stage 8 , at mid blastula transition (MBT), before the onset of active degradation of maternal mRNA (Duval et al., 1990). The reporter RNA staining intensities were found to be nearly similar for all reporter RNAs at this early stage; interestingly, mut1 and mut2 reporter RNA staining levels in PGCs became markedly reduced at stage 32 , when the wt version was well detectable (Fig 3.19A).

Another set of embryos was injected with the reporter RNAs and grown to stage 32, after in situ hybridization, those embryos with PGC staining like that in (Fig. 3.19A) were score as a percentage of the total injected. The outcome of this second experiment confirmed the above observation that reporter RNAs of the mutant versions of XDE LE were much less stable in the PGCs as compared to those of the wild type (Fig. 3.19B). There were only few embryos injected with reporter RNAs of the mutant versions of XDE LE, which showed PGC staining, but intensities were much weaker as compared to the wild-type. These observations strongly suggest that the ElrA/B proteins participate not only in mRNA localization in the oocyte but might also be required for PGCs stabilization via the same regulatory RNA element. 
A
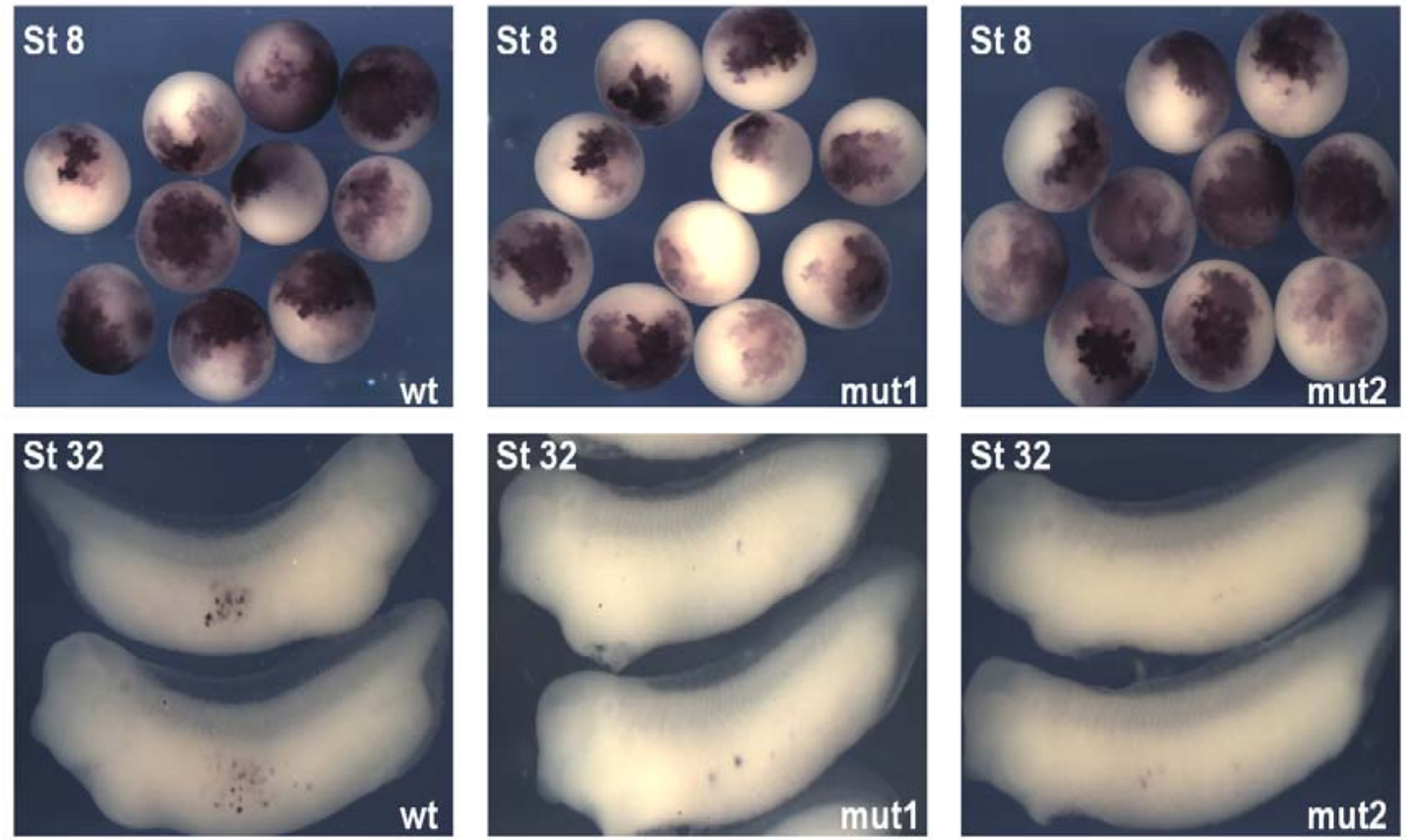

B

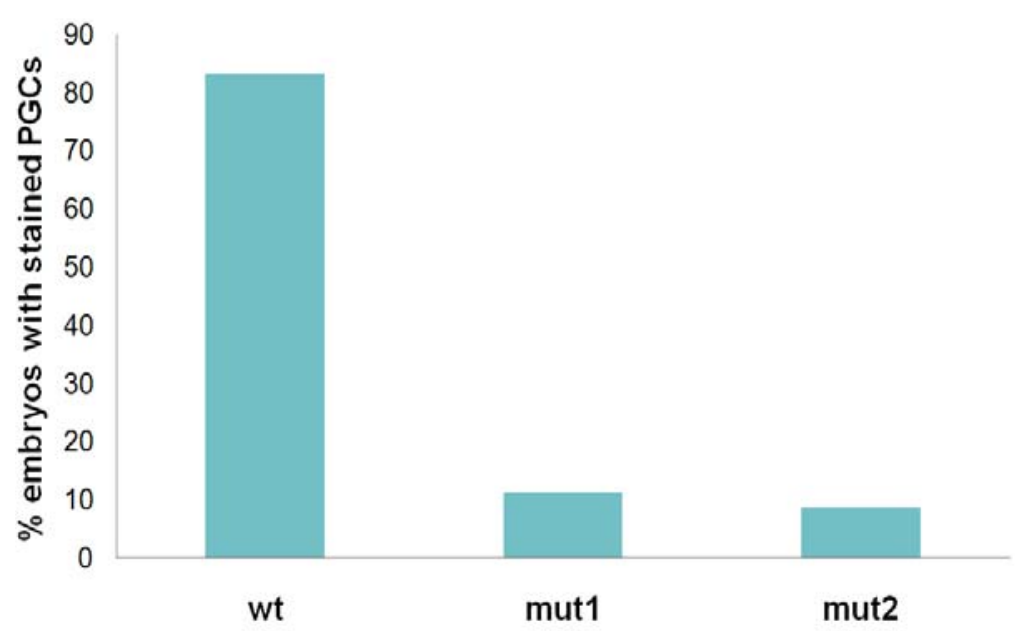

Figure 3.19 Loss of binding mutation in XDE LE strongly decreases mRNA stability in PGCs during embryogenesis.

(A) Reporter mRNA of mGFP having the XDE LE and its mutant version as the 3' UTR were injected into embryo at $150 \mathrm{ng} / \mathrm{embryo}$ in an experiment where embryo were fixed at stage 8 and stage 32 of development. in situ hybridization using Dig-labelled antisense probe against the mGFP (B) Similar experiment as in (A), this time using a larger number of injected embryos ( $w t: n=78$; mut1:n=71; mut2:n=88), the graph showing the extent of reporter RNA stability was scored as number of embryos with staining within their PGCs for the 3 reporters. 


\subsection{Subcellular distribution of Elr-type proteins in Xenopus}

It has been shown that proteins that function in vegetal mRNA localization in the oocyte, such as Vg1RBP (Zhang et al., 1999), XStaufen1 (Yoon and Mowry, 2004) and VgRBP60 (Kress et al., 2004), 40LoVe (Czaplinski et al., 2005), exhibit vegetal cortex enrichment reminiscent of the distribution of their target mRNAs. Assuming a functional role of ElrA and $B$ in vegetal mRNA localization, immunostaining experiments on paraffin sections of stage III and IV oocytes were performed in order to examine the subcellular distribution of these proteins in the oocyte. ElrA and B staining was detected in the cytoplasm with some degree of vegetal cortex enrichment in both, sections from stage III and stage IV oocytes (Fig. 3.20a and 20b).

Staining for 40LoVe and Vg1RBP served as control, using sections from the same oocyte as the one used for ElrA/B protein staining; 40LoVe shows very strong staining in the nucleus, consistent with previous report (Czaplinski and Mattaj, 2006). In order to confirm the immunostaining results, protein extracts from manually dissected oocyte nuclei and cytoplasm were analysed by western blotting. In good agreement with observations from the immunostaining approach, ElrA/B proteins were detected mainly in the cytoplasmic fraction (Fig. 3.21A and $B)$; there were very low, but perhaps significant levels of ElrA were detected in the nuclear fractions.

The distribution of 40LoVe in the dissected nuclear-cytoplasmic fractions perfectly correlated with the immunostaining results; by using UV crosslinking analysis a protein with size appropriate to be nuclear protein Nucleolin was detected only in the nuclear fraction suggesting that there was no cross-contamination of the two fractions (Fig. 3.21B). As an additional evidence of no cross-contamination of the two fractions generated, the higher molecular weight 40LoVe protein isoform reported to be detectable only in the nucleus (Czaplinski and Mattaj, 2006), was indeed found in the nuclear fraction from the same preparation but not in the cytoplasm. In the UV crosslinking analysis of the same fractions, a protein band could be detected in the nuclear fraction (marked with white star in Fig. 3.21B) with the size appropriate for 40LoVe. This could be the first indication that 40LoVe also binds directly to the XDE LE, since analyses so far did not reveal this activity. 
Detection of endogenous ElrA/B proteins on the paraffin sections or the manually dissected nuclear and cytoplasmic fractions reflects their steady-state distribution between these compartments. However, there could be dynamic protein exchange between the oocyte nucleus and cytoplasm, as shown for HuR in somatic cells (Atasoy et al., 1998). To test for a possible shuttling of ElrA and B1 in and out of the nucleus, microinjection experiments were performed (by Susanne Koch) using myc-tagged versions of ElrA and B1. Myc-ElrA was found to be readily exported into the cytoplasm upon injection into the nucleus, while ElrB1 remained almost entirely in the nucleus under the same conditions (Fig. 3.21C). Conversely, when both proteins were injected into the cytoplasm, neither protein was imported into the nucleus; this reflects their predominantly cytoplasmic distribution.

Taken together, these results indicate that some amount of Elr-type proteins colocalizes with their target mRNAs at the vegetal cortex. Furthermore, the rapid export of ElrA from nucleus to cytoplasm is compatible with the idea of a possible early function for this protein in the transport pathway that leads from the nucleus to the vegetal cortex in Xenopus oocytes. 


\section{St III}
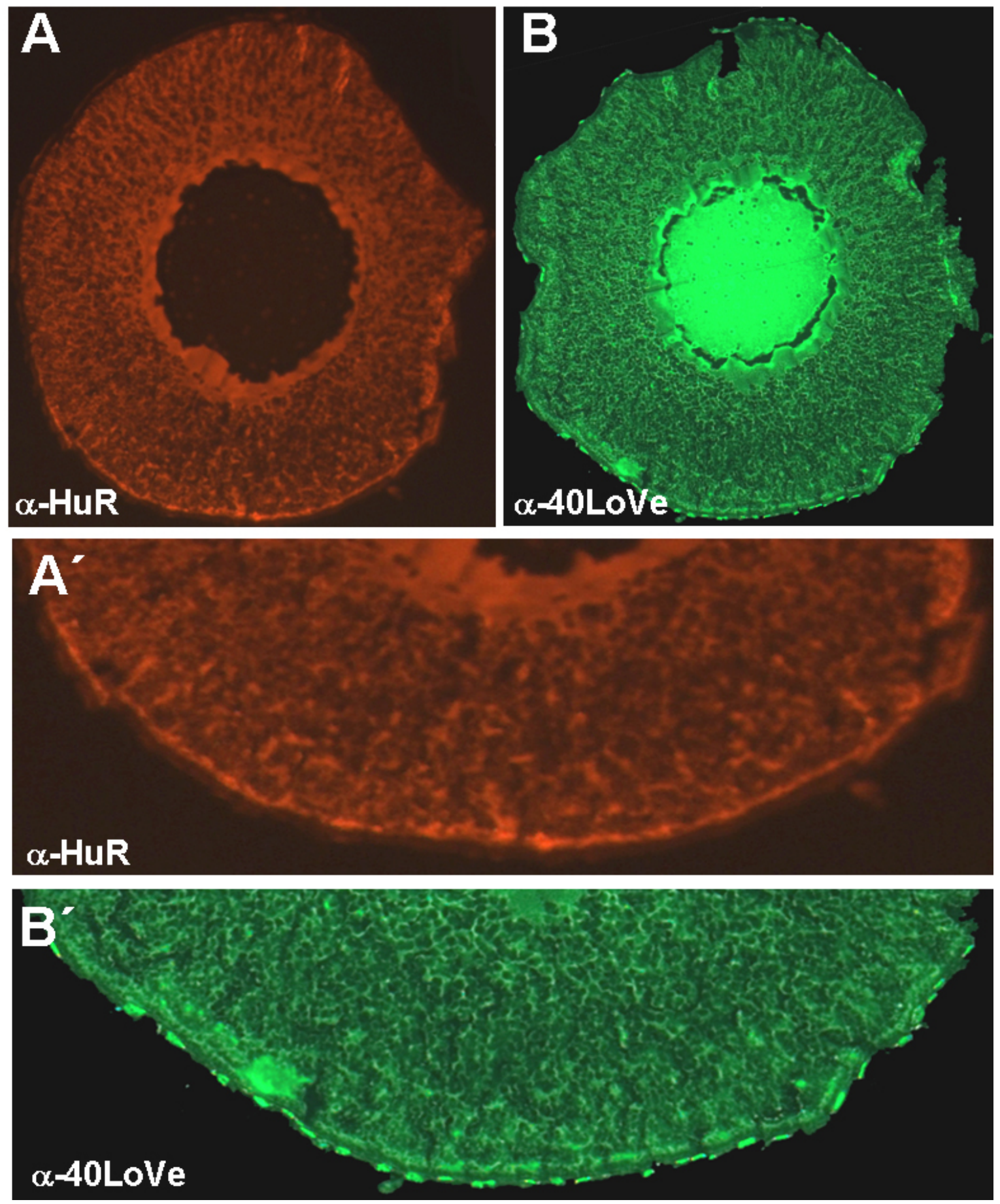

Figure 3.20a Subcellular distribution of ElrA and $B$ in stage III oocytes

(A) Immunostaining on paraffin sections of a stage III oocyte using a $\alpha$-HuR antibody. (B) $\alpha$ 40LoVe staining using adjacent sections from the same oocyte as shown in (A). ( $A^{\prime}$ and $B^{\prime}$ ) are magnifications of the vegetal cortices shown in (A) and (B). 

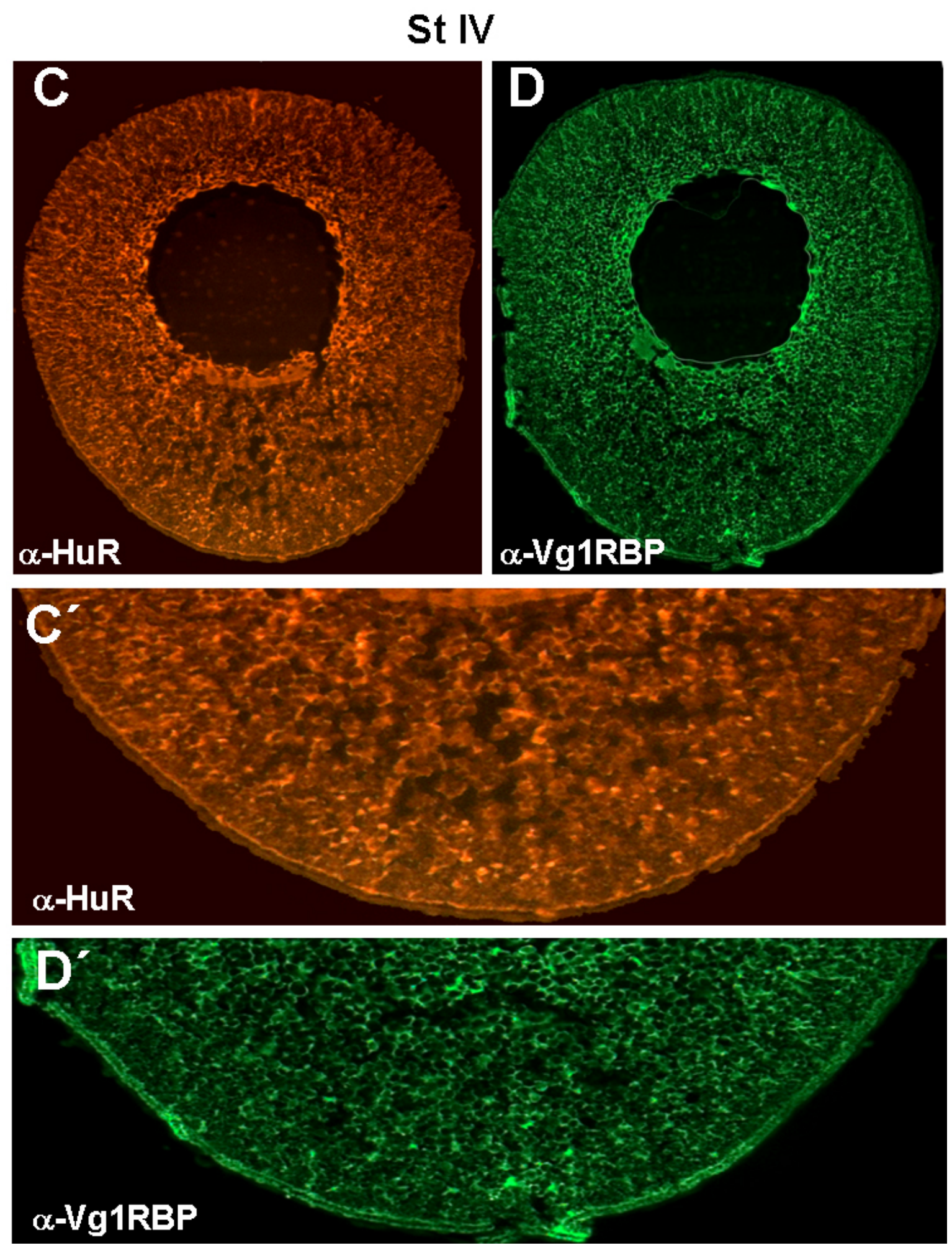

Figure 3.210b Subcellular distribution of EIrA and B in stage IV oocytes

(C) $\alpha$-HuR staining of Stage IV oocyte sections. (D) $\alpha$-Vg1RBP immunostaining using adjacent sections from same oocyte as shown in (C). (C'and $D^{\prime}$ ) are magnifications of the vegetal cortices shown in (C) and (D), respectively. 
A
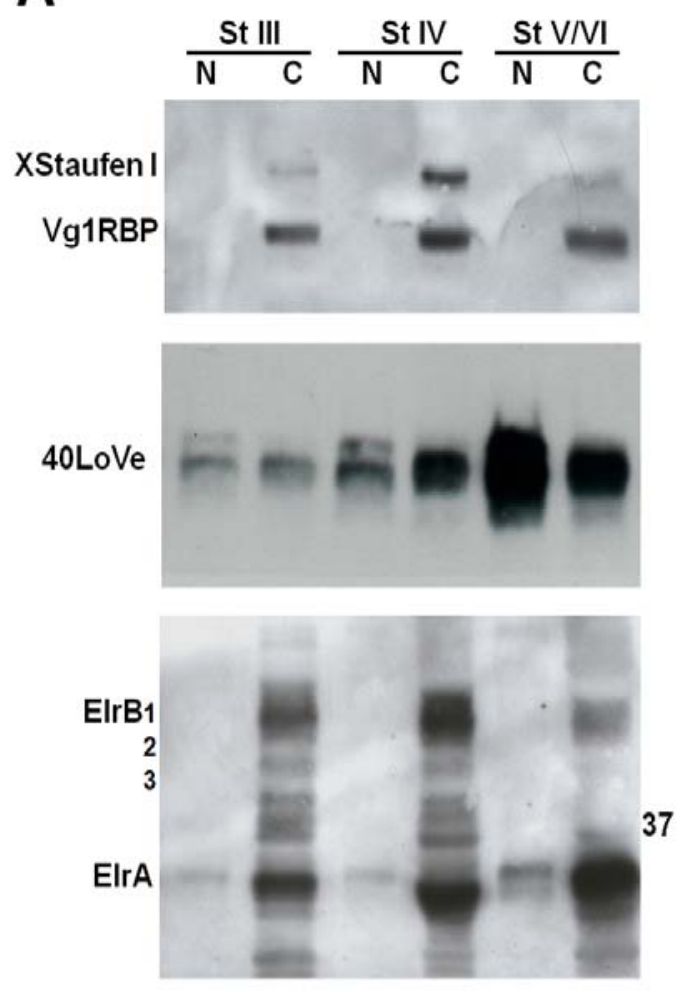

C

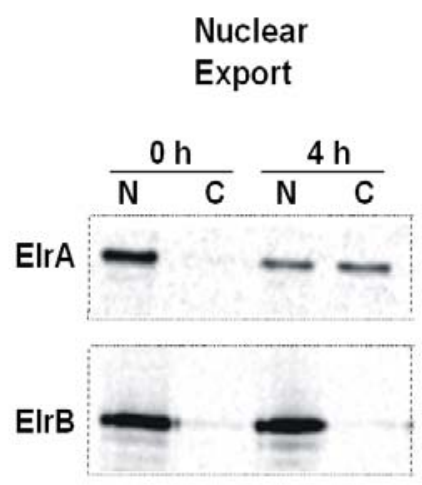

B

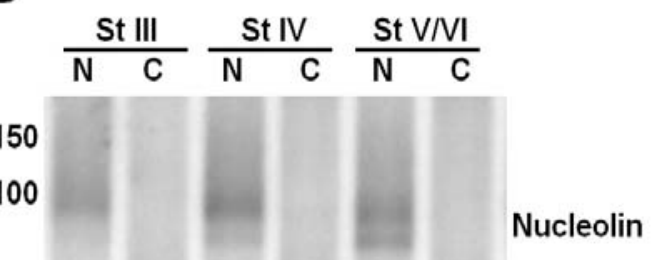

75

Vg1RBP

FRGY2 a/b

50

37

25

Nuclear

Import

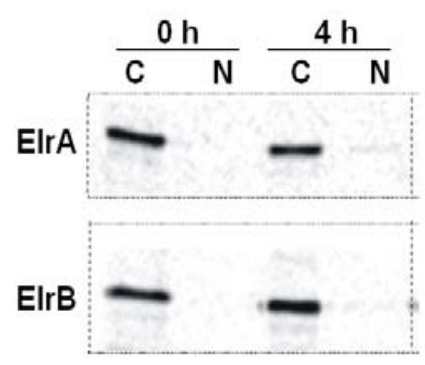

Figure 3.21 Nucleo-cytoplasmic distribution of ElrA/B protein in oocytes

(A) Nuclei and cytoplasm of St. III-VI oocytes were manually dissected. ElrA/B and 40LoVe proteins were detected by western blotting. (B) The same fraction as in (A) was analysed by UV crosslinking using radiolabelled XDE LE, the protein band marked by an asterisks could correspond to 40LoVe according to size and nuclear localization as seen in the western blot.

(C) Nucleo-cytoplasmic transport assay with ElrA and B. ${ }^{35}$ S-labelled, myc-tagged versions of the proteins were injected into the cytoplasms or nuclei of stage VI oocytes. These were dissected either directly or four hours after injection. Myc-tagged proteins were immunoprecipitated from these fractions, separated by SDS-PAGE and detected by phosphoimaging. 


\subsection{ElrA/B proteins are constitutive components of RNPs throughout oogenesis}

The ElrA/B proteins were isolated as components of large RNPs specifically binding to several LEs; we were further interested in testing if these RNPs exhibit structural changes during oogenesis, also since ElrB is degraded during stages $\mathrm{V}$ VI. The glycerol gradient profile for ElrA/B proteins was examined using extracts from different stages of oogenesis; the proteins are clearly detectable in RNP fractions in all stages analysed and the same is true for Vg1RBP (Fig 3.22A and $B)$. The profile of both ElrA/B and Vg1RBP exhibited a subtle shift in the size of the RNPs as oogenesis proceeds, the peak of these proteins shifted by two fractions, comparing stage I-III to stage IV-VI. The functional relevance of this observation is not clear, but perhaps it may suggest that the differences in the RNP composition and correlate with different functions during oogenesis; e.g. the fact that mRNA localization occurs mostly during stage I-III suggests that large RNP complexes might be required to mediate the transport process.

The stained gel of glycerol gradient fractions from stage I oocytes shows remarkably high levels of proteins with the appropriate size to fit the FRGY-type proteins and another protein with a size fitting to that of Vg1RBP (Fig. 3.23). These proteins being visible within such a complex protein mixture, as represented by the total $\mathrm{S} 16$ extract, underscores the relative abundance of RNA binding proteins and RNPs during early oogenesis in comparison to the amount of total protein at the same stages. Interestingly, Vg1RBP co-immunoprecipitated with ElrA/B from stages I - VI, even though the amounts of Vg1RBP per ElrA/B proteins appear to drop slightly in late stage oocytes (Fig. 3.22C). This perhaps supports the observation of an apparent shift to smaller size of RNPs during late oogenesis, in that lower copy numbers of proteins could be bound to a single RNA molecule; the removal of ElrB proteins could also account for same effect. 
A

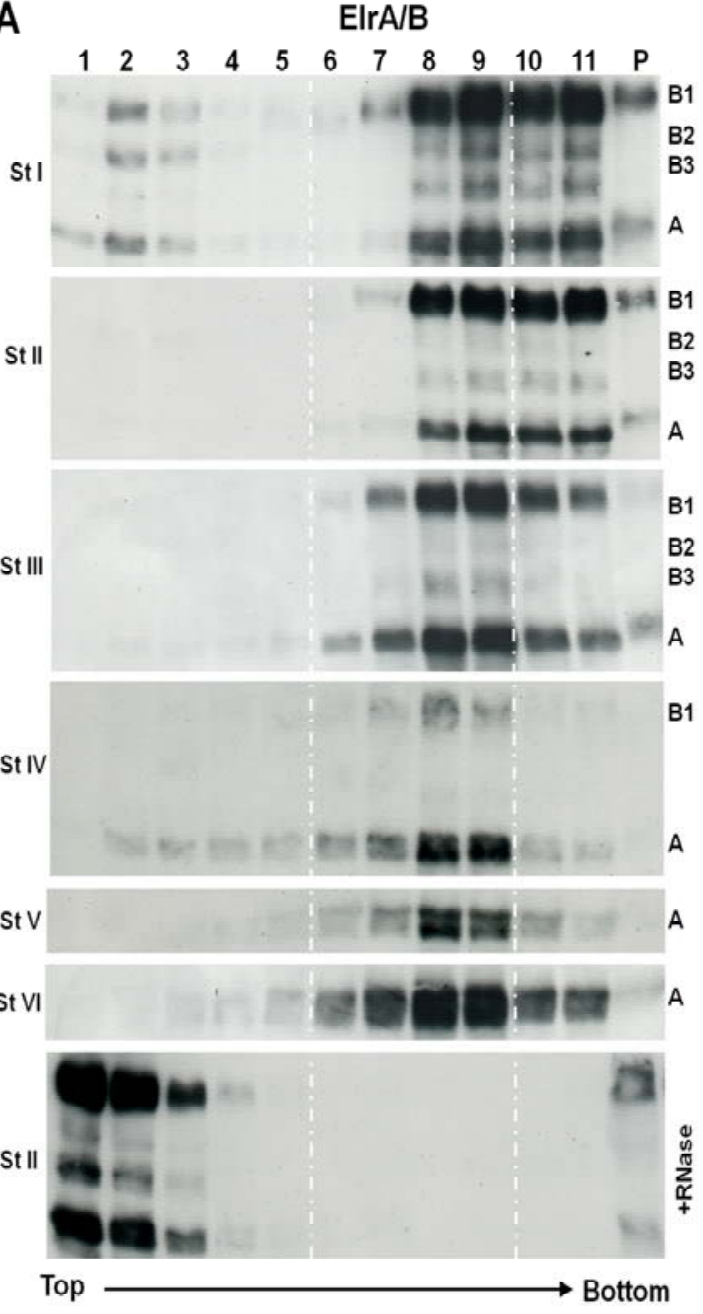

B

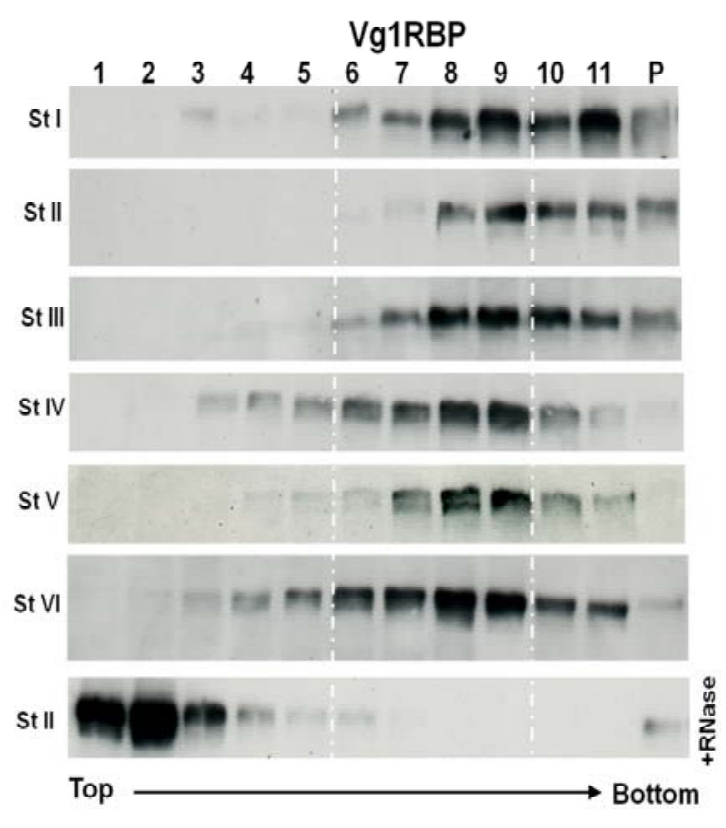

C

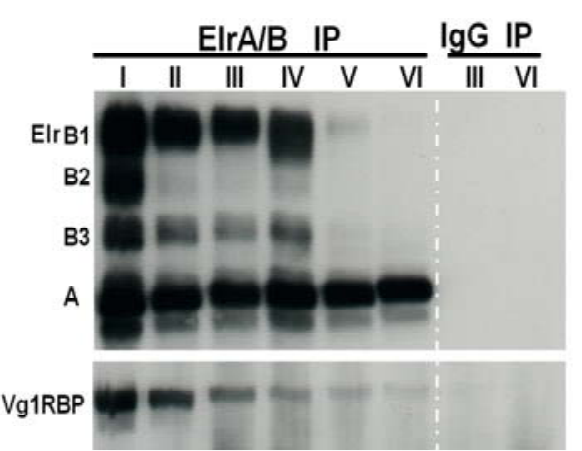

Figure 3.22 ElrA/B and Vg1RBP proteins are constitutive RNP components throughout oogenesis

(A) Glycerol gradient (10\%-60\%) fractionation of S16 oocyte extracts from individual oocyte stages (I-VI), stage II oocyte extract was RNase treated and fractionated in the same way. ElrA/B protein distribution was analysed by western blotting, (B) western blotting analysis of the fractions in (A) using antibody against Vg1RBP. (C) Co-immunoprecipitation experiment using extract of all 6 stages and anti-HuR, precipitated proteins were analysed by western blot for Vg1RBP and ElrA/B. 


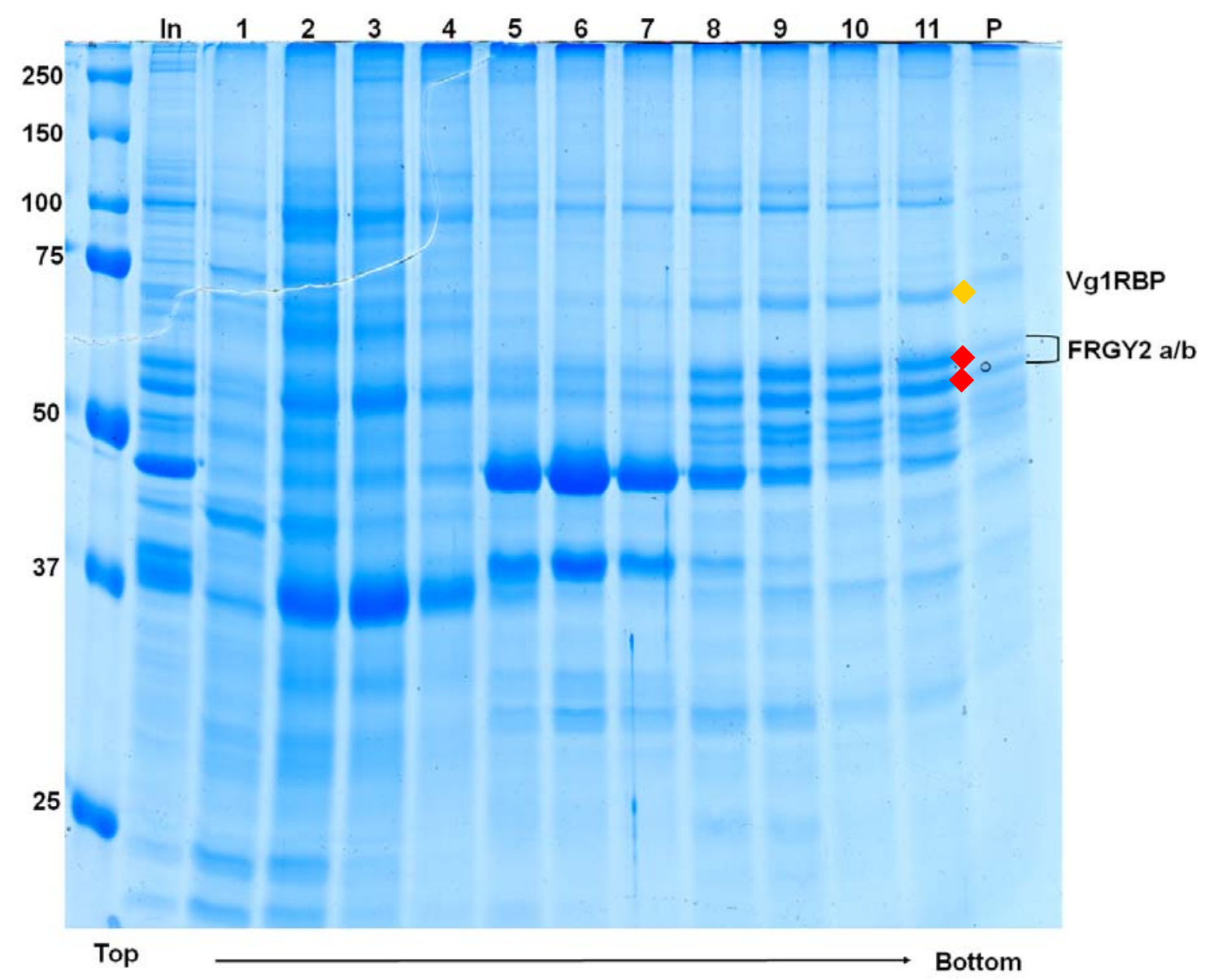

Figure 3.23 Profile of total protein from stage I oocytes on glycerol gradient

Coomassie stained SDS-PAGE gel corresponding to the same glycerol gradient fractions of stage I oocytes as analysed by western blot in Fig 3.22A and B. Proteins were separated on $11 \%$ SDSPAGE. Proteins marked by yellow diamond (Vg1RBP) and red diamond (FRGY-type proteins) were determined based on the size that is appropriate for these proteins. 


\section{Discussion}

Taken together, this work reveals that Xenopus Elr-type proteins, homologs of $\mathrm{Hu} / \mathrm{ELAV}$ proteins, are binding specifically to the XDE LE, as well as to a number of vegetal LEs. EIrA/B proteins co-precipitated with known localization proteins such as Vg1RBP, XStaufen1, VgRBP60 and 40LoVe, indicating that they assemble into the same RNP. Mutagenesis studies and co-injection of antisense morpholino oligonucleotides provide strong evidence that ElrA/B binding is required for the vegetal localization of XDE LE RNA. Comparative UV crosslinking analysis suggests that ElrA/B proteins might function also in the localization of other vegetally localized mRNAs. However, the fact that LEs of Xvelo1 and XNIF mRNAs do not exhibit binding activities for these proteins indicates that ElrA/B-binding may not be a prerequisite for vegetal localization.

\subsection{Elav}

Elav is an acronym for embryonic lethal abnormal vision, a gene first described in Drosophila as being crucial for the proper differentiation and maintenance of the nervous system (Campos et al., 1985). The domain structure was determined as consisting of three RRMs; two of these RRMs are close together at the N-terminal end, whilst the third is separated by a hinge region, as depicted in (Fig. 4.1) (Yao and White, 1991). The hinge region has a role in the subcellular distribution of the protein; even though the nuclear import/export signal is not intact and functional in all isoforms existing in vertebrates, these proteins shuttle between the nucleus and cytoplasm in somatic cells (Kasashima et al., 1999).

There are four isoforms of the Elav proteins known in vertebrates including Xenopus; in humans, they are referred to as Hu proteins and they differ in their tissue specific expression. HuA (HuR) is ubiquitously expressed; HuB is found in neurons and ovaries, whilst $\mathrm{HuC}$ and $\mathrm{HuD}$ are exclusively expressed in neurons (Antic and Keene, 1997). In Xenopus, the four main isoforms equivalent exist, which exhibit identical expression pattern and are referred to as ElrA, ElrB, ElrC and ElrD (Good, 1995). 


\section{Xenopus Elav protein}

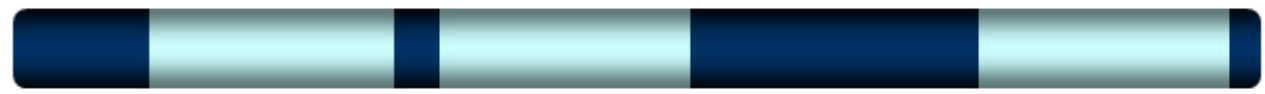

RNARecognition Motif - RRM

Figure 4.1 Domain structure of Xenopus Elav protein, showing 3 RRM domains

The second and third separated by a hinge region. RRM domains in general have about 80-90 amino acids and are characterized by two conserved motifs, the octameric RNP1 and the hexameric RNP2 (Kenan et al., 1991).

Hu/Elav proteins are known to function at almost every step of mRNA metabolism, from the regulation of nuclear pre-mRNA splicing (Zhu et al., 2006) and polyadenylation (Zhu et al., 2007) to mRNA decay; they are best known function in somatic cells is the stabilization of short-lived, AU-rich element (ARE) containing mRNAs (Brennan and Steitz, 2001). These proteins are considered as the multi-tasking workhorse of post-transcriptional regulation of gene expression owing to their involvement in all the different aspects of this process (Wilusz and Wilusz, 2007).

\subsection{Vegetal localization proteins are components of a large RNP}

Vegetal localization proteins such as Vg1RBP and XStaufen1 were observed in high density fractions together $80 \mathrm{~S}$ ribosomes or even polysomes (see appendix I). This property has allowed for a substantial enrichment of the localizing RNP and the identification of novel components. What accounts for these large sized RNPs in oocytes remains to be determined, but examples from other systems may help to shed light on their structure and composition. One possible scenario could be that a number of proteins associate with the same mRNA, or alternatively, smaller RNPs could oligomerise. The oligomerization could be mediated by protein-protein interactions (Chekulaeva et al., 2006) or by RNA-RNA interaction (Ferrandon et al., 1997; Wagner et al., 2001).

Localizing RNPs co-fractionate with many other high density particles, prominent among these are ribosomes, but also hnRNPs, nucleolar particles (Nucleolin), and cytosolic particles called vaults (Kedersha et al., 1990; Kedersha and Rome, 1986); a number of proteins identified could be components of heat-shock 
granules (Nover et al., 1989; Smykal et al., 2000). Also contained in the high density fractions are stress granules, as indicated by the presence of G3BP proteins (Tourriere et al., 2003), TCP chaperonin and proteasomal complexes. Ribosomal proteins were largely absent from protein preparations generated using RNase treatment; this is in contrast to the ribosomal proteins identified from high salt treated samples. Whilst most ribosomes may remain intact at the salt concentration used and were subsequently removed by the second step of high speed centrifugation, the RNase activity could have led to precipitation of ribosomal proteins accounting for their complete absence and this view is consistent with the observation that the solution turns cloudy shortly after addition of RNase. Another clue for this notion comes from the observation that ribosomal protein S6, which, instead of shifting into low density fractions upon RNase treatment, could not be detected in any gradient fraction at all, unlike Vg1RBP and XStaufen1 (Appendix I - shows rpS6 in fractions 7-11). The reason for ribosomal proteins precipitating, whilst many proteins identified (such as Vg1BP, XStaufen1, FRGY2) were released from the RNP particles into the high speed supernatant, could be the nature of the ribosome structure. It is known that ribosomes are assembled in such a way that protein components are added to the rRNA cotranscriptionally, and as such these proteins are perhaps not properly folded within the ribosome structure to be soluble upon their release by the RNase, as reviewed in (Fromont-Racine et al., 2003).

\subsection{Isolation of ElrA/B as a novel vegetal localization element binding proteins}

High speed centrifugation of RNP fractions obtained from glycerol gradients made it possible to sufficiently enrich localization proteins and to isolate new ones. This was important since the process and mechanism of vegetal mRNA localization can be better understood as more trans-acting factors are identified. The biochemical purification approach used was based on the principle that mRNAs form RNP complexes by recruiting regulatory proteins which control posttranscriptional events; as such these proteins acquire a buoyant density different from majority of soluble proteins in the cell, reviewed in (Keene, 2007). Thus, this approach enriched proteins in their functional unit, although some sample 
complexity problems remain, since this density property is shared by other particles in the cell (as discussed in section 4.1).

The complexity of the enriched protein sample could be solved with the resolving power of 2-D gel electrophoresis. By this means, ElrB1 was identified as candidate protein, due in part to its relatively high abundance, as corresponding to one of the specific RNA binding activities in the partially purified protein fraction (Fig 3.1D). It was also possible to confirm that indeed ElrB1 along with its putative isoforms is directly interacting with the XDE LE by making use of specific antibodies for immunoprecipitations from UV crosslinking reactions (Fig 3.3). Anion exchange chromatographic fractionation did not succeed in reducing sample complexity to allow for individual proteins to be identified; however the profile of the specific RNA binding proteins and the western blotting analysis provided supporting evidence for the identification Elr-type proteins as interacting with XDE LE (Fig 3.4). The other forms of the Elr-type protein including ElrA, could not be identified from the 2-D gel electrophoresis, perhaps due to the relatively low levels of expression in contrast to ElrB1, but these were also enriched in RNP fractions and bind specifically to XDE LE with similar specificities.

\subsection{Heterogeneity of the localizing RNP}

Results presented in Fig. 3.5, reveal that the Xenopus Elr-type proteins bind specifically to the XDead end LE, as well as to several other vegetal localization elements (LEs). In particular, they provide important insights into the nature of the RNP complex that assembles on the minimal cis-acting localization elements (LEs) which mediate the vegetal transport of the maternal mRNAs harboring them. There is a clear demonstration of the existence of RNP heterogeneity in terms of their protein composition, as judged by the level Vg1RBP and ElrA/B proteins which are specifically recruited by the LEs.

The comparative crosslinking analysis provides a powerful way of distinguishing at least five different types of RNPs that assemble with LEs in the oocyte as illustrated in Fig. 4.2. The first two classes of RNPs are those that recruit approximately equal levels of Elr-type proteins and Vg1RBP, but either with overall high (e.g. Velo76 LE) or low (e.g. Velo45 LE) levels of both proteins. The 
third and fourth classes have the stoichiometric ratios tilting either in favour of Elrtype proteins (e.g. XDE LE) or Vg1RBP (e.g. Vg1 LE). The fifth class binds mainly Vg1RBP with levels of Elr-type protein being undetectable (e.g. XVelo1 LE). It is interesting that ElrA/B bind to mRNAs localizing via all three pathways, which is consistent with earlier reports that a common machinery is utilized by both early and late pathways in the oocytes (Choo et al., 2005; Claussen et al., 2004).

The observations of RNP heterogeneity however, leave open the question of what fundamentally defines the signal that elicits vegetal mRNA localization, just as primary sequence homology such as E2 and VM1 elements found to cluster in Vg1 LE (Bubunenko et al., 2002; Lewis et al., 2004), are not conserved in other localized mRNAs such as Xvelo1 (Claussen and Pieler, 2004) and XDead end (Horvay et al., 2006). The suggestion that RNA localization signals may assemble a common set of proteins (Bubunenko et al., 2002), is not supported by RNP heterogeneity demonstrated in this comparative crosslinking analysis using several LEs. It has to be taken into consideration how these different localizing RNPs could be recognized and coupled to the same transport machinery, rather than just primary and secondary sequence elements.

VgRBP60/hnRNP I binding was not analyzed on the same comparative basis in this study, but the expectation would be that it will also exhibit a similar level of heterogeneity as suggested by the difference in number of its binding site (VM1 element) in the different LEs (Horvay, 2005). Also since VgRBP60 has been shown to modulate the binding of Vg1RBP to Vg1 LE (Kress et al., 2004; Lewis et al., 2007), it may vary in the level recruited to the different LEs. In view of the RNP heterogeneity observed here, the question of what triggers mRNA localization should not be limited to a focus on just how different LEs with varied sequences are recognized by a common transport machinery but should go further to include the different localizing RNPs. Contrary to previous suggestions, the different LEs with varied sequences apparently do not assemble a common set of trans-acting factors, but rather the difference in sequences is also reflected in the factors recruited. 
The transport competent RNP could well be defined by the molecular architecture of the RNP superstructure (an oligomerised RNP complex), with an identical RNP superstructure formed from the variety of sequence and structural elements as well the small RNPs these form with trans-acting factors. Conversely, the transport machinery could be viewed as having a specific recognition range to cover all the varied "small" localizing RNPs of the individual LEs while excluding non-localized mRNA elements, even if they have binding sites for the same proteins that bind to LEs. Binding sites for Vg1RBP and VgRBP60, in fact, do exist in other parts of the localized mRNA outside of the LE, however mRNAs lacking the LEs have been found not to localize to the vegetal cortex (Claussen and Pieler, 2004; Horvay et al., 2006; Kress et al., 2004). The large size of endogenous localization RNP complexes observed, especially in stage I-III oocytes (Fig 3.22), supports the first scenario of an RNP superstructure but the nature of interactions (RNA-RNA or protein-protein) required to form this remains to be determined.

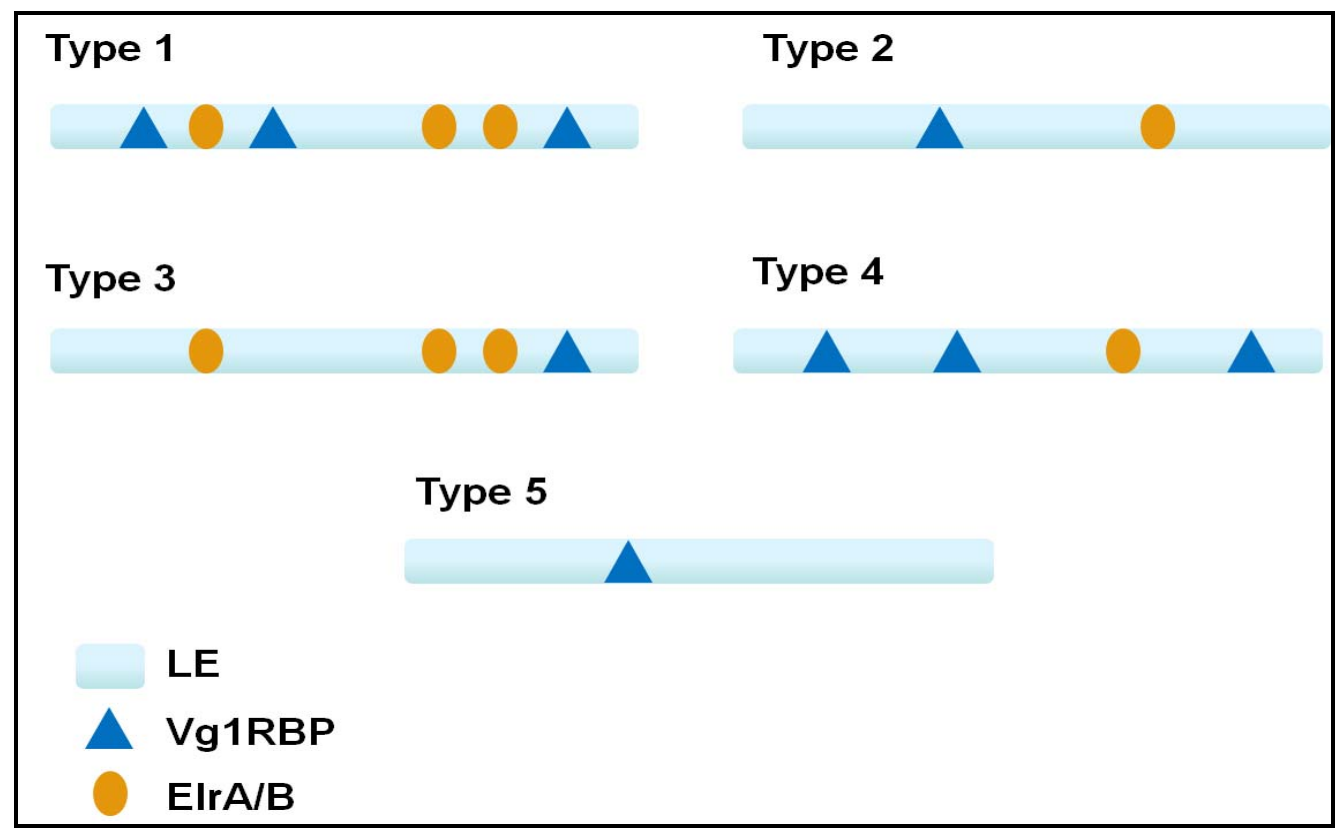

Figure 4.2 Model of RNP heterogeneity exhibited by the various vegetal localization elements

Localizing RNP structure depicted is based on results in Fig 3.4B, with three protein symbols per LE corresponding to strong binding whilst one correspond to weak binding as judged from the comparative crosslinking assay. 


\subsection{Identity of protein components of EIrA/B RNP complexes}

The human Elav proteins Hel-N1/Hel-N2 bind to polyA+ mRNAs and were detected in granular RNP structures which colocalize with ribosomes in medulloblastoma cells; multimerization of these proteins is mediated by the RRM3 (Gao and Keene, 1996; Toba and White, 2008)\}. These hElav mRNPs interact with microtubules and can also associate with microfilaments upon forming larger complexes containing ribosomes. This is suggested as the mechanism by which hElav proteins may affect post-transcriptional regulation of gene expression of key growth regulatory factors through intracellular localization and translation as mRNP granules (Antic and Keene, 1998).

In this study, Xenopus ElrA/B proteins were co-precipitated with known localization proteins such as Vg1RBP, XStaufen1, VgRBP60 and 40LoVe, indicating that they assemble into the same vegetal localization RNP, even though the stoichiometric ratios could differ for each mRNA, as described above (section 4.4). The density gradient analysis shows that Vg1RBP, XStaufen1 and also ElrA/B all exhibit an almost exclusive migration in RNP fractions (Fig. 3.1B and 3.22) with little or no amount existing as free protein in the oocyte. In view of this, the relative amounts of these proteins detected from the RNP enriched fraction could be interpreted roughly as their proportion within these RNPs, even though the different RNP types are not made clear from these analyses. It does show that Vg1RBP and ElrB1 (Fig 3.2) are the two most abundant proteins, with levels comparable to that of FRGY-type proteins, ElrA/B2/B3, XStaufen1 and others present in much lower copy numbers.

The immuno-isolation of ElrA/B RNPs thus goes further to shed light on the molecular architecture of the putative localizing RNP. It is more specific and accurate in the determination of proportional RNP composition compared to density gradient RNP fractions, although proteins identified from isolated ElrA/B RNPs could also be found in the gradient RNP fractions. For example, the ratio of Vg1RBP to FRGY2-type proteins, which in the gradient RNPs is approximately 1:50 (Fig 3.2A), but in the ElrA/B RNP these two proteins are roughly equal in quantity (Fig 3.11A), indicating that there are subsets of FRGY2 containing RNPs. The diverse protein components (released by RNase) identified provide a good 
indication that the EIrA/B RNP could be multi-functional in nature; particularly intriguing is the high level of localization protein Vg1RBP. The FRGY-type proteins, which are non-sequence specific RNA binding proteins involved in maternal mRNA masking and storage, are significant components of this specific RNP which functions in the vegetal transport of an estimated $5 \%$ of maternal RNA (Carpenter et al., 1982). These prominent FRGY-type protein components could be fulfilling a broad function of translation repression of maternal mRNA, which may not exclude vegetally localized mRNAs as reviewed in (Matsumoto and Wolffe, 1998; Sommerville and Ladomery, 1996a; Sommerville and Ladomery, 1996b).

Additional RNase released components of this isolated RNP, such as Xp54 and RAP55 related proteins called here as RAP42/46, further support the suggestion that translational repression of localized mRNA maybe a function of the global mRNA masking machinery. This is because Xp54 is an RNA helicase, known to function in the assembly of stored RNPs (Ladomery et al., 1997; Smillie and Sommerville, 2002; Weston and Sommerville, 2006) and translation repression of maternal mRNAs (Minshall and Standart, 2004) in Xenopus oocytes. Furthermore, Xp54 localizes to processing bodies in somatic cells (Cougot et al., 2004); the same is true for RAP55 (Tanaka et al., 2006) and by extension the RAP42/46 proteins could be predicted to share similar functional properties as RAP55, on the basis of the conserved N-terminal Lsm domain. Translational control of localized mRNAs in the oocyte could also be achieved by selective activation of translation, as suggested for maternal mRNA in general (Tafuri and Wolffe, 1993), through the mechanism of removing the masking proteins and association with ribosomes. Additional mechanisms of regulating translation may exist for certain localized mRNAs, for example $\mathrm{Vg} 1 \mathrm{mRNA}$, where an element with the activity of repressing translation has been mapped to a region in the $3^{\prime} U T R$ distinct from the LE (Otero et al., 2001). Homologs of FRGY2 and Xp54, namely Yps (Mansfield et al., 2002; Wilhelm et al., 2000a) and Me31B (Nakamura et al., 2001) respectively, have been identified and implicated in translational repression of localized mRNA in Drosophila oocytes, and they may be fulfilling a similar function specific for localized mRNA in Xenopus oocytes, despite their apparently high abundance and general role masking of maternal mRNAs. 
Proteins interacting with ElrA/B in an apparently RNA independent manner are higher in number compared to those released by RNase (RNA dependent) but it remains to be verified whether the interactions are actually independent of the RNA scaffold (Fig. 3.9 and 3.11B). Indication to the effect that proteins that are not release by RNase might not interact directly with ElrA/B (i.e. protein-protein interaction), comes from the observation that these same proteins fail to coprecipitate with ElrA/B when RNA was degraded prior to protein isolation. A possible explanation for this could be that the RNA digestion during the protein isolation abolishes protein-protein interactions either due to, firstly, changes in the chemical environment caused by an increase in the amount of short RNA species, or, secondly, an induced precipitation of these proteins upon the removal / degradation of RNA much like what is presumed to happen to many ribosomal proteins (discussed in section 4.2). If the second scenario holds true, it would be consistent with the partitioning of these proteins into the pellet fraction following RNase mediated release after the protein isolation. What is certain is that proteins identified from this fraction are indeed components of the isolated ElrA/B RNPs and their identities would again shed light on the structural and functional features of the putative localizing RNP.

One group of proteins, i.e. egg specific protein (P100), elF4E-T and CPEB1 may define general components of RNPs during oogenesis; however, the egg specific protein has no known function, while elF4E-T and CPEB1 interact to repress translation in oocytes (Minshall et al., 2007). These three proteins have been identified in isolated FRGY2 RNPs from stage VI Xenopus oocytes (Tanaka et al., 2006), so they appear to be more general rather than specific components of ElrA/B RNPs from stage I-II oocytes. On the other hand, the CPEB1 homolog in Drosophila oocytes orb acts in an antagonistic fashion, with FRGY2 homolog Yps, to regulate the specific localization and translation of Oskar mRNA (Chang et al., 1999 210; Mansfield et al., 2002 1101); in oligodendrocytes CPEB also facilitates mRNA localization to the dendrites (Huang et al., 2003). Interestingly, Elr-type proteins were not identified in the isolated FRGY2 RNP from stage VI Xenopus oocytes; on the other hand, the isolated FRGY2 RNP also had components like ribosomal proteins which are clearly not detectable in ElrA/B RNPs isolated here. It is fair to state that the FRGY2 identified in ElrA/B RNPs may reflect a general 
component in a specific RNP rather than ElrA/B proteins being part of a general FRGY2 RNP.

Another group of proteins is defined by LDH and GAPDH; even though these are metabolic enzymes, they have also been shown to be RNA binding proteins and much like for ElrA/B, they have specificity for AU-rich elements (Hentze, 1994; Kyrpides and Ouzounis, 1995; Nagy and Rigby, 1995; Pioli et al., 2002). Gnb2l1, also known as RACK1 (receptor of activated protein kinase C 1), has been shown in yeast to interact with ribosomes forming a docking site for other regulatory proteins and also stimulates translation (Nilsson et al., 2004; Sengupta et al., 2004; Shor et al., 2003). The fact that XhermesR, a protein related to XHermes, encoded by an intermediate localized mRNA (Zearfoss et al., 2004) and the oocyte specific histone mRNA stem loop binding protein 2 (SLBP2) were also identified as components of ElrA/B RNPs is quite striking, although a possible function within this RNP is not immediately clear. Mammalian SLBP has been found to upregulate translation in oocytes (Allard et al., 2005); whilst Hermes functions during meiotic maturation of oocytes and early embryogenesis in Xenopus through a proposed mechanism of translational repression of key targets such as Xcat2, RINGO/Spy and mos mRNAs (Song et al., 2007; Zearfoss et al., 2004).

Most of the proteins were not properly focused in the IEF, except for ß-actin; this might be due to presence of a post-translational modification, possibly phosphorylation, as shown for FRGY-type proteins (Cummings et al., 1989). The presence of $ß$-actin protein in the RNPs was puzzling in itself but this could be due to the high levels of FRGY-type protein which have been shown to bind F-actin (Ruzanov et al., 1999) and therefore could also explain the co-purified Myosin motor protein. Elr-type protein containing RNPs have been shown to interact with microtubules (Gao and Keene, 1996); this might explain the detection of tubulin a/b proteins in the isolated RNP. Vg1RBP, a major ElrA/B RNP component could account for the co-precipitated tubulin $a / b$, on the basis of its interaction with microtubules in oocytes (Elisha et al., 1995). 
The identification of all 3 isoforms of ElrB and ElrA proteins from immunoprecipitation experiments further confirms their expression in the oocyte which adds to the evidence from western blot analyses. The fact that more of these Elr-type proteins are immuno-precipitated upon RNase treatment (Fig 3.9 and Fig 3.10b), suggest that the localizing RNP superstructure forms in a such a way that a portion of the proteins are buried in the interior of this structure concealing the antigenic parts.

\subsection{Participation of Elr-type proteins in vegetal mRNA localization}

Considering the lengthy period of Xenopus oogenesis, oocytes are not usually amenable to the use of genetic approaches, such as gene knockout or knockdown to achieve genetic loss-of-function, mutagenesis and antisense morpholino oligonucleotides mediated blocking of ElrA/B biding sites was employed. Mutations that abolished ElrA/B binding to XDE LE RNA provided strong evidence that these proteins play a crucial role in the vegetal localization. The comparative UV cross-linking analysis suggests that ElrA/B proteins might function also in the localization of other vegetally localized mRNAs. However, ElrA/B binding per se does not seem to be a prerequisite for vegetal localization in general since the LEs of localized mRNAs like Xvelo1 and XNIF do not exhibit binding activities for these proteins. Vg1RBP on the other hand is bound efficiently by these two LEs; it thus seems possible that localizing mRNAs might assemble into different localization RNPs, either containing or lacking ElrA/B proteins. These points to a scenario where the recruitment of ElrA/B is integral to structure and function of localizing RNPs that form on LEs with AU-rich elements, and the loss of the binding ability then renders these RNPs non-functional. How mRNAs such as XVelo1 and XNIF, with non-EIrA/B binding LEs, are able to still assemble a transport competent RNP remains to be determined.

A comparative analysis of isolated RNPs formed in vivo with XDE LE wt, mut1, mut2 versions and XVelo1 LE could yield insights into the conserved features of the proposed "RNP superstructure", and how this is recognized and coupled to the transport machinery. The possible function of ElrA/B, usually with several putative binding sites within an LE, in the localizing RNP could be to promote oligomerization of small RNPs to form the so-called RNP superstructure. Elr-type 
proteins have indeed been demonstrated to oligomerise on target RNA even as short as 20 nucleotides long (David et al., 2007; Fialcowitz-White et al., 2007), and in Fig 3.16B, ElrB1 also forms differently sized RNPs on XDE LE. Since it is not well understood precisely what defines localization elements, it is important to exclude the possibility that mutations introduced to create loss-function for ElrA/B, did not have indirect and non-specific effects besides that resulting from the loss of ElrA/B binding. The ability of XDE LE mut1 to still drive vegetal localization despite being extensively mutated and exhibiting only a reduced ElrA/B binding, argues against such view that the mutations introduced may have significant indirect effects such as those resulting from the disruption of secondary structural elements and binding sites of other proteins. The effect of the reduced binding of ElrA/B by XDE LE mut1 on its localization becomes visible when excess of competitor EBM (Elav binding motif - Fig 3.7C) is present (data not shown). The animal-vegetal contrast was observed to be weaker in the case of mut1 with EBM compared to mut1 without EBM; this indicates that reduced recruitment of Elr-type proteins could be tolerated in the robust RNP structure to drive vegetal localization.

The use of antisense morpholinos to block ElrA/B binding has confirmed the participation of Elr-type proteins in the events that lead to vegetal mRNA localization. It is interesting that individual MOs of just 25 bases in length were able to almost completely block ElrA/B binding, whilst introduction of point mutations in a single putative binding site was not sufficient to completely block binding. It is possible that the duplex formed by these MOs not only blocks the complementary sites but also affects binding to other sites through a mechanism that is not immediately clear.

\subsection{ElrA/B and translational control in oocytes}

$\mathrm{Hu} /$ Elav proteins also function in the regulation of translation under conditions where mRNA levels remain relatively unchanged; association of HuR with the 5 ' UTR of human IGF-IR mRNA have been shown to repress its translation, this repression effect was found to differ between cap- and IRES-dependent modes of translation (Meng et al., 2005). Similarly, the binding of HuR to the IRES (internal ribosomal entry site) within the $5^{\prime}$ UTR of p27 mRNA also leads to translation 
inhibition; the IRES is responsible for the elevation of p27 protein levels under conditions where cap-dependent translation is generally reduced.

HuR activates translation mostly by binding to the 3'UTR of mRNAs, such as p53 mRNA in response to UV irradiation (Mazan-Mamczarz et al., 2003). It appears, from what is known about translational control by Hu/Elav protein, that association with the $5^{\prime}$ UTR usually leads to inhibition, whilst $3^{\prime}$ UTR binding activates translation. However, association of HuR to the $5^{\prime}$ UTR and polypyrimidine track binding protein (PTB) to the $3^{\prime} \mathrm{UTR}$ of HIF1 $\alpha$ mRNA results in the activation of translation in response to hypoxia (Galban et al., 2008).

The binding of Elr-type proteins to the translational control element in the 3'-UTR of the vegetally localizing, maternal Xenopus Vg1 mRNA was reported to exert a repressing effect on its translation (Colegrove-Otero et al., 2005). Testing for the effect of Elr-type protein binding to the XDE LE localization element, a similar repressive activity could not be observed (Fig. 3.17B). What is clear from this study is that ablating the EIrA/B binding activity of XDE LE completely impairs its transport to the vegetal cortex, whilst the same mutation did not significantly alter the translatability of a reporter RNA harboring these mutant elements in the 3'UTR. Thus, it seems that the diverse functions of Elr-type proteins in Xenopus and those of their homologs in other biological systems are strictly contextdependent, which perhaps reflects their ability to cooperate with other proteins, such as with Vg1RBP in the process of mRNA localization.

ElrA/B proteins were found to upregulate translation by a moderate 2.5 fold (Fig. 3.17A), when tethered using the MS2 system to the 3' end of a reporter RNA in both stage III and VI oocytes. With this weak activation effect and the presence of considerably high amounts of translation repressors in ElrA/B RNPs, seems to contradict the idea that ElrB is responsible for the repression on $\mathrm{Vg} 1 \mathrm{mRNA}$ (Colegrove-Otero et al., 2005). It has long been thought that localized mRNAs are translationally repressed during transport (Lipshitz and Smibert, 2000), and as such the two processes seem to be mechanistically linked. Whilst this has been amply demonstrated with data from the Drosophila oocyte system, the same cannot be said for the Xenopus oocyte, since the XDE LE which localizes a 
reporter RNA does not have a significant effect on translation. In Drosophila oocytes, several translational repressors, e.g. Bruno (Chekulaeva et al., 2006), hrp48 (Huynh et al., 2004; Yano et al., 2004), specifically associate with and regulate localized mRNAs; the same notion does not hold true for Xenopus oocytes but rather translational repressors such FRGY2, Xp54 may regulate translation of both localized and non-localized mRNAs alike. This would support the suggestion that translational control of localized mRNAs in Xenopus oocytes may be the function of the FRGY2 masking proteins which are indeed detected as prominent components of the isolated putative localizing ElrA/B RNPs.

\subsection{EIrA/B and mRNA stability in oocytes}

Elav proteins exert their effect on mRNA stability by binding to AU rich motifs leading to a marked increase of the life-span of target mRNAs, which are rapidly degraded in the absence of binding (Fan et al., 1997; Fan and Steitz, 1998; Myer et al., 1997). Most of the target mRNAs of Hu/Elav encode key regulators of different biological processes; for instance, cell proliferation is affected by the stabilization of cyclin A and B1 (Wang et al., 2000a). DNA damage response leading to either cell survival or cell cycle arrest and apoptosis is also controlled by the post-transcriptional regulation of mRNAs, such as p21, by Hu/Elav proteins (Gorospe, 2003; Wang et al., 2000b). The Hu/Elav proteins also exert an effect on cell survival and viability through the regulation of levels of expression of factors like SIRT1 (Abdelmohsen et al., 2007). And in cancer cells, cellular properties, such as adhesion and invasiveness, needed for metastasis are acquired through overexpression of HuR which ensures the required high levels of B-actin protein expression (Dormoy-Raclet et al., 2007).

Reporter mRNAs mentioned in section 4.8 were also used to test for the effect of Elr-type protein binding on mRNA stability in Xenopus oocytes; however, no significant effect was observed. Levels of reporter mRNA showed no significant changes, both those used in the MS2 tethering assay analyzed by RT-qPCR (data not shown) and those reporters harboring the XDE LE and the mutant version in the 3'UTR analyzed by RPA (Fig 3.18). These analyses show in general that mRNA turnover in Xenopus oocytes is very slow, or that the ARE mediated mRNA decay does not operate in oocytes; levels of injected RNA were not observed to 
significantly change even over 3-4 days of culture. This is in sharp contrast to the situation observed in somatic cells, where, upon inhibition of transcription, levels of ARE containing mRNAs have been found to become markedly reduced in a matter of hours, when HuR expression was knocked down (Benjamin et al., 2006).

\subsection{Mutations inhibiting ElrA/B binding lead to a reduction in mRNA stability in PGCs}

Inhibition of ElrA/B binding was not observed to have a significant effect on mRNA stability in oocytes; however the mutant versions of XDE LE exhibited loss of the ability to selectively stabilize RNA in the PGCs compared to the wild type (Fig. 3.19). This is consistent with the notion that the overall mRNA turnover in oocyte is very slow if not entirely, as opposed to the interpretation that the Elr-type proteins do not influence mRNA stability in oocyte as they do in somatic cells (Brennan and Steitz, 2001). This result, showing a potential link between selective stabilization in PGCs and EIrA/B binding, provides further support for the view that Elr-type proteins are integral to the structure and function of the localizing RNP. A very important way of verifying evidence obtained from the oocytes implicating ElrA/B in vegetal mRNA localization, on the basis that there is a mechanistic link between the two processes (conserved RNP functions in both systems) as suggested by Koebernick et al, ( 2008).

It is a well known function of HuR protein that it stabilizes target mRNAs by antagonising the ARE mediated decay of these mRNAs; interestingly HuR has also been shown to be capable of relieving miRNA mediated repression of translation in response to cellular stress. This occurs in hepatic cells, by the mobilization of repressed mRNA, e.g. cationic amino acid transporter CAT-1 mRNA, stored in processing bodies into polysomes in response to amino acid starvation (Bhattacharyya et al., 2006). 


\subsection{Subcellular distribution of ElrA/B, a constitutive RNP component} throughout oogenesis

The fact that ElrA/B predominantly localized to the cytoplasm indicates that it may join the localizing RNP complex in the cytoplasm, as is the case for XStaufen1 and Prrp (Kress et al., 2004). But the rapid export of ElrA from the nucleus coupled with its low but perhaps significant levels in the nucleus makes it a possible scenario that an Elr-type protein is involved in the nuclear step of the vegetal mRNA localization as described for Vg1RBP and VgRBP60 (Kress et al., 2004). Vegetal cortex enrichment of the Elr-type proteins goes to confirm their active role in mRNA localization. EIrA/B RNPs seem to exist during the entire period of oogenesis; however a slight change in their mobility on glycerol was observed, which could be interpreted as changes in the RNP size/composition that reflect different functions at stages I-III and IV-VI of oogenesis. The marked decrease in the amount of Vg1RBP co-precipitating with ElrA/B protein in stage IV-VI could be consistent with this slightly reduced RNP size observed in late oocytes; but could also be due to the removal of ElrB proteins (the most abundant of the Elr-type proteins expressed in oocytes) from the oocytes at stages V-VI. 


\section{Summary}

Directional transport of specific mRNAs is a mechanism for the generation of asymmetry which is of primary biological importance. In Xenopus oocytes, mRNA localization to the vegetal cortex is important for germ layer formation and germ cell development. Using a biochemical purification approach for enriching localizing RNPs based on their large size, Xenopus Elr-type proteins which are in 4 isoforms, homologs of the Hu/ELAV proteins, were identified as novel components of the vegetal mRNA localization machinery.

They bind specifically to the localization elements of several different vegetally localizing Xenopus mRNAs of all three localization pathways and they are part of one RNP together with other localization proteins, such as Vg1RBP, XStaufen1, VgRBP60 and 40LoVe. Immuno-isolated ElrA/B RNPs reveal other interesting, novel components of the localizing RNPs, such as RAP42/46, XhermesR and SLBP2. In addition maternal mRNA masking proteins, namely FRGY2a/b and Xp54 were also identified implying that localized mRNAs may also be masked.

Blocking of Elr-type protein binding by either localization element mutagenesis or antisense morpholino oligonucleotides mediated masking of their target RNA sequences inhibits vegetal localization in Xenopus oocytes. ElrA/B proteins are predominantly cytoplasmic, with ElrA showing weak expression in the nucleus but perhaps joining the RNP complex in the nucleus. ElrA/B is also enriched at the vegetal cortex, a feature found to be similarly exhibited by the various localization proteins identified.

ElrA/B proteins were found to moderately upregulate translation, when tethered to the 3' UTR of a reporter mRNA in the oocytes, whilst XDE LE with mutations blocking ElrA/B binding has no significant alteration of translation. Analysis also shows ElrA/B binding to XDE LE has no significant effect on mRNA stability in the oocyte; however in the embryo, the mutant versions of XDE LE show reduce stability in PGCs compared to the wild type. 


\section{Literature References}

Abdelmohsen, K., Pullmann, R., Jr., Lal, A., Kim, H. H., Galban, S., Yang, X., Blethrow, J. D., Walker, M., Shubert, J., Gillespie, D. A. et al. (2007). Phosphorylation of HuR by Chk2 regulates SIRT1 expression. Mol Cell 25, 54357.

Abe, S. and Davies, E. (1986). Quantitative analysis of polysomes using a baseline from uncentrifuged blank gradients. Memoirs of the College of Agriculture, Ehime University 31, 187-199.

Afelik, S., Chen, Y. and Pieler, T. (2006). Combined ectopic expression of Pdx1 and Ptf1a/p48 results in the stable conversion of posterior endoderm into endocrine and exocrine pancreatic tissue. Genes Dev 20, 1441-6.

Ainger, K., Avossa, D., Morgan, F., Hill, S. J., Barry, C., Barbarese, E. and Carson, J. H. (1993). Transport and localization of exogenous myelin basic protein mRNA microinjected into oligodendrocytes. J Cell Biol 123, 431-41.

Allard, P., Yang, Q., Marzluff, W. F. and Clarke, H. J. (2005). The stem-loop binding protein regulates translation of histone mRNA during mammalian oogenesis. Dev Biol 286, 195-206.

Allison, R., Czaplinski, K., Git, A., Adegbenro, E., Stennard, F., Houliston, E. and Standart, N. (2004). Two distinct Staufen isoforms in Xenopus are vegetally localized during oogenesis. Rna 10, 1751-63.

Antic, D. and Keene, J. D. (1997). Embryonic lethal abnormal visual RNA-binding proteins involved in growth, differentiation, and posttranscriptional gene expression. Am J Hum Genet 61, 273-8.

Antic, D. and Keene, J. D. (1998). Messenger ribonucleoprotein complexes containing human ELAV proteins: interactions with cytoskeleton and translational apparatus. J Cell Sci 111 (Pt 2), 183-97.

Atasoy, U., Watson, J., Patel, D. and Keene, J. D. (1998). ELAV protein HuA (HuR) can redistribute between nucleus and cytoplasm and is upregulated during serum stimulation and T cell activation. J Cell Sci 111 (Pt 21), 3145-56.

Barbarese, E., Koppel, D. E., Deutscher, M. P., Smith, C. L., Ainger, K., Morgan, F. and Carson, J. H. (1995). Protein translation components are colocalized in granules in oligodendrocytes. J Cell Sci 108, 2781-90. 
Barkoff, A., Ballantyne, S. and Wickens, M. (1998). Meiotic maturation in Xenopus requires polyadenylation of multiple mRNAs. Embo J 17, 3168-75.

Bashirullah, A., Halsell, S. R., Cooperstock, R. L., Kloc, M., Karaiskakis, A., Fisher, W. W., Fu, W., Hamilton, J. K., Etkin, L. D. and Lipshitz, H. D. (1999). Joint action of two RNA degradation pathways controls the timing of maternal transcript elimination at the midblastula transition in Drosophila melanogaster. Embo J 18, 2610-20.

Bassell, G. J. and Kelic, S. (2004). Binding proteins for mRNA localization and local translation, and their dysfunction in genetic neurological disease. Curr Opin Neurobiol 14, 574-81.

Bassell, G. J., Oleynikov, Y. and Singer, R. H. (1999). The travels of mRNAs through all cells large and small. Faseb $\mathrm{J} 13,447-54$.

Benjamin, D., Colombi, M., Stoecklin, G. and Moroni, C. (2006). A GFP-based assay for monitoring post-transcriptional regulation of ARE-mRNA turnover. $\mathrm{Mol}$ Biosyst 2, 561-7.

Bertrand, E., Chartrand, P., Schaefer, M., Shenoy, S. M., Singer, R. H. and Long, R. M. (1998). Localization of ASH1 mRNA particles in living yeast. Mol Cell 2, 437-45.

Betley, J. N., Heinrich, B., Vernos, I., Sardet, C., Prodon, F. and Deshler, J. O. (2004). Kinesin II mediates Vg1 mRNA transport in Xenopus oocytes. Curr Biol 14, 219-24.

Bhattacharyya, S. N., Habermacher, R., Martine, U., Closs, E. I. and Filipowicz, W. (2006). Relief of microRNA-mediated translational repression in human cells subjected to stress. Cell 125, 1111-24.

Blum, H., Beier, H., and Gross, H.J. (1987). Improved silver staining of plant proteins, RNA and DNA in polyacrylamide gels. Electrophoresis 8, 93-99.

Brennan, C. M. and Steitz, J. A. (2001). HuR and mRNA stability. Cell Mol Life Sci 58, 266-77.

Bubunenko, M., Kress, T. L., Vempati, U. D., Mowry, K. L. and King, M. L. (2002). A consensus RNA signal that directs germ layer determinants to the vegetal cortex of Xenopus oocytes. Dev Biol 248, 82-92.

Campos, A. R., Grossman, D. and White, K. (1985). Mutant alleles at the locus elav in Drosophila melanogaster lead to nervous system defects. A developmental-genetic analysis. J Neurogenet 2, 197-218. 
Carpenter, C. D., Bruskin, A. M., Spain, L. M., Eldon, E. D. and Klein, W. H. (1982). The 3' untranslated regions of two related mRNAs contain an element highly repeated in the sea urchin genome. Nucleic Acids Res 10, 7829-42.

Castagnetti, S., Hentze, M. W., Ephrussi, A. and Gebauer, F. (2000). Control of oskar mRNA translation by Bruno in a novel cell-free system from Drosophila ovaries. Development 127, 1063-8.

Chan, A. P., Kloc, M. and Etkin, L. D. (1999). fatvg encodes a new localized RNA that uses a 25-nucleotide element (FVLE1) to localize to the vegetal cortex of Xenopus oocytes. Development 126, 4943-53.

Chang, J. S., Tan, L. and Schedl, P. (1999). The Drosophila CPEB homolog, orb, is required for oskar protein expression in oocytes. Dev Biol 215, 91-106.

Chang, P., Torres, J., Lewis, R. A., Mowry, K. L., Houliston, E. and King, M. L. (2004). Localization of RNAs to the mitochondrial cloud in Xenopus oocytes through entrapment and association with endoplasmic reticulum. Mol Biol Cell 15, 4669-81.

Chartrand, P., Singer, R. H. and Long, R. M. (2001). RNP localization and transport in yeast. Annu Rev Cell Dev Biol 17, 297-310.

Chekulaeva, M., Hentze, M. W. and Ephrussi, A. (2006). Bruno acts as a dual repressor of oskar translation, promoting mRNA oligomerization and formation of silencing particles. Cell 124, 521-33.

Choo, S., Heinrich, B., Betley, J. N., Chen, Z. and Deshler, J. O. (2005). Evidence for common machinery utilized by the early and late RNA localization pathways in Xenopus oocytes. Dev Biol 278, 103-17.

Chung, S., Jiang, L., Cheng, S. and Furneaux, H. (1996). Purification and properties of HuD, a neuronal RNA-binding protein. J Biol Chem 271, 11518-24.

Claussen, M. (2002). Identifizierung und funktionelle Charakterisierung von vegetal lokalisierten RNAs in der Xenopus laevis Oozyte. In Dept. of Developmental Biochemistry, vol. PhD (ed., pp. 156. Göttingen: Georg-AugustUniversität Göttingen.

Claussen, M., Horvay, K. and Pieler, T. (2004). Evidence for overlapping, but not identical, protein machineries operating in vegetal RNA localization along early and late pathways in Xenopus oocytes. Development 131, 4263-73. 
Claussen, M. and Pieler, T. (2004). Xvelo1 uses a novel 75-nucleotide signal sequence that drives vegetal localization along the late pathway in Xenopus oocytes. Dev Biol 266, 270-84.

Colegrove-Otero, L. J., Devaux, A. and Standart, N. (2005). The Xenopus ELAV protein ElrB represses Vg1 mRNA translation during oogenesis. Mol Cell Biol 25, 9028-39.

Collombat, P., Mansouri, A., Hecksher-Sorensen, J., Serup, P., Krull, J., Gradwohl, G. and Gruss, P. (2003). Opposing actions of Arx and Pax4 in endocrine pancreas development. Genes Dev 17, 2591-603.

Cooper, G. M. (2000). The Cell: A Molecular Approach. Sunderland, Missachusetts.

Cote, C. A., Gautreau, D., Denegre, J. M., Kress, T. L., Terry, N. A. and Mowry, K. L. (1999). A Xenopus protein related to hnRNP I has a role in cytoplasmic RNA localization. Mol Cell 4, 431-7.

Cougot, N., Babajko, S. and Seraphin, B. (2004). Cytoplasmic foci are sites of mRNA decay in human cells. J Cell Biol 165, 31-40.

Coutinho-Mansfield, G. C., Xue, Y., Zhang, Y. and Fu, X. D. (2007). PTB/nPTB switch: a post-transcriptional mechanism for programming neuronal differentiation. Genes Dev 21, 1573-7.

Cummings, A., Barrett, P. and Sommerville, J. (1989). Multiple modifications in the phosphoproteins bound to stored messenger RNA in Xenopus oocytes. Biochim Biophys Acta 1014, 319-26.

Czaplinski, K., Kocher, T., Schelder, M., Segref, A., Wilm, M. and Mattaj, I. W. (2005). Identification of $40 \mathrm{LoVe}$, a Xenopus hnRNP D family protein involved in localizing a TGF-beta-related mRNA during oogenesis. Dev Cell 8, 505-15.

Czaplinski, K. and Mattaj, I. W. (2006). 40LoVe interacts with Vg1RBP/Vera and hnRNP I in binding the Vg1-localization element. Rna 12, 213-22.

Dahm, R. and Kiebler, M. (2005). Cell biology: silenced RNA on the move. Nature 438, 432-5.

David, P. S., Tanveer, R. and Port, J. D. (2007). FRET-detectable interactions between the ARE binding proteins, HuR and p37AUF1. Rna 13, 1453-68.

Deshler, J. O., Highett, M. I., Abramson, T. and Schnapp, B. J. (1998). A highly conserved RNA-binding protein for cytoplasmic mRNA localization in vertebrates. Curr Biol 8, 489-96. 
Deshler, J. O., Highett, M. I. and Schnapp, B. J. (1997). Localization of Xenopus Vg1 mRNA by Vera protein and the endoplasmic reticulum. Science 276, 1128-31.

Dormoy-Raclet, V., Menard, I., Clair, E., Kurban, G., Mazroui, R., Di Marco, S., von Roretz, C., Pause, A. and Gallouzi, I. E. (2007). The RNA-binding protein HuR promotes cell migration and cell invasion by stabilizing the beta-actin mRNA in a U-rich-element-dependent manner. Mol Cell Biol 27, 5365-80.

Dreier, B. (2005). Identifizierung und funktionelle Charakterisierung von velo45, einer vegetal lokalisierten mRNA in Xenopus laevis Oozyten. In Dept. Developmental Biochemistry, vol. Diploma (ed., pp. 129. Göttingen: Georg-August-Universität Göttingen.

Driever, W. and Nusslein-Volhard, C. (1988a). The bicoid protein determines position in the Drosophila embryo in a concentration-dependent manner. Cell 54, 95-104.

Driever, W. and Nusslein-Volhard, C. (1988b). A gradient of bicoid protein in Drosophila embryos. Cell 54, 83-93.

Driever, W., Siegel, V. and Nusslein-Volhard, C. (1990). Autonomous determination of anterior structures in the early Drosophila embryo by the bicoid morphogen. Development 109, 811-20.

Dumont, J. N. (1972). Oogenesis in Xenopus laevis (Daudin). I. Stages of oocyte development in laboratory maintained animals. J Morphol 136, 153-79.

Duval, C., Bouvet, P., Omilli, F., Roghi, C., Dorel, C., LeGuellec, R., Paris, J. and Osborne, H. B. (1990). Stability of maternal mRNA in Xenopus embryos: role of transcription and translation. Mol Cell Biol 10, 4123-9.

Elisha, Z., Havin, L., Ringel, I. and Yisraeli, J. K. (1995). Vg1 RNA binding protein mediates the association of Vg1 RNA with microtubules in Xenopus oocytes. Embo J 14, 5109-14.

Eom, T., Antar, L. N., Singer, R. H. and Bassell, G. J. (2003). Localization of a beta-actin messenger ribonucleoprotein complex with zipcode-binding protein modulates the density of dendritic filopodia and filopodial synapses. $J$ Neurosci 23, 10433-44.

Fan, X. C., Myer, V. E. and Steitz, J. A. (1997). AU-rich elements target small nuclear RNAs as well as mRNAs for rapid degradation. Genes Dev 11, 2557-68. 
Fan, X. C. and Steitz, J. A. (1998). Overexpression of HuR, a nuclearcytoplasmic shuttling protein, increases the in vivo stability of ARE-containing mRNAs. Embo J 17, 3448-60.

Ferrandon, D., Elphick, L., Nusslein-Volhard, C. and St Johnston, D. (1994). Staufen protein associates with the 3'UTR of bicoid mRNA to form particles that move in a microtubule-dependent manner. Cell 79, 1221-32.

Ferrandon, D., Koch, I., Westhof, E. and Nusslein-Volhard, C. (1997). RNARNA interaction is required for the formation of specific bicoid mRNA 3' UTRSTAUFEN ribonucleoprotein particles. Embo J 16, 1751-8.

Fialcowitz-White, E. J., Brewer, B. Y., Ballin, J. D., Willis, C. D., Toth, E. A. and Wilson, G. M. (2007). Specific protein domains mediate cooperative assembly of HuR oligomers on AU-rich mRNA-destabilizing sequences. $\mathrm{J}$ Biol Chem 282, 20948-59.

Forrest, K. M. and Gavis, E. R. (2003). Live imaging of endogenous RNA reveals a diffusion and entrapment mechanism for nanos mRNA localization in Drosophila. Curr Biol 13, 1159-68.

Fromont-Racine, M., Senger, B., Saveanu, C. and Fasiolo, F. (2003). Ribosome assembly in eukaryotes. Gene 313, 17-42.

Galban, S., Kuwano, Y., Pullmann, R., Jr., Martindale, J. L., Kim, H. H., Lal, A., Abdelmohsen, K., Yang, X., Dang, Y., Liu, J. O. et al. (2008). RNA-binding proteins HuR and PTB promote the translation of hypoxia-inducible factor 1 alpha. Mol Cell Biol 28, 93-107.

Gao, F. B. and Keene, J. D. (1996). Hel-N1/Hel-N2 proteins are bound to poly $(A)+m R N A$ in granular RNP structures and are implicated in neuronal differentiation. J Cell Sci 109 (Pt 3), 579-89.

Gard, D. L., Cha, B. J. and King, E. (1997). The organization and animal-vegetal asymmetry of cytokeratin filaments in stage VI Xenopus oocytes is dependent upon F-actin and microtubules. Dev Biol 184, 95-114.

Gavis, E. R., Lunsford, L., Bergsten, S. E. and Lehmann, R. (1996). A conserved 90 nucleotide element mediates translational repression of nanos RNA. Development 122, 2791-800.

Geng, C. and Macdonald, P. M. (2006). Imp associates with squid and Hrp48 and contributes to localized expression of gurken in the oocyte. Mol Cell Biol 26, 9508-16. 
Gilbert, S. F. (2000). Developmental Biology. Sunderland, Massachusetts: SINAUER ASSOCIATES, INC.

Gillian-Daniel, D. L., Gray, N. K., Astrom, J., Barkoff, A. and Wickens, M. (1998). Modifications of the 5 ' cap of mRNAs during Xenopus oocyte maturation: independence from changes in poly $(\mathrm{A})$ length and impact on translation. Mol Cell Biol 18, 6152-63.

Git, A. and Standart, N. (2002). The KH domains of Xenopus Vg1RBP mediate RNA binding and self- association. Rna 8, 1319-33.

Gonsalvez, G. B., Urbinati, C. R. and Long, R. M. (2005). RNA localization in yeast: moving towards a mechanism. Biol Cell 97, 75-86.

Good, P. J. (1995). A conserved family of elav-like genes in vertebrates. Proc Natl Acad Sci U S A 92, 4557-61.

Gorg, A., Weiss, W. and Dunn, M. J. (2004). Current two-dimensional electrophoresis technology for proteomics. Proteomics 4, 3665-85.

Gorospe, M. (2003). HuR in the mammalian genotoxic response: posttranscriptional multitasking. Cell Cycle 2, 412-4.

Groisman, I., Huang, Y. S., Mendez, R., Cao, Q., Theurkauf, W. and Richter, J. D. (2000). CPEB, maskin, and cyclin B1 mRNA at the mitotic apparatus: implications for local translational control of cell division. Cell 103, 435-47.

Gu, W., Deng, Y., Zenklusen, D. and Singer, R. H. (2004). A new yeast PUF family protein, Puf6p, represses ASH1 mRNA translation and is required for its localization. Genes Dev 18, 1452-65.

Gu, W., Pan, F., Zhang, H., Bassell, G. J. and Singer, R. H. (2002). A predominantly nuclear protein affecting cytoplasmic localization of beta-actin mRNA in fibroblasts and neurons. $J$ Cell Biol 156, 41-51.

Gunkel, N., Yano, T., Markussen, F. H., OIsen, L. C. and Ephrussi, A. (1998). Localization-dependent translation requires a functional interaction between the $5^{\prime}$ and 3' ends of oskar mRNA. Genes Dev 12, 1652-64.

Guraya, S. S. (1979). Recent advances in the morphology, cytochemistry, and function of Balbiani's vitelline body in animal oocytes. Int Rev Cytol 59, 249-321.

Hachet, O. and Ephrussi, A. (2004). Splicing of oskar RNA in the nucleus is coupled to its cytoplasmic localization. Nature 428, 959-63.

Harland, R. M. (1991). In situ hybridization: an improved whole-mount method for Xenopus embryos. Methods Cell Biol 36, 685-95. 
Hausen, P. and Riebesell, M. (1991). The Early Development of Xenopus Laevis. Heidelberg - Germany: Springer-Verlag.

Havin, L., Git, A., Elisha, Z., Oberman, F., Yaniv, K., Schwartz, S. P., Standart, N. and Yisraeli, J. K. (1998). RNA-binding protein conserved in both microtubuleand microfilament- based RNA localization. Genes Dev 12, 1593-8.

Hentze, M. W. (1994). Enzymes as RNA-binding proteins: a role for (di)nucleotide-binding domains? Trends Biochem Sci 19, 101-3.

Ho, S. N., Hunt, H. D., Horton, R. M., Pullen, J. K. and Pease, L. R. (1989). Site-directed mutagenesis by overlap extension using the polymerase chain reaction. Gene 77, 51-9.

Hollemann, T., Panitz, F. and Pieler, T. (1999). In situ Hybridization Techniques with Xenopus Embryos. In A Comparative Methods Approach to the Study of Oocytes and Embryos, (ed. J. D. Richter), pp. 279-290. Oxford: Oxford University Press Inc.

Horb, M. E. and Thomsen, G. H. (1997). A vegetally localized T-box transcription factor in Xenopus eggs specifies mesoderm and endoderm and is essential for embryonic mesoderm formation. Development 124, 1689-98.

Horvay, K. (2005). Identifizierung neuer vegetal lokalisierter RNAs in der Xenopus laevis Oozyte und deren funktionelle Charakterisierung. In Dept. of Developmental Biochemistry, vol. PhD (ed., pp. 143. Göttingen: Geord-August Universität Göttingen.

Horvay, K., Claussen, M., Katzer, M., Landgrebe, J. and Pieler, T. (2006). Xenopus Dead end mRNA is a localized maternal determinant that serves a conserved function in germ cell development. Dev Biol 291, 1-11.

Houston, D. W., Zhang, J., Maines, J. Z., Wasserman, S. A. and King, M. L. (1998). A Xenopus DAZ-like gene encodes an RNA component of germ plasm and is a functional homologue of Drosophila boule. Development 125, 171-80.

Huang, Y. S., Carson, J. H., Barbarese, E. and Richter, J. D. (2003). Facilitation of dendritic mRNA transport by CPEB. Genes Dev 17, 638-53.

Hudson, C. and Woodland, H. R. (1998). Xpat, a gene expressed specifically in germ plasm and primordial germ cells of Xenopus laevis. Mech Dev 73, 159-68. 
Huttelmaier, S., Zenklusen, D., Lederer, M., Dictenberg, J., Lorenz, M., Meng, X., Bassell, G. J., Condeelis, J. and Singer, R. H. (2005). Spatial regulation of beta-actin translation by Src-dependent phosphorylation of ZBP1. Nature 438, 512-5.

Huynh, J. R., Munro, T. P., Smith-Litiere, K., Lepesant, J. A. and St Johnston, D. (2004). The Drosophila hnRNPA/B homolog, Hrp48, is specifically required for a distinct step in osk mRNA localization. Dev Cell 6, 625-35.

Irion, U. and St Johnston, D. (2007). bicoid RNA localization requires specific binding of an endosomal sorting complex. Nature 445, 554-8.

Jahn, O., Hesse, D., Reinelt, M. and Kratzin, H. D. (2006). Technical innovations for the automated identification of gel-separated proteins by MALDITOF mass spectrometry. Anal Bioanal Chem 386, 92-103.

Jansen, R. P. (2001). mRNA localization: message on the move. Nat Rev Mol Cell Biol 2, 247-56.

Jenny, A., Hachet, O., Zavorszky, P., Cyrklaff, A., Weston, M. D., Johnston, D. S., Erdelyi, M. and Ephrussi, A. (2006). A translation-independent role of oskar RNA in early Drosophila oogenesis. Development 133, 2827-33.

Jonson, L., Vikesaa, J., Krogh, A., Nielsen, L. K., Hansen, T., Borup, R., Johnsen, A. H., Christiansen, J. and Nielsen, F. C. (2007). Molecular composition of IMP1 ribonucleoprotein granules. Mol Cell Proteomics 6, 798-811.

Kasashima, K., Terashima, K., Yamamoto, K., Sakashita, E. and Sakamoto, H. (1999). Cytoplasmic localization is required for the mammalian ELAV-like protein HuD to induce neuronal differentiation. Genes Cells 4, 667-83.

Kedersha, N. L., Miquel, M. C., Bittner, D. and Rome, L. H. (1990). Vaults. II. Ribonucleoprotein structures are highly conserved among higher and lower eukaryotes. J Cell Biol 110, 895-901.

Kedersha, N. L. and Rome, L. H. (1986). Isolation and characterization of a novel ribonucleoprotein particle: large structures contain a single species of small RNA. J Cell Biol 103, 699-709.

Keene, J. D. (2007). RNA regulons: coordination of post-transcriptional events. Nat Rev Genet 8, 533-43.

Kenan, D. J., Query, C. C. and Keene, J. D. (1991). RNA recognition: towards identifying determinants of specificity. Trends Biochem Sci 16, 214-20. 
Kiebler, M. A., Hemraj, I., Verkade, P., Kohrmann, M., Fortes, P., Marion, R. M., Ortin, J. and Dotti, C. G. (1999). The mammalian staufen protein localizes to the somatodendritic domain of cultured hippocampal neurons: implications for its involvement in mRNA transport. J Neurosci 19, 288-97.

King, M. L., Messitt, T. J. and Mowry, K. L. (2005). Putting RNAs in the right place at the right time: RNA localization in the frog oocyte. Biol Cell 97, 19-33.

Kloc, M., Bilinski, S., Chan, A. P., Allen, L. H., Zearfoss, N. R. and Etkin, L. D. (2001). RNA localization and germ cell determination in Xenopus. Int Rev Cytol 203, 63-91.

Kloc, M., Bilinski, S., Pui-Yee Chan, A. and Etkin, L. D. (2000). The targeting of Xcat2 mRNA to the germinal granules depends on a cis- acting germinal granule localization element within the 3'UTR. Dev Biol 217, 221-9.

Kloc, M. and Chan, A. P. (2007). Centroid, a novel putative DEAD-box RNA helicase maternal mRNA, is localized in the mitochondrial cloud in Xenopus laevis oocytes. Int J Dev Biol 51, 701-6.

Kloc, M., Dougherty, M. T., Bilinski, S., Chan, A. P., Brey, E., King, M. L., Patrick, C. W., Jr. and Etkin, L. D. (2002a). Three-Dimensional Ultrastructural Analysis of RNA Distribution within Germinal Granules of Xenopus. Dev Biol 241, 79-93.

Kloc, M. and Etkin, L. D. (1998). Apparent continuity between the messenger transport organizer and late RNA localization pathways during oogenesis in Xenopus. Mech Dev 73, 95-106.

Kloc, M. and Etkin, L. D. (1999). Analysis of Localized RNAs in Xenopus Oocytes. In A Comparative Methods Approach to the Study of Oocytes and Embryos, (ed. J. D. Richter), pp. 256-278. Oxford: Oxford University Press Inc.

Kloc, M., Larabell, C., Chan, A. P. and Etkin, L. D. (1998). Contribution of METRO pathway localized molecules to the organization of the germ cell lineage. Mech Dev 75, 81-93.

Kloc, M., Larabell, C. and Etkin, L. D. (1996). Elaboration of the messenger transport organizer pathway for localization of RNA to the vegetal cortex of Xenopus oocytes. Dev Biol 180, 119-30.

Kloc, M., Spohr, G. and Etkin, L. D. (1993). Translocation of repetitive RNA sequences with the germ plasm in Xenopus oocytes. Science 262, 1712-4. 
Kloc, M., Wilk, K., Vargas, D., Shirato, Y., Bilinski, S. and Etkin, L. D. (2005). Potential structural role of non-coding and coding RNAs in the organization of the cytoskeleton at the vegetal cortex of Xenopus oocytes. Development 132, 344557.

Kloc, M., Zearfoss, N. R. and Etkin, L. D. (2002b). Mechanisms of subcellular mRNA localization. Cell 108, 533-44.

Koebernick, K. J. L., Patrick Arthur, Katsiaryna Tarbashevich and Pieler, T. (submitted 2008). A novel role for vegetal RNA localization in the selective protection of Xenopus germline mRNAs from miRNA-mediated decay.

Kofron, M., Demel, T., Xanthos, J., Lohr, J., Sun, B., Sive, H., Osada, S., Wright, C., Wylie, C. and Heasman, J. (1999). Mesoderm induction in Xenopus is a zygotic event regulated by maternal VegT via TGFbeta growth factors. Development 126, 5759-70.

Kolev, N. G. and Huber, P. W. (2003). VgRBP71 Stimulates Cleavage at a Polyadenylation Signal in Vg1 mRNA, Resulting in the Removal of a cis-Acting Element that Represses Translation. Mol Cell 11, 745-55.

Kosturko, L. D., Maggipinto, M. J., Korza, G., Lee, J. W., Carson, J. H. and Barbarese, E. (2006). Heterogeneous nuclear ribonucleoprotein (hnRNP) E1 binds to hnRNP A2 and inhibits translation of $A 2$ response element mRNAs. Mol Biol Cell 17, 3521-33.

Kress, T. L., Yoon, Y. J. and Mowry, K. L. (2004). Nuclear RNP complex assembly initiates cytoplasmic RNA localization. J Cell Biol 165, 203-11.

Kroll, T. T., Zhao, W. M., Jiang, C. and Huber, P. W. (2002). A homolog of FBP2/KSRP binds to localized mRNAs in Xenopus oocytes. Development 129, 5609-19.

Ku, M. and Melton, D. A. (1993). Xwnt-11: a maternally expressed Xenopus wnt gene. Development 119, 1161-73.

Kwon, S., Abramson, T., Munro, T. P., John, C. M., Kohrmann, M. and Schnapp, B. J. (2002). UUCAC- and Vera-Dependent Localization of VegT RNA in Xenopus Oocytes. Curr Biol 12, 558-64.

Kyrpides, N. C. and Ouzounis, C. A. (1995). Nucleic acid-binding metabolic enzymes: living fossils of stereochemical interactions? J Mol Evol 40, 564-9. 
Ladomery, M., Wade, E. and Sommerville, J. (1997). Xp54, the Xenopus homologue of human RNA helicase p54, is an integral component of stored mRNP particles in oocytes. Nucleic Acids Res 25, 965-73.

Laemmli, U. K. (1970). Cleavage of structural proteins during the assembly of the head of bacteriophage T4. Nature 227, 680-5.

Lane, M. E. and Kalderon, D. (1994). RNA localization along the anteroposterior axis of the Drosophila oocyte requires PKA-mediated signal transduction to direct normal microtubule organization. Genes Dev 8, 2986-95.

Lecuyer, E., Yoshida, H., Parthasarathy, N., Alm, C., Babak, T., Cerovina, T., Hughes, T. R., Tomancak, P. and Krause, H. M. (2007). Global analysis of mRNA localization reveals a prominent role in organizing cellular architecture and function. Cell 131, 174-87.

Lehmann, R. and Ephrussi, A. (1994). Germ plasm formation and germ cell determination in Drosophila. Ciba Found Symp 182, 282-96.

Lewis, R. A., Gagnon, J. A. and Mowry, K. L. (2007). PTB/hnRNP I is Required for RNP Remodeling during RNA Localization in Xenopus Oocytes. Mol Cell Biol.

Lewis, R. A., Kress, T. L., Cote, C. A., Gautreau, D., Rokop, M. E. and Mowry, K. L. (2004). Conserved and clustered RNA recognition sequences are a critical feature of signals directing RNA localization in Xenopus oocytes. Mech Dev 121, 101-9.

Lipshitz, H. D. and Smibert, C. A. (2000). Mechanisms of RNA localization and translational regulation. Curr Opin Genet Dev 10, 476-88.

Mansfield, J. H., Wilhelm, J. E. and Hazelrigg, T. (2002). Ypsilon Schachtel, a Drosophila Y-box protein, acts antagonistically to Orb in the oskar mRNA localization and translation pathway. Development 129, 197-209.

Matsumoto, K. and Wolffe, A. P. (1998). Gene regulation by Y-box proteins: coupling control of transcription and translation. Trends Cell Biol 8, 318-23.

Mazan-Mamczarz, K., Galban, S., Lopez de Silanes, I., Martindale, J. L., Atasoy, U., Keene, J. D. and Gorospe, M. (2003). RNA-binding protein HuR enhances p53 translation in response to ultraviolet light irradiation. Proc Natl Acad Sci U S A 100, 8354-9.

Melton, D. A. (1987). Translocation of a localized maternal mRNA to the vegetal pole of Xenopus oocytes. Nature 328, 80-2. 
Melton, D. A., Ruiz i Altaba, A., Yisraeli, J. and Sokol, S. (1989). Localization of mRNA and axis formation during Xenopus embryogenesis. Ciba Found Symp 144, 16-29.

Meng, Z., King, P. H., Nabors, L. B., Jackson, N. L., Chen, C. Y., Emanuel, P. D. and Blume, S. W. (2005). The ELAV RNA-stability factor HuR binds the 5'untranslated region of the human IGF-IR transcript and differentially represses cap-dependent and IRES-mediated translation. Nucleic Acids Res 33, 2962-79.

Merlie, J. P. and Sanes, J. R. (1985). Concentration of acetylcholine receptor mRNA in synaptic regions of adult muscle fibres. Nature $317,66-8$.

Micklem, D. R., Adams, J., Grunert, S. and St Johnston, D. (2000). Distinct roles of two conserved Staufen domains in oskar mRNA localization and translation. Embo J 19, 1366-77.

Min, H., Turck, C. W., Nikolic, J. M. and Black, D. L. (1997). A new regulatory protein, KSRP, mediates exon inclusion through an intronic splicing enhancer. Genes Dev 11, 1023-36.

Minshall, N., Reiter, M. H., Weil, D. and Standart, N. (2007). CPEB interacts with an ovary-specific elF4E and 4E-T in early Xenopus oocytes. J Biol Chem.

Minshall, N. and Standart, N. (2004). The active form of Xp54 RNA helicase in translational repression is an RNA-mediated oligomer. Nucleic Acids Res 32 , 1325-34.

Morris, R. L. and Hollenbeck, P. J. (1995). Axonal transport of mitochondria along microtubules and F-actin in living vertebrate neurons. J Cell Biol 131, 131526.

Mosquera, L., Forristall, C., Zhou, Y. and King, M. L. (1993). A mRNA localized to the vegetal cortex of Xenopus oocytes encodes a protein with a nanos-like zinc finger domain. Development 117, 377-86.

Mowry, K. L. (1996). Complex formation between stage-specific oocyte factors and a Xenopus mRNA localization element. Proc Natl Acad Sci U S A 93, 1460813.

Mowry, K. L. and Melton, D. A. (1992). Vegetal messenger RNA localization directed by a 340-nt RNA sequence element in Xenopus oocytes. Science 255 , 991-4. 
Munro, T. P., Kwon, S., Schnapp, B. J. and St Johnston, D. (2006). A repeated IMP-binding motif controls oskar mRNA translation and anchoring independently of Drosophila melanogaster IMP. J Cell Biol 172, 577-88.

Myer, V. E., Fan, X. C. and Steitz, J. A. (1997). Identification of HuR as a protein implicated in AUUUA-mediated mRNA decay. Embo J 16, 2130-9.

Nagy, E. and Rigby, W. F. (1995). Glyceraldehyde-3-phosphate dehydrogenase selectively binds AU-rich RNA in the $\mathrm{NAD}(+)$-binding region (Rossmann fold). $J$ Biol Chem 270, 2755-63.

Nakamura, A., Amikura, R., Hanyu, K. and Kobayashi, S. (2001). Me31B silences translation of oocyte-localizing RNAs through the formation of cytoplasmic RNP complex during Drosophila oogenesis. Development 128, 323342.

Neuhoff V., S. R., Eibl H. (1985). Clear background and highly sensitive protein staining with Coomassie Blue dyes in polyacrylamide gels: A systematic analysis. Electrophoresis 6, 427-448.

Nilsson, J., Sengupta, J., Frank, J. and Nissen, P. (2004). Regulation of eukaryotic translation by the RACK1 protein: a platform for signalling molecules on the ribosome. EMBO Rep 5, 1137-41.

Nover, L., Scharf, K. D. and Neumann, D. (1989). Cytoplasmic heat shock granules are formed from precursor particles and are associated with a specific set of mRNAs. Mol Cell Biol 9, 1298-308.

Otero, L. J., Devaux, A. and Standart, N. (2001). A 250-nucleotide UA-rich element in the 3' untranslated region of Xenopus laevis $\mathrm{Vg} 1$ mRNA represses translation both in vivo and in vitro. Rna 7, 1753-67.

Pannese, M., Cagliani, R., Pardini, C. L. and Boncinelli, E. (2000). Xotx1 maternal transcripts are vegetally localized in Xenopus laevis oocytes. Mech Dev 90, 111-4.

Pfeiffer, D. C. and Gard, D. L. (1999). Microtubules in Xenopus oocytes are oriented with their minus-ends towards the cortex. Cell Motil Cytoskeleton 44, 3443.

Pioli, P. A., Hamilton, B. J., Connolly, J. E., Brewer, G. and Rigby, W. F. (2002). Lactate dehydrogenase is an AU-rich element-binding protein that directly interacts with AUF1. J Biol Chem 277, 35738-45. 
Rand, K. and Yisraeli, J. K. (2007). Vg1 RNA localization in oocytes in the absence of xVICKZ3 RNA-binding activity. Differentiation 75, 566-74.

Rebagliati, M. R., Weeks, D. L., Harvey, R. P. and Melton, D. A. (1985). Identification and cloning of localized maternal RNAs from Xenopus eggs. Cell 42 , 769-77.

Reumann, S., Babujee, L., Ma, C., Wienkoop, S., Siemsen, T., Antonicelli, G. E., Rasche, N., Luder, F., Weckwerth, W. and Jahn, O. (2007). Proteome Analysis of Arabidopsis Leaf Peroxisomes Reveals Novel Targeting Peptides, Metabolic Pathways, and Defense Mechanisms. Plant Cell.

Ross, A. F., Oleynikov, Y., Kislauskis, E. H., Taneja, K. L. and Singer, R. H. (1997). Characterization of a beta-actin mRNA zipcode-binding protein. Mol Cell Biol 17, 2158-65.

Rudt, F. and Pieler, T. (1996). Cytoplasmic retention and nuclear import of $5 S$ ribosomal RNA containing RNPs. Embo J 15, 1383-91. abs.html.

Rupp, R. A., Snider, L. and Weintraub, H. (1994). Xenopus embryos regulate the nuclear localization of XMyoD. Genes Dev 8, 1311-23.

Ruzanov, P. V., Evdokimova, V. M., Korneeva, N. L., Hershey, J. W. and Ovchinnikov, L. P. (1999). Interaction of the universal mRNA-binding protein, p50, with actin: a possible link between mRNA and microfilaments. J Cell Sci 112 (Pt 20), 3487-96.

Sambrook, J., Fritsch, E. F. and Maniatis, T. (1998). Molecular cloning. A laboratory manual. Cold Spring Harbor: CSH Press.

Sarkar, B., Xi, Q., He, C. and Schneider, R. J. (2003). Selective degradation of AU-rich mRNAs promoted by the p37 AUF1 protein isoform. Mol Cell Biol 23, 6685-93.

Schuldt, A. J., Adams, J. H., Davidson, C. M., Micklem, D. R., Haseloff, J., St Johnston, D. and Brand, A. H. (1998). Miranda mediates asymmetric protein and RNA localization in the developing nervous system. Genes Dev 12, 1847-57.

Schupbach, T. and Wieschaus, E. (1986). Germline autonomy of maternal-effect mutations altering the embryonic body pattern of Drosophila. Dev Biol 113, 443-8.

Sengupta, J., Nilsson, J., Gursky, R., Spahn, C. M., Nissen, P. and Frank, J. (2004). Identification of the versatile scaffold protein RACK1 on the eukaryotic ribosome by cryo-EM. Nat Struct Mol Biol 11, 957-62. 
Sheets, M. D., Fox, C. A., Hunt, T., Vande Woude, G. and Wickens, M. (1994). The 3'-untranslated regions of c-mos and cyclin mRNAs stimulate translation by regulating cytoplasmic polyadenylation. Genes Dev 8, 926-38.

Sheets, M. D., Wu, M. and Wickens, M. (1995). Polyadenylation of c-mos mRNA as a control point in Xenopus meiotic maturation. Nature 374, 511-6.

Shor, B., Calaycay, J., Rushbrook, J. and McLeod, M. (2003). Cpc2/RACK1 is a ribosome-associated protein that promotes efficient translation in Schizosaccharomyces pombe. J Biol Chem 278, 49119-28.

Smibert, C. A., Lie, Y. S., Shillinglaw, W., Henzel, W. J. and Macdonald, P. M. (1999). Smaug, a novel and conserved protein, contributes to repression of nanos mRNA translation in vitro. Rna 5, 1535-47.

Smibert, C. A., Wilson, J. E., Kerr, K. and Macdonald, P. M. (1996). smaug protein represses translation of unlocalized nanos mRNA in the Drosophila embryo. Genes Dev 10, 2600-9.

Smillie, D. A. and Sommerville, J. (2002). RNA helicase p54 (DDX6) is a shuttling protein involved in nuclear assembly of stored mRNP particles. J Cell Sci 115, 395-407.

Smith, R. (2004). Moving molecules: mRNA trafficking in Mammalian oligodendrocytes and neurons. Neuroscientist 10, 495-500.

Smykal, P., Hrdy, I. and Pechan, P. M. (2000). High-molecular-mass complexes formed in vivo contain smHSPs and HSP70 and display chaperone-like activity. Eur J Biochem 267, 2195-207.

Sommerville, J. and Ladomery, M. (1996a). Masking of mRNA by Y-box proteins. Faseb J 10, 435-43.

Sommerville, J. and Ladomery, M. (1996b). Transcription and masking of mRNA in germ cells: involvement of $Y$-box proteins. Chromosoma 104, 469-78.

Song, H. W., Cauffman, K., Chan, A. P., Zhou, Y., King, M. L., Etkin, L. D. and Kloc, M. (2007). Hermes RNA-binding protein targets RNAs-encoding proteins involved in meiotic maturation, early cleavage, and germline development. Differentiation 75, 519-28.

St Johnston, D. (2005). Moving messages: the intracellular localization of mRNAs. Nat Rev Mol Cell Biol 6, 363-75.

St Johnston, D., Beuchle, D. and Nusslein-Volhard, C. (1991). Staufen, a gene required to localize maternal RNAs in the Drosophila egg. Cell 66, 51-63. 
Stennard, F., Carnac, G. and Gurdon, J. B. (1996). The Xenopus T-box gene, Antipodean, encodes a vegetally localised maternal mRNA and can trigger mesoderm formation. Development 122, 4179-88.

Stohr, N., Lederer, M., Reinke, C., Meyer, S., Hatzfeld, M., Singer, R. H. and Huttelmaier, S. (2006). ZBP1 regulates mRNA stability during cellular stress. J Cell Biol 175, 527-34.

Tafuri, S. R. and Wolffe, A. P. (1993). Selective recruitment of masked maternal mRNA from messenger ribonucleoprotein particles containing FRGY2 (mRNP4). $J$ Biol Chem 268, 24255-61.

Tanaka, K. J., Ogawa, K., Takagi, M., Imamoto, N., Matsumoto, K. and Tsujimoto, M. (2006). RAP55, a cytoplasmic mRNP component, represses translation in Xenopus oocytes. J Biol Chem 281, 40096-106.

Tarbashevich, K., Koebernick, K. and Pieler, T. (2007). XGRIP2.1 is encoded by a vegetally localizing, maternal mRNA and functions in germ cell development and anteroposterior PGC positioning in Xenopus laevis. Dev Biol 311, 554-65.

Tekotte, H. and Davis, I. (2002). Intracellular mRNA localization: motors move messages. Trends Genet 18, 636-42.

Thomsen, G. H. and Melton, D. A. (1993). Processed Vg1 protein is an axial mesoderm inducer in Xenopus. Cell 74, 433-41.

Toba, G. and White, K. (2008). The third RNA recognition motif of Drosophila ELAV protein has a role in multimerization. Nucleic Acids Res 36, 1390-9.

Tourriere, H., Chebli, K., Zekri, L., Courselaud, B., Blanchard, J. M., Bertrand, E. and Tazi, J. (2003). The RasGAP-associated endoribonuclease G3BP assembles stress granules. J Cell Biol 160, 823-31.

Vanzo, N. F. and Ephrussi, A. (2002). Oskar anchoring restricts pole plasm formation to the posterior of the Drosophila oocyte. Development 129, 3705-14.

Wagner, C., Palacios, I., Jaeger, L., St Johnston, D., Ehresmann, B., Ehresmann, C. and Brunel, C. (2001). Dimerization of the 3'UTR of bicoid mRNA Involves a Two-step Mechanism. J Mol Biol 313, 511-24.

Wang, C., Dickinson, L. K. and Lehmann, R. (1994). Genetics of nanos localization in Drosophila. Dev Dyn 199, 103-15.

Wang, S. and Hazelrigg, T. (1994). Implications for bcd mRNA localization from spatial distribution of exu protein in Drosophila oogenesis. Nature 369, 400-03. 
Wang, W., Caldwell, M. C., Lin, S., Furneaux, H. and Gorospe, M. (2000a). HuR regulates cyclin $A$ and cyclin B1 mRNA stability during cell proliferation. Embo J 19, 2340-50.

Wang, W., Furneaux, H., Cheng, H., Caldwell, M. C., Hutter, D., Liu, Y., Holbrook, N. and Gorospe, M. (2000b). HuR regulates p21 mRNA stabilization by UV light. Mol Cell Biol 20, 760-9.

Wang, W., van Niekerk, E., Willis, D. E. and Twiss, J. L. (2007). RNA transport and localized protein synthesis in neurological disorders and neural repair. Dev Neurobiol 67, 1166-82.

Werner, H. B., Kuhlmann, K., Shen, S., Uecker, M., Schardt, A., Dimova, K., Orfaniotou, F., Dhaunchak, A., Brinkmann, B. G., Mobius, W. et al. (2007). Proteolipid protein is required for transport of sirtuin 2 into CNS myelin. $J$ Neurosci 27, 7717-30.

Weston, A. and Sommerville, J. (2006). Xp54 and related (DDX6-like) RNA helicases: roles in messenger RNP assembly, translation regulation and RNA degradation. Nucleic Acids Res 34, 3082-94.

Wilhelm, J. E., Mansfield, J., Hom-Booher, N., Wang, S., Turck, C. W., Hazelrigg, T. and Vale, R. D. (2000a). Isolation of a ribonucleoprotein complex involved in mRNA localization in Drosophila oocytes. J Cell Biol 148, 427-40.

Wilhelm, J. E., Vale, R. D. and Hegde, R. S. (2000b). Coordinate control of translation and localization of $\mathrm{Vg} 1$ mRNA in Xenopus oocytes. Proc Natl Acad Sci U S A 97, 13132-7.

Wilsch-Brauninger, M., Schwarz, H. and Nusslein-Volhard, C. (1997). A sponge-like structure involved in the association and transport of maternal products during Drosophila oogenesis. J Cell Biol 139, 817-29.

Wilusz, C. J. and Wilusz, J. (2007). HuR-SIRT: the hairy world of posttranscriptional control. Mol Cell 25, 485-7.

Wischnewski, J. (2002). Analyse der differentiellen Regulation der Aktivität von nucleocytoplasmatischen Transportfaktoren. In Institut für Biochemie und Molekulare Zellbiologie, Abteilung Entwicklungsbiochemie, (ed. Göttingen: Georg-August-Universität Göttingen.

Yaniv, K. and Yisraeli, J. K. (2001). Defining cis-acting elements and transacting factors in RNA localization. Int Rev Cytol 203, 521-39. 
Yano, T., Lopez de Quinto, S., Matsui, Y., Shevchenko, A. and Ephrussi, A. (2004). Hrp48, a Drosophila hnRNPA/B homolog, binds and regulates translation of oskar mRNA. Dev Cell 6, 637-48.

Yao, K. M. and White, K. (1991). Organizational analysis of elav gene and functional analysis of ELAV protein of Drosophila melanogaster and Drosophila virilis. Mol Cell Biol 11, 2994-3000.

Yisraeli, J. K. and Melton, D. A. (1988). The material mRNA Vg1 is correctly localized following injection into Xenopus oocytes. Nature 336, 592-5.

Yisraeli, J. K., Sokol, S. and Melton, D. A. (1990). A two-step model for the localization of maternal mRNA in Xenopus oocytes: involvement of microtubules and microfilaments in the translocation and anchoring of $\mathrm{Vg} 1$ mRNA. Development 108, 289-98.

Yoon, Y. J. and Mowry, K. L. (2004). Xenopus Staufen is a component of a ribonucleoprotein complex containing Vg1 RNA and kinesin. Development 131, 3035-45.

Zearfoss, N. R., Chan, A. P., Wu, C. F., Kloc, M. and Etkin, L. D. (2004). Hermes is a localized factor regulating cleavage of vegetal blastomeres in Xenopus laevis. Dev Biol 267, 60-71.

Zhang, J., Houston, D. W., King, M. L., Payne, C., Wylie, C. and Heasman, J. (1998). The role of maternal VegT in establishing the primary germ layers in Xenopus embryos. Cell 94, 515-24.

Zhang, Q., Yaniv, K., Oberman, F., Wolke, U., Git, A., Fromer, M., Taylor, W. L., Meyer, D., Standart, N., Raz, E. et al. (1999). Vg1 RBP intracellular distribution and evolutionarily conserved expression at multiple stages during development. Mech Dev 88, 101-6.

Zhao, W. M., Jiang, C., Kroll, T. T. and Huber, P. W. (2001). A proline-rich protein binds to the localization element of Xenopus $\mathrm{Vg} 1 \mathrm{mRNA}$ and to ligands involved in actin polymerization. Embo $\mathrm{J} 20,2315-25$.

Zhou, Y. and King, M. L. (1996). Localization of Xcat-2 RNA, a putative germ plasm component, to the mitochondrial cloud in Xenopus stage I oocytes. Development 122, 2947-53.

Zhu, H., Hasman, R. A., Barron, V. A., Luo, G. and Lou, H. (2006). A nuclear function of $\mathrm{Hu}$ proteins as neuron-specific alternative RNA processing regulators. Mol Biol Cell 17, 5105-14. 
Zhu, H., Zhou, H. L., Hasman, R. A. and Lou, H. (2007). Hu proteins regulate polyadenylation by blocking sites containing U-rich sequences. J Biol Chem $\mathbf{2 8 2}$, 2203-10. 


\section{Appendix}

\subsection{Appendix I}

\subsubsection{Appendix I: Density gradient profile of localization proteins and} ribosomes (Legend).

(A) Total S16 extract from stage I-IV oocytes was fractionated on a 5-60\% glycerol gradient, fractions 1 ; top of the gradient, 11; bottom of the gradient, $\mathrm{P}$; pellet. The fractions were analysed by Western blotting using antibodies against Vg1RBP, XStaufen1 and ribosomal protein S6 (Santa Cruz)

(B) RT-PCR analysis of the various vegetally localized mRNAs and others from the gradient fractions; total RNA from the individual glycerol gradient fractions were isolated by phenol/chloroform extraction and RNAeasy kit clean up. RNAs generated in this way was used for cDNA synthesis and this served as template PCR using the specific primers for the different RNA tested.

(C) The density gradient profile of total RNA from stage I-IV oocytes was generated by isolating total RNA using phenol/chloroform extraction and RNAeasy kit clean up, this was then applied onto the gradients and centrifuged. The RNAs in fraction were precipitated by Isopropanol and directly analysed on a $2 \%$ agarose gel. 
7.1.2. Appendix I: Density gradient profile of localization proteins and ribosomes

A
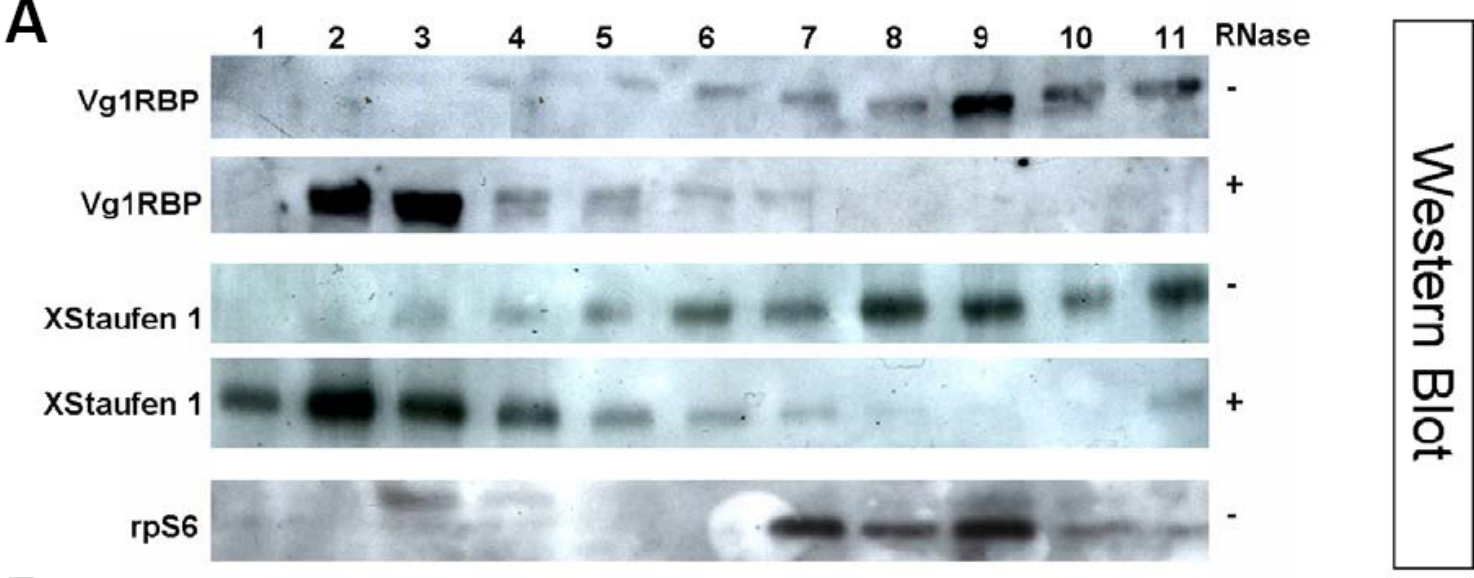

B Vg1

Xvelo1

XDeadend

Velo45

XNIF

Deadsouth

XPTB

Xdazl

28S rRNA

$18 \mathrm{~S}$ rRNA

H4

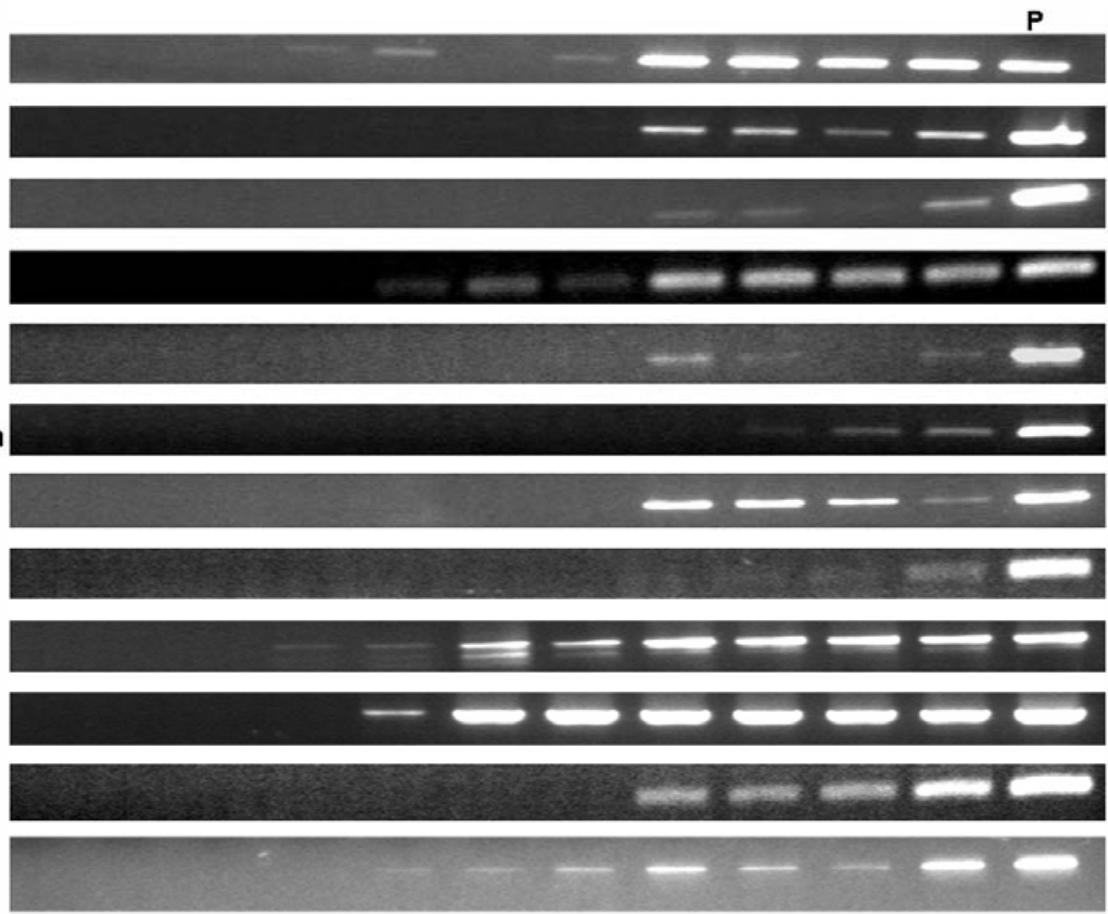

TFIIIA

C
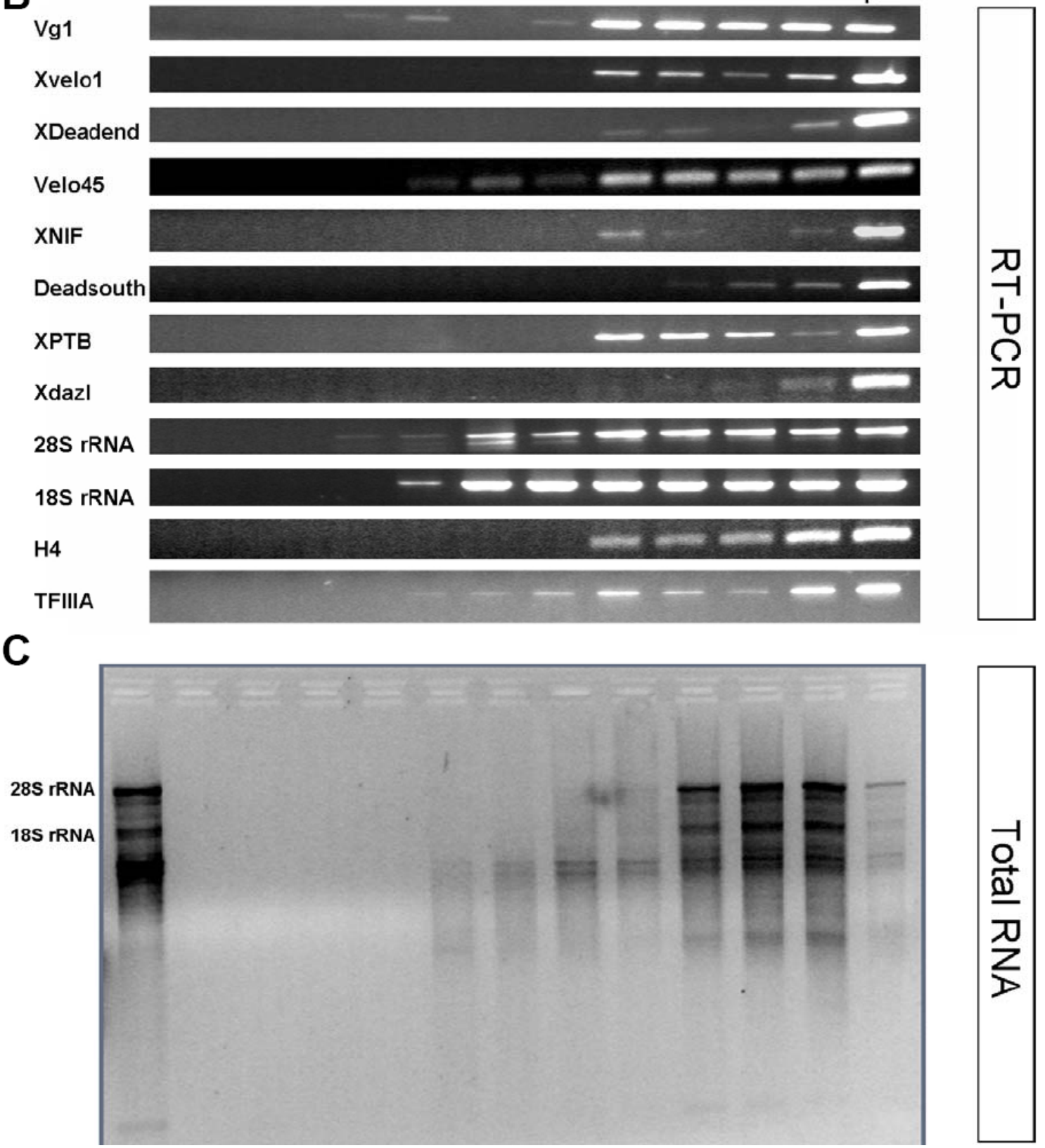


\subsection{Appendix II}

7.2.1. Appendix II: Identification of proteins in the RNP S200 - pH3-10 (Legend)

RNP S200 protein sample was generated from RNP fractions of Xenopus oocyte stage I-IV extracts by high speed centrifugation after RNase treatment. The RNP fractions were obtained by glycerol gradient fractionation of extracts which were monitored by Western blotting for Vg1RBP and XStaufen1. The RNP S200 protein preparation was resolved by $2 \mathrm{D}$ gel electrophoresis $(\mathbf{B})$ using immobilised $\mathrm{pH}$ gradient (IPG) strip with pH 3-10 (Bio-Rad). Circles covering groups of protein spots indicate that identified proteins were found to be the same but which did not focus into one discrete spot during the IEF. (A) The same gel as in (B) which is without annotations

The table shows a complete list of proteins which were identified from the $2 \mathrm{D}$ gel of RNP S200 protein preparation by mass spectroscopy (MS). Proteins were identified using peptide mass fingerprinting and proteins with MASCOT score of 50 or higher were confirmed by sequencing of two peptides from each protein using MS/MS (see section 2.5.8). The database search with peptide masses and sequences, the nominal molecular mass and the putative isoelectric point $(\mathrm{pl})$ estimation from the amino acid sequences were done using Mascot Software 2.0 (Matrix Science). Spot numbers given in the list corresponds to numbered circles indicated on the gel picture. (Protein identification was performed by Dr Olaf Jahn, Proteomics group, MPI-em, Göttingen) 
7.2.2. Appendix II: Identification of proteins in the RNP S200 - pH3-10 (Gel)

A $\quad(+) \mathrm{pH}_{3}$ $(-) \mathrm{pH} 10$ $\mathrm{kDa}$

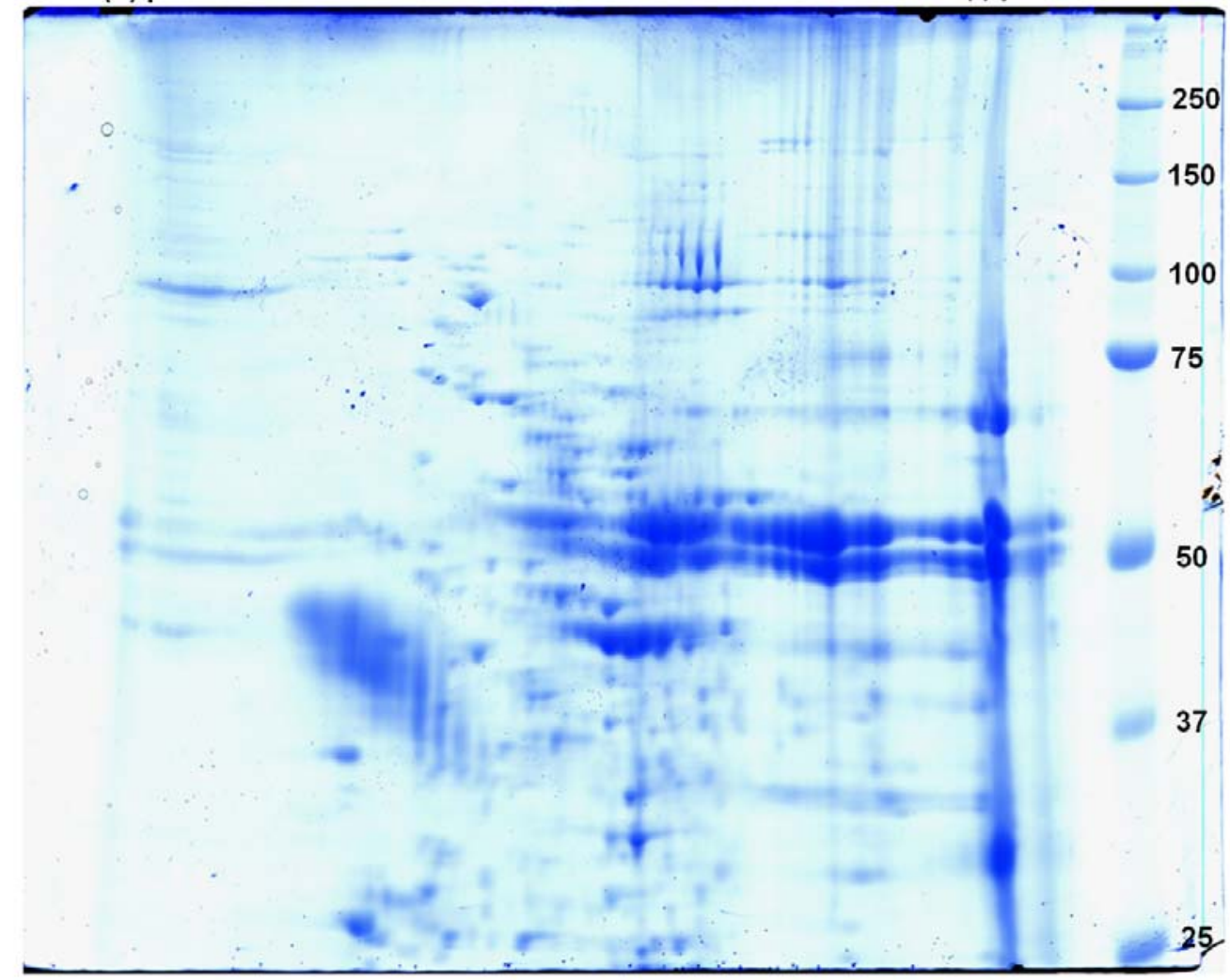

B (+) $\mathrm{pH} 3$ (-) $\mathrm{pH} 10$ $\mathrm{kDa}$

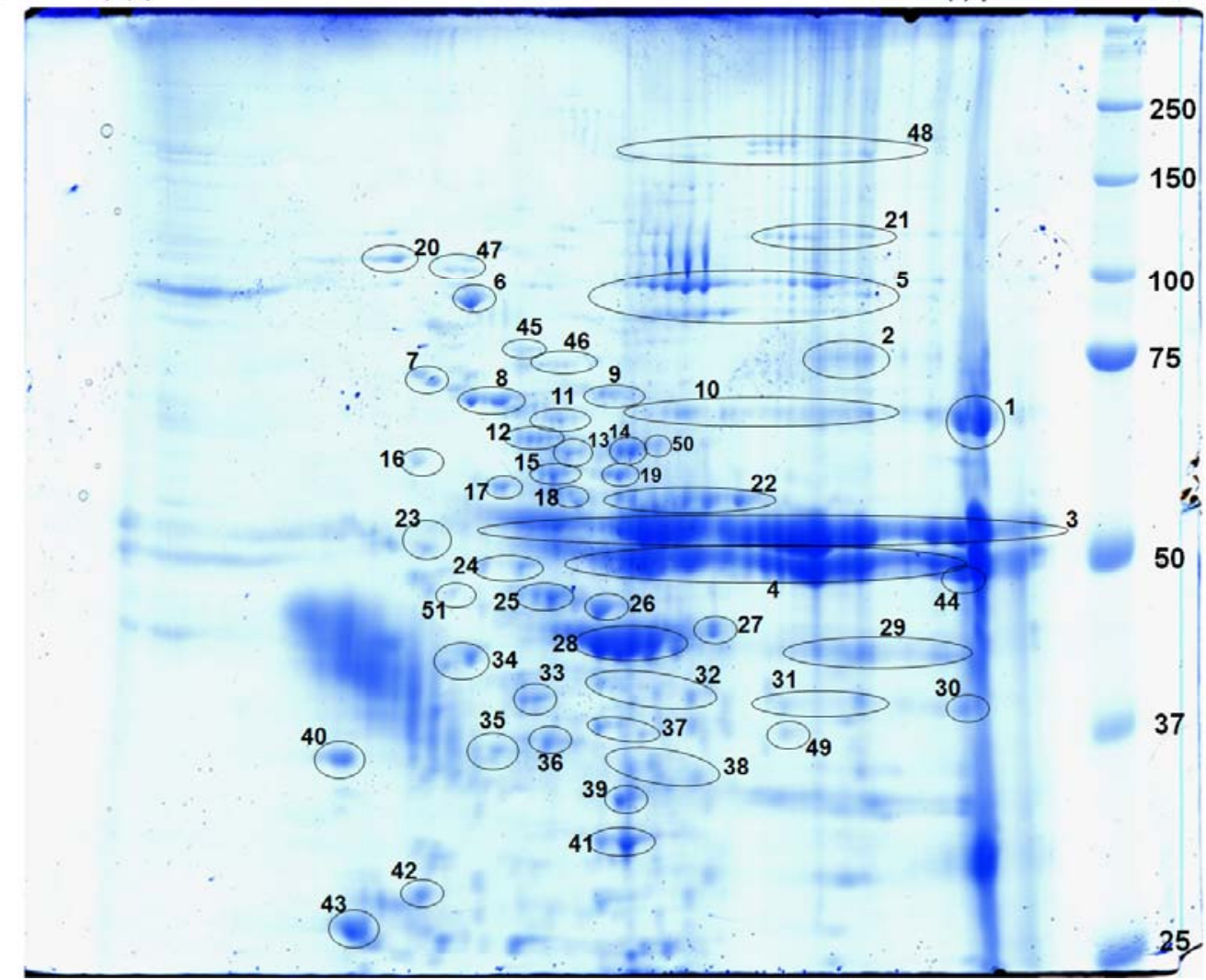




\subsubsection{Appendix II: Identification of proteins in the RNP S200 - pH3-10} (Table)

\begin{tabular}{|c|c|c|c|c|}
\hline Spot \# & Protein Name & Accession \# & $\mathrm{kDa}$ & pl \\
\hline 1 & Vg1RBP & gi|3136158 & 65,61 & 9,68 \\
\hline 2 & Xstaufen1 & gi|56698874 & 78,11 & 10,03 \\
\hline 3 & Ybox BP p56 (FRGY2-A) & gi|1175535 & 37,18 & 10,02 \\
\hline 4 & Ybox BP p54 (FRGY2-B) & gi|1175534 & 35,93 & 9,38 \\
\hline 5 & Eukaryotic translation elongation factor 2 , & gi| 27882475 & 95,42 & 6,45 \\
\hline 6 & Valosin containing protein, p97 ATPase & gi|28422362 & 89,21 & 4,96 \\
\hline 7 & Heavy-chain binding protein BiP & gi|50417653 & 72,66 & 4,75 \\
\hline 8 & Heat shock protein 70 & gi|27371247 & 71,18 & 5,21 \\
\hline 9 & Smu- 1 suppressor of mec- 8 and unc- 52 homolog & gi|47123903 & 57,62 & 6,74 \\
\hline 10 & $\begin{array}{l}\text { Ras-GTPase-activating protein (GAP120) } \\
\text { SH3-domain binding protein } 2 a-G 3 B P 2 a\end{array}$ & gi|49903639 & 54,36 & 5,21 \\
\hline 11 & Lysyl-tRNA synthetase & gi|28838485 & 69,69 & 6,15 \\
\hline 12 & Methionine aminopeptidase 2 & gi|27694969 & 51,48 & 5,78 \\
\hline 13 & T-complex protein 1 subunit gamma & gi|1729875 & 60,61 & 5,81 \\
\hline 14 & Transketolase & gi|33585659 & 67,45 & 6,22 \\
\hline 15 & Chaperonin containing TCP1, subunit 5 (epsilon) & gi|27924333 & 59,58 & 5,61 \\
\hline 16 & Phosphorylase phosphatase & gi|49256169 & 65,38 & 4,72 \\
\hline 17 & Chaperonin containing TCP1, subunit 8 (theta), & gi|27924345 & 59,35 & 5,21 \\
\hline 18 & T-complex polypeptide 1 & gi|46249640 & 60,17 & 5,82 \\
\hline 19 & Chaperonin containing $T C P 1$, subunit $6 \mathrm{~A}$ (zeta 1 ) & gi|54038656 & 57,78 & 6,14 \\
\hline 20 & $\begin{array}{l}\text { Similar to Breat Cancer Suppressor Candidate 1; } \\
\text { BCSC1 }\end{array}$ & gi||48734665 & 94,48 & 4,56 \\
\hline 21 & $\begin{array}{l}\text { dsRNA-binding protein } 4 \mathrm{~F} .2 \text { or interleukin enhancer } \\
\text { binding factor } 3\end{array}$ & gi|29126828 & 93,41 & 9,18 \\
\hline 22 & $\begin{array}{l}\text { Cytosolic thyroid hormone binding protein/pyruvate } \\
\text { kinase type M2 }\end{array}$ & gi|51258124 & 57,52 & 6,48 \\
\hline 23 & beta-Tubulin & gi|32450639 & 49,81 & 4,59 \\
\hline 24 & Cytosolic nonspecific dipeptidase & gi|33417134 & 52,74 & 5,07 \\
\hline 25 & Similar to enolase 1, alpha non-neuron & gi|27371000 & 47,46 & 5,36 \\
\hline 26 & Enolase & gi|64680 & 47,51 & 5,73 \\
\hline 27 & elongation factor 1 gamma & gi|545505 & 49,86 & 7,81 \\
\hline 28 & similar to proliferation-associated $2 \mathrm{G} 4,38 \mathrm{kD}$ & gi|54311187 & 43,48 & 6,49 \\
\hline 29 & estrogen-regulated protein Ep45 & gi|283798 & 49,57 & 8,91 \\
\hline 30 & similar to aldolase $\mathrm{A}$ & gi|28302293 & 39,38 & 9,39 \\
\hline 31 & hnRNP A3(A) & gi|1710625 & 38,58 & 6,78 \\
\hline 32 & hnRNP A3(B) & gi|1710626 & 39,43 & 6,78 \\
\hline 33 & hnRNP A/B & gi|49257602 & 35,93 & 5,71 \\
\hline 34 & actin gamma, cytoskeletal type 5 & gi|280660 & 41,84 & 5,11 \\
\hline 35 & p37 AUF1, hnRNP D & gi|52082714 & 33,09 & 5,69 \\
\hline 36 & similar to glyoxylate reductase & gi|72679350 & 36,05 & 5,64 \\
\hline 37 & Aldolase C & gi|28175655 & 39,27 & 6,01 \\
\hline 38 & hnRNP A1a & gi|47938744 & 37,91 & 9,11 \\
\hline 39 & Similar to Cytosolic malate dehydrogenase & gi|38014771 & 36,42 & 6,39 \\
\hline 40 & Elongation factor-1 delta & gi|56970676 & 28,64 & 4,35 \\
\hline 41 & L-lactate dehydrogenase B chain (LDH-B). & gi|1170735 & 36,35 & 6,21 \\
\hline 42 & proteasome (macropain) subunit, alpha type, 3 & gi|27371303 & 28,36 & 4,78 \\
\hline 43 & Elongation factor 1 beta & gi|64662 & 25,17 & 4,42 \\
\hline 44 & RAP46 & gi|71679778 & 46,10 & 9,81 \\
\hline 45 & DEAD box protein & gi|2134051 & 78,24 & 5,45 \\
\hline 46 & Moesin & gi|6648536 & 68,1 & 5,78 \\
\hline 47 & Major vault protein (MVP). & gi|34784593 & 95,66 & 4,96 \\
\hline 48 & Hdlbp/Xvigilin & gi|27882206 & 143 & 6,18 \\
\hline 49 & hnRNP A1 & gi|28374304 & 40,47 & 9,29 \\
\hline 50 & hnRNP L & gi|50416457 & 58,68 & 6,41 \\
\hline 51 & similar to elF4A I & gi|28278797 & 46,07 & 5,13 \\
\hline
\end{tabular}




\subsection{Appendix III}

7.3.1. Appendix III: Identification of proteins in the RNP S200 - pH7-11 (Legend)

RNP S200 protein sample was generated from RNP fractions of Xenopus oocytes stage I-IV extracts by high speed centrifugation after RNase treatment. The RNP fractions were obtained by glycerol gradient fractionation of extracts which were monitored by Western blotting for Vg1RBP and XStaufen1. The RNP S200 protein preparation was resolved by $2 \mathrm{D}$ gel electrophoresis $(\mathbf{B})$ using immobilised $\mathrm{pH}$ gradient (IPG) strip of pH 7-11 gradients (Amersham) which allow highly basic proteins to be better resolved. Circles covering groups of protein spots indicate that identified proteins were found to be the same but which did not focus into one discrete spot during the IEF. (A) The same gel as in (B) which is without annotations

The table shows a complete list of proteins which were identified from the $2 \mathrm{D}$ gel of a RNP S200 protein preparation by mass spectroscopy (MS). Proteins were identified using peptide mass fingerprinting and proteins with MASCOT score of 50 or higher were confirmed by sequencing of two peptides from each protein using MS/MS (see section 2.5.8). The database search with peptide masses and sequences, the nominal molecular mass and the putative isoelectric point ( $\mathrm{pl}$ ) estimation from the amino acid sequences were done using Mascot Software 2.0 (Matrix Science). Spot numbers given in the list corresponds to numbered circles indicated on the gel picture. (Protein identification was performed by Dr Olaf Jahn, Proteomics group, MPI-em, Göttingen) 
7.3.2. Appendix III: Identification of proteins in the RNP S200 - pH7-11 (Gel)

A $\quad$ (+) $\mathrm{pH} 7$

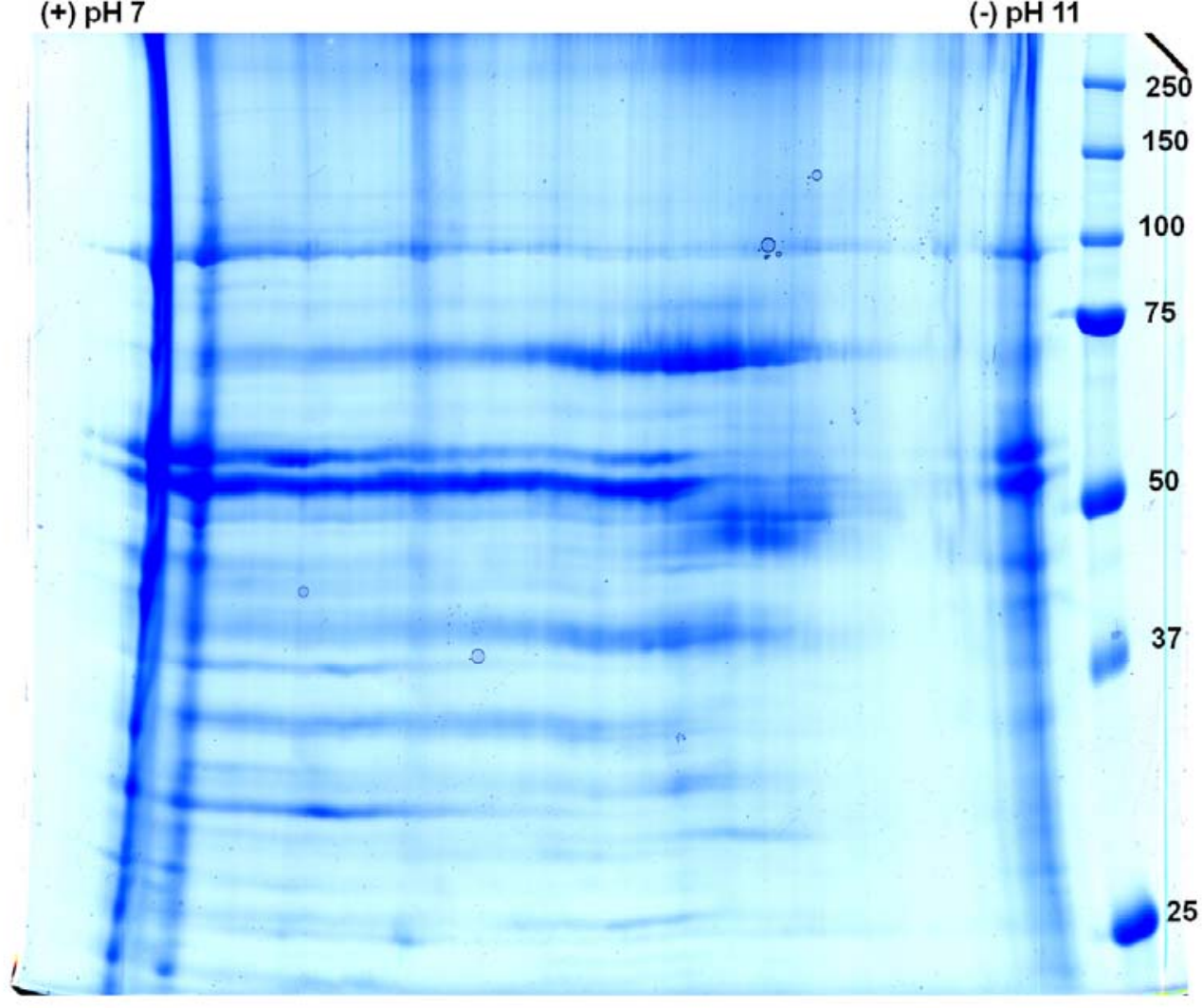

B

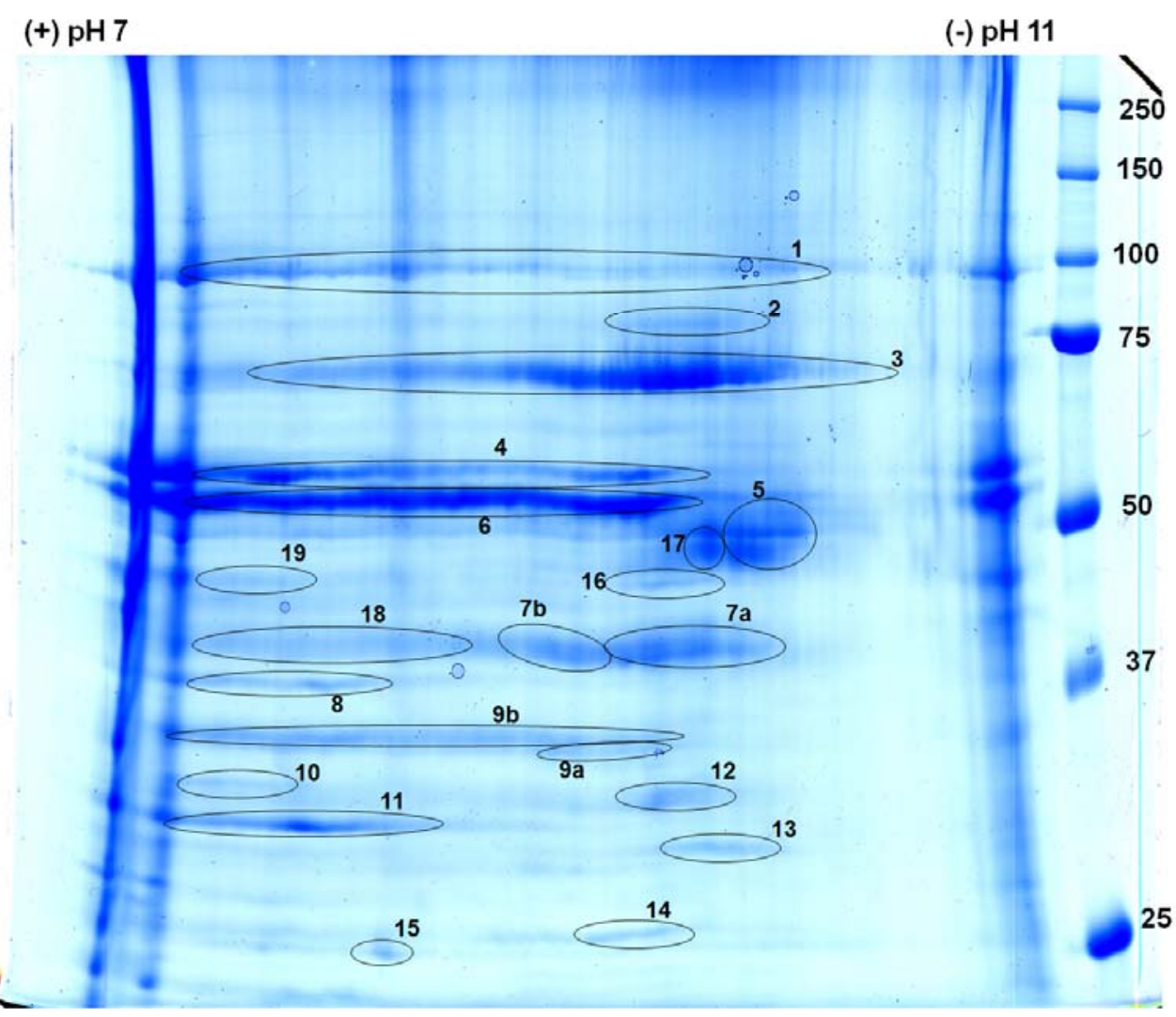


7.3.3. Appendix III: Identification of proteins in the RNP S200 - pH7-11 (Table)

\begin{tabular}{|c|c|c|c|c|}
\hline Spot \# & Protein Name & Accession \# & kDa & pl \\
\hline 1 & EeF2 & gi|27882475 & 96,5 & 6,51 \\
\hline 2 & Xstaufen1 & gi|33469621 & 78,4 & 9,56 \\
\hline 3 & Vg1RBP & gi|3136158 & 65,9 & 9,01 \\
\hline 4 & p56 & gi|1175535 & 37,2 & 9,6 \\
\hline 5 & $\mathrm{EF} 1 \alpha$ & gi|28280017 & 50,5 & 9,23 \\
\hline 6 & p54 & gi|1175534 & 35,9 & 7,93 \\
\hline $7 a$ & ElrB 1 & gi|608539 & 43,1 & 9,04 \\
\hline $7 \mathrm{~b}$ & ElrB 2 (Elav2-A) & gi|62739311 & 39,9 & 9,17 \\
\hline 8 & hnRNPE2 (3KH domains) & gi|5459450 & 37,5 & 7,63 \\
\hline $9 a$ & G3PDH (typeB) & gi|24415375 & 36,2 & 8,44 \\
\hline $9 b$ & G3PDH (typeC) & gi|27882192 & 36,1 & 8,16 \\
\hline 10 & hnRNP D ( 2 RRMs) & gi|46249880 & 33,1 & 8,9 \\
\hline 11 & Guanine nucleotide BP (WD40 domain) & $\mathrm{gi} \mid 27371211$ & 35,5 & 7,6 \\
\hline 12 & $\begin{array}{l}\text { Double stranded RNA BP A-XIRBPA ( } 2 \\
\text { DSRMs) }\end{array}$ & gi|3334381 & 33,3 & 8,5 \\
\hline 13 & ePABP2(embryonic nuclear type) & gi|28273596 & 24,5 & 8,8 \\
\hline 14 & Proteasome $\alpha 4$ subunit & gi|49522772 & 28,1 & 9,9 \\
\hline 15 & RP L10a & gi|27735445 & 24,9 & 9,9 \\
\hline 16 & $\begin{array}{l}\text { Nuclease sensitive RNA BP (Nsep1) - } \\
\text { Cold Shock Domain }\end{array}$ & gi|27503841 & 34,4 & 9,46 \\
\hline 17 & RAP42 & gi|71679779 & 41,9 & 9,72 \\
\hline 18 & $\begin{array}{l}\text { Unknown protein with RNA cyclase } \\
\text { domain }\end{array}$ & gi|49116091 & 38,5 & 8,86 \\
\hline 19 & EF $1 \gamma$ & gi|545505 & 50,2 & 7,01 \\
\hline
\end{tabular}




\subsection{Appendix IV}

7.4.1. Appendix IV: Identification of proteins in the HS RNP S200 - pH3-10 (Legend)

HS RNP S200 protein sample was generated from RNP fractions of Xenopus oocytes stage I-IV extracts by high speed centrifugation after high salt treatment. The RNP fractions were obtained by glycerol gradient fractionation of extracts which were monitored by Western blotting for Vg1RBP and XStaufen1. The HS RNP S200 protein preparation was resolved by 2D gel electrophoresis (B) using immobilised pH gradient (IPG) strip with pH 3-10 (Bio-Rad). Circles covering groups of protein spots indicate that identified proteins were found to be the same but which, for no clear reason, did not focus into one discrete spot during the IEF. (A) The same gel as in (B) which is without annotations

The table shows a complete list of proteins which were identified from the 2Dgel of RNP S200 protein preparation by mass spectroscopy (MS). Proteins were identified using peptide mass fingerprinting and proteins with MASCOT score of 50 or higher were confirmed by sequencing of two peptides from each protein using MS/MS (see section 2.5.8). The database search with peptide masses and sequences, the nominal molecular mass and the putative isoelectric point ( $\mathrm{pl}$ ) estimation from the amino acid sequences were done using Mascot Software 2.0 (Matrix Science). Spot numbers given in the list corresponds to numbered circles indicated on the gel picture. (Protein identification was performed by Dr Olaf Jahn, Proteomics group, MPI-em, Göttingen) 
7.4.2. Appendix IV: Identification of proteins in the HS RNPS200 - pH3-10 (Gel)

A

(+) $\mathrm{pH} 3$

(-) $\mathrm{pH} 10$

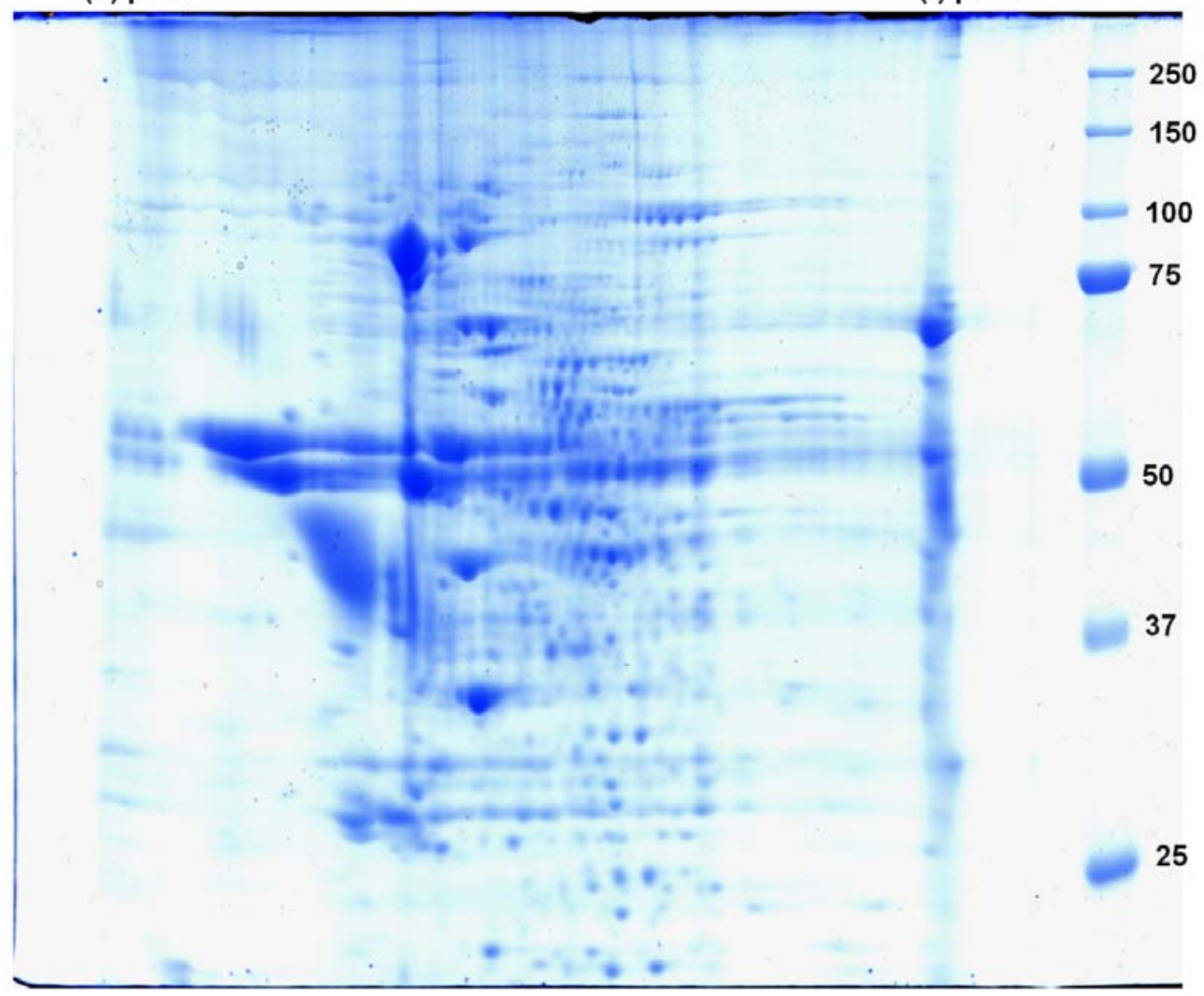

B

(+) $\mathrm{pH}_{3}$

(-) $\mathrm{pH} 10$

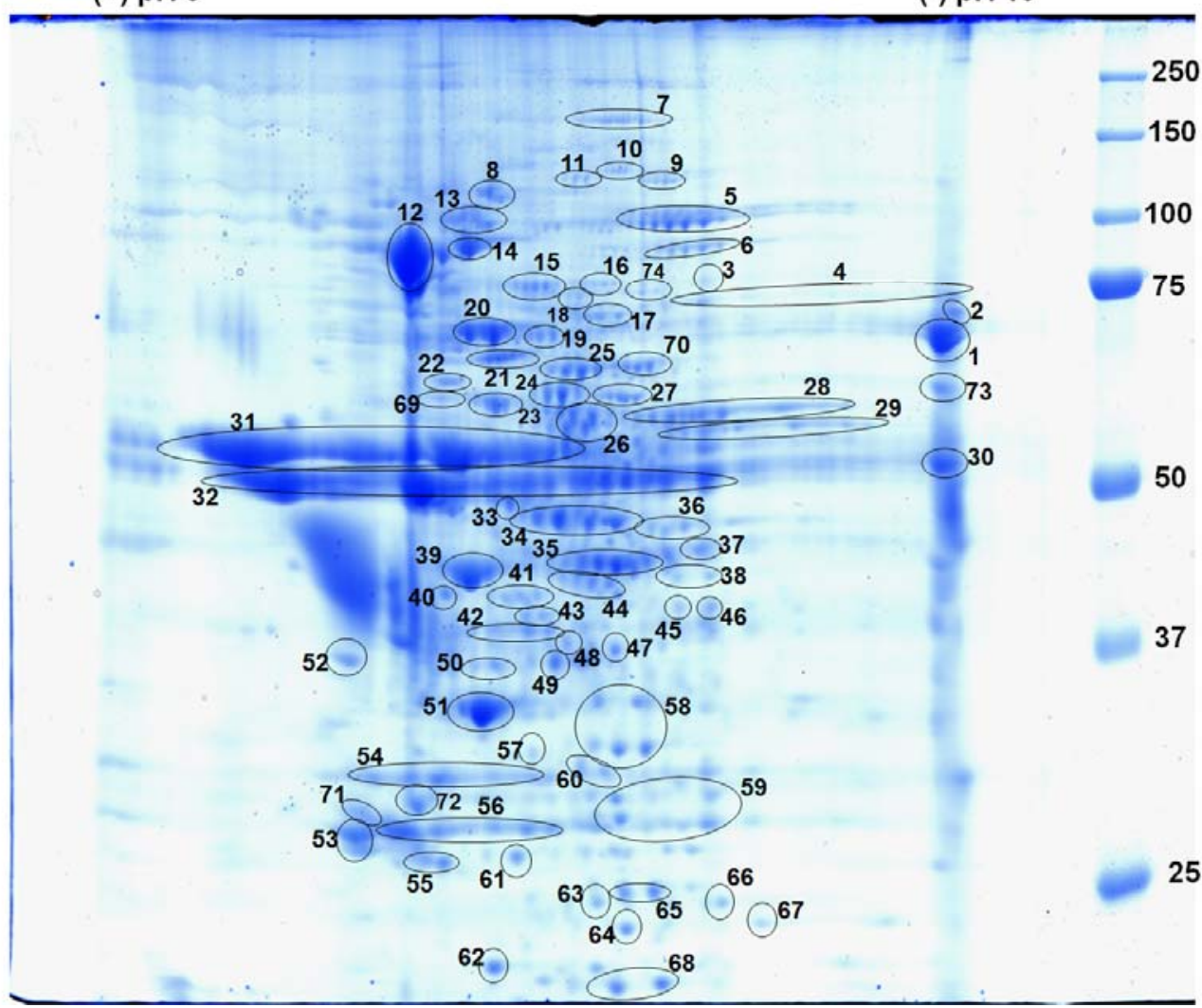


7.4.3. Appendix IV: Identification of proteins in the HS RNPS $200-\mathrm{pH} 3-10$ (Table)

\begin{tabular}{|c|c|c|c|c|}
\hline Spot \# & Protein Name & Accession \# & $\mathrm{kDa}$ & pl \\
\hline 1 & Vg1RBP & gi|3136158 & 65,61 & 9,68 \\
\hline 2 & Embryonic Poly(A)-binding protein 1-B & gi|47940242 & 70,6 & 9,94 \\
\hline 3 & Xstaufen1 & gi|56698874 & 78,11 & 10,03 \\
\hline 4 & Cytoplasmic poly $(\mathrm{A})$ binding protein 1 & gi|30353795 & 70,46 & 10,01 \\
\hline 5 & Eukaryotic translation elongation factor 2 , & gi| 27882475 & 95,42 & 6,45 \\
\hline 6 & undefined & & & \\
\hline 7 & Hdlbp/Xvigilin & gi|27882206 & 143 & 6,18 \\
\hline 8 & undefined & & & \\
\hline 9 & ATP citrate lyase & gi|54311201 & 120,78 & 6,52 \\
\hline 10 & Pyruvate carboxylase & gi|37748213 & 130,09 & 6,43 \\
\hline 11 & undefined & & & \\
\hline 12 & Nucleolin (4 RRMs) & gi|295899 & 75,53 & 4,58 \\
\hline 13 & Oocyte-specific protein $\mathrm{P} 100$ & gi|283815 & 83,51 & 5,14 \\
\hline 14 & Valosin containing protein, p97 ATPase & gi|28422362 & 89,21 & 4,96 \\
\hline 15 & DEAD box protein (VLG1) & gi|2134051 & 78,24 & 5,45 \\
\hline 16 & cysteinyl-tRNA synthetase & gi|28436794 & 85,78 & 5,92 \\
\hline 17 & $\begin{array}{l}\text { Propionyl-Coenzyme A carboxylase } \\
\text { Peptidyl arginine deiminase, type } 2\end{array}$ & $\begin{array}{l}\text { gi|59862015 } \\
\text { gi|28436863 }\end{array}$ & $\begin{array}{l}78,44 \\
74,09\end{array}$ & $\begin{array}{l}6,13 \\
5,82\end{array}$ \\
\hline 18 & Moesin & gi|6648536 & 68,1 & 5,78 \\
\hline 19 & Similar to Arac & gi|58402671 & 75,88 & 5,43 \\
\hline 20 & Heat shock protein 70 & gi|27371247 & 71,18 & 5,21 \\
\hline 21 & G3B & gi 49 & 54,36 & 5,21 \\
\hline 22 & G3BP-1 & gi 49 & 52,65 & 4,79 \\
\hline 23 & Chaperonin containi & gi|27924345 & 59,35 & 5,21 \\
\hline 24 & $\begin{array}{l}\text { Chaperonin containing TCP1, subunit } 5 \\
\text { (epsilon) }\end{array}$ & gi|27924333 & 59,58 & 5,61 \\
\hline 25 & chaperonin subunit CCTgamma & gi|1 & 60,6 & 5,8 \\
\hline 26 & T-complex polypeptide 1 & gi|46249640 & 60,17 & 5,82 \\
\hline 27 & $\begin{array}{l}\text { Chaperonin containing TCP1, subunit } 6 \mathrm{~A} \text { (zeta } \\
\text { 1) }\end{array}$ & gi|54038656 & 57,78 & 6,14 \\
\hline 28 & $\begin{array}{l}\text { Cytosolic thyroid hormone binding } \\
\text { protein/pyruvate kinase type } \mathrm{M} 2\end{array}$ & gi|51258124 & 57,52 & 6,48 \\
\hline 29 & $\begin{array}{l}\text { Predicted Protein with HABP4_PAI-RBP1 } \\
\text { domain }\end{array}$ & gi|37748539 & 45,52 & 7,91 \\
\hline 30 & RNA helicase p54 & gi|1044938 & 54,1 & 9,65 \\
\hline 31 & Ybox BP p56 (FRGY2-A) & gi|1175535 & 37,18 & 10,02 \\
\hline 32 & Ybox BP p54 (FRGY2-B) & gi|1175534 & 35,93 & 9,38 \\
\hline 33 & xMSS1 & gi|695772 & 48,66 & 5,44 \\
\hline 34 & Enolase & gi|64680 & 47,51 & 5,73 \\
\hline 35 & similar to proliferation-associated $2 \mathrm{G} 4,38 \mathrm{kD}$ & gi|54311187 & 43,48 & 6,49 \\
\hline 36 & elongation factor $1 \mathrm{gamma}$ & gi|545505 & 49,86 & 7,81 \\
\hline 37 & 42Sp50; tRNA binding protein & gi|64489 & 50,67 & 10,28 \\
\hline 38 & Proteasome 26S ATPase subunit 6 & gi|28278099 & 44,14 & 7,93 \\
\hline 39 & actin gamma, cytoskeletal type 5 & gi|280660 & 41,84 & 5,11 \\
\hline 40 & Similar to Methylosome protein 50 & gi|46249480 & 36,05 & 4,96 \\
\hline 41 & $\begin{array}{l}\text { Similar to Proteasome } 26 \mathrm{~S} \text { subunit } \\
\text { ATPase, } 13\end{array}$ & 1703928 & 43,06 & 5,41 \\
\hline
\end{tabular}




\subsubsection{Appendix IV: Identification of proteins in the HS RNP S200 - pH3-10} (Table - continued)

\begin{tabular}{|c|c|c|c|c|}
\hline Spot \# & Protein Name & Accession \# & $\mathrm{kDa}$ & pl \\
\hline 42 & Transcription Factor TFIIIA & gi|5679716 & 39,76 & 10,24 \\
\hline 43 & heterogeneous nuclear ribonucleoprotein $A / B$ & gi|49257602 & 35,93 & 5,71 \\
\hline 44 & Creatine Kinase & gi|27503418 & 42,24 & 6,07 \\
\hline 45 & GDP-mannose 4, 6-dehydratase & gi|49257299 & 41,59 & 6,44 \\
\hline 46 & $\begin{array}{l}\text { Heterogeneous nuclear ribonucleoprotein A3 } \\
\text { homolog } 2 \text { (hnRNP A3(B)) }\end{array}$ & gi|1710626 & 39,43 & 6,78 \\
\hline 47 & Aldolase C & gi|28175655 & 39,27 & 6,01 \\
\hline 48 & $\begin{array}{l}\text { Eukaryotic translation initiation factor } 3 \text {, } \\
\text { subunit } 3 \text { gamma }\end{array}$ & gi|56270000 & 38,39 & 5,56 \\
\hline 49 & $\begin{array}{l}\text { Glyoxylate reductase/hydroxypyruvate } \\
\text { reductase }\end{array}$ & gi|28278096 & 36,05 & 5,64 \\
\hline 50 & p37 AUF1, hnRNP D & gi|52082714 & 33,09 & 5,69 \\
\hline 51 & Acidic Ribosomal Protein PO & gi|27503344 & 34,09 & 5,17 \\
\hline 52 & Elongation factor- 1 delta & gi|56970676 & 28,64 & 4,35 \\
\hline 53 & Elongation factor 1 beta & gi|64662 & 25,17 & 4,42 \\
\hline 54 & Ribosomal Protein S3a & gi|28958133 & 29,94 & 10,32 \\
\hline 55 & Proteasome beta type- 3 subunit & gi|56270462 & 23,04 & 4,77 \\
\hline 56 & Proteasome Subunit, alpha type 3 & gi|27371303 & 28,36 & 4,78 \\
\hline 57 & Similar to Annexin A3 & gi|49117950 & 35,79 & 5,47 \\
\hline 58 & L-lactate dehydrogenase $B$ chain $(\mathrm{LDH}-\mathrm{B})$. & gi|1170735 & 36,35 & 6,21 \\
\hline 59 & Proteasome Subunit, alpha type 4 & gi|27924191 & 29,41 & 7,76 \\
\hline 60 & 20 S proteasome alpha6 subunit & gi|51968294 & 29,32 & 5,91 \\
\hline 61 & Peroxiredoxin 6 & gi|32450305 & 25,06 & 5,23 \\
\hline 62 & Proteasome subunit, beta type 4 & gi|33417170 & 27,36 & 5,38 \\
\hline 63 & Glutathione S-transferase theta 1 & gi|47937622 & 27,65 & 6 \\
\hline 64 & Proteasome subunit $\mathrm{XC3}$ & gi|48735053 & 25,83 & 6,24 \\
\hline 65 & $\begin{array}{l}\text { Similar to CLE protein (transcriptional } \\
\text { Activator) }\end{array}$ & gi|52430487 & 27,62 & 6,35 \\
\hline 66 & Triosephosphate isomerase & gi|28461382 & 26,76 & 7,93 \\
\hline 67 & glutathione S-transferase, mu 2 & gi|32484222 & 25,39 & 9,05 \\
\hline 68 & Peroxiredoxin 2 & gi|48734656 & 22,43 & 6,5 \\
\hline 69 & Brain zinc finger protein - $\mathrm{p} 48 \mathrm{ZF}$ & gi|50417682 & 48,71 & 4,74 \\
\hline 70 & Transketolase & gi|33585659 & 67,45 & 6,22 \\
\hline 71 & String of Pearls, SOP/ Ribosomal Protein S2 & gi|33417132 & 30,27 & 10,87 \\
\hline 72 & $\begin{array}{l}\text { Tyrosine 3-monooxygenase/Tryptophan 5- } \\
\text { monooxygenase activation protein, epsilon } \\
\text { polypeptide }\end{array}$ & gi|27924430 & 29,18 & 4,48 \\
\hline 73 & RAP55 & gi|27503869 & 51,26 & 9,99 \\
\hline 74 & ATP dependent RNA helicase & gi|27924277 & 77,13 & 6,37 \\
\hline
\end{tabular}




\subsection{Appendix V}

7.5.1. Appendix V: Identification of proteins in the HS RNP S200 \#2 - pH3-10 (Legend)

HS RNP S200 \#2 protein sample was generated from the pellet fractions of HS RNP S200 by another around of high speed centrifugation after RNase treatment. The HS RNP S200 \#2 protein preparation was resolved by 2D gel electrophoresis (B) using immobilised pH gradient (IPG) strip with pH 3-10 (Bio-Rad). Circles covering groups of protein spots indicate that identified proteins were found to be the same but which, for no clear reason, did not focus into one discrete spot during the IEF. (A) The same gel as in (B) which is without annotations

The table shows a complete list of proteins which were identified from the $2 \mathrm{D}$ gel of HS RNP S200 \#2 protein preparation by mass spectroscopy (MS). Proteins were identified using peptide mass fingerprinting and proteins with MASCOT score of 50 or higher were confirmed by sequencing of two peptides from each protein using MS/MS (see section 2.5.8). The database search with peptide masses and sequences, the nominal molecular mass and the putative isoelectric point $(\mathrm{pl})$ estimation from the amino acid sequences were done using Mascot Software 2.0 (Matrix Science). Spot numbers given in the list corresponds to numbered circles indicated on the gel picture.

(Protein identification was performed by Dr Olaf Jahn, Proteomics group, MPI-em, Göttingen) 
7.5.2. Appendix V: Identification of proteins in the HS RNPS200 \#2 - pH3-10 (Gel)

A $\quad(+) \mathrm{pH}^{3}$ $(-) \mathrm{pH} 10$

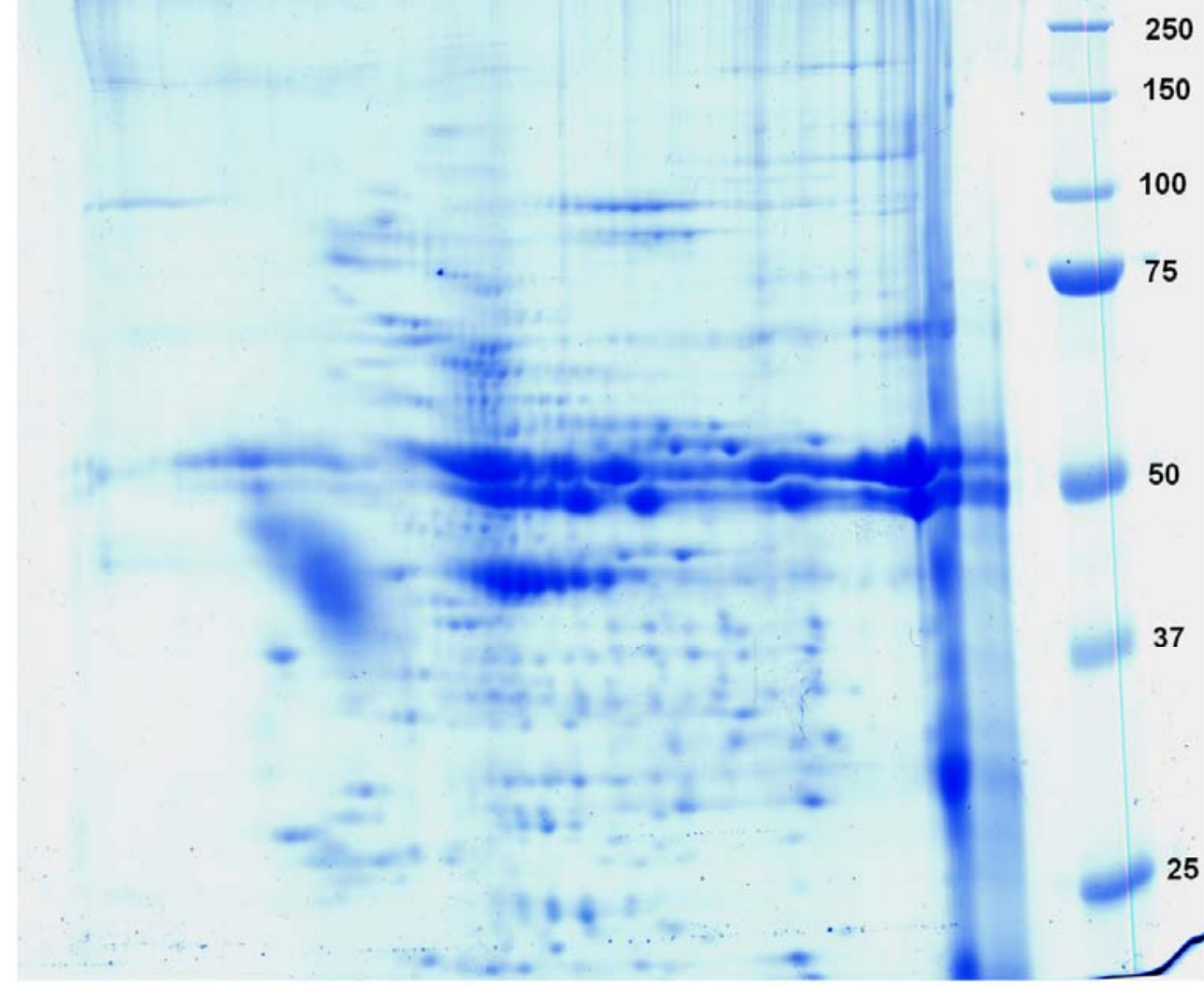

B

(+) $\mathrm{pH}_{3}$

$(-) \mathrm{pH} 10$
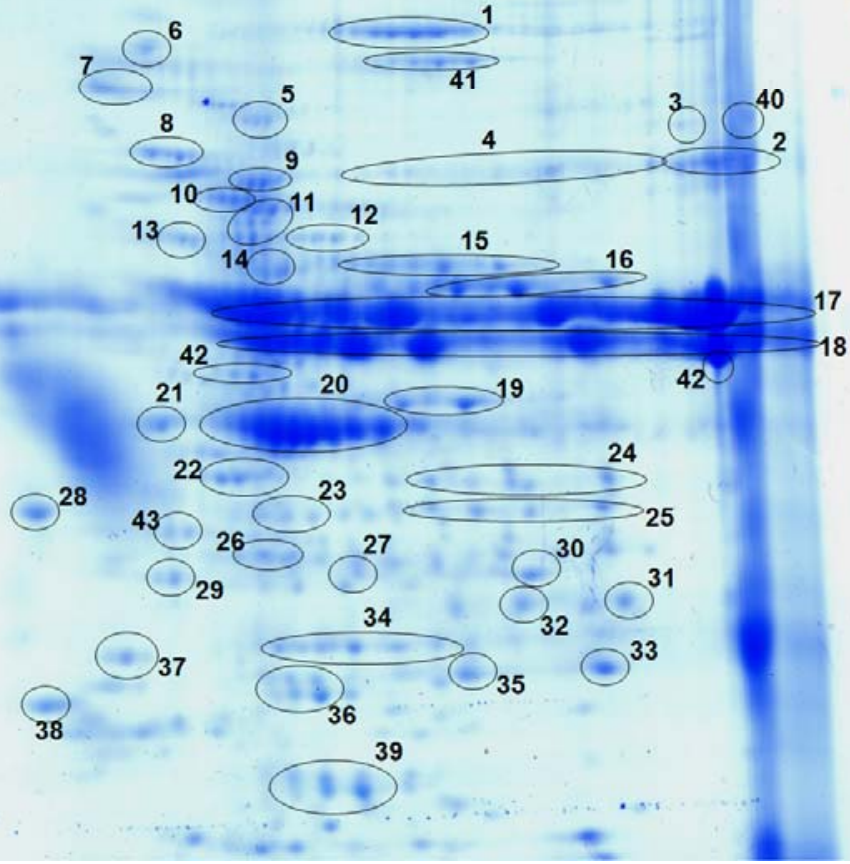

37 
7.5.3. Appendix V: Identification of proteins in the HS RNPS200 \#2 - pH3-10 (Table)

\begin{tabular}{|c|c|c|c|c|}
\hline Spot \# & Protein Name & Accession \# & kDa & pl \\
\hline 1 & Eukaryotic translation elongation factor 2 , & gi|27882475 & 95,42 & 6,45 \\
\hline 2 & Vg1RBP & gi|3136158 & 65,61 & 9,68 \\
\hline 3 & Similar to hnRNP Q1 & gi|47122815 & 69,3 & 9,13 \\
\hline 4 & G3BP-2a & gi|49903639 & 54,36 & 5,21 \\
\hline 5 & Moesin & gi|66912039 & 68,13 & 5,58 \\
\hline 6 & p97 subunit of $15 \mathrm{~S} \mathrm{Mg}(2+)-$ ATPase & gi|64966 & 89,13 & 4,96 \\
\hline 7 & Nucleolin (4 RRMs) & gi|64937 & 70,19 & 4,64 \\
\hline 8 & HSP70 & gi|27371247 & 71,18 & 5,21 \\
\hline 9 & Lysyl-tRNA synthetase & gi|28838485 & 69,69 & 6,15 \\
\hline 10 & methionine aminopeptidase 2 & gi|27694969 & 51,48 & 5,78 \\
\hline 11 & chaperonin subunit CCTgamma & gi|1045604 & 60,6 & 5,8 \\
\hline 12 & chaperonin containing TCP1, subunit $6 \mathrm{~A}$ (zeta 1) & gi|54038656 & 57,78 & 6,14 \\
\hline 13 & Chaperonin containing TCP1, subunit 8 (theta), & gi|27924345 & 59,35 & 5,21 \\
\hline 14 & chaperonin subunit 7 (eta), & gi|27769226 & 59,18 & 5,73 \\
\hline 15 & $\begin{array}{l}\text { Cytosolic thyroid hormone binding } \\
\text { protein/pyruvate kinase type M2 }\end{array}$ & gi|51258124 & 57,52 & 6,48 \\
\hline 16 & Predicted Protein with HABP4_PAI-RBP1 domain & gi|37748539 & 45,52 & 7,91 \\
\hline 17 & Ybox BP p56 (FRGY2-A) & gi|1175535 & 37,18 & 10,02 \\
\hline 18 & Ybox BP p54 (FRGY2-B) & gi|1175534 & 35,93 & 9,38 \\
\hline 19 & $\mathrm{EF} 1 \gamma$ & gi|545505 & 50,2 & 7,01 \\
\hline 20 & similar to proliferation-associated $2 \mathrm{G} 4,38 \mathrm{kD}$ & gi|54311187 & 43,48 & 6,49 \\
\hline 21 & actin gamma, cytoskeletal type 5 & gi|280660 & 41,84 & 5,11 \\
\hline 22 & serine proteinase inhibitor & gi|32450604 & 42,81 & 5,39 \\
\hline 23 & undefined & & & \\
\hline 24 & heterogeneous nuclear ribonucleoprotein A1 & gi|28374304 & 40,47 & 9,29 \\
\hline 25 & $\begin{array}{c}\text { hnRNP E2 (3KH domains) - mixed with } \\
\text { hnRNP A3(A) (2 RRM s) }\end{array}$ & $\begin{array}{c}\text { gi|} 5459450 \\
\text { and } \\
\text { gi| } 1710625\end{array}$ & $\begin{array}{c}37,5 \\
\text { and } \\
38,58 \\
\end{array}$ & $\begin{array}{l}7,63 \\
\text { and } \\
6,78 \\
\end{array}$ \\
\hline 26 & undefined & & & \\
\hline 27 & undefined & & & \\
\hline 28 & Elongation factor-1 delta & gi|56970676 & 28,64 & 4,35 \\
\hline 29 & Acidic Ribosomal Protein P0 & gi|27503344 & 34,09 & 5,17 \\
\hline 30 & undefined & & & \\
\hline 31 & G3PDH (typeC) & gi|27882192 & 36,1 & 8,16 \\
\hline 32 & undefined & & & \\
\hline 33 & GTP BP ß2 & gi|27371211 & 35,5 & 7,6 \\
\hline 34 & L-lactate dehydrogenase & gi|1170735 & 36,7 & 6,25 \\
\hline 35 & undefined & & & \\
\hline 36 & U8 snoRNA-binding protein X29 & gi|62185795 & 24,35 & 6,66 \\
\hline 37 & WD repeat domain 61 & gi|49256488 & 33,33 & 4,97 \\
\hline 38 & Elongation factor 1 beta & gi|64662 & 25,17 & 4,42 \\
\hline 39 & similar to homeobox prox 1/CGI-99 protein & gi|56540940 & 27,52 & 6,66 \\
\hline 40 & Cytoplasmic poly(A) binding protein 1 - cPABP1a & gi|30353795 & 70,46 & 10,01 \\
\hline 41 & undefined & & & \\
\hline 42 & undefined & & & \\
\hline 43 & undefined & & & \\
\hline
\end{tabular}




\subsection{Appendix VI}

7.6.1. Appendix $\mathrm{VI}$ : Identification of proteins associated with $40 \mathrm{LoVe}-$ pH 3-10 (gel)

(A) Proteins identified in the eluate fraction of immuno-isolated 40LoVe RNPS,

Immuno-isolation of 40LoVe RNPs was done on a preparative a scale from $50 \mathrm{mg}$ of stage I-II oocyte S16 extract in 50 aliquots and incubated in $2 \mathrm{ml}$ IP reactions. After protein isolation the washed beads were treated with RNase to generate the eluate fraction was precipitated by use of acetone and analysed on 2D gel using immobilised pH gradient (IPG) strip with pH 3-10 (Bio-Rad). Circles covering groups of protein spots indicated that identified proteins were found to be the same protein but which, for no clear reason, did not focus into one discrete spot during the IEF.

(B) Proteins identified in the corresponding pellet fraction.

The proteins remaining on the beads after RNase treatment were eluted by SDS/DTT buffer and the proteins from this was precipitated by acetone and analysed as in (A)

The table shows a complete list of proteins which were identified from the $2 \mathrm{D}$ gel of eluate (A) and pellet (B) protein fractions by mass spectroscopy (MS): Proteins were identified using peptide mass fingerprinting and proteins with MASCOT score of 50 or higher were confirmed by sequencing of two peptides from each protein using MS/MS (see section 2.5.8). The database search with peptide masses and sequences, the nominal molecular mass and the putative isoelectric point $(\mathrm{pl})$ estimation from the amino acid sequences were done using Mascot Software 2.0 (Matrix Science). Spot numbers given in the list corresponds to numbered circles indicated on the gel picture. 
7.6.2. Appendix VI: Identification of proteins associated with $40 \mathrm{LoVe}-$ pH3-10 (gel)

(A) Proteins identified in the eluate fraction of immuno-isolated 40LoVe RNPS,

(B) Proteins identified in the corresponding pellet fraction.

A

$(+) \mathrm{pH} 3$

$(-)$ pH 10

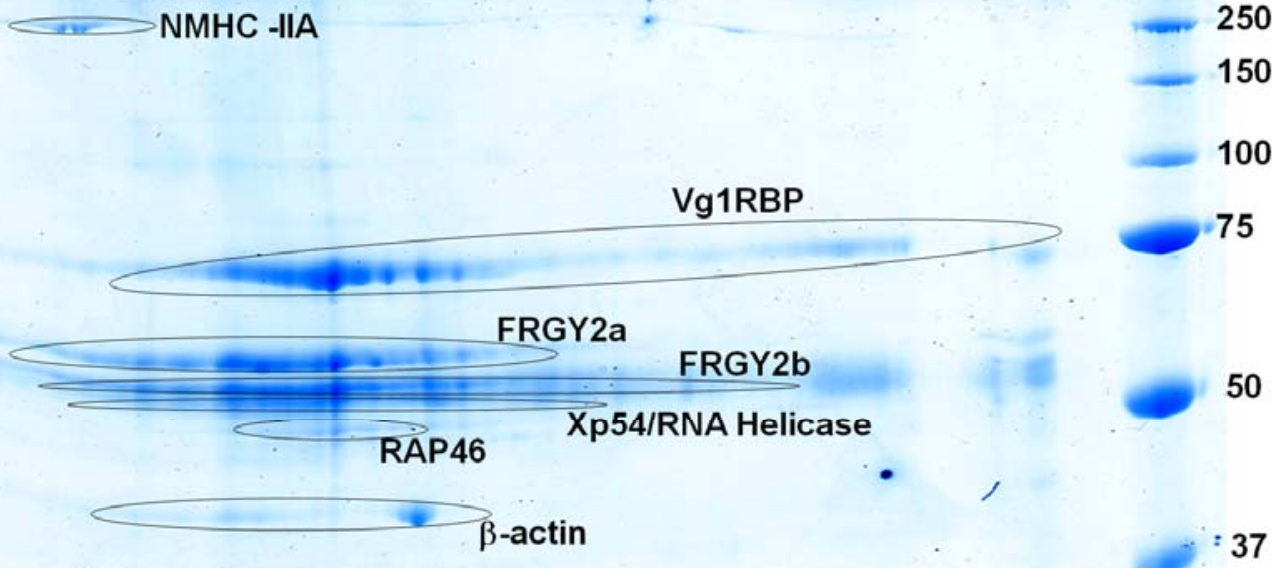

25

B

(+) $\mathrm{pH} 3$

(-) $\mathrm{pH} 10$
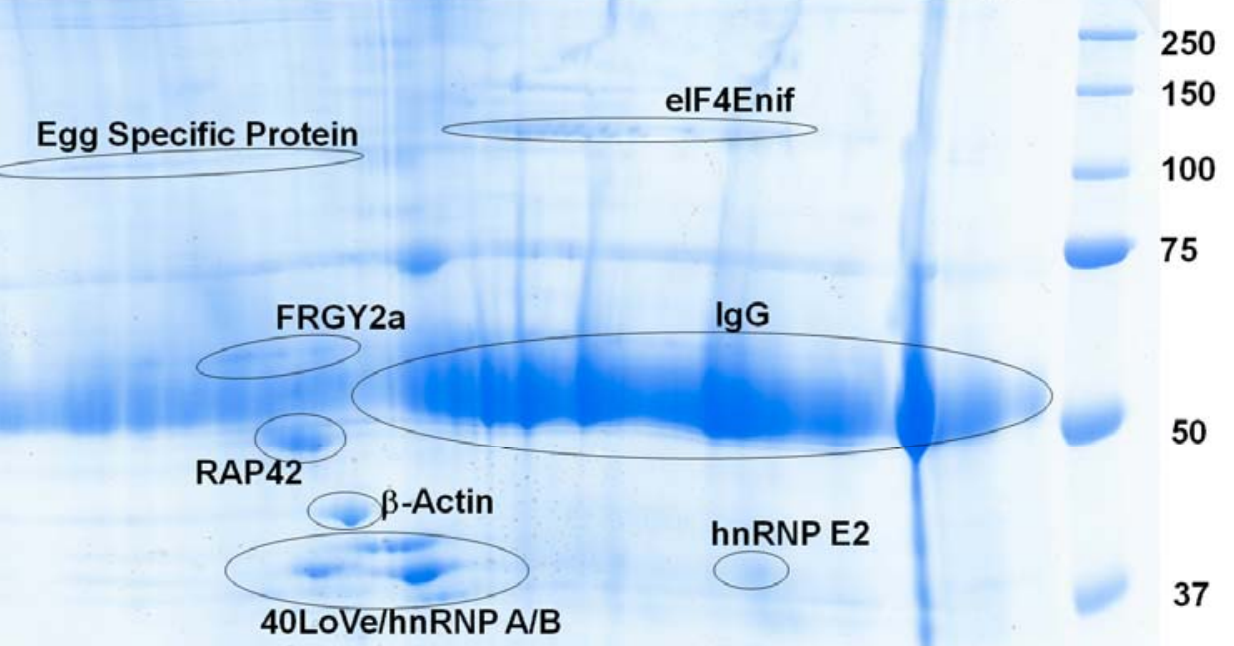

$\lg G$

50

37

$\lg G$

hnRNP E2 
7.6.3. Appendix VI: Identification of proteins associated with $40 \mathrm{LoVe}-$ pH3-10 (Table)

\begin{tabular}{|c|c|c|c|c|}
\hline Protein Name & Accession \# & Size (kDa) & $\mathrm{pl}$ & Remarks \\
\hline$N M H C-\| A$ & gi|3660672 & 227,6 & 5,44 & $\begin{array}{l}\text { nonmuscle myosin II } \\
\text { heavy chain } \mathrm{A}\end{array}$ \\
\hline Vg1RBP & gi|2801766 & 65,6 & 9,08 & \\
\hline FRGY2a & gi|1175535 & 37,2 & 9,6 & \\
\hline FRGY2b & gi|1175534 & 36 & 7,93 & \\
\hline Xp54 & gi|1709533 & 54,5 & 8,9 & \\
\hline RAP46 & gi|51258579 & 46,2 & 9,37 & \multirow{2}{*}{$\begin{array}{l}\text { Related to RAP55 - } \\
\text { contain N-terminal } \\
\text { Lsm domain }\end{array}$} \\
\hline RAP42 & gi|71679779 & 42 & 9,72 & \\
\hline$\beta$-actin & gi|1703123 & 42,1 & 5,3 & \\
\hline $\begin{array}{l}\text { Egg specific } \\
\text { Protein }\end{array}$ & gi|214636 & 83,8 & 5,3 & \\
\hline elF4E-T & gi|50414847 & 85,8 & 8,07 & \\
\hline $\begin{array}{c}\text { hnRNP A/B } \\
\text { (40LoVe) }\end{array}$ & gi|27694771 & 36,05 & 5,71 & \\
\hline ePABP1b & gi|82236619 & 70,8 & 9,35 & \\
\hline hnRNP E2 & gi|5459450 & 37,5 & 7,63 & \\
\hline
\end{tabular}


7.7. Appendix VII: Identification of proteins associated with EIrA/B pH3-10 (Gel without annotations)

A $\quad(+) \mathrm{pH}_{3}$

(-) $\mathrm{pH} 10$

B

(+) $\mathrm{pH}_{3}$

(-) $\mathrm{pH} 10$

250

150

100

75 
7.8. Appendix VIII: Identification of proteins associated with $40 \mathrm{LoVe}-$ pH3-10 (Gel without annotations)

A
$(+)$ pH 3

$(-) \mathrm{pH} 10$

250

150

100

75

B

(+) $\mathrm{pH} 3$

(-) $\mathrm{pH} 10$ 


\section{CURRICULUM VITAE}

\section{Personal Information:}

$\begin{array}{ll}\text { Surname: } & \text { Arthur } \\ \text { First name: } & \text { Patrick } \\ \text { Middle name: } & \text { Kobina } \\ \text { Date of Birth: } & 14^{\text {th }} \text { February, } 1978 . \\ \text { Place of Birth: } & \text { Saltpond, Ghana. } \\ \text { Citizenship: } & \text { Ghanaian } \\ \text { Marital Status: } & \text { Married }\end{array}$

\section{Education:}

2003 - To date: PhD studies (yet to be completed), University of Göttingen - Germany Thesis title: Identification and functional characterization of trans-acting factors involved in vegetal mRNA localization in Xenopus oocytes.

Thesis adviser: Prof. Dr. Tomas Pieler, Dept of Developmental Biochemistry Institute for Biochemistry and Molecular Cell Biology.

2001 - 2003: $\quad$ MSc Molecular Biology, University of Göttingen - Germany Thesis title: $\quad$ Analysis of novel amylase genes

Thesis adviser: Prof. Dr. Wolfgang Liebl, Dept. of Genomic and Applied Microbiology Institute for Microbiology and Genetics

1997 - 2001: $\quad$ BSc Biochemistry, University of Ghana, Legon - Ghana

Thesis title: Determination of existence of polymorphism in full length clones of mild strains of cocoa swollen shoot virus (CSSV)

Thesis adviser: Dr. Samuel Sackey, Dept. of Biochemistry

1993 - 1995: $\quad$ SSSCE - Mfantsipim School (est. 1876), Cape Coast - Ghana 